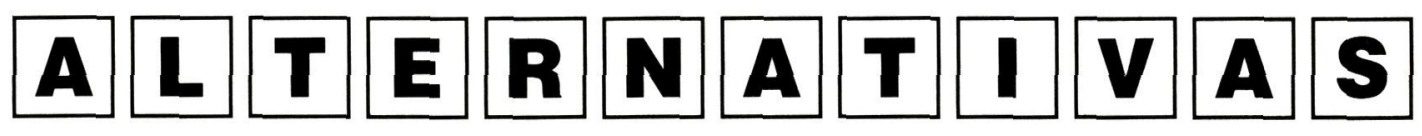

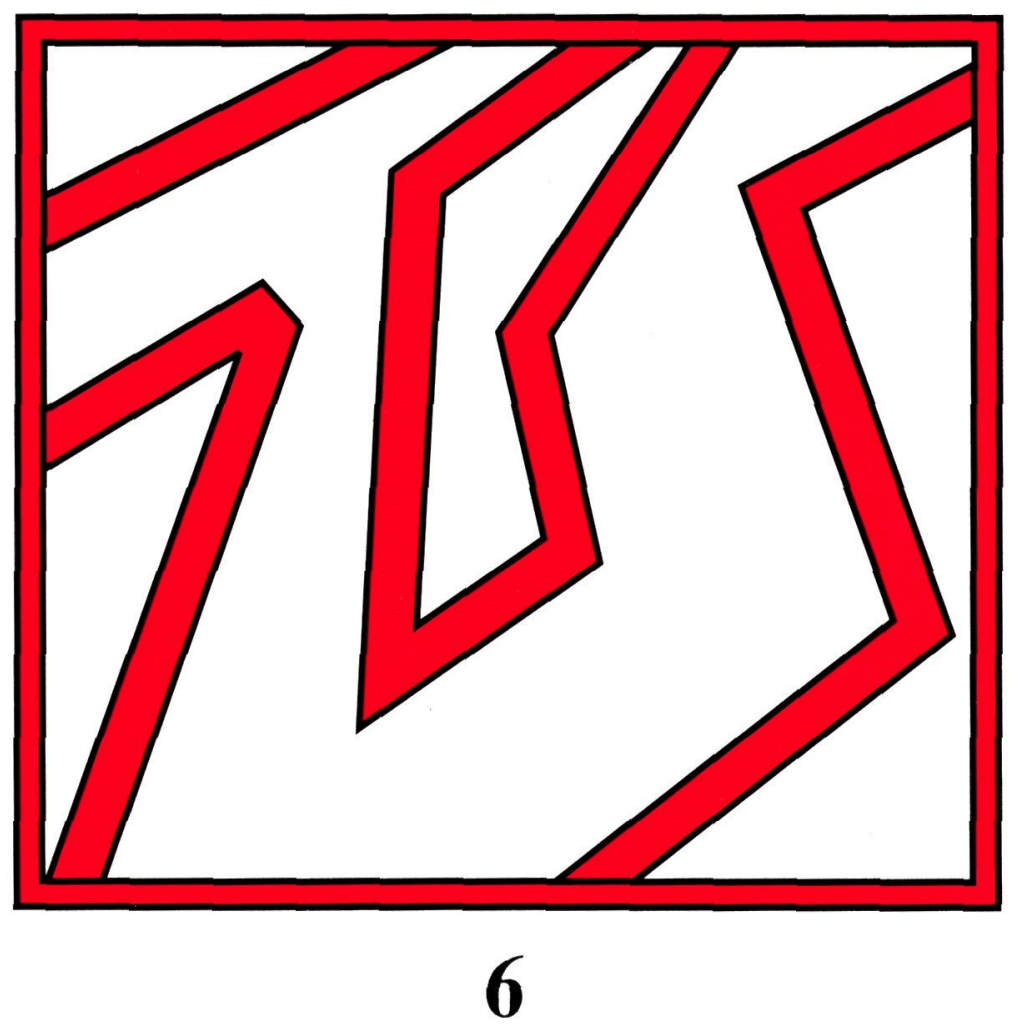

\begin{tabular}{lrrr} 
CUADERNOS & DE & TRABAJO & SOCIAL \\
\hline N. 6 & & Octubre 1998
\end{tabular} 




\section{ALTERNATIVAS}

CUADERNOS

DE

TRABAJO SOCIAL 
ALTERNATIVAS. CUADERNOS DE TRABAJO SOCIAL. N." 6. Octubre 1998.

\section{CONSEJO EDITORIAL:}

Directora de la revista: M. ${ }^{\text {a }}$ Teresa Mira Perceval

Directora técnica: $\quad$ M. $^{\mathrm{a}}$ Asunción Martínez Román

Secretaria: Hortensia Redero Bellido

Vocales: $\quad$ M. ${ }^{a}$ Dolores Díez García

Yolanda Domenech López

M. ${ }^{a}$ José Frau Llinares

Elena Roselló Nadal

\section{EDICIÓN Y ADMINISTRACIÓN:}

Escuela Universitaria de Trabajo Social. Universidad de Alicante.

03690 San Vicente del Raspeig. Alicante. España.

Telf.: 9659037 70. Fax: 965903572 .e-mail (escuela): eu.trabajosocial@ua.es

Depósito Legral: M. 37.152-1992.

I.S.S.N.: $\quad 1133-0473$.

Impresion:

ROMGRAFIC, S.L.

Martínez de Velasco, 17. 03013 Alicante. España.

\section{Encuadernación:}

LIMENCOP, S.L. (Centro Especial de Empleo)

Zarandieta, 7. Tel. 9652571 12. 03010 Alicante. España.

Precio del ejemplar: 2.500 ptas.

Reservados todos los derechos

Suscripciones y ventu:

Librería Compás-Universidad, S.L.

Centro de Servicios Universitarios. Universidad de Alicante.

03690 San Vicente del Raspeig. Alicante. España. Apdo. de correos n. 203.

Telf:: 965909390 . Fax: 9659093 91. e-mail: compasun@fedecali.es

\section{PRÓXIMA SECCIÓN MONOGRÁFICA:}

\section{Integración socio-laboral}

Plazo para la presentación de artículos: 30 de mayo de 1999. 


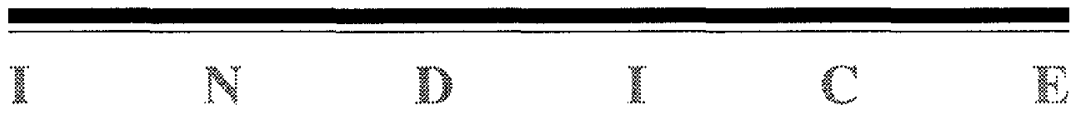



M. a Asunción Martínez Román y Hortensia Redero Bellido. Directora técnica y Secretaria respectivamente del Consejo Editorial de la Revista «Alternativas. Cuadernos de Trabajo Social».

Presentación

I. EI marco actual de la acción social: ¿Servicios Sociales públicos o privados?

M. ${ }^{a}$ del Carmen Alemán Bracho. Catedrática E.U. de Servicios Sociales. Universidad de Granada. Mercedes García Serrano. Universidad de Granada.

Tercer sector: buscando el equilibrio entre solidaridad y eficiencia.

Michael Barratt Brown. Universidad de Sheffield (Reino Unido).

Defending the Welfare State.

Antonio Gutiérrez Resa. Catedrático E.U. de Trabajo Social y Servicios Sociales. Universidad de Zaragoza.

Público-privado. Un modo de intervenir en la sociedad global-local.

Manuel Enrique Medina Tornero. Profesor titular de Servicios Sociales. E.U. de Trabajo Social. Universidad de Murcia.

El debate de lo público y lo privado en Servicios Sociales. 


\section{Tribuna libre}

Agustín Bueno Bueno y Conrado Moya Mira. Area de Psicología Social. Universidad de Alicante.

La delincuencia juvenil como síntoma: perspectivas de intervención psicosocial.

José Cabanes Hernández. Sociólogo. Servicios Sociales Municipales de Villena (Alicante). Monitor de minorías étnicas.

La escolarización de los niños gitanos en el País Valenciano.

Yolanda Domenech López. Profesora titular de Trabajo Social de la E.U.T.S. Universidad de Alicante.

Los grupos de autoayuda como estrategia de intervención en el apoyo social.

Alfredo Hidalgo Lavié. Profesor de Servicios Sociales y Política Social. E.U. de Trabajo Social de Jerez de la Frontera. Universidad de Cádiz.

Ciencia Política y Servicios Sociales. Den entendimiento al «concubinage».

Silvia Quesada Díez. Universidad Pontificia de Comillas, ICADE.

La acción social en la Unión Europea: evolución histórica.

Elena Roselló Nadal. Profesora ayudante del Depto. de Trabajo Social y Servicios Sociales. Universidad de Alicante.

Reflexiones sobre la intervención del trabajador social en el contexto educativo. 
Ana Rosser Limiñana. Psicóloga de la Unidad de Adopción de la Conselleria de Bienestar Social. Alicante.

Marco legislativo del acogimiento familiar.

Octavio Vázquez Aguado. Profesor titular de E.U. Depto de Sociología y Trabajo Social. Universidad de Huelva.

Pensar la epistemología del Trabajo Social.

\section{Libros}

José María Tortosa. Catedrático de Sociología. Universidad de Alicante.

Título: "Trabajo Social Experimental». Tirant lo Blanch. Valencia, 1998. Autora: Rosario Conde Megías.

\section{Números publicados}

Número 1 (1992)

293

Número 2 (1993) 295

Número 3 (1995)

Número 4 (1996) 298

Número 5 (1997) 299

Pautas generales para la presentación de artículos 



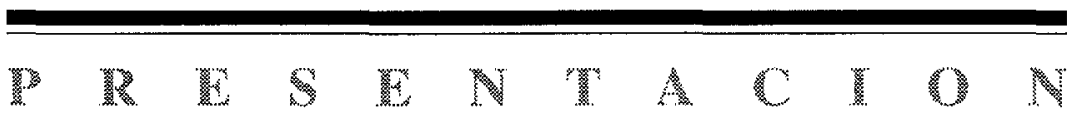





\section{M. ${ }^{a}$ ASUNCIÓN MARTÍNEZ ROMÁN.}

Directora técnica del Consejo Editorial de la Revista «Alternativas. Cuadernos de Trabajo Social».

\section{HORTENSIA REDERO BELLIDO.}

Secretaria del Consejo Editorial de la Revista «Alternativas. Cuadernos de Trabajo Social».

Presentamos el número SEIS de la Revista «Alternativas. Cuadernos de Trabajo Social», editada por la Escuela Universitaria de Trabajo Social de la Universidad de Alicante. El tema central, tal como se proponía en el número anterior de la Revista, es «El marco actual de la acción social ¿Servicios Sociales públicos o privados?»y, sobre este tema, versan los artículos centrales de este monográfico que, desde diferentes enfoques, constituyen importantes aportaciones en el ámbito de los Servicios Sociales y el Trabajo Social.

Entre los cambios sufridos por los modelos de Estado de Bienestar, hay que destacar la ruptura con la tradicional identificación de estos modelos de Estado como prestadores directos de servicios públicos, con tendencia a su privatización. Y, con frecuencia, cuando se habla de la privatización de los servicios públicos, se hace de modo dogmático, bien defendiendo esta opción como la panacea o, por el contrario, atacándola por considerarla como un retroceso social. Si los Servicios Sociales son medios de la política social, será fundamental mantener la responsabilidad pública en la promoción del desarrollo humano de todos los ciudadanos y, en especial, de aquellos que se encuentren en situación de desventaja social. Por lo tanto, no se trata de oponer servicios públicos a servicios privados, sino de elegir el mejor medio para garantizar las oportunidades de desarrollo.

Los agentes del desarrollo humano son tanto los gobiernos como la iniciativa privada (fundamentalmente la iniciativa social, no lucrativa), sin olvidar los grupos primarios. Hay diferencias esenciales entre hablar de responsabilidad pública para garantizar los servicios básicos considerados de interés general o hacerlo sobre la producción/prestación pública de esos servicios. La privatización de la producción/pres- 
tación de los servicios no puede hacerse a costa del abandono o megua de la responsabilidad pública. Lo esencial es que ésta no disminuya, logrando el equilibrio que permita la necesaria participación social.

En los últimos años han sido numerosas las críticas al funcionamiento de la Administración pública y, especialmente, en el tema de los Servicios Sociales. Pero, muchas veces, se recurre a la contratación externa como modo de gestión indirecta de los servicios sin que, previamente, se haya demostrado qué mejoras supone esa modalidad de gestión. Del mismo modo que los servicios directamente prestados por la Administración pública no son necesariamente sinónimo de calidad, la privatización, que puede ser la mejor opción en algunos casos, no es tampoco la única opción posible y, en cualquier caso, la posible elección precisa un estudio previo de las ventajas e inconvenientes de las diferentes opciones, para valorar la más idónea. Esto supone un debate en el que entran en juego aspectos no sólo ideológicos y políticos sino, también, otros aspectos directamente relacionados con la prestación del servicio a los ciudadanos. Hay que elegir qué, quién y cómo se hace.

En la primera parte de este número de Alternativas, se analizan aspectos del tema propuesto: globalización, territorio y servicios sociales; el papel de los diversos actores; pros y contras del protagonismo de cada uno de ellos; búsqueda del equilibrio entre responsabilidad pública, participación social y eficacia-eficiencia; necesidad del control público para asegurar el cumplimiento de los fines públicos; modernización de la administración; modalidades de relación público-privado en la prestación de servicios públicos; técnicas de privatización o la calidad de los servicios. Como novedad, destacamos la inclusión de un texto en lengua inglesa, de gran interés y actualidad, que analiza la política social reciente del Reino Unido.

En la Tribuna Libre, se presentan diversas colaboraciones. Unas se ocupan de la intervención social con menores, con temas relativos a la escolarización de los niños gitanos, prevención y tratamiento de la delincuencia juvenil, acogimiento familiar y Trabajo Social escolar. Otra serie de aportaciones se refieren a los grupos de autoayuda, la Unión Europea, la epistemología del Trabajo Social o la interrelación entre Ciencia Política y Servicios Sociales. Agradecemos a los autores su colaboración y deseamos que este número de Alternativas contribuya a sugerir nuevas pistas de análisis.

Para concluir, comunicamos que el Consejo Editorial, considerando los nuevos desafíos a los que se enfrentan el Trabajo Social y los Servicios Sociales, propone como tema monográfico para el número 7 de la Revista: «La inserción socio-laboral». Esperamos vuestras colaboraciones. 
1. EL MARCO ACTUAL DE

LA ACCIÓN SOCIAL:

¿SERVICTOS SOCHALES

PÚBLICOS O PRIVADOS? 



\title{
TERCER SECTOR: BUSCANDO EL EQUILIBRIO ENTRE SOLIDARIDAD Y EFICIENCIA
}

\author{
Ma DEL CARMEN ALEMÁN BRACHO \\ Catedrática E.U. de Servicios Sociales. Universidad de Granada. \\ MERCEDES GARCÍA SERRANO
}

\section{INTRODUCCIÓN}

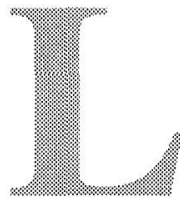

a participación del Tercer Sector en la contribución al bienestar social no supone, a pesar de la importancia que cobra la misma en nuestro tiempo, una novedad. Distintas formas de iniciativa social se han venido sucediendo y se mantienen con mayor o menor peso específico. La familia, el grupo de iguales, la donación, la beneficencia..., constituyen algunos ejemplos de esta trayectoria.

Sin embargo, diversas circunstancias confluyen a la hora de dotar de un mayor peso específico a la iniciativa social. La crisis que afecta al Estado de Bienestar de tipo Keynesiano y el incremento de la demanda de participación social a través de organizaciones no gubernamentales posicionan al Tercer Sector en un papel central dentro de la agenda del bienestar. Desde esta situación de partida, se plantea el incremento de la participación de las entidades voluntarias en la acción social, apoyada en todo caso por políticas de fomento de la misma por parte de los actores públicos.

El sector no lucrativo presenta una serie de ventajas que lo sitúan en una posición privilegiada como agente de bienestar social, sin embargo, la actuación de las entidades que lo componen ha venido marcada por una trayectoria desigual, siendo objeto la misma de diversas críticas, no siempre exentas de fundamento.

La mejora de la gestión de las entidades no lucrativas, así como de los programas de promoción y formación del voluntariado, serán elementos a tener en cuenta por parte de este sector a la hora de salvar dichas críticas, haciendo en cualquier caso compatibles eficiencia con solidaridad.

Trataremos, a continuación, de ofrecer algunas líneas a través de las cuales abordar esta tarea, no sin antes realizar una breve descripción de la situación de las entidades voluntarias en nuestro país. 


\section{TERCER SECTOR Y ACTORES PÚBLICOS ANTE LA CRISIS DEL SISTEMA DE BIENESTAR.}

Entidades voluntarias y administración social se establecen como sujetos de una relación cada vez más estrecha en las políticas sociales que tratan de satisfacer unas necesidades mayores y más diversas en la población. En efecto, no hay duda de que diversos cambios producidos en el ámbito político, económico y social coinciden en el tiempo, afectando simultáneamente a la lógica del Estado de Bienestar y al movimiento propio de la iniciativa social representada por entidades voluntarias, amparadas, en sus diversas formas, bajo el amplio paraguas de la denominación de Organizaciones No Gubernamentales (ONGs).

Por un lado, si bien es cierto que el Estado de Bienestar, configuración que da forma política a las democracias occidentales surgidas tras la Segunda Guerra Mundial, trata de centrar la responsabilidad acerca de la calidad de vida de los ciudadanos sobre los poderes públicos, diversas notas, ya presentes desde la década de los setenta, pero subrayadas en los últimos tiempos, parecen poner de manifiesto una cierta «crisis» en los cimientos de dicha forma política!.

Exceso de demandas planteadas por los ciudadanos, incapacidad de los actores públicos para adaptarse a las transformaciones económicas y sociales para otros, y al final de cada uno de los cabos, la puesta en tela de juicio de la legitimidad de los actores gubernamentales. ${ }^{2}$

Dicha crisis del Estado de Bienestar, vendrá a coincidir con la revitalización del papel de la sociedad civil en su multiplicidad de formas, -movimientos sociales, asociaciones, ONGs...-dentro del escenario público. La misma, con el respaldo de nuevos valores -tildados en diversas ocasiones de postmateriales- y buscando formas alternativas de participación que traspasen los cauces institucionalizados afectados por el déficit de legitimidad -tales como los partidos políticos y sindicatos-, toma parte dentro de un nuevo modelo concebido desde los marcos del «Pluralismo del Bienestar» o la «Sociedad del Bienestar», en el que diversos actores sociales, públicos y privados, compar-

Ascoli, U. (1987): «Estado de Bienestar y acción voluntaria» en Revista Española de Investigaciones Sociológicas. Ascoli,U. (1988): «Voluntariado organizado y sistema público de 'Welfare': Potencialidad y límites de una cooperación» en Documentación Social. n' 1 ; VV.AA.(1992): «Voluntariato e Stato Sociale». Rev. Polis. $n^{\circ} 3$.

2 Ver diversas interpretaciones al respecto en Habermas, J. (1991): Lat crisis de legitimación del capitalismo tardís. Ed. Amorrortu. Buenos Aires; O'Connor, J. (1994): La Crisis Fiscal del Estado de Bienestar. Ed. Península. Barcelona; Bell, D. (1996): Las contradicciones culturales del capitalismo. Ed. Alianza.Madrid. 
ten su responsabilidad en la satisfacción de las necesidades de los ciudadanos $^{3}$.

De esta forma, se tiende hacia una cierta desregularización de la actividad estatal, en la que las actividades centralizadas anteriormente en la administración social tienden a desconcentrase bien hacia el mercado, bien hacia las entidades voluntarias, incrementándose así las relaciones entre los diversos sectores implicados en la generación del bienestar. Relaciones que no dejan de desplazarse entre los parámetros de la colaboración y el conflicto.

Con el fin de despejar la actuación de la iniciativa social respecto a otro tipo de acciones, se hace necesario aclarar los términos de la relación, estableciendo un marco normativo que, adaptado a una realidad cambiante, ordene las formas jurídicas que se encuadran dentro del «Tercer Sector» y las relaciones que se establecen con dichas formas organizativas. Muestra de estas iniciativas son, sin duda, la Ley del Voluntariado y la Ley de Fundaciones que entran en vigor en torno al meridiano de los noventa.

Dentro de esta intención se encuentra el tratamiento que acerca de la materia realizamos seguidamente. Trataremos de abordar, desde este punto de vista, los conceptos a los que hacemos referencia con asiduidad dentro de este ámbito, tales como voluntariado, entidades voluntarias, asociaciones, fundaciones..., así como a la realidad que da contenido a los mismos. Conoceremos el marco jurídico en torno al voluntariado, señalando los límites y posibles mejoras de éste en diversos niveles: europeo, nacional y autonómico, para centrarnos más tarde en la singularidad de tres entidades de especial importancia: Cáritas, Cruz Roja y la Organización Nacional de Ciegos. Por último, nos detendremos en los argumentos que respaldan la opción por el sector no lucrativo en la acción social, así como en los métodos de gestión que permitan un mayor desarrollo organizacional de las entidades que lo conforman, y una mejora en el impacto a que dan lugar las acciones emprendidas por las mismas.

\section{III.TERCER SECTOR Y VOLUNTARIADO: EN BUSCA DE UNA DEFINICIÓN PARA LA PLURALIDAD.}

Dentro del denominado «Tercer Sector»-definido en la mayor parte de las ocasiones por exclusión, diferenciándolo del Estado y del ámbito mercantil- la realidad adopta una diversidad de formas asocia- 
tivas y organizacionales que hacen difícil, en su pluralidad, establecer una definición comprehensiva de la totalidad de las mismas.

En este sentido, sería necesario conocer, en primer lugar, qué entendemos por «Tercer Sector» e, incluyendo dentro del mismo a las organizaciones voluntarias, establecer las notas que caracterizan a estas últimas y que pudieran trasladarse a aquél. Entre las definiciones que han encontrado mayor eco dentro de la doctrina, se encuentra la de Salamon y Anheier ${ }^{4}$ para quienes tal sector presenta los siguientes rasgos:

1. Se requiere de una organización donde haya unos objetivos generales y en la que los recursos estén destinados a conseguir dichos objetivos. Estas características se extienden tanto a Asociaciones y Fundaciones, como a otra serie de movimientos con un carácter más «informal» en los que, en todo caso, se hace necesario un mínimo de organización.

2. Privada. Las Entidades No Lucrativas estarán reguladas en todo caso por el Derecho Privado, excluyéndose Institutos y Patronatos Públicos, Entes Autónomos de las Administraciones Públicas, etc.

3. No pueden distribuir los beneficios. Ello no quiere decir que no puedan generar beneficios, sí que pueden hacerlo tal y como ocurre en diversas entidades de nuestro país, pero no se hace con un fin lucrativo, sino con el fin de generar el máximo de utilidad social.

4. Gobernadas autónomamente. Deben establecer órganos de gobierno propios y no estar controladas por organizaciones externas.

5. Altruista. Implica la participación del voluntariado en algún grado.

Este Tercer Sector vendría a encontrar su propia identidad en contraste con el resto de los sectores que contribuyen al bienestar social, esto es, el sector gubernamental y el privado mercantil. En gran parte, también se definirán por exclusión algunas de las entidades que forman parte del mismo, subrayando, en todo caso, cada una de las denominaciones que reciben, una de las notas que caracteriza a las mismas. Entidades no lucrativas, entidades filantrópicas, organizaciones no gubernamentales, sector del voluntariado, entidades voluntarias economía social..., son denominaciones para realidades muy próximas, en la mayor parte de los casos, superpuestas.

No obstante, y a pesar de que se ha venido entendiendo el fenómeno del voluntariado dentro de estas entidades, no todos los voluntarios trabajan en organizaciones, los hay que realizan su actividad altruista

4 Cit. en Rodríguez Cabrero, G. y Monserrat Codorniu, J. (dirs.) 1996: Las Entidades Voluntarias en España. Institucionalización, estructura económica y desarrollo asociativo. Ed. Ministerio de Asuntos Sociales. Madrid, págs. 23-24.; y en Billis, D. y Glennerster, H. (1998) «Human Services and Voluntary Sector» en Journal of Social Policy, vol.27, $\mathrm{n}^{\circ} 1$, págs. 8081 
al margen de los canales más o menos institucionalizados para tal fin, de ahí que debamos evitar la identificación entre voluntarios y entidades voluntarias, distinción que deberemos tener en cuenta a la hora de establecer la dinámica interna de la organización y los parámetros de gestión de la misma.

\section{IV.EL FENÓMENO DEL VOLUNTARIADO EN ESPAÑA: ANTE- CEDENTES Y SITUACIÓN ACTUAL.}

El fenómeno del voluntariado, o, si se quiere, de las entidades voluntarias -ya que, aunque siendo conscientes de la diferencia entre ambos términos, resulta difícil para los propósitos que abarcamos referirnos de forma continua a la distinción entre los mismos- no es nuevo en España, sino que bajo diversas formas se halla presente a lo largo de nuestra historia.

Estableciendo como punto de partida nuestro pasado más reciente, no hay duda de que los cambios políticos y sociales que contempla el país marcarán las pautas del fenómeno que nos ocupa. En efecto, el paso a un nuevo régimen democrático con una mayor apertura a las libertades y derechos fundamentales del ciudadano -entre ellos el de asociación-, así como la modernización social, fomentará el crecimiento de las asociaciones y la participación en las mismas, rompiendo de esta forma una imagen que había permanecido durante el régimen anterior, en la que «El voluntariado sólo podía evocar el sentido militar del término» ${ }^{5}$.

Será, por tanto, la llegada de la democracia, la que contemple un auge mayor del voluntariado -así como de las entidades en que se encuadra la acción del mismo-. Siguiendo el esquema ofrecido por Rodríguez Cabrero, podrían contemplarse, a partir de este periodo, las siguientes etapas en la evolución del concepto de voluntariado y la realidad a la que hace referencia:

a) Los primeros años de la democracia. Tal y como señala Demetrio Casado ${ }^{6}$, durante esta primera fase, el clima ideológico favorecerá el desarrollo de una imagen positiva en torno al sector voluntario en España. No obstante, la tendencia a la desmovilización y la integración de muchos líderes asociacionistas en el ámbito de la política «profesional», por un lado, y, por otro, la borrosa memoria acerca

5. Mora Rosado, S. (1996): «El fenómeno del voluntariado en España: aproximación a la evolución del términor en Documentación Social, $\mathrm{n}^{\circ}$ 104, pág. 117.

"Casado, D. (1994): «Acción social y Servicios Sociales» en Informe Sociológico sobre la Situación Social en España, Ed. FOESSA, págs. 1.833 y ss. 
de un fenómeno apenas conocido, harán que se mire al mismo con un cierto recelo, considerando que debe ser el incipiente Estado de Bienestar español el que se encargue del ámbito de la acción social.

b) La legitimación desde arriba. Durante la época de los 80, se comienza a registrar el apoyo -aún de forma tímida- a las entidades no lucrativas. La legitimación de la acción voluntaria vendrá por parte de los poderes públicos, quienes, conscientes de la dificultad de hacer frente a los problemas sociales como actor único de la política social, comenzarán a considerar al sector voluntario como un complemento necesario.

c) Será la década de los noventa la que dé paso a un mayor auge del voluntariado. El concepto de voluntariado se expande a toda actividad no remunerada y adquiere una carga emotiva más cercana a lo sentido que a lo pensado. Paralelamente, el desempeño de diversos programas e iniciativas sociales por parte de las entidades voluntarias y la necesidad de evaluar los logros conseguidos tanto ante la población como ante los financiadores, harán necesario un mayor avance en el componente técnico y en la formación de las personas que integran la organización.

A la vez que se produce un proceso en el que a raíz de los cambios sociales y políticos registrados en España, se transforma positivamente la imagen del voluntariado y de las entidades voluntarias, las mismas verán aumentar su número en el territorio nacional, en una progresión ascendente con una serie de momentos más destacados, entre ellos, el ascenso del número de asociaciones contabilizado a raíz del registro de gran parte de las mismas a partir de la anterior Ley de asociaciones de $1964^{7}$. A partir de ese momento, la tendencia alcista en el número de asociaciones coincide con la época democrática, en la cual el año 85 se establece como «suelo» del asociacionismo. Frente a 2.573 asociaciones creadas en 1985, tenemos casi 7.000 en 1990,2'7 veces más. No obstante, esta cifra tan optimista queda relativizada en la comparación con los datos del resto de los países europeos, donde el incremento anual de asociaciones ha sido mayor.

\section{MARCOS NORMATIVOS PARA LA SOLIDARIDAD.}

A la vez que la realidad social y política ha venido constatando la dinamización de la vida asociativa y el incremento de la participación ciudadana, se ha hecho necesario establecer unos marcos de referencia que promuevan y a la vez regulen el fenómeno del voluntariado.

Alberich Mistral, T. (1994): «Aspectos cuantitativos del asociacionismo en España» en Doctmentación Social, $\mathrm{n}^{\circ} 94$. 
La regulación jurídica aparece en los niveles comunitario, nacional y autonómico dibujando un entramado que progresivamente se consolida y en el que uno de sus últimos pilares se establece a raíz de la Ley del Voluntariado 6/1996 de 15 de enero. Pero vayamos por partes.

\section{I. La regulación del voluntariado en el plano europeo.}

Perteneciendo España a un contexto supranacional que incide en sus políticas directamente, tal y como viene siendo el de la Unión Europea, son diversos los textos que, bien desde las propias instituciones de la UE, bien desde el Consejo de Europa, han influido en el ordenamiento institucional de la acción voluntaria. El mismo se ha venido recogiendo en distintas disposiciones:

- La Carta Social Europea establece la necesidad de «estimular la participación de los individuos y de las organizaciones benéficas o de otra clase en la creación y mantenimiento» de servicios de carácter social.

- Emitida, igualmente, por el Consejo de Europa, la Recomendación de 21 de junio de 1985 del Comité de Ministros, adoptada en la 387 reunión de los Delegados de Ministros, profundiza en la promoción del voluntariado, reconociendo, a un tiempo, «la necesidad de fijar algunas reglas para el ejercicio de las acciones voluntarias al servicio de la comunidad, aunque sin privarles de su carácter espontáneo». Dicha recomendación serviría de impulso en nuestro país a medidas tales como la Plataforma para la Promoción del Voluntariado.

- La Resolución del Parlamento Europeo de 16 de octubre de 1983 reconoce la necesidad de una atención sistemática al voluntariado, y compromete al mismo en la puesta en marcha de los programas europeos contra la pobreza.

- A estas disposiciones se unirá, en 1989, la Decisión 89/457/CEE del Consejo de las Comunidades Europeas de 18 de julio de 1989 , en el que se hará mención importante a la acción voluntaria como medio de atención e integración de las personas económicamente menos favorecidas.

No hay duda de que todas estas medidas son muestra y profundizan en una cultura política favorable al fomento de las asociaciones y la protección de la acción voluntaria, generando así programas de actuación inclinados hacia esta vertiente, entre los cuales destacan las medidas encaminadas al intercambio y movilidad de jóvenes voluntarios dentro del territorio de la Unión, la creación del Comité de Coordinación del voluntariado de los países de la Unión, fundado en 1990, la «Carta Europea para los Voluntarios» promovida por dicho Comité y 
el respaldo a actuaciones de desarrollo socioeconómico a través de recientes iniciativas tales como «Tercer Sector y Empleo», puesta en marcha por la Comisión Europea.

\subsection{La regulación juridica del voluntariado en España: La Ley 6/ 1996 de 15 de enero.}

El marco legal en torno al voluntariado y las asociaciones que acogen al mismo, se redimensiona con el paso al nuevo régimen democrático y la aparición del texto que constituye su base: la Constitución. En ella se encuentra un decidido compromiso político con la participación de los ciudadanos dentro de la vida social y política del país, siendo numerosos los artículos donde se halla presente esta filosofía. Muestra de ello es el art. 9.2, cuando formula el compromiso de los poderes públicos con la participación; el art. 22, que establece el reconocimiento del derecho a la participación en los asuntos públicos; o el art. 34, donde se reconoce el derecho de fundación para fines de interés general.

De igual manera, en distintas disposiciones sobre servicios sociales se contempla la intervención del voluntariado. Así, en el art. 64 de la Ley de Integración Social de los Minusválidos de 1982 o la Ley de Protección Civil de 1985 en cuyos arts. 1 y 14.d, organiza la protección civil contemplando el concurso del voluntariado. Igualmente, el Real Decreto de 15 de julio de 1988, por el que se regulan los fines de interés social de la asignación tributaria del Impuesto General sobre la Renta de las personas físicas, en su artículo 2 , se refiere a los programas de cooperación y voluntariado social de la Cruz Roja y de las otras organizaciones no gubernamentales.

De esta forma, el voluntariado, y con él las organizaciones sociovoluntarias, se han convertido en los últimos años en objeto de diversas iniciativas legislativas tanto autonómicas como estatales. Si bien fueron las regulaciones autonómicas las pioneras en el tratamiento de la materia que nos ocupa ${ }^{8}$, será la Ley estatal sobre voluntariado 6/1996, de 15 de enero, el hito fundamental en el desarrollo legislativo acerca de la materia.

Fruto del consenso entre los dos partidos mayoritarios (Partido Popular y Partido Socialista Obrero Español), la Ley de Voluntariado tiene según su Exposición de Motivos una triple tarea: por un lado «garantizar la libertad de los ciudadanos a expresar su compromiso solida-

\footnotetext{
Haciendo referencia a la misma en la mayor parte de las leyes de servicios sociales (excepto Aragón y País Vasco) y desarrollando legislaciones específicas sobre voluntariado en algunas Comunidades como Cataluña, Castilla-La Mancha, Castilla-León, Aragón, La Rioja, Madrid y Andalucía.
} 
rio a través de los cauces que mejor se acomoden a sus más íntimas convicciones»; en segundo lugar, «promover e impulsar eficazmente la acción voluntaria en sus diversas modalidades; y, finalmente, «respetar el orden constitucional de distribución de competencias y, por tanto, las normas que sobre esta materia hayan dictado o puedan dictar en el futuro las Comunidades Autónomas».

Se consideran, por parte de la Ley, como voluntarios/as a aquellas personas que desarrollen actividades de carácter altruista y solidario, de forma libre y sin contraprestación de carácter económico (art. 3 de la citada Ley).

Igualmente, establece la Ley los derechos y obligaciones del voluntario. Así, el artículo 4 reconoce entre los derechos del mismo, el de recibir información y formación, participar activamente en la organización en que se inserten, así como el de ser asegurados contra los riesgos de accidente y enfermedad derivados directamente del ejercicio de la actividad voluntaria.

Pero también al voluntario se le prescriben una serie de deberes que salvaguardan la integridad de las actividades que desarrolla dentro de la entidad en que se encuentre. De esta forma, aparecen como obligaciones del voluntariado el cumplir con los compromisos adquiridos con las organizaciones en las que se integran, guardar, cuando proceda, confidencialidad de la información recibida y conocida en el desarrollo de su actividad voluntaria y rechazar cualquier contraprestación material que pudieran recibir bien del beneficiario o de otras personas relacionadas con su acción.

La aportación solidaria realizada a través del voluntariado no puede convertirse en un deber jurídico -aunque sí moral-, no obstante, la fijación de este artículo 7 trataría en parte de dar salida a los problemas de la organización y el voluntario, gran parte de ellos cifrados en la imposibilidad de planificación por parte de la entidad, debido al no siempre previsible comportamiento del voluntario.

La Ley del Voluntariado contempla la acción voluntaria integrada dentro de organizaciones, bien sean estas de carácter privado o público, jugando así la administración un doble papel al ser posible entidad de voluntariado, al tiempo que instancia de fomento del mismo. Tal hecho podría generar un modelo «público» de voluntariado no exento de riesgos tales como que el voluntariado se convierta en un «un mecanismo 'tapa agujeros', la tendencia hacia una progresiva 'voluntari-

- García Inda, A. (1996): «Aspectos legales del voluntariado: El modelo de la Ley 6/1996, de 15 de Enero» en Documentación Social, $\mathrm{n}^{\circ}$ 104, pág. 213. 
zación' del sistema público, y la posibilidad de que se produzca una excesiva administrativización e instrumentalización de la acción voluntaria»".

Sin embargo, si bien las posturas de los diversos agentes políticos y sociales coincidían en la necesidad de establecer cauces jurídicos adecuados para la regulación del voluntariado y las organizaciones voluntarias, la valoración de la ley que trata de cubrir este objetivo es desigual, centrándose las mayores críticas en los artículos 14 y 15 de la misma. En lo que se refiere al primero de ellos, su texto establece la posibilidad de que se concedan bonificaciones o reducciones en el pago de servicios públicos, así como «otros beneficios que reglamentariamente puedan establecerse como medida de fomento, reconocimiento y valoración social de la acción voluntaria». En este sentido, las críticas han surgido en torno a la posible contradicción que se pueda establecer con el propio concepto de acción voluntaria establecida en el texto de la ley, la cual es definida como una acción altruista. ${ }^{11}$

El art. 15 es otra de las disposiciones polémicas dentro del texto de la ley. En el mismo, se establece la posibilidad de que el tiempo prestado como voluntario pueda surtir efectos a la hora de sustituir el servicio militar o la prestación social sustitutoria. Sin embargo, la posibilidad de asimilar ambos tipos de servicio parece incierta en el mismo momento en que consideramos su carácter diferenciador de base: mientras que el voluntario actúa de forma libre, en el caso del servicio militar y la «PSS», se actúa bajo la coacción de las posibles sanciones establecidas por parte del Estado en caso de no prestar dichos servicios.

Por último, podrían apuntarse algunas cuestiones que aún están pendientes de resolver, tales como el ámbito de aplicación de la ley y las relaciones con los diferentes modelos autonómicos. En este sentido, sería necesario establecer si la ley debería jugar el papel de una «ley marco» que dictara las directrices fundamentales para el desarrollo jurídico de la materia. Igualmente, debería establecerse de forma más diáfana si los destinatarios son los voluntarios, las organizaciones en que se integran o ambos.

11) Esta crítica se hizo manifiesta por parte de diversas organizaciones políticas y sociales, entre ellas, Izquierda Unida, Cáritas, Cruz Roja o la Plataforma para la Promoción del Voluntariado, que en el manifiesto del «Día Internacional del Voluntario», del año de promulgación de la Ley, señalaba «...lo que verdaderamente nos identifica y nos une es la gratuidad desde la que realizamos nuestra tarea, las contraprestaciones e incentivos son contrarios al espíritu y a la esencia del voluntariado». En Documentación Social, $n^{\circ} 103$, pág. 240. 


\section{UN ESPACIO SOCIAL MULTIFORME.}

Tal y como venimos señalando, las formas organizativas que toma la iniciativa social son diversas. A cada una de ellas corresponde unas características específicas al tiempo que un tratamiento legislativo particular. A continuación, trataremos de aquellos tipos organizativos que resultan más significativos dentro de este espacio social multiforme, entre ellos, asociaciones, fundaciones y entidades singulares como Cáritas, la Organización Nacional de Ciegos o Cruz Roja.

\subsection{Asociaciones.}

La asociación ha venido constituyéndose en forma usual bajo la cual identificar las diversas solidaridades que al margen del Estado se vertebran. Una asociación voluntaria, desde esta concepción amplia, estaría constituida por un grupo de personas que tratan de lograr un objetivo común e independiente de la actuación del Estado y cuya afiliación sea voluntaria. ${ }^{11}$

No obstante, dicha definición incluiría a entidades que escapan a nuestro objeto de estudio, tales como sindicatos, partidos políticos, cooperativas, etc. De ahí que se haga necesaria una definición más restringida del concepto, pudiendo provenir la misma del reconocimiento legal del fenómeno.

Sin embargo, el derecho de asociación, recogido en el artículo 22 de nuestra Constitución, no ha recibido un tratamiento esclarecedor que establezca los cauces adecuados para tal realidad. El marco normativo que regula las asociaciones sigue definido por la Ley de 24 de diciembre de 1964, lo cual, dada la antigüedad de la misma, produce una situación de inseguridad jurídica frente a un fenómeno tan cambiante como el constituido por la realidad asociativa. ${ }^{12}$ En este sentido, nos encontramos con un marco normativo, en el que si bien se han producido progresos - a través de la Ley del Voluntariado y la Ley de Fundaciones-, será necesario seguir avanzando en la adaptación de dicha legislación a las necesidades que plantea la realidad asociativa.

Existen diversos tipos de asociaciones. Clasificados por el sector en el que desarrollan su actuación, nuestro interés se centra en aquellas asociaciones que desarrollan su actividad en el ámbito de la acción

11 Sills, D.L.: «Asociaciones Voluntarias» en Sills, D.L. (dii) (1972): Enciclopedia International de Ciencias Sociales. Ed.Aguilar. Madrid.

12 Op.cit. Aznar López, M., 1996; Aznar López, M. y Ruiz, B. (1991): «La configuración jurídica de las entidades no lucrativas de tipo social y humanitario: protección y promoción por el Estado» en VV.AA. (1993): El Sector no Lucrativo en España. Ed. Escuela Libre. Madrid. 
social. Es este mismo carácter de su actuación el que va a configurar la existencia de unas relaciones de especial interés con la administración social gubernamental. En efecto, partiendo del supuesto de la responsabilidad compartida sobre el bienestar social, se incentiva, por parte del Estado, la colaboración de las entidades voluntarias a través de diversas fórmulas: concesión de subvenciones, establecimiento de exenciones fiscales, diversas formas de colaboración a través de contratos, convenios y conciertos, o la declaración de utilidad pública.

En este sentido, las asociaciones distinguidas con este último carácter poseerán una serie de privilegios cuyo tratamiento se ha modificado en parte a raíz de la Ley de Fundaciones y de Incentivos Fiscales a la Participación Privada en Actividades de Interés general. Se trata, por tanto, de asociaciones dirigidas a la obtención de un «bien común» o, siguiendo la nueva regulación, de un «interés general», sin que medie ánimo de lucro y cuya actuación esté sujeta a la actividad interventora del Estado girando sus beneficios, fundamentalmente, en torno al régimen y tratamiento fiscal de las aportaciones realizadas a estas entidades por personas físicas y jurídicas. ${ }^{13}$

\subsection{Fundaciones}

La Fundación será otra de las figuras jurídicas fundamentales que darán forma a la realidad de la acción voluntaria. Los tipos de Fundación serán muy diversos dependiendo de los fines a los que dirijan su acción. En este sentido, dependiendo de los mismos, el protectorado de dichas entidades -característica que las distinguen de otras formas del Tercer Sector- recaerá sobre organismos públicos distintos. En el ámbito que nos ocupa, el Ministerio de Trabajo y Asuntos Sociales, mediante la Dirección General de Acción Social, ejerce el protectorado sobre fundaciones benéfico asistenciales y personas jurídicas privadas dotadas de patrimonios afectados a la realización de fines de interés general. En todo caso, y como parte integradora de esa función de protectorado, al Estado -bien sea a nivel central o a nivel autonómico, dependiendo del ámbito de la asociación-corresponderá velar por el efectivo cumplimiento de la voluntad del fundador para lograr la máxima rentabilidad social.

Rodríguez Cabrero, G. y Monserrat Codorniú, J. (dirs) 1996: Las Entidades Voluntarias en España. Institucionalización, estructura económica y desarrollo asociativo. Ed. Ministerio de Asuntos Sociales. Madrid, pág. 201. No obstante, es necesario especificar al respecto que no toda asociación por el hecho de adquirir el carácter de utilidad pública accederá de manera automática a este tratamiento fiscal, puesto que existen una serie de requisitos específicos previstos para tal fin. 
Las fundaciones cuentan con una larga trayectoria en su reconocimiento jurídico ${ }^{14}$, si bien será la Ley 39/1994, de 24 de noviembre, la que ordene la producción normativa en torno a las mismas y las dote de un marco renovado de actuación ${ }^{15}$. De esta forma, dicha ley vendrá a aclarar, tal y como señala en su exposición de motivos, una situación de «maraña legislativa constituida por reglas dispersas y dispares, con una vigencia y validez más que dudosas y del más variado tipo, lo que hacía imprescindible simplificar el sistema dotándole de claridad y racionalidad y reformando la seguridad jurídica».

La Ley 30/1994 define las fundaciones como «las organizaciones constituidas sin ánimo de lucro que, por voluntad de sus creadores, tienen afectado de modo duradero su patrimonio a la realización de un fin de interés general». En efecto, las fundaciones son instituciones con la cualidad de personas jurídicas, creadas por particulares, estableciendo un fondo de bienes propios para la realización de un bien general. De esta forma, podemos observar tres elementos fundamentales de la Fundación: patrimonio, ${ }^{16}$ organización y fin.

Atendiendo a la configuración autonómica de nuestro Estado, las competencias en materia de Fundaciones han venido siendo delegadas, en ocasiones totalmente y en otras en alguno de los aspectos que atañen a la materia, a las Comunidades Autónomas. En este sentido, existen Comunidades con autonomía plena y otras con autonomía gradual. Entre las primeras encontramos: Cataluña, País Vasco y Galicia, Andalucía por vía de referéndum, Navarra y las comunidades con competencias delegadas por el Estado por vía orgánica: Canarias y Valencia. Entre las segundas: Asturias, Aragón, Baleares, Cantabria, Castilla La Mancha, Castilla-León, Extremadura, Madrid, Murcia y La Rioja.

En cualquier caso, la regulación normativa de las fundaciones ha supuesto un importante avance en el tratamiento realizado sobre dicha realidad. Dicho esfuerzo se juzgaba cada vez más necesario a la hora de evitar un contexto propicio para la indefinición, en el cual se llegaran a camuflar intereses particulares bajo el halo del interés general. En efecto, los últimos años han protagonizado el auge de diversas fun-

14 Así, su reconocimiento jurídico parte de la instrucción sobre beneficiencia de 1899 y el Real Decreto de I de octubre de 1919. Con la aparición de la Constitución de 1978, quedará recogida su existencia en su art. 34.1 al establecer: «Se reconoce el derecho de fundación para fines de interés general».

15. Aznar López, M. (1996): «La configuración jurídica de las entidades no lucrativas de tipo social y humanitario: nuevas perspectivas» en Documentación Social, págs. 211 y ss.

16 Se considera imprescindible que la fundación cuente con unos fondos económicos que garanticen los fines fundacionales, estableciendo, el art. 10 de la mencionada Ley, que la dotacion deberá ser adecuada y suficiente para el cumplimiento de los fines fundacionales, con lo que parece salir al paso de la constitución de fundaciones vacías. 
daciones, muchas de ellas surgidas al calor de la banca, otras conexas con el mundo empresarial, cuya existencia era necesario regular, especialmente cuando la misma se movía entre el terreno lucrativo y no lucrativo sin clara definición, levantando de esta forma sospechas acerca de la creación de tales fundaciones como forma para lograr mayores beneficios e incentivos fiscales, medidas de apoyo tradicionalmente concedidas por el Estado dentro de su labor de protectorado sobre la fundación.

\subsection{Entidades singulares: Cáritas, Organización Nacional de Ciegos y Cruz. Roja.}

Con un amplio desarrollo histórico en nuestro país, y manteniendo vínculos de relación de carácter específico con la administración social, Cáritas, ONCE y Cruz Roja aparecen como entidades a las que dedicamos especial atención por su singularidad.

\subsubsection{Cáritas.}

Cáritas nace al amparo de la tradición dentro del campo de la acción caritativa emprendida por la Iglesia prácticamente desde su surgimiento hasta la actualidad -si bien con las peculiaridades que los cambios sociales y políticos han venido marcando a la luz de la trayectoria del devenir histórico--. Cáritas surge en 1942 como Secretariado Nacional de Caridad dentro de Acción Católica, organización esta última que trataba de coordinar las actividades de las asociaciones católicas.

Dentro de la trayectoria de Cáritas, y tal como señala Gutiérrez Resa $^{17}$, se pueden distinguir diferentes etapas caracterizadas por rasgos distintos:

1. Etapa fundacional (1942-1963). Destaca esta primera etapa por la atención a casos concretos y la intervención con motivo de grandes catástrofes nacionales e internacionales. Entre las acciones desarrolladas en esta época cabe destacar la organización en 1949 de la acogida de los niños abandonados tras la Segunda Guerra Mundial procedentes de Centroeuropa y la gestión de la Ayuda Social Americana.

2. Etapa de «tecnificación y planificación de la caridad» (1963-1973). En esta etapa se dirigirán los esfuerzos a hacer compatibles la cari-

17 Gutiérrez Resa, A. (1995): «Iniciativa social y servicios sociales» en Alemán Bracho, M.C. y Garcés Ferrer, J. Administración Social: servicios de Bienestar Social. Ed. Siglo XXI. Madrid, págs. 295 y ss. 
dad con la planificación de la acción social. El desarrollo del Plan Nacional de Promoción, Asistencia Social y Beneficencia y la creación de la fundación para el Fomento de Estudios Sociales y de Sociología Aplicada, FOESSA, como medio a través del cual realizar un diagnóstico adecuado de la realidad, serán muestra de esta filosofía.

3. «Etapa de denuncia profética o crítica» (1973-1976). Coincidiendo con la dinamización de la sociedad civil que conlleva la gestación del cambio político, Cáritas se alzará en diversas ocasiones como portavoz crítico que trata de denunciar las situaciones de injusticia social producida.

4. «Etapa de profundización» (1976-1979). Llegados a la recién inaugurada democracia, Cáritas conserva y profundiza las líneas de denuncia y asistencia social intentando atajar los problemas desde la raíz, consciente de que el desarrollo del incipiente 'Estado de bienestar' no supone la retirada de la sociedad civil del campo de la acción social.

5. «Etapa de las Autonomías y de la Animación». (1979-1983). Ante la aparición de nuevos problemas, tales como el crecimiento del desempleo, la organización emprende numerosas acciones en el campo de la animación comunitaria, la comunicación de bienes, el desarrollo institucional, cuidándose tanto los aspectos preventivos como formativos, y manteniendo labores de asistencia.

6. «Etapa de diálogo» (1983-1985). Se profundiza en la investigación social con estudios sobre la pobreza o la inmigración. Se trata de una etapa de diálogo entre las distintas posturas que se defienden en el seno de Cáritas, así como con la administración.

7. «Etapa de eficacia empresarial y espíritu cristiano comprometido» (1985-1988). Se busca la compatibilidad de ambos principios considerando que la búsqueda de la equidad no debe aparecer necesariamente reñida con la gestión adecuada de unos recursos escasos.

8. «Etapa de cohesión, coherencia y eficacia» (1989-1991). La coordinación se sigue poniendo de manifiesto como un principio fundamental dentro de la institución, tanto a nivel nacional como europeo.

Cáritas Española, tal y como ponen de manifiesto los Estatutos aprobados en la VI Asamblea Plenaria celebrada en 1967 -los cuales han sido objeto de sucesivas reformas-, es la Confederación oficial de las entidades de acción caritativa de la Iglesia Católica en España, instituida por la Conferencia Episcopal, entendiéndose como instrumento de la acción de los seglares en pro de la justicia social definida como deber como miembros de la Iglesia. 
Los fines de la organización, tal y como recoge el art. 10 de los citados estatutos serán «la realización de la acción caritativa y social de la Iglesia en España, a través de sus miembros confederados. Para ello se pone al servicio del Pueblo de Dios con el fin de promover y coordinar la comunicación cristiana de bienes en todas sus formas y de ayudar a la promoción humana y al desarrollo integral de todos los hombres».

Cáritas, al formar parte de la Iglesia, depende de la Comisión Episcopal de Pastoral Social, como 'departamento' dentro de la Conferencia Episcopal. Dicha Comisión elige al presidente y al secretario de la organización, contando para el mejor desarrollo de los fines trazados con una estructura organizativa compuesta por la Asamblea, el Consejo y la Comisión permanente. ${ }^{18}$ Junto a estos órganos establecidos a nivel central, Cáritas cuenta con Cáritas Diocesanas que trabajan en ámbitos locales coincidiendo este, aunque no necesariamente, con el provincial.

En la actualidad los recursos económicos de Cáritas provienen, tal y como señala Gutiérrez Resa, de tres fuentes fundamentales: la cuota de las Cáritas Diocesanas, los ingresos por actividades (recuperación de propaganda y publicación, donaciones de terceros, intereses bancarios...) y las subvenciones concedidas por la administración pública. ${ }^{19}$

Con el establecimiento de estos soportes organizativos, económicos y humanos, Cáritas se sitúa en un lugar destacado dentro de la acción social actual. En efecto, junto a los planteamientos de caridad cristiana y denuncia que se habían planteado con anterioridad, y que aún se consideran líneas prioritarias en la actuación de Cáritas, se apuesta, como se puso de manifiesto en la XLII Asamblea de Cáritas Española de 1987, por la solidaridad, no sólo de servicios sino preventiva, pudiendo esta establecer las condiciones que permitan evitar los riesgos de exclusión social ${ }^{20}$. En dicha labor, la participación de la comunidad resulta fundamental, de ahí que, desde la organización, se elaboren acciones destinadas a la promoción y formación del voluntariado.

No obstante, son diversos los retos que se le plantean a Cáritas, así lo reconocía María Antonia Guillén, quien considera que, en ocasiones, el trabajo con cada colectivo se realiza de manera aislada, sin aplicar el principio de coordinación anteriormente expuesto. Asimismo, se plantea desde la misma organización la necesidad de incidir más en los

18 Gutiérez Resa, A. (1993): Cáritas Española en la Sociedad del Bienestar. 1942-1990. Ed. Hacer: Barcelona, págs. 298 y ss.

19. Idem, 310

20) Idem, 396 
aspectos relacionados con la prevención y la reinserción, así como en la actuación sobre aquellos grupos en alto riesgo de exclusión social. ${ }^{2 !}$

\subsubsection{Organización Nacional de Ciegos (ONCE)}

La Organización Nacional de Ciegos Españoles, se constituye como agrupación de deficientes visuales españoles, que, admitidos estatutariamente en ella, deberán afiliarse obligatoriamente para acceder a sus prestaciones y prerrogativas sociales, y sin perjuicio de gestionar y defender sus funciones privativas, ejercer determinadas funciones delegadas de las Administraciones públicas. ${ }^{22}$

La ONCE fue creada el 13 de diciembre de 1938, por un Decreto dictado en plena Guerra Civil. ${ }^{23}$ De esta forma, el Estado distinguió al colectivo de los invidentes de otros colectivos de minusválidos que igualmente pudieran haber sido favorecidos por la administración.

Desde entonces, y especialmente a partir de la década de los ochenta en la que el intervencionismo estatal se frena con el cambio de régimen político y se demanda una nueva estructura más democrática de la organización, diversas transformaciones se han producido, siendo éstas recogidas en varias propuestas normativas que se suceden a lo largo del tiempo. Así, desde 1980, la ONCE atraviesa un proceso de transformación interna, expansión económica y orientación de actividades que ha llevado a proyectar su acción hacia otros grupos en desventaja, además de los invidentes.

El Real Decreto 1041/81, de 22 de mayo, organizó la ONCE y posibilitó la realización de las primeras elecciones en 1982. Posteriormente, el Real Decreto 2385/85, de 27 de diciembre, modifica su estructura orgánica, desarrollada más tarde por Orden de 14 de febrero de 1986, aprobándose sus Estatutos dos años más tarde. Entre las más recientes medidas, concernientes a la estructura y funciones de la organización se encuentra el Real Decreto 358/1991 de 15 de marzo, por el que se reordena la ONCE, así como los Estatutos sometidos a revisión parcial.

21 Gutiérrez Resa, A. (1993): Cáritas Española en la Sociedad del Bienestar. 1942-1990. Ed. Hacer. Barcelona, pägs. 407-408.

22 Según el Título I de los estatutos de la organización, definida bajo la protección del Estado a través del Real Decreto 358/1991, de 15 de marzo. Acerca de la naturaleza jurídica de la ONCE, ver De Lorenzo García, en VV.AA. (1993): El sector no lucrativo en España. Ed. Escuela Libre. Madrid.

2.3 El Decreto fundacional se desarrolló por Orden del Ministerio de Gobernación de 28 de octubre de 1939, el cual reconoce la existencia de la principal fuente de recursos de la organización: el cupón. 
En función de sus fines -reconocidos tanto en el R.D. 358/1991 art. 2, como en los Estatutos de la Organización, art. 6- la ONCE aparece como Entidad prestadora de servicios en acción social, servicios educativos, culturales y de apoyo al empleo para las personas invidentes y discapacitadas.

La estructura de la organización se configura en: Consejo General y Dirección General. El Consejo es el órgano de elaboración de la política de la entidad en sus diversos aspectos. Aprueba las reglamentaciones internas, promueve medidas legislativas, elabora los estatutos, aprueba los presupuestos, establece la política general de la entidad y los planes de actuación, nombra y cesa al Director General, convoca elecciones, etc. En el ámbito territorial se cuenta con los Consejos Territoriales que poseen competencias análogas al General. A la Dirección le corresponde la ejecución y gestión de los acuerdos del Consejo así como la responsabilidad de la gestión administrativa.

La ONCE es una entidad singular tanto por el alto número de afiliados -no podía ser de otra manera ya que para acceder a las prestaciones y servicios de la Fundación hay que ser miembro de la misma-, como por la excepcionalidad de su fuente financiadora: el cupón.

Al comienzo, la ONCE tenía entre sus fines -de hecho, aún lo mantiene- el de procurar a los invidentes un trabajo productivo en igualdad de condiciones al resto de los trabajadores, siendo una minoría de ellos los que se dedicarían a la venta del cupón. Pero, tal y como señala Garvía Soto, después de 40 años, la mayor parte de los afiliados vendía el cupón y sólo una minoría había encontrado trabajo externo.

De 1939 a 1983 la forma del cupón no experimentó variación, siendo el porcentaje destinado a premios de un $47 \%$ de la recaudación. En 1984 se produce un salto en el volumen de ingresos, debido en parte a la Primera Reforma del cupón. La Segunda Reforma del cupón, realizada en 1985, concederá el sábado como día de descanso para el personal, compensando esta medida con el sorteo especial del viernes.

El éxito de las reformas emprendidas, con un aumento de recaudación considerable, tuvo como consecuencia que el Ministerio de Economía y Hacienda considerase que ello colisionaba con los intereses comerciales de los juegos que gestionaba su Organismo Nacional de Loterías y Apuestas del Estado, por lo que, en uso de las prerrogativas que la administración tiene sobre la ONCE se estableció un férreo control sobre el mecanismo referente a la venta del cupón. El mismo dio lugar a un descenso de las ventas que trató de ser recuperado a través de nuevas bonificaciones en los premios. ${ }^{24}$ 
La expansión económica de la ONCE y los cambios en la orientación motivaron que el Consejo del Protectorado aprobara en 1987 la utilización de un 3\% de los ingresos por ventas del cupón en un programa destinado a personas con minusvalías. Para ello, se constituyó la Fundación ONCE, para la cooperación e integración social de las personas con minusvalía.

De esta forma, se ha ido produciendo progresivamente un cambio en la población objeto de las actuaciones de la ONCE, ya que proporciona más de mil puestos de trabajo a otros minusválidos físicos, psíquicos y sensoriales. Al mismo tiempo, ha tratado de introducir nuevas actividades económicas, invirtiendo en sectores distintos del juego para obtener de esta manera una diversificación de riesgos -diversas empresas, entre ellas alguna relacionada con el ámbito de las comunicaciones, contempla, la entrada de capital de la ONCE-.

Sin embargo, son varias las particularidades de esta organización, algunas de las cuales han puesto en tela de juicio su propia adscripción como Organización No Gubernamental -dado el protectorado ejercido por la Administración-, como su encuadre dentro del Tercer Sector, o sector no lucrativo, al acercarse al ámbito empresarial y de la inversión en esta nueva etapa que trata de diversificar los posibles riesgos de unos fondos económicos dependientes únicamente de la venta del cupón. En este sentido, y tal como plantea Garvía, «para la organización de ciegos, el problema consiste en convencer a la sociedad española de que una organización sin ánimo de lucro no tiene porqué congelar sus recursos, o arrinconarlos en una cuenta bancaria» (Garvía Soto, 1993: 259).

\subsubsection{Cruz. Roja Española.}

Nacida la sección de Cruz Roja española en 1864, el paso del tiempo ha marcado una progresiva consolidación de dicha organización. Se trata de una institución humanitaria de carácter voluntario y de interés público, que desarrolla su actividad bajo la protección del Estado español. Posee personalidad jurídica propia y plena capacidad jurídica y patrimonial para el desempeño de sus fines. Forma parte del movimiento internacional de la Cruz Roja, acomodando su actuación a los principios fundamentales de este: humanidad, imparcialidad, neutralidad, independencia, unidad, voluntariado y universalidad.

Entre los objetivos de la Cruz Roja española se encuentran la búsqueda y fomento de la paz, defensa de los Derechos Humanos fundamentales, atención a personas y colectivos que sufren, y la promoción y colaboración en acciones de bienestar social tanto en el ámbito de los servicios sociales como en programas de salud. Todo ello sin discrimi- 
nación de sexo, edad, raza, nacimiento, religión, credo político o cualquier otra condición.

Cruz Roja dirige, de esta forma, su atención hacia la población en general, a través de la acción socio-sanitaria, la promoción de la salud, creación de centros hospitalarios, programas de donación de órganos, transporte sanitario, búsqueda de personas desaparecidas y salvamento marítimo y asistencia en playas y aguas interiores. No obstante, junto a estos servicios ofrecidos a la población de forma general, Cruz Roja, particulariza su atención hacia los colectivos desfavorecidos, entre ellos personas mayores, refugiados y extranjeros, toxicómanos, enfermos y afectados de SIDA, población reclusa, infancia y juventud marginada y personas con discapacidad..$^{25}$

Cruz Roja llevará a cabo, igualmente, una labor de sensibilización y actuación en áreas que atañen bien a la protección del medio ambiente, bien a la colaboración con pueblos menos favorecidos, fomentando de esta forma la cooperación al desarrollo como estrategia en la búsqueda del bienestar internacional. Entre las acciones que ha venido poniendo en marcha dentro de este último ámbito se encuentran la asistencia y desarrollo comunitario con colectivos especialmente vulnerables, tales como la integración de refugiados en Centroamérica, la atención primaria de salud y otros aspectos sanitarios a través, por ejemplo, de acciones de lucha contra el SIDA en buena parte de África, así como formación, acción social y asistencia técnica para el desarrollo.

Para la puesta en marcha de las acciones inscritas en estos diversos campos señalados, la Cruz Roja cuenta con una estructura en la que la Asamblea General es el máximo órgano de gobierno, emanando del mismo el Comité Nacional a quien corresponde la dirección y control de la gestión de la Cruz Roja. Sus órganos de gobierno se estructuran territorialmente a través de los niveles autonómico, provincial y local; en todos ellos se cuenta con Asambleas y Comités que coordinan las acciones de la organización.

Igualmente, cuenta con un fuerte soporte formado por socios activos, voluntarios, socios suscriptores, los donantes de sangre y los miembros de Cruz Roja Juventud, sin olvidar aquellos que realizan con Cruz Roja la prestación social sustitutoria. 


\section{LA NECESARIA BÚSQUEDA DE LA EFICIENCIA.}

Siendo las coordenadas de las entidades voluntarias las expuestas anteriormente para el caso español, conviene detenernos en los criterios que argumentan la participación de la iniciativa social, frente o junto a, el mercado o la acción gubernamental. Desde este punto de vista, atenderemos a continuación a los elementos que permiten el establecimiento de unas coordenadas de acción para un marco de desarrollo institucional adecuado a dichas entidades que permita la superación de las críticas de las que, en ocasiones, han venido siendo objeto.

\subsection{La opción más adecuada: ¿Estado, Mercado o Tercer Sector?}

Diversos actores, bajo distintas formas en su evolución histórica, se han venido dando cita en la contribución al bienestar social. Formando parte los mismos bien del Estado, del Mercado o del Tercer Sector, presentan una serie de caracteres propios que se convierten en ventajas comparativas, en ocasiones, dentro del ámbito de la acción social. Desde diversos frentes, se viene haciendo hincapié en el necesario aumento del Tercer Sector en el desarrollo social y la mejora de la calidad de vida de los ciudadanos, especialmente de aquellos que se encuentran en desventaja o riesgo de exclusión social. Pero, ¿cuáles son las ventajas de la iniciativa social frente al resto de los actores? y, ¿hasta qué punto la misma se mantiene en todas las situaciones y sectores sociales a cuyas necesidades se trata de hacer frente?

A continuación, trataremos de avanzar algunos intentos de respuesta para estas cuestiones, tratando de conocer aquellos elementos que definen a los actores públicos y privados en su contribución al bienestar.

\subsubsection{El Estado.}

La intervención pública aparece, en términos relativos, como uno de los actores más recientes dentro del ámbito de la acción social: primero, reglamentando otras modalidades de actuación frente a las necesidades, como fue el caso de la reglamentación de la beneficencia particular y de las ayudas a los necesitados, más tarde siendo agente directo de las acciones encaminadas a tal fin.

Como argumentos en favor de la acción pública se han señalado diversas ventajas en favor de la provisión pública de bienes y servicios sociales, entre ellas las siguientes:

a. Se promueve un fin social más que el interés personal, la integración social más que la diferenciación individual. 
b. El control colectivo de los servicios sociales, a través de representantes democráticamente elegidos, aboga en contra de la explotación de aquellos cuya posición de necesidad puede colocarlos en una situación de debilidad ante los proveedores que tratan más de maximizar el beneficio que de lograr un bien social.

c. Los servicios colectivos son distribuidos de acuerdo con la necesidad social, y no siguiendo un estrecho baremo de prioridades económicas.

d. El control público es necesario para proveer servicios regulares, estandarizados y eficientes

e. Por último, los servicios sociales pueden contrarrestar la tendencia natural de la empresa capitalista a incrementar las desigualdades en la distribución de recursos, estatus y poder. ${ }^{26}$

Es el ámbito de lo público el que aparece ante la ciudadanía como mayor responsable de la satisfacción de las necesidades, y no sólo de la iniciativa, sino de la calidad y control de las acciones realizadas tanto por el mismo como por otros actores. En este sentido, la actuación del sector público será central, pero también mejorable. Tal y como reconoce Donahue, «ello es así por tres razones fundamentales. En primer lugar, porque algunas de las funciones más cruciales de cualquier sociedad deben desarrollarse en forma colectiva. (...). Segundo, porque el público en general -precisamente por tratarse de una categoría amplia y diversa- está particularmente expuesto a descuidos por parte de las autoridades, en lo que respecta a que éstas no tomen debidamente en cuenta sus intereses. Tercero, el individuo es naturalmente vulnerable frente a los poderes gubernamentales, aspecto que la historia ilustra profusamente y que la Constitución trata ingeniosamente de remediar». ${ }^{27}$

El trabajo de la administración pública no tiene porqué ser necesariamente sinónimo de eficacia y equidad. Hemos de estar, por tanto, precabidos ante el hecho de que bajo el paraguas de lo público se amparen acciones cuya calidad podría ser mejorada, sirviendo tal amparo para el rechazo de nuevas formas de gestión, muchas de ellas ya experimentadas en el ámbito privado, que pudieran incrementar la calidad de los servicios y prestaciones de carácter público.

De ahí que, en muchas ocasiones y en gran parte ante la crisis que en diversos ámbitos sufre el Estado -incluido el de la gerencia de políticas y programas públicos- se postule una mayor participación del

26) Walker, A. (1984): «The political economy of privatization» en Robinson, R. y Le Grand, J. (eds): Privatization and the Welfare State. Ed. Unwin Hyman. Boston, págs. 20-21.

27 Donahue, J.D. (1991): La decisión de privatizar. Fines públicos, medios privados. Ed. Paidós. Barcelona, pág. 27. 
resto de los agentes de bienestar, bien desde el mercado, bien desde el Tercer Sector en sus diversas formas, en la provisión de acciones que generen medios para hacer frente a las necesidades.

\subsubsection{El mercado.}

Las acciones llevadas a cabo desde el mercado tienen un fin lucrativo y exclusivista ante el cual podríamos cuestionarnos la idoneidad de dicho mecanismo como forma de satisfacer las necesidades sociales. En efecto, por un lado la búsqueda del beneficio parece ser incompatible con la prestación de unos servicios en los que los costes son, en la mayor parte de los casos, más altos que los beneficios, y la inversión más arriesgada. Por otro lado, la acción dentro del mercado es exclusivista desde el momento en que los beneficios son percibidos por un individuo o un grupo de individuos, no repercutiendo, al menos de forma directa, en el bienestar de la colectividad.

No obstante, y a pesar de lo anteriormente expuesto, el mercado supone un mecanismo más de satisfacción de necesidades, un principio para la organización de la producción y distribución a través del sistema de precios, sin el cual difícilmente podríamos establecer el valor de aquello que deseamos. Obviando este mecanismo, apenas llegaríamos entonces a conocer y valorar las necesidades. Así lo pone de manifiesto Donahue: «aún una sociedad de altruistas requeriría de ciertos medios fiables para que sus miembros se enterasen de qué es lo que haría felices a sus vecinos (...). Los precios trasmiten información. . ${ }^{28}$

Sin embargo, el mercado presenta una serie de limitaciones a la hora de dar cuenta de las necesidades que presentan los individuos y grupos sociales. Entre ellas será preciso tener presentes las que siguen:

- No tiene en cuenta las consecuencias de su acción productiva, las cuales generarían una serie de costes sociales y ecológicos que suscitarían más necesidades, y no la satisfacción de las mismas ${ }^{29}$

- Difícilmente se pueden aplicar los criterios de eficacia que corresponden al mercado a servicios que escapan a la medición en términos de Producto Interior Bruto.

Existen, por tanto, tareas que no pueden organizarse a través del mercado, pudiendo señalar, junto a las limitaciones anteriores, al menos dos tipos de motivos por los que resulta inadecuado que dicho sistema monopolice la provisión de bienestar ${ }^{30}$.

2s Idem, pág. 33.

29 De Alessi: «How markets alleviate Scarcity» en Ostrom, V. y otros: Rethinking Institutional analysis and development. Ed. International Center for Self-Governance. San Francisco, págs. 360-369.

3) Op.cit. Donahue, págs. 35 y ss. 
a. Motivos de ineficiencia del mercado. Existen una serie de «bienes públicos» que no pueden ser suministrados por el mercado ya que los beneficios no llegarían a cubrir los costes del inversor privado, tal y como sucede normalmente con las grandes obras e infraestructuras o determinados servicios que entran dentro del campo del bienestar social.

b. Motivos morales o filosóficos, ya que algunas metas morales y filosóficas pueden ser más eficientemente acometidas por el Estado. Así lo señala Donahue: «La iniciativa privada funciona muy bien cuando se trata de alimentar a víctimas de un terremoto, no tan bien cuando hay que apoyar guerrillas ideológicamente afines y bastante mal si se trata de explorar las lunas de Marte».3.1

Pese a estas dificultades presentadas por la opción en pro del mercado, es preciso advertir que en las dos últimas décadas esta vía ha cobrado especial relevancia como consecuencia de dos factores mutuamente relacionados. De una parte, la crisis económica ha impulsado a numerosos Gobiernos a orientar hacia el mercado la satisfacción de necesidades. Y de otra, el influjo del liberalismo ha acrecentado igualmente la presencia de los mecanismos del mercado mediante la política de privatizaciones.

\subsubsection{El Tercer Sector.}

Contando con una amplia participación del voluntariado, el Tercer Sector presenta una serie de elementos que, en principio, dotarán de una serie de ventajas comparativas a su actuación frente al resto de los sectores.

A diferencia del mercado, no presenta como prioridad la búsqueda del beneficio económico, lo cual lo hace más adecuado a un ámbito en el que los servicios y prestaciones no siempre pueden someterse a la balanza coste-beneficio en términos puramente económicos. En este sentido, las entidades no lucrativas dirigirán hacia los colectivos más desfavorecidos aquellos servicios en los que la rentabilidad social es mayor que la económica.

Por otro lado, dichas entidades presentan también ventajas comparativas respecto a los actores públicos. Frente a estos, se considera que las organizaciones que forman parte del Tercer Sector poseen unos niveles inferiores de burocratización y, consecuentemente, permiten una mayor capacidad de innovación y adaptación a las nuevas necesidades, muchas de ellas en nuevos colectivos, tal y como es el caso de los inmigrantes o las personas afectadas por SIDA. De igual forma, al 
contar gran parte de estas organizaciones con una alta participación del voluntariado, el mismo supondrá un recurso humano valioso, motivado para un trabajo que no requiere remuneración económica. Por último, pero sin agotar las ventajas que puedan presentar las entidades del Tercer Sector, se considera que las mismas poseen un carácter más democrático y participativo, tanto a nivel interno, como hacia el exterior, lo cual permite un mayor acercamiento entre la entidad y la población a la que se dirigen sus actividades.

Partiendo de este cuadro de ventajas presentadas por las entidades no lucrativas, se viene considerando el incremento de la participación de las mismas en acción social como una posible alternativa innovadora que haga frente a la crisis del sistema de bienestar. Desde este punto de vista, se considera que su acción será más eficiente en la atención a los colectivos más desfavorecidos y en la actuación sobre un marco de necesidades cambiantes. Queda por ver si estas previsiones se vienen cumpliendo.

\subsection{El papel del voluntariado en el desarrollo social.}

Las ventajas que presenta el sector no lucrativo en la contribución al bienestar pueden contemplarse en un doble plano de acción. Esto es, tanto en lo que se refiere a acción a través de las diferentes políticas de bienestar, tal y como es el caso de su participación dentro de los servicios sociales, como a su actuación dentro de la dinamización económica, dando lugar a una serie de iniciativas destinadas a prevenir las situaciones de desventaja y posibilitar la integración de las personas en la periferia dentro de la sociedad.

Dentro del ámbito de los servicios sociales, las entidades voluntarias presentan ventajas comparativas cuando coinciden desventaja económica y desventaja social. Para el sector público dichos «clientes» no son objeto de acción claro ya que su peso en el mercado político es comparativamente menor en relación a las preferencias de otros grupos. Sin embargo, si dichas personas poseen recursos económicos serán atendidos por las entidades lucrativas (clínicas para personas con dependencia de diversos tipos de drogas serían un ejemplo). No obstante, ambos tipos de desventaja, económica y social, suelen venir dadas de la mano lo que refuerza la acción del sector voluntario hacia estos colectivos.

Igualmente, la actuación del Tercer Sector adquiere un peso específico en las comunidades en desventaja, las cuales presentan con frecuencia una sociedad civil débil, reciben los servicios del Estado en la mayor parte de las ocasiones de manera puntual e incoherente, sin llevar los mismos a una mejora de las condiciones estructurales que pro- 
vocan la situación. En este sentido, el tercer sector presentará ventajas comparativas a la hora de protagonizar iniciativas de acción social, siendo más efectivas aquellas que vengan de la movilización de la propia comunidad, a través de grupos de auto-ayuda, por ejemplo, que directamente mediante entidades voluntarias externas. ${ }^{32}$

No obstante, la relación del voluntariado con la gestación del bienestar social no concluye en la prestación de servicios sociales, sino que puede contribuir igualmente a la búsqueda de una identidad y el logro de una mayor cohesión social y dinamización económica, tanto para la persona que realiza este tipo de trabajo solidario como para la comunidad o grupos sobre los que ejerce su acción. En este sentido, dentro de unas sociedades caracterizadas por la escasez y precariedad del empleo, y considerando el trabajo como el principal medio de evitar el menoscabo de la calidad de vida del individuo, la acción voluntaria contribuirá a la búsqueda activa del bienestar, potenciando la creación de nuevos yacimientos de empleo, contribuyendo a la dinamización social y productiva y paliando en la medida de lo posible las causas que crean situaciones de desventaja económica, personal, social y comunitaria.

Por un lado, la movilización dentro de la comunidad y la gestación del trabajo voluntario reconstruyen la identidad de aquellas personas que han quedado en situación de desempleo, genera iniciativas de asociación y autodesarrollo y permite la creación de empleo, ya que es frecuente que lo que ha empezado como trabajo voluntario se convierta en un empleo. De ahí que gran parte de las iniciativas de fomento de empleo y dinamización económica propuestas desde las diversas administraciones -incluida la europea, tal y como vimos al hablar del programa Empleo y Tercer Sector-pasen en la mayor parte de las ocasiones por la gestión de las mismas a través de diversas formas de economía social, incluyendo las entidades voluntarias, al considerar la recuperación del tejido social como premisa previa al desarrollo económico.

Al mismo tiempo, a camino entre el Tercer Sector y el ámbito empresarial, se establecen una serie de iniciativas que forman parte de la economía social. Las mismas presentan formas tales como las cooperativas de iniciativa social o las empresas sociolaborales.

Las primeras presentan campos de actuación variados: integración socio-laboral de discapacitados, ex-drogodependientes, pobreza, etc., atención a la infancia, educación especial y muchos otros servicios de atención a las personas. Las empresas sociolaborales constituirán, por 
su parte, empresas de inserción con el propósito de acoger a personas que tienen problemas de integración en el mundo laboral, ampliando sus acciones a las tareas de prevención, rehabilitación e inserción. Entre sus características, tal y como señala Vilanova y Vilanova ${ }^{33}$, se encuentra el hecho de carecer de ánimo de lucro y la apuesta por potenciar una financiación solidaria que cree fondos sociales y rotativos dentro de la empresa.

Por último, las entidades voluntarias aparecen también como generadoras directas de empleo. Tal y como ponen de manifiesto Monserrat Codorniu y Rodríguez Cabrero ${ }^{34}$, las entidades voluntarias generan en nuestro país en torno a los 99.038 empleos en términos de «personal equivalente» (en términos de «personal equivalente», esto es, transformando los diversos contratos de jornada inferior a las 40 horas en «equivalentes» a una jornada completa), lo cual representa un $1,41 \%$ de empleos en relación al total de ocupados en el sector servicios.

Sin embargo, la contribución de las entidades voluntarias a la creación de empleo no se cifra tan sólo en la aparición de puestos de trabajo directos. En efecto, existen igualmente entidades que, además de crear dichos puestos, consideran como fin social de la organización el apoyo a las personas que buscan empleo, dando respuesta a sus necesidades y ayudándolas a encontrar trabajo. Tal sería el caso en nuestro país de las entidades que se integran dentro de la Red Araña.

\subsection{La Gestión de las Entidades Voluntarias.}

Si, tal como hemos señalado, las entidades voluntarias constituyen un actor privilegiado en la búsqueda del bienestar social, no menos cierto es que, aún partiendo de este reconocimiento prácticamente generalizado, diversas son las críticas que han venido a poner de manifiesto los puntos débiles en la gestión de dichas organizaciones. La excesiva dependencia de la financiación pública y la consiguiente pérdida de autonomía, los déficits en el estilo democrático de gestión y la falta de un modelo profesional de desempeño han sido eje de algunas de estas críticas.

Conscientes de estos puntos débiles, se empieza a poner en marcha, desde el seno de las propias organizaciones, una labor de desarrollo de un nuevo modelo de gestión en el que no son incompatibles la solidaridad con la eficiencia. Para la elaboración del mismo se toman ele-

33 Ródenas Rigla, F. y Sánchez Flórez, S- (1998): «Política Social y Empleo» en Alemán Bracho, M.C. y Garcés Ferrer, J.: «Política Social». Ed. McGraw-Hill. Madrid.

34 Op.cit. Rodríguez Cabero,G. y Monserrat Codorniú, J., págs. 264-266. 
mentos propios del nuevo «management» privado, de los nuevos diseños resultantes de la modernización administrativa del ámbito público, haciendo compatibles los mismos con los caracteres propios aparecidos en la dinámica y experiencia de las propias organizaciones. Independientemente del ámbito del que provenga cualquier instrumento de gestión puede ser incluido siempre que cumpla un requisito: la búsqueda del equilibrio entre solidaridad y eficiencia.

Trataremos, a continuación, de mostrar las claves centrales para el establecimiento de un modelo de gestión de entidades no lucrativas. No obstante, y antes de pasar a este punto, será necesario detenerse en la posición de partida con que contamos, esto es, el diagnóstico de la entidad como organización.

\subsubsection{La entidad voluntaria como organización.}

Vivimos en una sociedad de organizaciones, y el sector no lucrativo no constituye una excepción a dicha característica. La misma búsqueda de los fines propuestos requiere de la asociación de las personas que persiguen los mismos, de forma tal que, si bien dicha unión se produce de una manera relativamente espontánea, el desarrollo de las actuaciones y la consolidación en el tiempo llevará a un mayor grado de institucionalización.

Será preciso conocer nuestra organización, los actores que forman parte de la misma, así como sus fortalezas y debilidades, antes de iniciar el diseño de un modelo de gestión adecuado para sus actividades. La gestión, administración, los socios, el voluntariado y otros colectivos que forman parte de la organización de forma más transitoria (personas acogidas a objeción de conciencia o algún tipo de prestación sustitutoria, por ejemplo) forman parte de la organización, y, aunque cada una de ellas posee un interés común con el resto de los grupos -el fin de la organización- presentan simultáneamente intereses particulares que no siempre coinciden, llevando con frecuencia a situaciones de tensión dentro de la entidad.

Comencemos por el grupo que se encuentra en la dirección (Consejo, Asamblea, Junta Directiva...). Sus actividades se dirigen fundamentalmente hacia el exterior de la organización poseyendo un fuerte componente de carácter político ${ }^{35}$. En efecto, la dirección tratará de establecer redes tanto con diferentes organizaciones, tanto del ámbito privado como público, tratando de lograr la financiación necesaria para el desarrollo de las actividades de la organización. Las personas de la

35 Middleton, M. (1987): «Nonprofit Boards of Directors: Beyond the Governance Function» en Power, WW.(ed): The Nonprofit Sector. Ed. Yale University Press. London, págs. 141 y ss. 
dirección poseen generalmente un elevado nivel de recursos, bien humanos -formación, trayectoria en otras organizaciones...-, bien sociales -redes con otras y personas clave a la hora de conseguir recursos para la entidad-, conformándose, de esta forma, una relación entre élites, de la que está excluida la administración de la entidad, y sobre todo, la población beneficiaria, la cual pertenece a un estatus social y una configuración cultural particular y distinta de aquella que posee la dirección. En este sentido, cabe señalar que, como ha venido ocurriendo en la administración social dentro del ámbito público, las organizaciones han partido de unos patrones culturales de clase media, incluso en ocasiones media-alta, distintos de los de la población a la que se dirige la acción.

Dicha función, fundamentalmente política, de la dirección vendrá a chocar en ocasiones con la visión de las personas que se encuentran dentro de las funciones más operativas que desarrolla la entidad, las personas que constituyen la administración de la misma. Más cercanas al ámbito del desarrollo interno de la organización acusan a la Dirección de tratar de intervenir en unos procesos operativos que en la mayor parte de las ocasiones desconocen. La relación entre la dirección y la administración posee un especial carácter paradójico; para muchas decisiones importantes, la dirección es la autoridad final, pero esta depende a su vez del ejecutivo en el suministro de información, respecto a la articulación de las políticas y la articulación de las mismas. Las habilidades de negociación de cada una de las partes jugarán un papel fundamental a la hora de determinar las orientaciones de la entidad.

No obstante, el posible conflicto con la Dirección no es el único peligro que acecha a la administración de la entidad. La carencia de una visión abierta al cambio puede llevar a una burocratización de las tareas que realiza, acercándose, de esta forma, a algunas de las críticas que se habían vertido sobre la administración social. En este sentido, equidad no quiere decir uniformidad, sino igual atención a cada persona dentro de un tratamiento particularizado de su caso.

Por último, encontraríamos a los socios y voluntarios dentro de la organización. El peso de los primeros en la toma de decisiones dependerá de la contribución efectiva -bien en redes personales, bien en recursos económicos- a la organización. Los voluntarios, igualmente, tendrán una posición diferente. Aquellos que, siendo fundadores, permanezcan como voluntarios dentro de la organización, pueden tener un peso importante en la toma de decisiones, siendo muy distinta la situación del voluntariado que se une de forma más reciente a la organización. Los mismos no sólo tienen escaso poder de decisión -en muchas organizaciones prácticamente nulo- sino que, en ocasiones, ni 
siquiera son informados del plan de actuación de la entidad o tienen comunicación con las personas que ejercen las funciones directivas de la misma.

De esta forma, se va dibujando una estructura jerárquica en la entidad que se aleja del estilo participativo y de comunicación horizontal que aparece como elemento propio de la filosofía del sector no lucrativo. Ante esta situación, puede darse el riesgo de que el voluntario comience a percibir su colaboración como carente de significado para la organización, intentando dar cauce a su altruismo en otra entidad distinta, incrementando así los niveles de movilidad, y la interrupción de la permanencia, entrando de esta forma en un círculo en el que no se dan mayores responsabilidades al voluntario, pues se considera que el mismo es inestable y no puede contarse con él en la planificación, y el voluntario no acaba de encontrar sentido a la actividad, muchas veces periférica, que realiza en la entidad.

No es este el diagnóstico del sector no lucrativo, sin embargo, una parte de estos elementos que venimos señalando se repiten con asiduidad. De esta forma, se observa que la gestión de la entidad se hace poco democrática, las tensiones entre los diferentes grupos se multiplican y los riesgos de alejamiento de la población beneficiaria se incrementan. Estos elementos, unidos a la falta de una planificación que cuente con metas claras para todos, hace urgente la necesidad de redefinir el proyecto institucional de la entidad.

En el mismo, la medida del desempeño y el impacto de las acciones que lleve a cabo la entidad exigirá de la definición de los objetivos centrales planteados en la misma, así como del establecimiento de una serie de indicadores que den cuenta de estos. Atendiendo al proyecto institucional, los indicadores de desempeño deberán definirse en tres niveles centrales para la entidad ligados a tres tipos de funciones ${ }^{36}$ :

- Fortalecimiento institucional. Las mismas atañen fundamentalmente al soporte de la legitimidad de la organización y a la capacidad de movilización de recursos de la misma.

- De gestión. Tratarán de ofrecer información acerca de las actividades de la entidad, de los problemas planteados para alcanzar las mismas, así como de la correspondencia entre éstas y la localización de recursos realizada. Por tanto, la vertiente de gestión girará en torno a la adecuación de la estructura y procesos de la organización, al tiempo que de distribución de recursos realizada a nivel interno.

36 Moss Kanter, R. y Summers, D.V. (1987): «Doing Well while Doing Good: Dilemmas of Performance Measurement in Nonprofit Organizations and the Need for a Multiple-Constituency approach» en op.cit. Powell,W.W. pág.159. 
- Funciones Técnicas. Dichos indicadores tratarán de ofrecer información acerca de la eficiencia y la calidad de los servicios y prestaciones que realiza la entidad.

Desde las bases del diagnóstico de la organización, y teniendo en cuenta la necesidad de vertebrar los logros de la organización, y considerando que la eficiencia, la calidad y, en definitiva el impacto de las actividades que emprenda la entidad dependerán del proyecto institucional de la misma. Trataremos, a continuación, de presentar algunos de los elementos básicos que forman parte de la apuesta por un modelo de gestión integrado dentro de las organizaciones no lucrativas.

\subsubsection{El Marco de Desarrollo Institucional.}

Diversas son las propuestas que comienzan a realizarse para la mejora de la gestión dentro del ámbito no lucrativo. Por la claridad de su planteamiento, y la capacidad de dar lugar a una aplicación práctica de la misma a aquellas personas que no estén necesariamente especializadas en el ámbito de la gestión, partiremos de la propuesta realizada por el Marco de Desarrollo Institucional para el sector no lucrativo. ${ }^{37}$

Establece dicho Modelo, como principios básicos de actuación, la trasparencia, el énfasis puesto en la orientación hacia el beneficiario, una orientación que tenga en cuenta el entorno externo así como las fuentes de ventajas o bien de amenazas a la entidad, y, sobre todo, la necesidad de poner en marcha un modelo de gestión y toma de decisiones de carácter participativo.

Desde dichas bases, el Modelo plantea la necesidad de avance en una serie de vertientes organizativas, valorando su situación a lo largo del proceso de crecimiento y consolidación de la entidad. De manera gráfica, podría reflejarse de forma primaria en el cuadro de la página siguiente.

Cada una de las vertientes del cuadro deberán contemplarse en un doble nivel. Por un lado, podremos definir un cuadro (como el que aparece a continuación), en el cual establecer las debilidades y fortalezas para cada una de las vertientes que contribuyen al proyecto institucional de nuestra entidad. Por otro, y manteniendo las mismas variables en los ejes de columnas y de filas podríamos establecer un cronograma que actuara como termómetro en el avance o retroceso de cada uno de los aspectos contemplados.

37 Dicho Modelo será planteado por Renzi, M. (1996); «An integrated Toolkit for institutional development» en Public Administration and Development, vol. 16, págs. 469 y ss. 
MARCO DE DESARROLLO INSTITUCIONAL

\begin{tabular}{|c|c|c|c|c|}
\hline Capacidades & Comienzo & Desarroilo & Expansión & Sostenibilidad \\
\hline $\begin{array}{l}\text { Visión General: } \\
\text { - Dirección. } \\
\text { - Misión de la entidad. } \\
\text { - Autonomía. }\end{array}$ & & & & \\
\hline $\begin{array}{l}\text { Recursos de Gestión: } \\
\text { - Estilo de liderazgo. } \\
\text { - Gestión participativa. } \\
\text { - Planificación. } \\
\text { - Seguimiento y evaluación. } \\
\text { - Sistemas de gestión. }\end{array}$ & & & & \\
\hline $\begin{array}{l}\text { Recursos Humanos: } \\
\text { - Cualificación del personal. } \\
\text { - Desarrollo del personal. } \\
\text { - Diversidad organizacional. }\end{array}$ & & & & \\
\hline $\begin{array}{l}\text { Recursos Financieros: } \\
\text { - Gestión financiera. } \\
\text { - Dependencia financiera. } \\
\text { - Autonomía financiera. }\end{array}$ & & & & \\
\hline $\begin{array}{l}\text { Recursos Externos: } \\
\text { - Relaciones públicas. } \\
\text { - Habilidad para trabajar con } \\
\text { las instancias gubernamen- } \\
\text { tales. } \\
\text { - Habilidad para trabajar con } \\
\text { otras organizaciones no gu- } \\
\text { bernamentales. }\end{array}$ & & & & \\
\hline
\end{tabular}

FUENTE: Adaptación de las figuras 1 y 3, de Renzi, M. (1996): «An Integrated Toolkit for Institutional Development» en Public Administration and Development, vol. 16 , págs. 470 y 475 .

Al diagnóstico de la organización, y al marco de desarrollo institucional propuesto para la misma, será necesario unir un plan de formación, así como un programa de acción adecuado que permita al voluntario encontrar su papel específico dentro de la entidad, alcanzando una participación real dentro de la misma.

Desde estas coordenadas básicas, el planteamiento de la gestión de las entidades no lucrativas entiende la necesidad de adaptar instrumentos de acción provenientes de ámbitos distintos al de la iniciativa so- 
cial, de forma tal que, adaptándolos a las características de las entidades que la componen, supongan una forma de avance en la mejora de los logros conseguidos desde este sector. 



\section{DEFENDING THE WELFARE STATE}

\section{MICHAEL BARRATT BROWN}

Economista, doctor Honoris Causa, Open University y doctor Honoris Causa en Educación, Universidad de Sheffield. Fue Principal del Northen College, desde su fundación, en 1977, a 1984. Fundador y Presidente desde 1985, de TWIN (Third World Information Network) y TWIN Trading (Comercio justo), Director de la Bertrand Russell Peace Foundation y autor de numerosas publicaciones de Economía Política, Educación y Política Social.

Este artículo procede de su libro The May Day Manifesto. Part One. Defending the Welfare State. For a working group of the Independent Labour Network. Spokesman, 1998. Nottingham.

\section{EUROPEAN COMPARISONS}

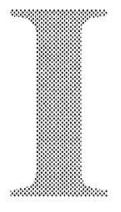

$\mathrm{f}$ there seems to be no recent rising trend in UK Government social security spending to be detected, it might be that spending in Britain has been moving ahead of that in continental countries, and that this is the cause of Mr Blair's concern to achieve savings. There are, of course, some big differences in the size and wealth and in the economic structures of the several European countries, even among those already in the European Union. Populations vary from Germany's 81 millions and the UK's 59 millions to Luxemburg's half million and Ireland's 3 '5 million. National incomes per head range almost as widely, from Switzerland and Norway's US $\$ 40,000$ a year, outside the European Union, to Greece and Portugal's US $\$ 9000$ inside the Union. The range is not so wide if incomes are measured in purchasing power parities instead of being translated into dollars according to exchange rates, but Switzerland still comes out at three times the level of Portugal and Greece.

European countries' economies have been growing at different rates. While Sweden, Finland and even Germany have had negative 'growth' rates in the last decade, Ireland, Spain and Portugal have been catching up with much higher growth rates than the average, but this cannot be said of poor little Greece. As for the UK, it will surprise many to know that at the end of years of 'growth' the UK comes very near the bottom of the pile, in the European Union only above Ireland, Spain, Portugal and Greece in income however measured. What distinguishes the UK is the yawning gap between the rich and the poor. No other country has the poorest 20 per cent of its people with less than 5 per cent of the 
incomes and only Switzerland as well as the UK has the richest 20 per cent with over 44 per cent.

Variations in the proportion of national incomes spent by governments are also very wide, and there has been some convergence here too. But the UK has been stuck in a position near to the bottom -today with only Luxemburg and Ireland having lower proportions. There has been a rising trend in government spending on average throughout Europe, but two governments -Belgium and the Netherlands as well as the UK- have cut their spending proportion since 1980. So the UK government spending spree that Mr Blair is seeking to cut back as quickly as possible seems not to exist, and to be relatively quite slight in the field of social protection.

The share of the national income going to social security in the UK is, moreover, well below others except for Greece and Portugal.

TABLE 1: General Government Spending, 1970, 1980, $1992-95$ and 1997. European Countries in order of total spend per GDP, 1997

\begin{tabular}{|c|c|c|c|c|c|c|c|c|c|}
\hline \multirow{4}{*}{$\begin{array}{l}\text { Country } \\
\text { Sweden }\end{array}$} & \multirow{2}{*}{\multicolumn{3}{|c|}{$\begin{array}{c}\text { Public Expenditure } \\
\text { as \% pof } G D P\end{array}$}} & \multicolumn{6}{|c|}{ Shares of Central Govt. Spending $\%$} \\
\hline & & & & \multirow{2}{*}{\multicolumn{2}{|c|}{$\begin{array}{l}\text { Social Security } \\
19801992 / 5\end{array}$}} & \multicolumn{2}{|c|}{ Healih } & \multirow{2}{*}{\multicolumn{2}{|c|}{$\begin{array}{l}\text { Education } \\
19801992 / 5\end{array}$}} \\
\hline & 1970 & 1980 & 1997 & & & 1980 & $992 / 5$ & & \\
\hline & 43.2 & 61.6 & 66.9 & 46.4 & 48.2 & 2.0 & 0.2 & 10.5 & 5.0 \\
\hline Denmark & 42.0 & 54.8 & 58.2 & 41.2 & 39.9 & 1.4 & 1.1 & 10.0 & 10.6 \\
\hline Norway & ---- & ---- & $\cdots$ & 33.5 & 39.5 & 10.3 & 10.2 & 8.5 & 9.7 \\
\hline Finland & 30.5 & 39.4 & 56.5 & 26.0 & 4.5 .6 & 11.2 & 11.2 & 14.5 & 11.3 \\
\hline France & 38.1 & 46.6 & 53.5 & 43.9 & 45.0 & 14.7 & 15.5 & 8.3 & 7.0 \\
\hline Belgium & 41.2 & 57.4 & 53.0 & 41.6 & --- & 1.7 & $m$ & 14.4 & -- \\
\hline Austria & 39.1 & 48.8 & 51.7 & 45.1 & 45.8 & 13.2 & 13.2 & 9.6 & $\cdots$ \\
\hline Italy & 32.4 & 42.4 & 51.0 & 31.4 & --- & 10.8 & --- & 9.1 & --- \\
\hline Netherlands & 41.8 & 56.7 & 50.1 & 37.0 & 37.2 & 11.7 & 14.2 & 12.5 & 10.1 \\
\hline EUR II & 37.0 & 46.6 & 49.4 & -- & -- & --- & -- & -- & --- \\
\hline Germany & 38.5 & 48.0 & 48.9 & 49.5 & -- & 19.2 & 16.8 & 0.8 & 0.8 \\
\hline Greece & --- & 27.3 & 44.9 & 30.6 & 13.4 & 10.5 & 7.4 & 9.6 & 8.5 \\
\hline Portugal & 20.2 & $-\cdots$ & 44.3 & 24.6 & $\ldots$ & 10.4 & --- & 10.3 & $\cdots$ \\
\hline Spain & 21.6 & 32.9 & 43.5 & 59.0 & 39.0 & 0.6 & 6.2 & 7.7 & 4.4 \\
\hline UK & 37.3 & 43.2 & 41.3 & 28.3 & 29.6 & 13.2 & 14.0 & 2.2 & 3.3 \\
\hline Luxemburg & 30.1 & 50.3 & 40.7 & --- & -- & -- & $\ldots$ & --- & -- \\
\hline Ireland & 35.5 & 47.8 & 35.2 & -.. & 28.2 & --- & 14.0 & --- & 12.8 \\
\hline
\end{tabular}

Notes: Public Expenditure includes central and local spending, and public investment

Central Government spending, e.g. on Education, however, excludes local government spending. Thus UK total public spending on education in 1994 as a \% of GNP was 5.4 and Germany's was $4.8 \%$.

Social Security $=$ social security and welfare, but not housing.

Sources: "Public Expenditure" from EC, European Economy: Annual Economic Report for 1997 "Shares of Central Government Spending" from UNDP, Human Development Report, 1997, Table 35, p. 212. 
Perhaps, figures showing shares in national income give a false impression and the real increase of social spending has been faster in Britain. But this is not true either. Whether measured in real terms or in purchasing power parities, the UK from 1980 to 1994 retained its position just below the European average in expenditure on social protection.

\subsection{Costs to Industry}

Who has been feeding the Prime Minister with false information? And why? Could it be that the threats and rumours that Mr Blair says he wishes to discount are in fact being spread by his own spin doctors, that the aim is to continue the Tories' salami cuts in social provision so as to reduce employers' social costs? If so it is somewhat disingenuous for the 'road show' organisers to tell all who might think of joining that those business sponsors who are likely to gain from the reforms will not be welcome. In fact, all employers can expect to gain at the expense of labour. So what is the actual evidence of the comparative taxes and social contributions and comparative social costs which British industry bears compared with potential competitors?

Once again the story is the same. The UK lies in 13th place out of 20 in the list of countries ranked in order of taxes and social security contributions as a percentage of national income. Of the European countries, only Switzerland, Spain and Portugal come below the UK, joined here by the USA and Japan from outside Europe. Taxes on corporate profits made in the UK are equivalent to the European average and even somewhat below that of the USA and Japan. But social security contributions paid by employers in the UK, as a proportion of national income, are absolutely the lowest in Europe and less than those paid in the USA and Japan. And the difference is not slight: the European average is nearly three times what UK employers pay. Moreover, unit labour costs have been cut back further in real terms in the 1990s in the UK than anywhere else in Europe except in Italy and Finland.

What is more important for the argument about the costs of social security is that, at the last time these were compared, in 1988, the UK had the lowest proportion of indirect costs in total industry labour costs of any of the then twelve members of the European Community. Indirect costs comprise statutory and non-statutory social security, vocational training and other services paid for by the employer. Just to add to this bonanza for employers in the UK, workers put in longer hours of work in the UK than those worked anywhere else in the European Union -32 per cent working over 44 hours a week and 20 
per cent over 48 hours, compared with a European average of 15 per cent and 8 per cent respectively. The UK was, moreover, the only country where working hours were lengthened in the period recorded by Eurostat studies, between 1987 and 1991, making it the sweatshop of Europe, as Jacques Santer once implied.

\subsection{Benefit and the Incentive to Work}

How can one prove that it is lack of jobs rather than the attractions of welfare provision that determines the level of unemployment in any country or region? There is no doubt, of course, about the correlation of lack of economic activity with the provision of income support. Of 36 English and Welsh districts, in 1993, with more than 20 per cent of households receiving income support, all but eight had lower than average economic activity rates and some of them very much lower. The eight that were above the average were only just above, and were not concentrated in any particular region -Hastings, Merthyr Tydfil, Lambeth for example. Similarly, if we look at the European figures, there is no doubt also that social protection spending has risen as unemployment has risen since 1980 .

Apart from these two phenomena moving together, there appears to be no other correlation between levels of unemployment and social spending among European countries. High social spending does not necessarily go with high unemployment. Indeed, taking the three years separately, 1980, 1990 and 1994: in 1980 and 1990 the countries with highest social protection -Finland, Germany, Luxemburg- had the lowest unemployment. Only in 1994 does high unemployment go with high social protection, and the argument that high spending on social protection followed upon high unemployment, rather than the other way round, is strongly indicated by all the other reasons that are known for the rise in Scandinavian and German unemployment after 1990. In particular, there was the collapse of the Soviet market and the reunification of Germany.

Payments to the unemployed may take up as much as one tenth of all expenditure on social protection, when unemployment is high, and thus have a major influence on the size of the overall social security budget. The rising trend of unemployment throughout Europe has probably accounted largely for rising social security expenditure. The other reason for this rise is the same as in the UK, the increase in the number of old people in the population -in the European Union as a whole from 15 per cent in 1960 , to nearly 18 per cent in 1980 and over 20 per cent today. The proportion of persons of pensionable age in the UK has moved roughly in line with that elsewhere. Pensions 
TABLE 2: Social protection benefits by function, 1980 and 1994.

European Countries ranked in order of total benefits, 1994

\begin{tabular}{|lrrrrrrrr|r|}
\hline & \multicolumn{2}{c}{ Old Age (\%) } & \multicolumn{2}{c}{ Enployment $(\%)$} & \multicolumn{2}{c|}{ Sickness(\%) } & \multicolumn{2}{c|}{ Fomily(\%) } \\
Country & 1980 & 1994 & 1980 & 1994 & 1980 & 1994 & 1980 & 1994 \\
\hline Denmark & 36 & 38 & 11 & 16 & 36 & 28 & 11 & 8 \\
Luxemburg & 48 & 47 & 0 & 3 & 42 & 40 & 13 & 9 \\
Germany & --- & 42 & --- & 8 & $-\ldots$ & 39 & -- & 3 \\
France & 43 & 43 & 5 & 8 & 36 & 35 & 12 & 9 \\
Netherlands & 32 & 37 & 8 & 11 & 51 & 46 & 10 & 4 \\
Belgium & 41 & 44 & 12 & 11 & 35 & 35 & 11 & 8 \\
\hline UK & 42 & 42 & 11 & 12 & 34 & 32 & 15 & 10 \\
\hline Italy & 58 & 63 & 2 & 2 & 35 & 30 & 7 & 3 \\
Ireland & 31 & 27 & 9 & 12 & 44 & 38 & 12 & 13 \\
Spain & 42 & 44 & 16 & 18 & 36 & 35 & 3 & 2 \\
Portugal & 40 & 40 & 3 & 6 & 47 & 49 & 9 & 4 \\
Greece & 67 & 68 & 2 & 2 & 27 & 24 & 1 & 1 \\
\hline
\end{tabular}

Notes: Columns do not necessarily add up to 100, because for some countries there are other functions not shown on the Table. "Old Age" includes "Survivors".

"Employment" includes employment promotion and unemployment benefits. "Sickness" includes invalidity and occupational accidents.

"Family" includes maternity benefit.

Sources: EUROSTAT, Social Protection Expendifure and Receipts, 1980-1994, Luxemburg, 1996, Table B.6, pp. 28-29.

everywhere in Europe moved ahead faster than national incomes after 1980 , and this is largely the result of the spread of supplementary voluntary schemes, which amounted by 1993 to an additional 10 per cent on average on top of the basic pension. The UK and Ireland are distinguished, however, by the very large share of the pension accounted for by such supplementary, i.e. private, schemes -over one third in the case of the UK, something the authors of the DSS Focus file celebrate so enthusiastically.

Invalidity and sickness benefits in most European countries take the next largest proportion of social protection after old age pensions. It is the same in the UK as elsewhere. There is a suggestion in $\mathrm{Mr}$ Blair's Times article, confirmed in the Government's aim to cut back on invalidity benefit, that sickness and invalidity claims are sometimes fraudulent. They have certainly been rising in the UK, but they have not been rising much faster than national income and somewhat less rapidly in relation to national income than has been the experience in most European countries.

If only state pension provision is compared, the UK comes below even the USA and Japan at 5 per cent of national income spent in 1994, according to an article in the National Institute Economic Review, 
and that compares with over 12 per cent in France, Germany, Italy and Sweden.

\subsection{What about Fraud?}

Mr Blair refers to an estimate of between $£ 4$ and $£ 5$ billions of benefit fraud each year. But, in response, Professor Townsend quotes Baroness Hollis, in charge of the Government's 'Benefit Integrity Project', stating that they had not turned up any evidence of fraud affecting disability benefit. Mr Blair claims that more is spent on 'disability and incapacity benefits than... on the entire school system in the UK'. According to the Focus file 04, expenditure on disability and incapacity benefits rose to about $£ 12$ billion in 1995 , which was almost exactly the same as was spent on schools. Thanks to the Tory Government's $£ 3$ billion proposed cuts in allowances in that year, which the DSS authors of the file euphemistically refer to as 'the changes in April 1995', expenditure will fall back in future. The fact is, however, that while the schools population has been falling, even between 1981 and 1994 from 9' 1 million to 8 ' 2 million, the numbers drawing invalidity pensions had almost doubled -from one million to two million. And, as Professor Townsend has pointed out, providing for school children's needs requires only a small part of the income of their families compared with the needs of the disabled. Spending on education should be increased -all are agreed on that- but should those with a disablity and incapacity be penalised? They are among many who are deprived of educational opportunity through lack of funding.

The UK is one of several countries in the European Union with slightly above the average proportion of over $60 \mathrm{~s}$ in the population. But the increase of 90 per cent in numbers drawing invalidity allowances and disablement pensions in the UK over the years 1980 to 1992 was not a larger percentage increase than was shown in Germany, Spain and Greece, although in France and Belgium and Portugal the increase was only around 30 per cent, and in Italy the increase in disablement allowances paid seems to have cancelled out a reduction in invalidity pensions.

What is most striking in the Eurostat reports for 1992-3 on Social Protection (Figs $1 \& 2$ ) is that, whereas the estimates of the population of disabled persons show the UK having about the average proportion of the total population with a disablement, they show that it has only half the average proportion receiving financial aid linked to a disability. Once more the UK is down with Spain and Greece, at the bottom of the league table. And since that time the cuts in allowances made by the Tory Government have come into force, including the phasing out 
FIGURE 1: Estimate of the population of disabled persons (1992)

As a percentage of the total population

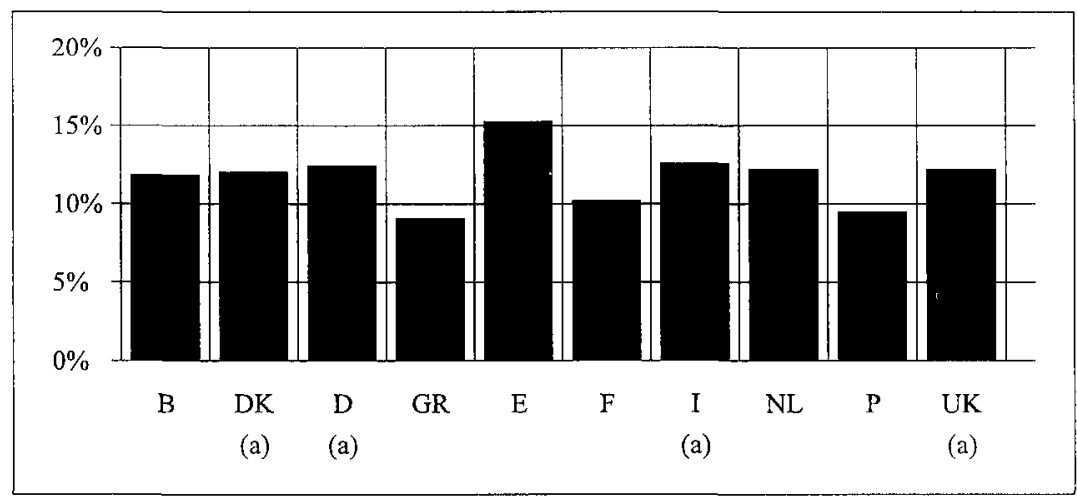

Notes: (a) 1991

FIGURE 2: Estimate of the population of disabled persons receiving financial and linked to a disability, 1991 ( $<60$ ans)

As a percentage of the total population ( $<60$ ans)

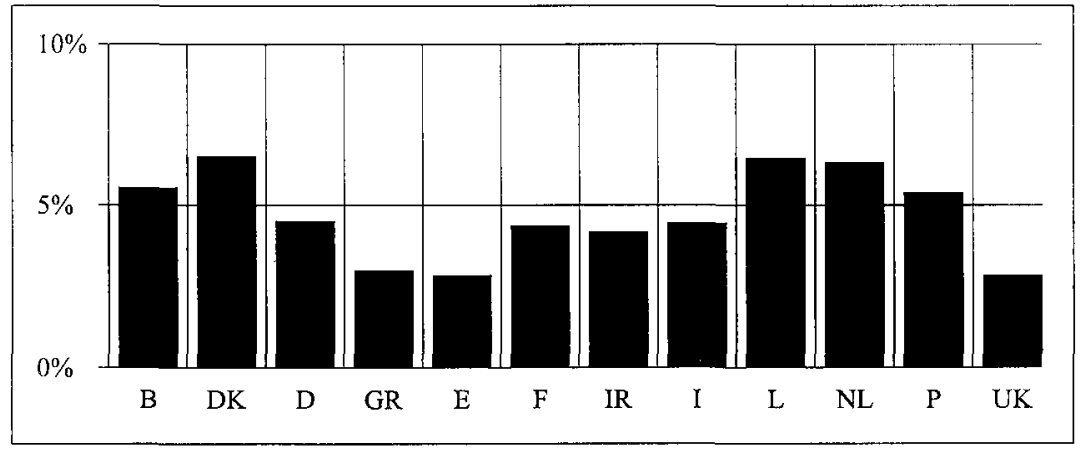

of the earnings related incapacity benefit, for which recipients had been making their contributions over many years.

In all countries, of course, those drawing war pensions have declined in numbers as old soldiers and their widows have died, but these are listed separately from disablement and invalidity. If there is fraud, as Mr Blair suspects, in the rapid increase in disability claims in the UK, then he must be claiming that it is going on also in Germany, Spain and Greece and to a lesser extent in other EU states, where numbers of claimants have been rising rapidly. And, indeed, the proportion of national income paid out in 1994 in UK sickness and invalidity benefits was below that in other countries in the European Union, except for Greece. Denmark and Italy also had lower figures, but these are accounted for by enhanced pension provision in those countries (Table 
2 above). The sharp rise in the UK in payments for sickness and disability in the years from 1991, up to the peak in 1996, when the new regulations came into force, might have been enough to make up for the UK's poor showing earlier but this must be doubted as the gap was so wide (Fig. 1); and the cuts had begun to bite in 1996 according to the DSS file.

Fraud is by its very nature hard to pin down but the evidence of Baroness Hollis quoted earlier was reassuring. The evidence on the ground concerning the results of the last Government's cut backs, now perpetuated by New Labour, suggests that much injustice is being done. Invalidity and sickness are determined by medical examination and rules can unfortunately be adjusted to meet the stringency of financial requirements. There is much evidence that men made redundant from industrial closures, and particularly from pit closures, have qualified for sickness benefit. Some may well have been 'carried' by their mates after injuries in their old jobs, but would not find a new job easily. Many will have tried and failed to find new work and applied for the higher rate of sickness benefit because of the absolute absence of alternative job creation in areas of industrial decline. This situation has been fully documented by the Coalfield Communities Campaign and reported in Ken Coates, MEP, and Michael Barratt Brown, Community under Attack: The Struggle for Survival in the Coalfield Communitt'es of Britain (Spokesman, 1997).

It would seem to be a strange way to tackle fraud to reduce the levels of social security payment. Most people faced by such reductions would seek to do everything possible to maximise their benefits. The campaign against fraud also consorts ill with Mr Blair's aim to get more money to those in need who do not now claim the income support to which they are entitled. More means testing and more inspectors will hardly encourage those who are too frightened or too ignorant to claim what is owing to them. At the root of all fraud must lie the lack of work and opportunities for work at a living wage. Create the jobs and the problem solves itself, and, as Professor Townsend has insisted, 'benefit fraud when properly investigated turns out to be much smaller than claimed, and is far smaller in total value than tax evasion and tax fraud.'

Family allowances form another benefit under attack from the salami chopper. Payments in the UK under this heading are only just above the average in value and in relation to national income, when compared with others in the European Union, but there is one big difference in the conditions for eligibility. In the UK a much larger proportion is subject to a means test than is normal elsewhere, except in Ireland. Moreover, while basic schemes have gone down in real value in the 
UK, down rather more than the average for the rest of the EU, the means tested proportion has risen correspondingly faster. According to the Focus files, the proportion of benefits that are means tested doubled between 1979/80 and 1995/6 from 16 per cent to 35 per cent. By contrast in Denmark and Luxemburg family benefit is more than twice what it is in the UK, and in France and Germany 50 per cent larger, and, except in Germany, almost all without means testing.

It was argued at the beginning, with authoritative support, that far from cutting child benefit the Government should greatly increase its value. This would do more than anything else to encourage women (and men too) to look for work, even at low wages, if they are not already doing so, but also provide for women who feel that they need to stay with their young children. Studies that have been made show that there is very little evidence of skiving, whatever the tabloid press may say. The Employment Services' 1992 Report, Employment in Britain, described a survey of a sample 1000 unemployed and 3000 employed people and found that commitment to work (defined as 'would work even if there was no financial necessity') was very high. It was higher among unemployed people ( 76 per cent) than among those in employment ( 68 per cent). Similar results were found in surveys made in Coalfield areas (see Community under Attack, Coates and Barratt Brown, Spokesman 1997).

\subsection{What Price Maternity?}

Maternity benefit in the UK has attracted the most criticism from the new Minister for Social Security, a mother herself. This benefit is not means tested, so that the criticism is presumably on the grounds of Mr Blair's criterion of 'spending the tax-payers' money wisely'. Since the cash benefit is paid on the basis of lost salary, one mother with an income of over $£ 1$ million was said to have been paid $£ 20,000$ in maternity benefit. The story was carefully supplied to the Murdoch press, which lapped it up as an example of the need for 'reform'. But it should surely never have been agreed that the employer should be refunded by the state for such employment costs.

In fact, as has already been emphasised, the reform needed would primarily be in the tax system, which fails to tax such grotesque incomes at higher rates, following the Tory Government's abolition of the higher rate bands, which New Labour apparently is not willing to restore. In any case the average cash benefit of all kinds for a non-retired household in the top 20 per cent of UK households is only $£ 800$ a year to add to an average original income of over $£ 40,000$. In the over $£ 1$ million a year income band, cash benefits of a few hundred pounds would not 
appear very large, and the number of such incomes among women must be very small. In fact, the Labour Research Department failed to find any such example, but did find that women earning over $£ 30,000$ a year only accounted for 5 per cent of the actual maternity payments.

There has been some talk of an affluence test, but this would not only be difficult to administer, but would be quite without effect until a serious effort is made to deal with all those tax dodges which $\mathrm{Mr}$ Gordon Brown, before he came to power, said he was going to stop. It also creates a difficult problem that already faces those who wish once more to treat partners as single tax units for tax credit schemes and thus end the woman's much treasured and only newly found financial independence.

In fact, maternity benefits as a proportion of national incomes have been declining in most European countries, but not in the UK. While the UK is among the higher spenders in Europe on maternity benefit, a far smaller proportion of this is paid in cash in the UK and a much larger proportion on hospital and other medical services than in other countries. Of course, European countries have different ways of providing hospital and other medical services, which accounts for the wide variation in cash payments.

Given that fertility rates have gone down very rapidly in Europe in the last 30 years -from 2'61 in 1960 to $1^{\prime} 48$ in 1992 on average among the EUR 12 and from $2^{\prime} 72$ to $1^{\prime} 79$ in the UK- further reductions in maternity benefits must be regarded as inadvisable. Any rate below $2^{\prime} 0$ per female member of the population naturally implies a declining population. Some might prefer this, but it carries the implication of an ever smaller population of young people to work for an ever larger population of old people. It looks like playing to the gallery of tabloid press readers rather than serious policy making for the Government to be fussing about putting curbs on universal maternity benefit.

\section{WHAT SHOULD BE REFORMED}

Mr Blair in his Times article listed the main changes in our society to which, he believed, the welfare state must adapt: most people changing jobs at least five or six times in their career, more women at work, people living longer, up to 30 years after retirement, more marriages ending in divorce. There is no doubt about the truth of all of these assumptions except the first one, which we can look at in a footnote ( $\mathrm{p} .65$ below).

But Mr Blair has drawn the wrong conclusions, which we can discuss at the end, and he has missed out the most important changes 
as they affect the provision of welfare. The first is the change in the balance in our lives of paid work and leisure. The second is the crumbling framework of the nation state which has to support the welfare state. We are already beginning to see the reduction in the hours and years of paid work and the corresponding increase in the time devoted to what we call leisure activities, including studying. This process is certain to continue, in spite of the long hours that those who have paid work spend at work. Many others find themselves without work or facing early retirement. Both are at present involuntary. Both are feared and abhorred. It is not so much the loss of income but the loss of work-mates and of an abiding interest in life.

\subsection{Work and Leisure}

Most leisure activities require money -for transport, for travel, for tools and equipment to pursue the arts, sports, gardening and other DIY activities. Moreover, they are only easily affordable with public provision -of transport, sports facilities, allotments, museums, galleries and concert halls. The individualistic view of welfare which sees individuals living on their own savings to follow their own pursuits irrespective of others is a narrow one; and Mr Blair's occasional appeal to a communitarian rhetoric finds a wide response. But there must be substance in the promise. There can be no community without some shared finance and shared services which are universal and not divisive and exclusive. Much of this can be supplied by voluntary effort, but it needs a foundation of public provision. And this should be part of the meaning of welfare. Where in the UK we talk about redistributive taxation, on the continent they speak of solidarity taxes.

All the pressure to get people off welfare and into work is quite misconceived, if machines are going to take over more and more of the labour we have now to supply to maintain our livelihood. The evidence supplied by expert opinion is that a working life of 1000 hours a year is likely within two or three decades. Already the average in Germany is 1500 compared with 1900 in the UK. The concern with finding paid work for all who want it is not misplaced, but the single minded concentration on work for work's sake and for some supposed competitive advantage is mistaken. The UK has the longest average hours of work of any European country. A tax framework that assists the sharing of work is what is required, not pressure to get everyone into work regardless. 


\subsection{The Limits of the Nation State}

The weakening of the nation state creates more serious problems for the future of welfare than any of the other changes. Increasing globalisation of capital accumulation has not destroyed the powers of the nation state, but it has put all but the most powerful states at the mercy of the giant transnational companies which dominate the world's economy. To attract the investment of these companies, each separate state enters a Dutch auction competing to offer the cheapest labour and the least regulated environment. Mr Blair has nailed his colours to the mast in the matter of deregulation. Britain is going to compete, not to have the best social protection, but the lowest taxes for the employer. As we have seen this was already achieved by a Tory Government in 1994. New Labour proposes to build on that, or rather to dismantle social protection still further.

There is a real problem here. So long as each nation seeks to manage its own welfare state, capitalist competition will tend to drive down labour costs. About a quarter of these are indirect. These are charges for social security and vocational training etc. The threat of unbridled competition to such social protection led to the inclusion of a Social Chapter in the Maastricht Treaty, which a Tory government opted out of and New Labour seems reluctant to accept in full. International agreement on social protection is the only answer to a bidding down everywhere of state provision.

A common European commitment to minimum levels of provision is not only imperative for social cohesion, but, as Stuart Holland has for long insisted, it is an economic imperative (Stuart Holland, The European Imperative, Spokesman, 1993). The reason for this lies in the reduced purchasing power of an increasingly unequal economy. High rates of growth and high levels of employment are associated everywhere, according to the UNDP Human Development Reports, with greater equality of incomes. The United States is the great exception. Actual unemployment in the US is masked by the massive prison population, but, more generally, the exception depends on the hegemonic economic and military power which allows the United States economy to draw in the loans and investment of the whole world.

\subsection{Welfare and Social Change}

What was the purpose of Mr Blair's list of changes in the way we live and work, especially in relation to women, when he asks us to agree to the reform of the welfare state'? More women at work means less reliance on a man's wage and pension rights. This should be a 
good thing, but most of the new employment of women is part-time and much of it carries no requirement on the employer (or employee) to contribute to National Insurance -or any other insurance. Mr Blair says nothing about making this requirement universa1, although noncontribution is doubtfully legal under the European Social Charter. More divorces strengthens the case for women to have their own pension rights and to have more and not less support as single parents. The attempt to move single mothers from welfare to work by reducing their benefit fails to take account not only of the absence of jobs and of adequate day care provision, but of the lack of insurance cover for women working part-time. Given the very low general level of their wages, there is little or no possibility that they might build up their own insurances.

In this matter as well as in the larger question of the state pension, the view of the new government seems to be that individuals -men and women- should now make their own individual private insurance arrangements against unemployment, sickness and old age. We are back to the Nineteenth Century with a vengeance. The fact that all incomes are higher now than then does not help the poor, for whom modern living in apartments and estates implies central heating, refrigerators, washing machines, packaged food and transport to the nearest shop, whose price is set by the average buyers and not by the poorer ones. Higher inomes, as we observed earlier, should imply more rather than less ability to pay taxes to ensure a proper health service and education system for all and the possibility of income redistribution to reduce inequalities.

The assumption by $\mathrm{Mr}$ Blair of frequent job changes is designed to support the idea of a personalised insurance system, which the individual worker can carry with him or her from job to job.

Requiring all employers to contribute to such schemes for parttime as well as full-time workers at appropriate rates would be a big step forward, but such schemes carry with them no element of redistribution by the Government. By contrast, as we have had it under the National Insurance scheme, payments are made progressively up to a point according to levels of earnings, but every one receives the same in benefits and in health and education. Where the scheme failed was that the cut-off point left the richest 20 per cent paying no more than those below them. Had they done so, the crisis of underfunding of the state pension need not have occurred. So we were assured by the leading expert on pensions, Professor Peter Townsend, in the pamphlet which he wrote jointly with Barbara Castle and in the Socialist Renewal pamphlet, New Directions for Pensions, written with Alan Walker (Spokesman, 1995). 


\subsection{The Case for the State Pension}

In their pamphlet, Peter Townsend and Alan Walker foresaw that

'Labour's policy on pensions will set the scene for its entire social and economic policy for five years. Its pension policy will be seen widely as a key indicator of Labour's will to change the unstable, divided and more widely impoverished socicty inherited from 16 years of Conservative free market policics.'

They put forward six arguments in favour of restoring the universal state pension plus SERPS rather than supporting further the increased role of occupational and private pensions with a safety net of a minimum state guarantee, which would inevitably be means tested. The arguments were first that means tested income support failed to be claimed by one third of eligible pensioners. These are the very people who Mr Blair says the welfare system is failing. So it is, but it is means testing, not the basic pension, they are refusing. Secondly occupational, private or personal pensions are of little or no use to those, especially women, without full-time labour market careers. Thirdly, only a universal public provision can give economic security in an increasingly flexible and insecure labour market (indeed Townsend and Walker argue that a basic pension will actually assist flexibility). Fourthly, a universal state pension minimises inequalities between older men and women. Fifthly, it is the cheapest form of pension to administer $-1 \mathrm{p}$ in the $f$, compared with $11 \mathrm{p}$ on means tested income support and $25 \mathrm{p}$ or more on private pensions, with all the possibilities we have seen of mis-selling and other abuse. Finally, its very universality and equitable basis enhances social cohesion and solidarity between the generations.

The cost of increasing the basic pension in line with earnings was calculated by Townsend and Walker at 0'4 per cent of annual GDP and for the restoration of SERPS a further 0'8 per cent of GDP. According to John Hills in a Joseph Rowntree Foundation Inquiry, the combined costs of these two over the next 50 years would come to less than a quarter of the cost of the 1992-5 recession. They would, moreover, be offset by reductions in the need for means-tested income support and other contingent benefits. The extra money would have to be found from raising the ceiling for National Insurance Contributions, raising the rate for highest salary earners, increasing the rate for employers of large numbers of employees, and limiting subsidies in the private sector while tightening up on tax avoidance. It will be impossible, Townsend and Walker believe, to develop a viable pensions policy without European policy collaboration. But that does not mean downgrading the provision in the rest of Europe to the mean levels of the UK. They quote as an example to emulate the Danish Social Pension. This provides the sole pension for four fifths of Danish 
pensioners, and at a level of disposable income after housing costs that is equal to 77 per cent of the average income of the whole population.

- The one exception in Mr Blair's statement about the changes affecting welfare provision is the one about the increase in job instability. The International Labour Office in the chapter entitled 'Is Full Employment Passé?' of its 1996/7 Report quoted a study of job stability by K. Swinnerton and H. Wial in the Industrial and Labour Relations Review for January 1995. This reached the following conclusions from studies of data in the United States and in the UK:

'The proportion of workers whose jobs will ultimately last zero to three years decreased slightly from $31^{\prime} 8$ per cent in the $1979-83$ period to $30^{\circ} 9$ per cent in the $1987-91$ period. The proportion of those who will keep the same job for four to seven years increased from $14 \mathrm{per}$ cent to 15 per cent over the same period, while the proportion of those staying in their job more than eight years remained stable at 54'I per cent...' Thus they believe that 'the data do not suggest that the entire 1979-91 period was a time of increasing job instability'.

Periods of boom and slump must affect stability, but over a longer period, the ILO's own studies suggested that in France and Germany around 60 per cent of male wage workers can expect to keep their jobs more than 15 years. The proportions are only somewhat lower in the USA and Canada, where we are told flexibility of employment is general. The ILO does not see increased instability occurring in the UK, although there is evidence of this in Spain. 


\section{TOWARDS A NEW MANIFESTO}

The old state pension was part of the universal welfare system devised by William Beveridge in 1942 and introduced by the 1945 Labour Government. Mr Blair says that New Labour's principles are still the same as Beveridge's, but they cannot be the same if he moves the welfare system from a universal system to a fall-back system of minimum guaranteed state benefits. We have seen that private pension arrangements have begun to supply an increasing part of the average pension in the UK, over a third by 1993. Increasing numbers of people who can afford it, take out medical insurance. The numbers of children being educated in Britain at private schools does not decline, indicating a rise in the proportion outside the state system. Payment of fees is now introduced for higher education with a personal loan system for maintenance in place of the old grant system.

Of course, $\mathrm{Mr}$ Blair is right to identify the changing structure of family life as affecting all welfare provision. The Beveridge system was based on the assumption that the man's wage supplied the contributions to ensure protection for wife and family in the event of sickness, unemployment and old age. The facts Mr Blair attests: that most women now work, though not necessarily, as we have seen, being covered by National Insurance; that the nuclear family is almost the exception and not the rule; and above all that women have won much greater independence, means that this aspect of the system needs to be changed. Individuals and not families need to be insured and guaranteed basic rights of social protection in a society where the overwhelming majority of both men and women can only get a living by selling their labour to a private employer.

The conclusion from all this, however, does not follow that it should be left to the individual to make his or her own best bargain and best arrangements. With the support of strong trade unions that might be more acceptable, but $\mathrm{Mr}$ Blair does not appear to be enamoured of strong trade unions, and the unions share with the nation state the weaknesses of being open to division and conquest by the international employing companies. The nation state, or the wider association of states today, still carries the responsibility to ensure the basic civil rights of all citizens and not just minimum rights for those who are excluded from the main stream of national life.

Abandoning universality in welfare must imply means testing and a steady differentiation in the services supplied. It can only mean a perpetuation of the inequalities that have grown under past Tory governments to make the UK the most inegalitarian of all the states of Western Europe through both cutting benefits and undermining wage 
levels with the abolition of the Wages Councils. But inequality means also persisting poverty. And poverty, as the UNDP Human Development studies reveal, is associated with a general lowering of human development. After Ireland and Spain, the UK has the largest proportion of its population in poverty of all Western European countries. From being third in rank in West Europe according to the UNDP's Human Development Index in 1960, it has fallen to ninth place, and in the world league from fifth to fifteenth (Table 3).

Yes $\mathrm{Mr}$ Blair we need reform to meet people's changing work styles, but not if that means dismantling what still exists of the social insurance system and keeping the iniquitous taxation arrangements.

Reform of the welfare state requires the most comprehensive official examination of the costs and benefits of the present system, not selective quotations from the statistics to justify a programme of cuts, laced with exhortations to self-improvement. Unofficially, this has already been done in John Hills report on Income and Wealth for the Joseph Rowntree Foundation in 1995. If it needs to be updated, the Department of Social Security and the Inland Revenue will have all the figures

TABLE 3: Human Development Index (HDI) and Poverty, 1960, 1980 and 1994. European Countries in HDI order 1994.

\begin{tabular}{|lcccc|}
\hline & \multicolumn{3}{c}{$\begin{array}{c}\text { Human Development Index } \\
\text { (maximum }=1.000)\end{array}$} & $\begin{array}{c}\text { Population in Poverty } \\
\text { \% under \$ 14 a day }\end{array}$ \\
Country & 1960 & 1980 & 1994 & 1989.94 \\
\hline France & 0.853 & 0.895 & 0.946 & 12 \\
Norway & 0.865 & 0.901 & 0.943 & 3 \\
Netherlands & 0.855 & 0.888 & 0.940 & 14 \\
Finland & 0.811 & 0.880 & 0.940 & 4 \\
Sweden & 0.867 & 0.899 & 0.936 & 5 \\
Spain & 0.636 & 0.851 & 0.934 & 21 \\
Austria & 0.797 & 0.880 & 0.932 & --- \\
Belgium & 0.826 & 0.873 & 0.932 & 12 \\
\hline UK & 0.857 & 0.892 & 0.931 & 13 \\
\hline Switzerland & 0.853 & 0.897 & 0.930 & --- \\
lreland & 0.710 & 0.862 & 0.929 & 37 \\
Denmark & 0.857 & 0.888 & 0.927 & 12 \\
Germany & 0.841 & 0.881 & 0.924 & -- \\
Greece & 0.573 & 0.839 & 0.923 & 2 \\
Italy & 0.755 & 0.857 & 0.921 & $-\cdots$ \\
Luxemburg & 0.826 & 0.869 & 0.899 & 4 \\
Portugal & 0.460 & 0.736 & 0.890 & \\
\hline
\end{tabular}

Notes: HDI is a composite index composed of three variables: life expectancy, educational attaintment (adult literacy and combined primary, secondary and tertiary enrolment) and real GDP per capita in (in PPP\$).

Sources: UNDP Human Development Report, 1997, Annexe Table A.2.1. and p. 53 and Table 5, p. 158 
which are required to find out who pays and who gains, who could pay more and who should receive more. Before any further cuts are made, we need to know all the facts. But we need also to have an open discussion involving independent experts with the power to reveal all the facts in the UK and in other countries, especially those in the European Union, and with the authority to publish them, so that the people of this country can discover what has been done to them and what will be done, unless the direction of welfare provision in Britain is radically changed to reduce inequalities in society instead of perpetuating them.

\section{I. A Labour Movement}

The idea of a Labour Movement in Britain is a very old one. It reflects the historic links between the trade unions and the Labour Party. It appears that these links are finally to be severed by New Labour. As this Manifesto is being written, the TUC General Council has returned from a meeting with the Prime Minister in Downing Street and the news is that Mr Blair will not provide the promised recognition in law for trade unions in establishments where a "majority among the relevant workforce' votes for it. Today no more than $20 \%$ of private sector employees belong to a union and collective bargaining covers less than $50 \%$ of the workforce. It is, as John Monks, the TUC General Secretary said, 'a defining moment'. After almost two decades of Conservative Government onslaught on their rights and privileges, the unions expected support from a New Labour government. It seems that they are not to get it.

The implications of this decision are enormous. The protection of men and women under the social security system, when they are out of work through sickness, unemployment or old age, which has been the subject of this Manifesto, cannot be separated from the protection that workers look to from their unions when they are in work. Some unions have been criticised for their lack of concern for the unemployed and the retired, but they have always assumed that this was the Responsibility of the political wing of the Movement. Without that, the position of labour in Britain in relation to the power of capital is severely weakened. What has been done to working people in two decades in the destruction of great industries without measures to create new employment and in the dismantling of the welfare state has amounted to a massive act of violence against whole communities, leaving in its wake a tide of bitterness and despair.

The virtual annihilation of the Tory Party in Labour's electoral victory a year ago was a collective act of revenge and an expression of 
hope and of faith that change was possible. It seems that that hope and that faith are to be betrayed. It is not just that the government of New Labour is neutral between capital and labour. Mr Blair before the election promised no favours for either. In the event it is the owners and managers of capital who have received the favours. Big business men, both industrialists and bankers, have been brought in by the Government to represent it in key positions, as in the negotiations with the European Union, and to head up QUANGOs and important inquiries into future policy. These include most particularly the review of taxes and benefits for the Chancellor by Sir Mark Turner of Barclays Bank. The traditional conservatism of the Treasury concerning all extensions of public spending and taxation has been constantly reinforced by the pressure of Big Business leaders including the moguls of the media.

\subsection{The Philosophy of New Labour in a Changing World}

The Independent Labour Network has maintained from the beginning that New Labour is not simply following where the last Conservative Government led, in dismantling the welfare state and destroying trade union power, but has its own particular philosophical position. New Labour spokesmen and women deny that the old battles of capital and labour are any longer relevant. They have returned to revive a still older struggle, that between the individual and the state. This is in response to three major changes in social relations in the last decades. The first is that a sizeable minority of the population, without inherited ownership of land or capital, have achieved through their intellectual, artistic or athletic skills a degree of financial independence that makes them unresponsive to traditional collective organisation. A new spirit of individualism has begun to spread through society, stimulated by the media of press and television which reflect the advertising power of the giant manufacturers and retailers of consumer goods and services. This individualism has found its own expression in the burgeoning informal economy and increasing lawlessness where the great industrial communities of the past have been destroyed.

The second change in social relations, which has greatly reinforced the first, is the rightful demand of women for economic and legal independence. The strongest case against the old welfare system is that it was based upon the male earner's income and social insurance contributions to protect his wife and family. After marriage a woman's earnings were regarded as marginal, the wife of an unemployed or sick working man was assumed to be dependent, in old age the woman shared the man's pension -at a lower rate for a couple than for two individuals. When Harriet Harman cries out against such a system, she carries the women with her. The failure of the new intake of women 
into the House of Commons to vote against the cut in the lone parents' benefit was not just done from cowardice or concern to protect a woman minister, but from a visceral rejection by professional women of a system that had for so long treated them as dependents. This flaw does not necessarily, however, put into question the whole system of social insurance, as we have demonstrated earlier.

The third reason for the abandonment of the collectivism of the welfare state is that the powers of the nation state, which was its foundation, have become suborned almost everywhere to the demands of the giant international accumulations of capital. Mr Blair is right to recognise that small to medium sized states have little power today to maintain tax regimes that are unacceptable to the great transnational companies. They will simply transfer their investments and their profits elsewhere to places where conditions are more favourable for their capital accumulation. This is not entirely a new phenomenon, but the new information technology has made the globalisation of production as well as of finance much more all embracing than before.

\subsection{The Alternatives: Competition or Cooperation}

In these new circumstances, there are two alternatives for a medium sized state like the United Kingdom. The first is that chosen by $\mathrm{Mr}$ Blair. That is to seek to make the local economy as competitive in world markets as is possible by offering to transnational capital the most skilled professionals, the cheapest labour, the lowest taxes and the least regulated environment, including trade union as well as physical and ecological controls, of any competing state economy. The drive to move men and women, young and old, able and disabled, out of welfare and into work not only reduces the indirect social protection costs of labour but by increasing the supply of labour lowers its direct price in the market. Mr Blair's constant repetition of the need to be competitive embraces the whole nation but is directed at every individual. Compete or die is the message.

How far Mr Blair and his colleagues actually see what they are doing like that may be doubted, but they are driven by the logic of events, once they have rejected the alternative. Mr Blair employs a communitarian rhetoric and a Christian zeal, but his appeal is to individual self-help. He refers to his policies as following a 'third way' between the extremes of unregulated private capital and of over regulated public ownership. He is right to say that this is the old choice, but his is not the only 'third way'. Indeed his 'third way' is hard to distinguish from the way of unregulated private capital, towards which he is inevitably driven by the power of capital in global markets. 
What then is the alternative which he has rejected? Is there in fact a real alternative that is based on collective action but allows to individuals the freedoms that many have come to enjoy? Or is it in the end indistinguishable from the overregulated totalitarian systems, which have collapsed everywhere? Democratic socialists have undoubtedly failed to make their case and the Blairites have won by default. A powerful argument has been mounted in this Manifesto against the individualist approach to welfare provision, but the collectivist alternative may seem all too similar to what has been rejected in the past. The study of social protection in other European countries which we have made has shown that, in spite of the financial difficulties of surviving individually in a competitive global economy and of the constraints of modelling an Economic and Monetary Union in Europe to compete in that economy, the welfare state outside the UK has survived. Only in Britain has it been cut back to the level of the poorest countries of southern Europe.

That is the first answer, that the welfare state is compatible with democratic government in mixed economies. It also suggests at once the alternative to going it alone in single handed competition to win the favours of international capital. It is to cooperate with others in Europe in defending their welfare states and resisting the power of the giant international companies' attempts to divide and conquer. The opportunity to work together rather than in competition exists. Under Conservative administrations the British people have been held back from taking advantage of these opportunities, but New Labour has given some indication of ending that stance. The possibilities of working together to draw on best practice rather than running a Dutch auction of worsening labour conditions are there to be seized. Harriet Harman in her Guardian article of March 31st 1998 wrote of the consultations that will follow the Government's acceptance of the 'Social Chapter' and its implications for shorter working hours, parental leave and part-time working. It will simply not be acceptable for Britain to continue to force down European wages and conditions of work.

Mr Blair will soon learn, if he does not yet understand, the importance of the collective role of trade unions and of a sense of social security in maintaining the enthusiasm, indeed the very morale, of any workforce. The fact is that the dichotomy between competition and cooperation, between individualism and collectivism is never so sharp in real life as it is drawn by the ideologists. The secret of Japanese economic success hitherto has been the encouragement of competition within a powerful cooperative framework, created, developed and maintained by state institutions. Competing private companies everywhere support professional and technical insitutions for the 
exchange of information about new research and development. The organisation of giant companies is less and less based upon hierarchies of command and increasingly upon networking between decentralised independent profit centres. Mr Blair in extolling individual self-help knows that in every enterprise, public or private, competitiveness has to be moderated by teamwork. We noted earlier how the Green Paper on welfare reform, in the middle of a rhapsody on individual self-help, appealed for the public service ethos in the delivery of welfare.

\subsection{Social Provision that is also Individual}

The conflict in human thought and action between the individual and the collective, between competition and co-operation, between rational calculation and mystical faith, is as old as recorded time. But for a thousand years it was fought out between individualist secular capitalism and a universal hierarchical church. The state has been the battleground sometimes captured by the Church (not only Catholic but also Communist); increasingly in recent years by capitalism. The modern welfare state was, however, created in response to a new force in world history -that of labour, struggling against both capitalist and bureaucratic power. Collectivity did not need to be based upon mysticism but could have firm scientific foundations. It was nation states that had supported the development of capitalism and it was to the nation state that the disinherited turned for protection. Even the workers' trade unions had first to win state recognition to be effective in defending their members' jobs and conditions of work. And from recognition they had moved under Labour Party leadership to make a challenge to capitalist power.

Today this challenge has been checked. This began with an open offensive by a government of the radical Right which started dismantling the welfare state and using unemployment as a tool of monetary management. It has been continued by New Labour in a less open manner, converting the welfare state from a universal source of solidarity into a safety net for those who can prove a 'genuine need' for what are offensively called 'hand-outs', and relegating full employment to second place after the value of money.

The challenge to capital by labour is transmuted into the promise of participation, with labour as the junior partner. The Unions' power is still to be firmly circumscribed, while business is given free rein. Working people whatever their endowment are to make their own way in the market. They will be divided and defeated if they do not find ways to unite in collective defence of the welfare state, with appropriate amendments to recognise the equality of women and the importance 
of part-time work; and in defence of the fundamental human right of a worthwhile occupation for all men and women.

The Independent Labour Network has argued in this Manifesto that no amount of preparation for work of young men, young mothers, long term unemployed or the disabled will be of any avail, if there are no jobs to be had at the end. The task of government has to be not only to provide advice and training and education, a service of health and protection for the disadvantaged; it must also be prepared to create employment. It is an ironic tragedy, which we have already recognised, that just when the main body of economic thought is moving back towards the conviction that full employment is a proper and possible aim of government policy, Mr Blair should be continuing to rely on the market to create jobs. Welfare into work is a splendid slogan if the work is being made available, and the work that needs to be done in our society is unbounded -in clearing up pollution, in recycling waste, in insulating houses, in creating and maintaining parks and leisure facilities, and above all in providing opportunities for lifelong learning.

All these issues crystallised in the European Appeal for Full Employment, which was launched in 1996. It attracted the support of over 600 parliamentarians, including more than 160 Members of the European Parliament, as well as hundreds of trade unions, church bodies and other non-governmental organisations concerned with social questions. The Appeal formed the basis for the first European Convention for Full Employment. This brought together nearly a thousand participants at the European Parliament in Brussels in May 1997. The second Full Employment Convention is planned to meet in Brussels in November 1998.

This Appeal (printed below) has proved capable of uniting socialists of different schools with the main green parties in Europe and other independent radicals in joint and common action. It has done this on the basis of its appreciation of the changing patterns of work in modern society, as well as the continuing humanistic recognition that full employment remains the very foundation of a free society.

\subsection{Full Employment: A European Appeal}

'In Europe today we live in a rich world. Yet our societies are deeply flawed. Millions of our fellow citizens seek paid work and cannot find it: many more than the 20 million officially unemployed. Many women, and many older men have given up the search. In some regions, among our young people, one in five cannot find paid work. In regions of high unemployment, up to half the young people are without employment. More than half of the unemployed have been without 
employment for over a year, and half of these even for two years or more. Ever more women and men are being excluded from any hope of earning their living by actively contributing to their societies' wealth. The welfare state is cut back, unable to cope with continuous unemployment. In some countries this misery has lasted for fifteen years.

We should call this exclusion from society by its right name: it is a disaster which is destroying people's lives, dissolving the social fabric in which we live and depend on one another, undermining the very foundations of democratic politics. It calls for urgent relief.

Creative work for each individual, personal participation in the production of wealth, and corresponding remuneration, are no less basic human needs than are the needs for food, clothing, and shelter. Unemployment generates insecurity and despair. Sickness frequently visits those who are unemployed, so that people may find their health undermined at the same time that they face poverty and social isolation.

Unemployment does not just happen. It is man made. Full employment can surely be achieved again, even if it is not the same kind of full employment we knew during the long post-war period in most Western European countries. Instead of guaranteeing a «family wage» to the male wage earners, leaving other necessary work to be done by women as unpaid work, full employment will now be about guaranteeing access to properly paid work to every independent member of society, thus furthering the redistribution of unpaid work in a fair and better way. And rather than relying on a continuous expansion of every kind of material production, full employment will now have to be based on careful stewardship of natural resources and decent environmental conditions. Since Western European societies are at least three times richer than they were at the birth of post-war welfare politics, we could, in fact, afford to achieve such a new kind of full employment -by supporting an ecologically sustainable recovery, by redistributing paid (and unpaid) work, as well as through private incomes and public goods.

Everywhere there is a need for public provision of shared services. No one doubts the usefulness, for example, of our caring services, or preventive health work, or of education and training. Why should we not also co-operate in restoring run-down areas, in recuperation of the natural environment, in improving housing security and energy efficiency, in developing sheltered housing for old people, or in offering better child care support, and sport and leisure centres for the young? Is there not equal benefit in support for small and medium enterprises, or for sustainable agriculture? Yet vital services are allowed to decline and decay in a destructive spiral. Public expenditure is reduced, instead 
of reducing public waste and tax fraud. At the same time, new technologies and methods of organisation are used to lay off ever more people, instead of offering them a role in a better network of public provision, and creating more, better qualified and better paid jobs.

Capital movements, all kinds of speculation and even production itself, are now more than ever arranged on an international, global scale. National governments have been set against each other, and trade unions and the working people of each country have been dragged into an economic war for competitive advantage. The arguments supporting this harmful process are misleading: in general, the rate of profitability in Western Europe is far above the global average, and even in countries which are at the forefront of world competition there are real alternatives to the kind of monetaristic policies currently being imposed.

The European Commission and Council of Ministers have launched various plans and proposals over the last few years to create large numbers of jobs all across the Union. But from the launch of the Delors White Paper to the Conclusions of the Essen Summit, in spite of a modest economic recovery in the meantime, the number of people in work has not risen. Throughout Western Europe, the numbers employed remain at least 16 million below what they were in 1990. At the same time, improvements in the number of women finding jobs in parts of the economy are marred by the insecurities of part-time work, and by severely exploitative low pay, while there has been a marked fall in male full-time jobs. The pattern of working time is still organised according to traditional roles for men and women, without adequately recognising the profound changes that have already taken place. Continued large increases in productivity mean that working hours overall can, and should be cut, without the reduction of the resources allocated to pay. At the same time, new fiscal policies could help safeguard earnings and income levels. Indeed, we now face the danger that unemployment and poor jobs will increase, as governments cut back their spending to meet their very restrictive interpretation of the terms of the Maastricht Treaty for a single currency. Now, in many countries, we face a combination of social cuts with the removal of social protection in the labour market. A new misery threatens: the descent into poverty of those who have been long excluded, and of those others who now endure painfully low wages, saps the confidence and strength of their neighbours, and brings fear and insecurity to large parts of Europe.

This European crisis is replicated throughout the world, and we seek allies in every continent to work out employment policies based on co-operation rather than raw competition. 
There is no case for a fortress economy, either at the level of Europe, or at the levels of a nation, a region, or a family. Some have tried: the rich in some countries fortify their suburbs, carry guns and teach their children to shoot. This will not work. The only way forward is to act together, each for all, striking a «new deal» from below, between the poor and the better-off, using the instruments of public policy to advance common interests capable of stabilising broad popular alliances. At local, regional, national and European levels, we need joint and common action to create and to safeguard sufficiently wellpaid jobs, and to re-distribute working time.

We have to persuade a broad majority of the people that it is better to finance socially useful and ecologically sustainable work than to subsidise unemployment. We want to press for a common European economic strategy to reduce unemployment, exclusion, and poverty on the way towards a new era of full employment. This choice involves a wide variety of public and private programmes, including a European level of borrowing and funding, and sustained efforts to reduce working time, share work, and make possible a rich programme of lifelong learning, while at the same time safeguarding the income levels of the working population.

New technologies and new management systems need fewer workers to produce more goods and services. Labour is, in fact, saved this way. We need, however, to use this saved labour in a new sharing of paid and unpaid labour, reducing the gap between those who are overworked, and those who are excluded from society's work, as well as using some of the additional earnings for funding the creation of jobs in the environment, education, and the caring services. Voluntary bodies, churches, and trade unions have already begun to study the effect of sabbatical leave for parents, the provision of training and schooling in working time, and other relevant methods of sharing work, as well as creating humane and satisfying forms of work to replace much labour that is boring and repetitive drudgery.

This Appeal seeks to encourage all forms of action and all modes of employment which will end the disaster of unemployment. Its signatories will seek ways to come together to exchange ideas, examine experiences, and co-ordinate their work. We shall seek to encourage relevant action in the political field, so that employment takes its place at the top of the agenda. We shall also do whatever we can to influence our neighbours and communities to refuse a Europe of exclusion and mass unemployment. Europe must include all its citizens, and afford to each the space in which to develop his or her capacity for happiness and social solidarity.' 


\title{
PÚBLICO-PRIVADO \\ UN MODO DE INTERVENIR EN LA SOCIEDAD GLOBAL-LOCAL
}

\author{
ANTONIO GUTIÉRREZ RESA \\ Catedrático E.U. de Trabajo Social y Servicios Sociales. Universidad de Zaragoza.
}

\section{INTRODUCCIÓN}

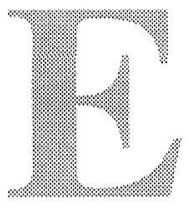

1 objetivo de las páginas siguientes consiste en razonar la conveniencia de que las intervenciones, sobre todo en el ámbito social, se asuman conjuntamente por parte de la responsabilidad pública y por parte del interés privado lucrativo y no lucrativo.

Cumplir con el objetivo de explicar las intervenciones sociales público-privadas, nos remite a las condiciones que configuran la sociedad actual como una realidad global y local al mismo tiempo. De esta manera, comprenderemos los límites y, sobre todo, las posibilidades que nos permiten hablar de cambio de rumbo en las exposiciones teóricas y en la resolución de los problemas sociales que aquejan a cualquier reducida localidad, gran ciudad, autonomía o nación.

La abundante literatura sobre la globalización, y el sin fin de pareceres sobre cómo conducirse en las políticas sociales y los servicios sociales, me ha animado a mostrar mi punto de vista. Como una reflexión más, expongo lo que es resultado de manejar algunos de los datos más recientes. De hacerlo de otra manera, sin el conocimiento previo y pormenorizado de lo que significa globalidad-local, abundaría en la "metafísica" al uso cuando nos reunimos para hablar sobre cuestiones sociales.

II. ACLARANDO CONCEPTOS: GLOBAL Y LOCAL, CARACTERÍSTICAS DE LA SOCIEDAD ACTUAL, ACTUACIÓN PÚBLICO-PRIVADA

Lo global se define como la globalidad económica existente en estos momentos. Aunque existen diversas globalizaciones tales como la de la información, las drogas, el crimen y el medio ambiente, entre otras, nosotros subrayamos la globalización de las finanzas. La activi- 
dad económica como actividad estratégica dominante está organizada en redes globales de decisión e intercambio. Significa, más exactamente, que las citadas actividades económicas funcionan como una unidad en todo el mundo y además lo hacen en tiempo real.

Local se entiende como centro que gestiona lo global. Y, aunque podríamos referirnos al ámbito de la competitividad y productividad, así como al de la representación y gestión políticas, lo haremos teniendo presente el ámbito de la integración socio-cultural. Más exactamente, importa conocer cómo afecta y se resuelven los problemas creados por la globalidad económica en pueblos y ciudades.

La sociedad actual se caracteriza por un conjunto de rasgos y tendencias, como: predominio del racionalismo científico y las sensaciones, aumento del control estatal y desarrollo de la sociedad civil, neocapitalismo de corte político variable, la existencia de una nueva Europa, secularización en aumento, envejecimiento de la población, multilocalidad de las personas, biotecnología humana, comportamientos humanos sin compromiso, de auto-realización, con referentes locales, que valora la naturaleza, tendente al hedonismo y permisividad, y permeable a los medios de comunicación de masas.

Actuación público-privada significa combinar la economía pública con la privada, economía mixta, con el objeto de conseguir mayor productividad, utilidad, aumento del consumo de masas y capitales, y ampliación de los mercados, sirviéndose de los medios de comunicación y propaganda. Lo que decimos de la actuación público-privada en general beneficia al bienestar de los "ricos" en detrimento de los pobres. La actuación público-privada en beneficio de los más débiles requiere de la decisión política capaz de combinar la cooperación de los agentes económicos locales más importantes con aquellos colectivos sociales (ONGs) dispuestos a gestionar o prestar directamente servicios, como, por ejemplo, atención a la tercera edad (planificación y desarrollo de actividades de ocio, ayuda a domicilio, compañía, enfermos terminales, etc).

\section{UNA PARADOJA MÁS: GLOBAL Y LOCAL AL MISMO TIEM- $\mathrm{PO}$}

No podemos tomarnos en serio que la realidad que nos envuelve, lo global y local, constituye una paradoja más. Precisamente porque afecta a la economía, a los sistemas de producción, al trabajo, a los medios de comunicación, al comportamiento de las personas y, en definitiva, al futuro de la sociedad es por lo que nos hemos permitido provocar a los 
bien documentados y llamar la atención de los distraídos con semejante apartado.

La globalización económica no puede producirse sin el sustento de bases territoriales, locales (unidades económicas), conectadas en red y suministradoras de la riqueza globalizada. Para que así suceda se requieren una serie de condiciones favorables que allanen el camino. Las naciones, por ejemplo, pueden ser un obstáculo si se oponen a una total liberalización de las transacciones de capital, de tecnología, de flujos de personas, etc. Sin embargo, existen hombres y mujeres en los territorios locales conectados. Significa precisamente que necesitan todo un conjunto de servicios para vivir adecuadamente y ser productivos: desde la enseñanza, salud, vivienda, servicios sociales, hasta la cultu$\mathrm{ra}$, ocio, etc. para estar integrados como conjunto de los ciudadanos. Si la globalización de la economía dispone nódulos privilegiados, las bases territoriales dependen de las autoridades locales, de los ayuntamientos y gobiernos autonómicos.

La economía global localiza y concentra lo que crea valor y se valo$\mathrm{ra}$, mientras que rechaza todo aquello que no se consume porque se devalúa. Esta doble vertiente que atrae y rechaza es posible porque se aplica conocimiento e información a la gestión, producción y distribución en los procesos y productos. El resultado final, a fecha de hoy, es que se han creado más puestos de trabajo, aunque se destruyan en algunas áreas del mundo (Europa). A pesar de lo cual añadiremos, para que no todo sea de color de rosa, que se han deteriorado las condiciones de empleo y se ha modificado la organización del trabajo. La consecuencia final es que disminuye el Estado de Bienestar. Es lo que ha venido sucediendo en países como Alemania, Suecia, Estados Unidos o Inglaterra en donde ha decrecido progresivamente el gasto público. En el año 1996 la única preocupación del Dresdner Bank era el descenso de los impuestos sobre el patrimonio y los depósitos de capital, la desregulación de todos los servicios financieros y el ahorro en los gastos de los servicios públicos y servicios sociales. En el mismo año, 1996, en Suecia el primer ministro socialdemócrata Goran Persson bajaba drásticamente el subsidio de parados y enfermos. Las promesas de 1992 de Bill Clinton se toparon bien pronto con la dificultad de justificar un aumento del presupuesto.

Las bases territoriales, locales, de la economía global serán las encargadas de lograr al mismo tiempo que la competitividad global, la inversión pública en puestos de trabajo de interés social y útiles a la comunidad local. De este modo, se desarrollan infraestructuras para una productividad competitiva y se logra la integración social a nivel local de los excluidos por la economía global. Un reciclaje necesario 
para mantener con empleo de proximidad y servicios complementarios los centros de alto rendimiento local (guarderías, acompañantes de ancianos y niños, servicios comunales de seguridad, transportes públicos flexibles y diversificados, servicios de apoyo a las asociaciones y a la solidaridad comunitaria, ayuda a domicilio cualificada, servicios de apoyo a hospitales y residencias de ancianos, centros de integración étnica, protectores del medio ambiente, servicios de ocio y cultura, entre otros).

Lo global y local no puede separarse porque sería "el final" del orden económico mundial. Sin el alto valor añadido en el origen de los procesos productivos, así como de los mismos productos, no sería posible ni la alta competitividad ni la economía global. Lo que pretendemos decir a partir de aquí es que los seres humanos espacialmente localizados, necesitan condiciones adecuadas para trabajar, moverse y trasladarse, disfrutar, descansar y morir. Condiciones que se han deteriorado para un buen número de ciudadanos, mientras se acelera, al mismo tiempo, la desaparición de referentes con que situarse ante la vida "competitiva" y comprender lo que ocurre cuando desaparece un ser querido, un amigo. Aquel trabajador rural español de los años cuarenta pasó a la historia. Pero nos interesa resaltar de entonces aquella vida unitaria, aquel trabajo de sol a sol, únicamente interrumpido por acontecimientos locales de gravedad o de máximo alborozo: un entierro, una boda.

En la actualidad, el hombre y la mujer dividen sus vidas teniendo que atender en ocasiones a principios contradictorios, que rigen sus destinos. La dificultad de sustraerse a semejantes principios rectores ocasiona no pocos problemas y obliga, en cierto modo, a romper la unidad de la persona, tal y como explica el profesor Pedro González Blasco. El ámbito del dinero, del poder, de las ideas y de las relaciones abarcan nuestras existencias. Y lo hacen de tal manera que: la eficacia alcanza la máxima valoración jerárquica impuesta por el dinero; la igualdad como consecuencia de la legitimidad, es fruto de un orden político establecido por el poder; la autorrealización y gratificación personal es fruto en cada cultura, sobre todo en las dominantes, del orden cultural que establecen las ideas; $y$, finalmente, la comunicación es el principio rector de las relaciones en la vida cotidiana. Por eso mismo, hemos avanzado ya el forcejeo que puede producirse cuando intentamos movernos en la sociedad y las tensiones apuntan y chocan con personas concretas o las dificultades que surgen, medibles unas veces, y en otras ocasiones incomprensibles. El trasiego de los cuatro principios provoca situaciones de desasosiego y descontento con uno mismo; no es de extrañar, entonces, que no pocas personas acaben por zanjar esta problemática atendiendo únicamente a su conciencia, a la propia tran- 
quilidad que provoca el control e identidad de uno mismo, lo que en expresión popular diríamos "dormir con la conciencia tranquila". Quienes no consiguen dominar las cuatro fuerzas, suelen decantarse por una o dos de ellas, normalmente, las más afines a los intereses egoístas de cada cual. También es lógico que, con semejantes contextualizadores, se produzcan toda una serie de combinaciones y de casos, llegando incluso, a situaciones patológicas. Los efectos no se han hecho esperar: desde el consumo de coca hasta las curas rápidas de reposo en el campo.

\section{IV.CARACTERÍSTICAS DE LA SOCIEDAD ACTUAL}

¿Cómo es la sociedad que vive entre la globalidad y la localidad? Importa conocer algunas de sus características porque son la clave del futuro y, por tanto, de aquellas alternativas posibles para mantener la globalidad y paliar los efectos de exclusión que tan evidentes se muestran en los niveles locales. En definitiva, se trata de saber si la sociedad se adecúa o no a la globalidad desde aquellos espacios locales por los que se transita diariamente.

Cualquier vecino o amigo te cuenta, saliendo del ascensor o entrando a casa, algunos de los planes de futuro para, en definitiva, vivir mejor. Se buscan alternativas para conseguir nuevos paraísos, nuevas tierras donde disfrutar de la vida. Cualquier acción que no dé resultados, casi inmediatos, de aproximación a un futuro mejor, la dejamos de lado y la llegamos a considerar poco menos que inútil. Nos invade el pragmatismo algo más pormenorizado que el que defienden los filósofos John Dewey y Donald Davidson, por ejemplo. Aun con todo, seguimos a los pensadores citados al desarrollar la autoconfianza con nuestras experiencias, desechando todo aquello que no es demostrable. Ahora bien, aunque no interesa más que lo científicamente útil y comprobable no por ello ha de ser obligatoriamente insolidario el ser humano.

No buscamos tanto la verdad y la perfección y sí que nos interesan las necesidades y sensaciones de los demás para satisfacerlas de otro modo y aumentar la simpatía con un número mayor de seres humanos. Si esto último se impone es porque abre alternativas, ofrece posibilidades y precipita resultados positivos; lo primero, la verdad y la perfección, pueden constituir hasta un retraso, tal como lo expone el filósofo norteamericano Richard Rorty.

En buena parte de lo que hablamos, de vivir cada vez mejor, el Estado y su decidida intervención ha sido el artífice. El estado de Bienestar ha logrado, por tanto, que disfrutemos de un alto nivel de vida, 
mientras el presente nos acucia para sostenerlo y hacerlo extensivo a la mayoría. Sin embargo, los profundos cambios en los sistemas de producción, y los consiguientes efectos en la economía, presionan sobre los estados y los someten a las reglas del ahorro y control. Las etnias, culturas, autonomías y comunidades locales reaccionan frente al control de los estados que cumplen escrupulosamente los dictámenes de la economía global (Fondo Monetario Internacional, Banco Mundial o Bruselas). El Estado de Bienestar deriva ahora en sociedad del bienestar. Se trata de que la sociedad civil participe activamente en aquello que desea conseguir. De hecho así sucede, al tiempo que los medios de comunicación estatales y público-privados adoctrinan sobre el modo de conducirse.

Consumir más y selectivamente ha de aportar sensaciones inmediatas y placenteras, mientras se convive con el displacer que padecen regiones del mismo país o de otras partes del mundo. No es de extrañar, por tanto, que la Comunidad Europea atraiga precisamente por querer alcanzar mayor libertad y democracia, conseguir la restauración de economías deshechas y lograr convergencias culturales, sociales y religiosas.

Se amplia el proceso secularizador porque el discurso y valores religiosos han dejado de ser referentes de la sociedad. Añade, al mismo tiempo, Pedro González Blasco, catedrático de Sociología en la Universidad Autónoma de Madrid, que la política y la economía se rigen por leyes propias y diferenciadas. No hay más que ver la hegemonía de la economía global sustentada por el principio de la utilidad y el dominio que ejerce sobre los estados. Paralelamente, se adolece de contextos capaces de encajar y explicar lo que ocurre, buscando refugio las personas en lo individual y practicando el escepticismo para con el resto. Ni siquiera los medios de comunicación informan adecuadamente; menos todavía explican lo que sucede con cierto nivel de complejidad, y sí que abundan los medios en la difusión de dormideras biográficas del espectáculo, de la fama y el simplismo más desechable.

Otra serie de características, no menos importantes, configuran nuestra sociedad. Crece la esperanza de vida y, por lo tanto, envejece la población, sin que aumenten los nacimientos. Las consecuencias son fáciles de adivinar y, sobre todo, para el sistema de los servicios sociales. Igualmente trascendentes son las posibilidades de manipulación genética.

En el trasiego del día a día es donde nos topamos con una sociedad que se relaciona más y sin tantos convencionalismos como antaño; también es cierto que apenas si se compromete, buscando principalmente la propia satisfacción y auto-realización más inmediata; se aprecia más la naturaleza y se concibe a la persona como parte del ecosistema 
global; perseguimos el placer inmediato, el gesto social fácil, mientras toleramos lo que ocurre, sin afectarnos, por practicar la indiferencia.

\section{ACTUACIÓN PÚBLICO-PRIVADA}

Es ineludible plantear la actuación público-privada, según diversas fórmulas, para mantenerse en la economía global y en el nivel de bienestar adecuado a las circunstancias imperantes. Decir lo contrario supondría justificar que el Estado exclusivamente reúne las condiciones para seguir manteniendo el nivel de bienestar alcanzado. La otra opción, nunca dada en la historia, consistiría en que el mercado proporcionara el citado bienestar para todos. No obstante, nos mantenemos en la idea de razonar las actuaciones público-privadas dirigidas a los más desfavorecidos, porque son estos últimos quienes más acusan los efectos de la globalización económica, la disminución de inversión pública y hasta de los controles nacionales.

El decisivo protagonismo del Estado en décadas pasadas y en beneficio de los intereses comunes sigue siendo imprescindible. Sólo que ahora las condiciones de producción y laborales han cambiado y la convergencia económica de los estados requiere del apoyo privado lucrativo y no lucrativo. La imperante necesidad de justificar la presión fiscal y los controles sociales exige mantener y aumentar los gastos en sanidad, vivienda, educación y servicios sociales. Para lograrlo, la intervención público-privada es necesaria bajo diversas fórmulas. Ahora bien, es preciso advertir que ni las ONGs van a sustituir la responsabilidad pública, ni el mercado se va a mostrar solidario disminuyendo la capacidad de aumentar las ganancias.

\section{a) Condiciones del mercado asistencial}

Entendemos por mercado asistencial la venta, por entidades públicas y sin ánimo de lucro, y la compra obligada por los más desfavorecidos (pobres, mendigos, vagabundos, excluidos, sin hogar, transeúntes), de una serie de productos o servicios exclusivos en su género que normalmente degradan a quien los consume y cuyos orígenes ya los encontramos en el siglo XVI. Algo más complicadas son las cosas porque el pago de semejantes mercancías no suele hacerse con dinero; se les roba toda serie de intimidades, codificadas adecuadamente en extensos formularios, imponiendo el control administrativo más férreo o el ilusorio contrato de integración, por no decir su ausencia de las calles como antaño. Hemos tenido ocasión hasta de verlo en filmes bastante recientes como Lady Bird lady bird, y Siempre hay un camino a 
la Derecha. Trato deshumanizado, profesionales haciendo su burdo ejercicio de poder y ausencia de soluciones para los problemas tratados. Lo que ha constituido parte de la tradición asistencial como su identificación y persecución se perpetúa en la actualidad, manteniendo la idea de que la condición de los más desfavorecidos es el resultado de una vida y no tanto una condición grupal y colectiva.

Las condiciones del mercado asistencial suelen ser, normalmente, cumplir con los requisitos que establece la administración pública o la entidad sin ánimo de lucro correspondiente. Aunque hayan desaparecido de los ayuntamientos españoles las ventanillas de los pobres (ciegos y viudas de antaño), el seguimiento ahora se ha encarecido, si tenemos presente los profesionales que intervienen, los prolijos formularios, la centralidad de las decisiones y las comisiones de evaluación, amén de las horas dedicadas a semejantes procesos claramente administrativos. Cumplir, por tanto, con las condiciones exigidas, significa tener opción a los beneficios asistenciales, tales como el pago del alquiler retrasado, de la luz y el agua, de una ayuda económica alimenticia, y hasta de un salario social o ingreso mínimo de inserción social (denominada jay, ay, ay! por la gente de la calle en Aragón), amén de comedores de caridad y servicios sociales que nos reeuerdan los servicios de antaño: albergues, casas de misericordia, inclusas y colegios de niños de la doctrina, asistencia a domicilio, hospicios, asilos, depósitos de mendigos, etc. De algún modo se sigue alimentando la clásica división entre los pobres dignos y quienes no lo son para poder atender a unos y castigar a otros (vigilar y castigar habría dicho Michèl Foucault).

Se trata de un mercado que no ofrece otras posibilidades; la oferta es unilateral para un conjunto de ciudadanos, mejor individuos, cada vez más diversificado. No podemos dejar de hacer mención a uno de los últimos estudios, al respecto titulado "Huéspedes del aire", cuỳo autor, Pedro José Cabrera Cabrera, indaga en la diversidad de biografías "errantes" de la ciudad de Madrid. La investigación demuestra que son personas sin hogar, dignas todas ellas, con una vida compleja, con opiniones propias sobre política, valores y creencias religiosas, capaces de volver a trabajar, que no están 'locos' ni son gente rara.

El variopinto mercado asistencial de tanta solera en España se planteó, básicamente, la identificación y persecución de los beneficiarios, sin ofrecer apenas alternativas (vivienda, trabajo, restauración del entramado social, cultura y aprendizaje, pisos tutelados, residencias, etc.). No se produce la integración porque los servicios, claramente identificados por la sociedad, clasifican y mantienen en la exclusiónmarginación a quienes los reciben, colaboren o no con el trabajador social. 


\section{b) Las virtudes de los vencidos}

Habiendo llegado a la globalización económica, uno de los efectos más fácilmente comprobable ha sido que un gran número de personas pierden poder adquisitivo, deben trabajar más horas y disminuye drásticamente su nivel de bienestar. Son, en definitiva, los perdedores; en torno al $80 \%$ de los ciudadanos. Los ganadores son los otros, el $20 \%$ restante. Se trata, por tanto, de comprender que, precisamente porque hay ganadores, también existen los perdedores, que constituyen la mäyơía casi silenciosa.

Los vencidos por el proceso productivo y de la información no quedan necesariamente al margen del conjunto de la sociedad. Precisamente porque constituyen la mayoría no ilustrada, se les brinda una serie de consejos y modos de comportarse que les ayudarán a sobrellevar mejor sus vidas, y hasta a triunfar si se presenta la ocasión. Es cuestión de èstar alerta y preparado para el triunfo.

En este gran mercado de virtudes liberales, nos recuerda Michael Baurmann la vieja tesis de la conveniencia de ser honesto y confiable para que el gran mercado funcione. En otras palabras, se necesitan unas reglas de juego o virtudes morales imprescindibles basadas únicamente en el individuo. Las críticas no se han hecho esperar desde el comunitarismo, así como desde los efectos de la competencia (huida), la desaparición de los intereses comunes y el comportamiento asocial.

Lo cierto es que sin un cierto orden moral es imposible que el gran mercado de los intereses individuales funcione adecuadamente; es más, la exigencia de la demanda moral no puede ser satisfecha únicamente en el ámbito del mercado económico. Nos hemos de extender a otro tipo de intercambios, no necesariamente económicos, en los que es imprescindible cierto grado de moralidad. Nos referimos expresamente a asociaciones económicas o políticas, asociaciones sin fines de lucro, etc., que, en definitiva, expresan la libertad de asociación de los ciudadanos. Libertad de cooperación y de asociación que produce las condiciones para que se den personalidades virtuosas capaces de someterse libremente y cumplir los principios de respeto para con los demás, así como de equidad social. "A la larga, puede serle más ventajoso y útil a una persona poseer virtudes y 'carácter' que maximizar en cada oportunidad su propia utilidad". De ahí, que se den cada vez más casos de personas que prestan sus servicios voluntariamente en una ONG con la esperanza de adquirir experiencia y encontrar trabajo en la misma entidad o en otra de semejantes características, pública o privada. El caso es tener la posibilidad de disfrutar de alternativas, de condiciones sociales que hagan posible el ejercicio y desarrollo del Estado de Bienestar. Luego se comprueba la combinación de utilidad, 
interés personal y altruismo que puede perseguir la misma persona, tanto cuando actúa solidariamente como cuando elige una opción política al hacer ejercicio de la democracia.

Las semejantes condiciones sociales en la economía global obligan a pensar en muestras de solidaridad comunes, en un mercado de la virtud, cada vez más universal, y capaz de sobrepasar los intereses de grupos locales y minoritarios. Estaríamos apuntando, entonces, a una sociedad del bienestar que, aunque vencida por la globalización económica, se mantendría en el cumplimiento de normas y desarrollo de virtudes morales propicias para los intereses comunes.

Las virtudes de los vencidos las vemos plausibles en el mercado si el Estado las propicia sin disminuir el nivel de bienestar de los ciudadanos. En caso contrario, volveremos a encontrar ladrones y rateros en el mercado, como antaño con el Lazarillo de Tormes. No puede olvidarse que se trata de un $80 \%$ de ciudadanos no rentable para el mercado de alta competitividad. ¿Quién vencerá a quién, el gran mercado de la globalización económica o el mercado de la virtud?.

Volver al asistencialismo es retroceder en el sentido completo del término, cuando estamos hablando de propiciar condiciones que desarrollen la iniciativa, creatividad, cooperación, solidaridad y compromiso de quienes se alejan de la primera línea de competitividad en el mercado. Seguir en la línea de distanciarse de las gentes, elaborando informes y centralizando respuestas administrativas, nos conduce al encarecimiento de la gestión, a paliar el paro de algunos profesionales y no solucionar los problemas sociales. Añadiremos, incluso, que conocemos, por numerosos trabajos de investigación, los pormenores de los más desfavorecidos; no han perdido su rostro humano ni la complejidad de sus biografías, a pesar de las estadísticas y desarrollos cualitativos. Sin embargo, las decisiones de las políticas sociales apenas si guardan relación con los datos cualificados. Es incomprensible que sigamos en la mayoría de las ciudades españolas con una red de servicios sociales claramente asistenciales, porque se deben al inmovilismo político de los partidos en lo que se refiere a los temas sociales. No obstante la cantinela es bien conocida, por no cumplida: proximidad, comunidad, participación, integración, etc.

\section{c) En el mercado de triunfadores y excluidos}

Si juntamos a triunfadores y vencidos o excluidos, seguramente, nos veremos en la obligación de razonar la existencia de unos y otros, sobre todo de los segundos.

Aun cuando el propio mercado justificaría buena parte de los vencidos en una nueva jerarquía productiva, quedarían otros muchos por 
integrar; y eso sin contar con ancianos y minusválidos, entre otros.

El gran mercado habrá de abrir sus puertas y, con la intervención del Estado, recomponer políticamente los fundamentos de la sociedad y hasta del propio mercado. Se oyen continuamente voces en pro de regular, limitar los movimientos de capital. De entrada, parece que esto último atenta a una de las bases de la globalización económica: el movimiento libre de capitales.

¿Existen otras posibilidades para zafarse del cerco de los excluidos?. Claro que sí. Están las mafias del crimen, los cárteles de la droga, el blanqueo de dinero, el tráfico de órganos..., y tantas variables de lo mismo mientras no le cojan a uno. Tampoco podemos olvidar la respuesta del Islam a millones de pobres desesperados.

En el apartado anterior, el mercado de la virtud era el mercado de los vencidos, el espacio moral de los débiles que se juntan para mostrarse fuertes ante los avatares de la vida. En esta ocasión, lo que planteamos es bien sencillo. Si el mercado no va contra los valores más intimos, tampoco los desarrolla del todo en el mero trasiego de ganancias económicas y utilidades. Hemos dicho que se necesitan unas condiciones para reequilibrar al $80 \%$ de los ciudadanos. Aun así, quedan más, que, sin el concurso del Estado, pasarían a ser un estorbo junto a buena parte de los anteriores. Nos inclinamos entonces porque en este gran mercado de vencedores y vencidos se negocie el bienestar de la derrota con la mediación del Estado. Estado, organizaciones civiles y mercado son los tres interlocutores del diálogo que marque el futuro de la sociedad en los próximos años del nuevo siglo.

Siguen siendo válidas las virtudes personales, pero son necesarias las condiciones idóneas para producir y ser rentable a la comunidad de intereses. La creatividad, entusiasmo, capacidad emprendedora, cooperación, solidaridad, compromiso, son algunas de las virtudes que constituyen la base para desarrollar servicios sociales de otra índole que los asistenciales o de beneficencia. Y no sólo eso; sabemos, por las investigaciones realizadas sobre los detalles cualitativos y perfiles cuantitativos de las personas a las que nos referimos; en otras palabras, no han desaparecido los rostros humanos sobre los que se trabaja con adecuadas metodologías científicas. No es de recibo, entonces, que se tomen decisiones político-sociales alejadas de los datos más objetivos, cuando se escucha incesantemente el estribillo de tener presente la proximidad, la comunidad y la participación de las gentes. Sabemos que no se cumple, mientras se practica y se pone en funcionamiento la profesionalidad administrativa y distante para con los problemas sociales, que sirve, en el mejor de los casos, para paliar el paro de algunas profesiones, encarecer la gestión y no solucionar los problemas sociales que aquejan a cualquiera de nuestras ciudades. De lo dicho, 
parece deducirse que únicamente se premian los planes capaces de mejorar las condiciones de los vencedores.

Seguimos hablando en este apartado de ese $20 \%$ de ciudadanos capaces de mantener en funcionamiento la economía mundial, mientras el $80 \%$ puede mantenerse con una mezcla de entretenimiento aturdidor y alimentación suficiente. La gran mayoría ha sido desplazada, eliminada y rescindida porque la economía de alto rendimiento y alta tecnología les ha arrebatado el trabajo y buena parte de su poder de consumo en la sociedad del bienestar alcanzada. Quiere decirse que casi nadie está seguro en su trabajo, se trate de lo que se trate.

La convivencia de vencedores y vencidos ha ido suscitando algunas respuestas y no está mal que conozcamos algunas de ellas. Precisamente, Hans-Peter Martin y Harald Schumann nos brindan su particular punto de vista, por lo demás, nada despreciable. "Con sobriedad, los ejecutivos discuten las posibles dosificaciones, reflexionan acerca de cómo la quinta parte acomodada podría ocupar el resto superfluo. El compromiso social de las empresas es exigible dada la presión de la competencia global, tendrán que ser otros los que se preocupen de los parados. Los participantes en los debates esperan que la integración y el sentido para su vida provenga del amplio campo de los servicios voluntarios a la comunidad, la ayuda a los vecinos, la práctica de deportes o la participación en asociaciones de todo tipo. "Se podrían revalorizar estas actividades mediante una modesta remuneración y fomentar así la autoestima de millones de ciudadanos", opina el profesor Roy. En cualquier caso, en los países industrializados, pronto habrá personas que limpien las calles casi por nada o encuentren un mísero efugio como trabajadores domésticos, esperan los dirigentes de los consorcios. Al fin y al cabo, la era industrial, con su bienestar de masas, no es más que "un pestañeo en la historia de la economía", analiza el futurólogo John Naisbitt.

Si a los vencidos se les imponen las virtudes y un aburrido nivel de bienestar, por qué no plantearse el limitado desarrollo de los espacios locales, que sobrepasan los más aventajados por su alto poder adquisitivo. La gran mayoría seguirá dependiendo de la existencia y buen estado del agua de consumo, de la flora y fauna circundante, de la calidad del aire que se respira, de la seguridad pública en las calles y plazas de las ciudades, de la educación y formación públicas, etc.

\subsection{La intervención público-privada en los intereses comunes}

Es conveniente recordar que tras la Segunda Guerra Mundial los ciudadanos del mundo occidental industrializado gozaron de unos niveles de bienestar gracias a la intervención decidida del Estado. Preci- 
samente por eso hablamos de Estado de Bienestar y no de sociedad del bienestar como se escribe ahora. Hasta los años setenta se habían seguido los dictámenes del economista John Maynard Keynes, quien coloca al Estado como inversor financiero central de la economía de las naciones, además de moderador ante el desempleo o ante los desequilibrios económicos. Y, en los Estados Unidos, tras la catástrofe de los años treinta del presente siglo, es el gobierno de Franklin Roosevelt el que con el New Deal inventa el moderno Estado social para salir de la crisis que había provocado el impulso globalizador de la economía mundial.

Con la crisis del petróleo cambian las cosas, al tiempo que se dirigen las miradas a neoliberales como Milton Friedman o August Hayek. Para estos últimos, el Estado es un mero guardián del orden, dejando libres a las empresas privadas. La libertad del capital es la norma a seguir desde los años ochenta. Lo que se impone claramente es la desregulación, la liberalización y la privatización. El bienestar futuro debe conseguirse cumpliendo las normas que acabamos de mencionar; en caso contrario, las medidas de castigo se harán presentes. Lo curioso es que, aun cumpliéndolas, es ya sabido el descenso del nivel de vida de los trabajadores norteamericanos en apenas diez años. Y hasta se dice con claridad que los precios de los servicios públicos son excesivamente altos, no teniendo por qué recaer en el sector productivo de la sociedad.

Así las cosas, parece ser que la intervención pública ha de seguir una serie de normas si quiere atraerse al sector privado en la tarea de defender los intereses comunes. No olvidemos tampoco el papel decisivo del Estado en la economía de los Tigres asiáticos: un camino diferente hacia el bienestar alejado de la tradicional trayectoria seguida por Occidente. No obstante, los resultados en el continente asiático están presentes, aun cuando temas como el de la seguridad social no existen para ellos, por disponer de estructuras familiares muy sólidas.

Adelantamos la necesidad de que el Estado siga existiendo y siga interviniendo. En caso contrario, es difícil equilibrar los movimientos xenófobos de la población en Europa y América; los siguientes en verse excluidos serán los perceptores de ayudas sociales, los parados, minusválidos y los jóvenes sin formación, ya que hasta las mismas clases medias son reticentes a la hora de pagar por ellos. Otra salida que se comenta cada vez más dejaría en manos de cada individuo la serie de infortunios que tienen lugar en la vida de cada persona.

Apenas si hemos citado hasta ahora la fuerza que desarrolla la sociedad civil. Interpretamos que se trata de una respuesta a la globalización y a la enorme e insostenible maquinaria de la burocracia. Miles de ciudadanos se comprometen diariamente en asociaciones y enti- 
dades de todo tipo con el bien común. En algunos países del norte de Europa se alcanza el $30 \%$ de personas voluntarias que dedican parte de su tiempo libre a actividades de todo tipo. En España no disponemos de estudios globales, pero el realizado por Pedro González y Antonio Gutiérrez arroja el 12\% en la Comunidad Autónoma de Madrid. Es más, se dice, en el referido estudio (La opinión pública ante el voluntariado), expresamente, por más del $80 \%$, que el Estado debe apoyar a las entidades voluntarias. El paso siguiente consistiría en consolidar la solidaridad de millones de personas repartidas por todo el mundo mediante la colaboración y entrelazamientos internacionales.

Tenemos presentadas ya las tres variables (lo público, lo privado y las llamadas ONGs) que pueden reducirse a dos: Estado (público) y mercado (privado). Ahora es el momento de plantear la intervención público-privada a nivel local, donde se conoce a la gente y se sabe de sus problemas. Sabemos además de la tendencia a la concentración humana en las ciudades, además, de la recomposición espacial del ámbito rural en comarcas (ley de comarcalización en Aragón). Son muestras inequívocas de contemplar los espacios donde vivimos y donde buscamos mantener el nivel de bienestar adquirido. La respuesta, entonces, ha de producirse en los marcos espaciales señalados, próximos a los ciudadanos.

La política económica global para lograr la integración ha de combinar la alta competitividad con el mantenimiento de un sector de empleo en torno a servicios públicos y parapúblicos, independientes de la competencia global, tal y como comentamos con anterioridad. Adecuar la fiscalidad, ejercer localmente controles económicos, sociales y medioambientales a partir de los espacios comarcales o mancomunados. No obstante, deben adecuarse conectados al mismo tiempo nacional e internacionalmente con el objeto de participar en redes activas y dinámicas que superen la pasividad administrativa al uso. Sólo así es posible defender lo local, la ciudad, el pueblo, la comarca, al mismo tiempo que se crean colectivos en la red capaces de entenderse internacionalmente y de influir localmente en la búsqueda de solución de los problemas. Se trata entonces de una red y no de un sistema jerárquico, variando las posiciones de los ciudadanos y las comarcas en función de la economía global. La red permite internacionalizar los espacios locales (barrios, ayuntamientos, ciudades, comarcas), acceder a los organismos internacionales, así como a los créditos internacionales.

Lograr la integración de los ciudadanos en los espacios locales va siendo admitido como condición imprescindible del desarrollo. Quiere decirse que la relación entre desarrollo económico, y los correspondientes costes sociales, exige también altos costes generales. Los agentes 
económicos toman las decisiones cuando los ámbitos locales presentan panoramas atractivos y un buen funcionamiento para afrontar la pobreza, la marginación, la sensación de seguridad ciudadana, el comportamiento individual y grupal en los espacios públicos, etc. La conclusión es que no hay desarrollo sin capacidad de integración. Jordi Borja y Manuel Castells afirman claramente que "hoy las grandes actuaciones de carácter social urbano aparecen como necesarias y urgentes y, por lo tanto, susceptibles de encontrar unos apoyos políticos y económicos que hace unos años no tenían".

Lograr la integración significa dar respuestas integrales y no sectoriales a los problemas de empleo, educación, ocio, exclusión y marginación, etc., así como aquellos otros de defensa del suelo y subsuelo públicos o la rehabilitación de los cascos antiguos y reciclaje de los espacios que ocupan las poblaciones más débiles. Igualmente, se exige el compromiso público-privado para el citado desarrollo y la exigida integración incluidos los más desfavorecidos. La gestión y sus formas deben procurar conseguir agilidad y transparencia, además de responder a criterios de eficiencia económica y social y no de control político y burocrático; únicamente de este modo se consigue la cooperación y la iniciativa social. Naturalmente que cuando hablamos de gestión nos referimos a una gestión empresarial de los servicios y actividades públicas.

La gestión de los servicios públicos puede adquirir muy diversas modalidades: desde los centros gestores autónomos para servicios que pueden deslindarse, hasta empresas mixtas o privadas a las que se concede la prestación de determinados servicios públicos. Aquí, precisamente, es donde cabe la actuación de las entidades de voluntariado, por separado o junto a empresas privadas con ánimo de lucro. Negociar las funciones a cumplir por cada uno de los participantes exige como acuerdo de conjunto mejorar el total del servicio por el coste estipulado, apuntando siempre a mantener y elevar la calidad de vida de los vecinos. Naturalmente que lo que decimos debe acompañarse de elementos complementarios que favorezcan la comunicación y la participación de los ciudadanos: ventanillas únicas, gestión por teléfono, valor de la declaración oral, consulta a domicilio, etc., utilización de las nuevas tecnologías para la descentralización territorial y funcional, así como programas concertados basados en la cooperación y la participación.

Según el Plan Integral de desarrollo de los servicios sociales de Barcelona, "el papel del sector público se centra básicamente en la planificación, coordinación, control de la calidad y evaluación de los servicios, así como la vertebración de la cooperación público-privada. El sector privado -lucrativo y no lucrativo- participa en la planificación y básicamente en la gestión de los servicios". 
Luego el partenariado de los asuntos comunes locales exige el pacto y la colaboración entre lo público-privado para actuar conjuntamente, mantener y elevar la calidad de vida de todos los vecinos, así como la competitividad global. A la vista del desarrollo que hemos tratado de mostrar, debe producirse un cambio de rumbo en los servicios sociales locales.

\section{BIBLIOGRAFIA}

ALEMÁN BRACHO, C. y GARCÉS FERRER, J. (coordinadores): Política social. Ed. MacGraw-Hill. Madrid, 1997.

ALONSO SECO, J.M. y GONZALO GONZÁLEZ, B.: La asistencia social y los servicios sociales en España. Estudios Jurídicos, Serie Derecho Público. Ed. Boletín Oficial del Estado. Madrid, 1997.

BAURMANN, M.: El mercado de la virtud. Moral y responsabilidad social en la sociedad liberal. Ed. Gedisa. Barcelona, 1998.

BECK, U.: ¿Qué es la globalización?. Falacias del globalismo, respuestas a la globalización. Ed. Paidós. Barcelona, 1998.

BORJA J. y CASTELLS, M.: Local y global. La gestión de las ciudades en la era de la información. Taurus. Madrid, 1997.

CASTELLS, M.: La era de la información. Vol. 1. La sociedad red. Ed. Alianza. Madrid, 1997.

CASTELLS, M.: La era de la información. Vol. 2. El poder de la identidad. Alianza. Madrid, 1998.

CASTELLS, M.: La era de la información. Vol. 3. Fin de milenio. Alianza. Madrid, 1998.

DIXON, J. y MACAROV, D.: Social welfare in Socialist countries. Ed. Routledge. London and New York, 1992.

GONZÁLEZ BLASCO, P.: "Sociedad: presente y futuro. Algunos rasgos y tendencias". Rev. Sociedad y Utopía. Revista de Ciencias Sociales, n. 11 de mayo. Madrid, 1998.

GONZÁLEZ BLASCO, P. y GUTIÉRREZ RESA, A.: La opinión pública ante el voluntariado. Consejería de Educación y Cultura de la Comunidad de Madrid, 1997.

GUTIÉRREZ RESA, A.: Acción Social No Gubernamental. Ed. Tirant Lo Blanch. Valencia, 1997.

HANS-PETER, M. y HARALD SCHUMANN: La trampa de la globalización. Ed. Taurus. Madrid, 1998.

JONES, C.: New perspectives on the welfare state in Europe. Ed. Routledge. London and New York, 1993. Págs. 133-198.

MUÑOZ MACHADO, S., GARCÍA DELGADO, J.L. y GONZÁLEZ SEARA, L.: Las estructuras del bienestar. Ed. Civitas. Madrid, 1997. Pág. 529596. 
PETRELLA, R.: El bien común. Elogio de la solidaridad. Ed. Temas de Debate. Madrid, 1997.

RORTY, R.: ¿Esperanza o conocimiento?. Una introdución al pragmatismo. Ed. Fondo de Cultura Económica. Buenos Aires, 1997.

STEYAERT, J.: Information technology and human services, more than computers?. Ed. NIZE-Causa. Utrech. Netherlands, 1996. Págs. 19-68. 



\title{
EL DEBATE DE LO PÚBLICO Y LO PRIVADO EN SERVICIOS SOCIALES
}

\author{
MANUEL ENRIQUE MEDINA TORNERO.
}

Profesor de Servicios Sociales. E.U. de Trabajo Social. Universidad de Murcia.

\section{INTRODUCCIÓN}

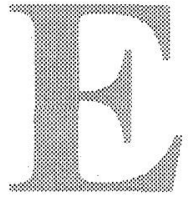

I debate sobre lo que debe ser una prestación realizada desde la Administración Pública o desde las entidades privadas, sean éstas de carácter lucrativo o no, no es nuevo, ni tampoco se va a acabar en los próximos años; somos de la opinión que acompañará durante mucho tiempo al todavía incompleto Sistema Público de Servicios Sociales. Pero lo que no podemos negar es que este tema siempre despierta un vivo interés, y estimo que cada vez se plantea con más virulencia, con más pasión que razón en los argumentos, tanto a favor como en contra. Se presentan opiniones sobre ideologías antisolidarias, sobre el mercantilismo como valor central de la vida social, como un proceso de recortes del bienestar social, como una permanente amenaza de privatización. Y todos estos argumentos olvidan en muchas ocasiones a los empleados públicos y a los usuarios, auténticos protagonistas de una obra de teatro en la que otros son los que reparten los papeles sin atenerse siquiera a un guión preestablecido, con una manifiesta falta de dirección, o, lo que es lo mismo, se critica la ausencia de eficiencia y no se pone en evidencia la poca inversión en formación o en transformación de las organizaciones necesitadas de profundos cambios que consigan desprenderse de culturas arcaicas, instaladas en el asistencialismo tan denostado y criticado por todos.

Algunos antecedentes de este tema nos indican que siempre ha estado vivo, Laparra (1989) nos planteaba un retrato auténtico de la privatización de los servicios sociales en Navarra; Cabrero y otros (1991) abordaban en una interesante obra colectiva los fenómenos de privatización y su relación con el bienestar social y en la misma línea el Institut de Treball Social i Serveis Socials (1991) convocaron unas jornadas de encuentro en torno al sugestivo título de lo público-privado y el bienestar social, en el que se dieron cita algunos de los pensadores con más interés sobre este tema. Desde una perspectiva más general, Manuel Jesús González (1994) ha abordado el tema mediante una pregunta ¿Adónde va el sector público? Del Estado de Bienestar al Bienestar con menos estado. La privatización de servicios sociales 
(Martín Santos, 1995), y, ya antes, Barinaga (1994) se preguntaba por una redefinición del Estado del Bienestar en el que se contemplaba la privatización. En este año algunas obras han puesto de relieve que el tema de la privatización puede ser un fantasma que aparece y desaparece como un efecto Guadiana (Mota, 1998); la influencia de las subvenciones para eliminar competencia siguiendo la política europea restrictiva (Ripoll, 1998), o el papel de las Administraciones en la dialéctica Estado-mercado (Subrá de Bieusses, El País, 6-XI-1998), entre otras publicaciones. Fuera de nuestras fronteras, y sin ánimo de ser exhaustivo, algunos apuntes nos pueden poner en antecedentes. El gran debate abierto en Francia en 1995 convocado por la revista Vie Sociale bajo la inquietante pregunta de L'Etat-providence, quel avenir?, o los trabajos de Donati (1996) que posteriormente insistiría (Donati, 1997) sobre la necesaria configuración moderna de los servicios de bienestar social entre los que no se olvida de los fenómenos privatizadores y contestado enseguida por Ranci (1996) y Puppo (1996) y acertadamente cerrado el debate, es un decir, por el maestro Ascoli (1996) y una de sus alumnas (Ota de Leonardis, 1996). En Inglaterra los trabajos clásicos de Kirk Mann (1991) o los siempre atrayentes de Peter Taylor-Goory (1991) nos acercan las posiciones inglesas que tanta tinta han hecho circular sobre un tema tan preocupante para los ingleses como los niveles de bienestar adquiridos; trabajos complementados por Cree (1996) y la visión de una americana en Londres como es Paula Kearns (1997) en torno a la privatización de los servicios personales, y las declaraciones del primer ministro Tony Blair sobre la reforma del bienestar social en el Reino Unido (El País, 17$\mathrm{V}$-1998). Y en nuestro país encontramos un debate abierto en los primeros días de diciembre sobre la creación de fundaciones sanitarias que gestionen los hospitales públicos, lo que ha puesto el tema de lo público y lo privado en el ojo del huracán, lo que, sin duda, viene a llenar de actualidad el tema que aquí vamos a abordar (véanse los artículos, a modo de ejemplo en el diario El País 1, 2, 3 y 4 de diciembre).

\section{EL ESTADO DE BIENESTAR Y EL MERCADO}

El Estado de bienestar se ha convertido en uno de los elementos centrales del debate económico, social y político de las sociedades desarrolladas, en especial de las europeas, en este final de siglo. De hecho, puede afirmarse que el sistema de protección social, tal como existe en la actualidad, atraviesa una crisis, cuyo origen puede resumirse en tres puntos esenciales, según algunos autores actuales (Buchanan, 1997; Espinosa de los Monteros, 1997): los cambios registrados en la estructura demográfica de las sociedades occidentales, los crecientes 
problemas financieros del Estado de bienestar, sus negativas consecuencias sobre la actividad económica y el empleo.

España es un caso paradigmático. El desarrollo del Estado de bienestar ha experimentado un importante impulso en los últimos quince años. Este país ha recorrido en poco más de diez años un camino que a otros países les ha costado décadas. La expansión de los llamados gastos sociales se ha producido, además, sin tener en cuenta si la economía española podía o no financiar en el largo plazo un sistema de protección social tan extenso y pretendidamente generoso.

El crecimiento del Estado de bienestar, tal y como está hoy concebido, es a largo plazo incontrolable. La mezcla de universalidad, gratuidad y carácter público de las prestaciones determina el crecimiento incontrolable del gasto, tanto por su propia estructura (a precios cero demanda infinita) como por ser objeto de competición entre los partidos políticos que concurren a las elecciones (Espinosa de los Monteros, 1997). En suma, el Estado de bienestar, en su versión actual, ha pasado de constituir una solución a convertirse en un problema. Las reformas orientadas al mercado que se produjeron en los países europeos a partir de los años ochenta no afectaron a los sistemas de protección social que emergen a finales de siglo como uno de los factores determinantes de la actual «euroesclerosis». El impacto de los costes del Estado de bienestar sobre la actividad económica y sobre la competitividad ha sido, y es, un factor determinante de la relativa decadencia económica del Viejo Continente, según la perspectiva de los sectores productivos privados, y, desde esta postura, para ellos es preciso constituir un nuevo modelo de protección social en Europa en el que la cobertura estatal se extienda sólo a quienes realmente la necesitan, que no genere desincentivos y que sea económicamente sostenible. De aquí que la reforma del Estado de bienestar deba enmarcarse en un proceso de reforma global de la economía, dirigida a reducir el papel del Estado en la vida económica y social y proponen para ello dos vías: primera, que el Estado libere a los ciudadanos de la obligación de consumir determinados bienes ofrecidos por el sector público y pagados mediante impuestos (sanidad, educación, pensiones, etc.), permitiéndoles cubrir su demanda de este tipo de bienes en el mercado; segunda, que el Estado garantice el acceso de todos los ciudadanos a un paquete de servicios públicos (donde público no es lo mismo que estatal), pero desmonopolice su prestación.

La primera alternativa supone, desde la perspectiva defendida por el Círculo de Empresarios en la X Conferencia Internacional dedicada a examinar el Estado del bienestar, desde la perspectiva del sector privado, la privatización del actual teórico estado del Bienestar Social y dar el paso hacia un Estado factible de bienestar; la segunda, más 
modesta, supone eliminar el papel monopolístico del Estado en la oferta de determinados servicios. Según estas posiciones, y en la actualidad, la inmensa mayoría de las tareas de bienestar social monopolizadas por los poderes públicos podrían ser desempeñadas por la sociedad civil, lo que no sólo sería más eficaz, sino que además contribuiría a fortalecer los cimientos morales sobre los que reposa una sociedad libre: la responsabilidad individual, la solidaridad natural y la cooperación voluntaria.

Sin embargo, en el caso de los Servicios Sociales, los ciudadanos han seguido y seguirán, aún durante bastante tiempo, demandando ayudas y asistencia, con una cultura asistencial anclada en sus demandas y, a veces, una cultura organizacional y profesional que como único recurso tenía, y en ocasiones sigue teniendo, la respuesta asistencial.

Aunque hemos de ser conscientes que esta situación está entrando en conflicto últimamente. La creciente preocupación por el crecimiento cada vez mayor de la Administración Pública y, consiguientemente, del gasto público y, más concretamente, del gasto social, sin una relación directa con su nivel de eficacia -en tiempos en los que la racionalización y optimización de los recursos son un elemento clave en cualquier tipo de gestión- ha generado este conflicto que, a su vez, ha hecho que países de un alto nivel de desarrollo (Estados Unidos, por ejemplo) aborden este tema como prioritario en sus debates políticos, es decir, como un elemento que puede contribuir notablemente a mejorar la calidad de vida de sus ciudadanos, incluyendo de forma paralela un amplio capítulo de recorte en sus gastos sociales que ha puesto en peligro la protección de diversos colectivos sociales. Sin embargo, en este punto conviene hacer una distinción que en ocasiones puede producir confusión, al ser traducido su significado desde Estados Unidos, y es el término welfare state (considerados como los servicios de carácter universal como la Seguridad Social) del welfare services (los servicios asistenciales que sí han sufrido un considerable recorte en Estados Unidos) tanto con políticas demócratas como republicanas, dependiendo de la bonanza económica (Navarro, 1998).

\subsection{El desmantelamiento del Estado de bienestar: algunas consecuen- cias sobre la equidad.}

En su "best-seller", The State We're in, Will Hutton (1995) ha destacado el crecimiento mundial de las últimas décadas convencido de que los mercados son la solución a las dificultades económicas.

Durante los años posteriores a la II Guerra Mundial se produjo una notable intervención del Estado en la economía de muchos países industrializados. La propiedad estatal de los componentes clave de los 
medios de producción, incluyendo los principales servicios públicos (agua, gas, ferrocarriles, electricidad, barcos y otros) estaba a la orden del día. Sin embargo, durante los últimos veinte años, la privatización se ha extendido desde las economías industrializadas hasta las naciones más pobres y, en la actualidad, a muchos países del antiguo bloque comunista. La pérdida de fe en la intervención y regulación del Estado ha sido reemplazada por una nueva confianza en la propiedad privada y en los precios flexibles de los mercados liberalizados. Como indica Hutton (1995, pág. 16): «Se ha puesto en marcha el gran concurso ideológico del siglo XX. Los mercados libres capitalistas han vencido; la planificación del Estado y el comunismo, de los que se deriva el capitalismo social, han sido derrotados».

Vemos la existencia de un amplio movimiento intelectual y de unas políticas que se dicen tendentes a revitalizar la iniciativa privada y el espíritu empresarial; aunque, están (y esto es, para nosotros, muy importante) las actitudes y expectativas ciudadanas con respecto al comportamiento estatal y a los papeles que lo público y lo privado asumen, como ya señalara a principios de esta década el profesor Cabrero (1991) en el cumplimiento de aquellas.

La dinámica de cambio social ha ido modificando y difuminando las fronteras entre lo que se denomina sector público y privado. Las continuas interconexiones parecen obligar a abrir un debate de reflexión sobre aquello que define uno y otro sector y la naturaleza de las relaciones que se van introduciendo.

Por otra parte, así como hace unos años el peso de este proceso de reflexión y aprendizaje se situaba en la necesaria democratización de las estructuras políticas representativas, y en el refuerzo del tejido asociativo, hoy, después de una cierta consolidación democrática, el acento empieza a ponerse en la capacidad de gestión de instituciones y asociaciones. Mejorar la gestión puede significar mejorar la calidad de las prestaciones y profesionalizar definitivamente el sector de servicios sociales que ha ido creándose y extendiéndose. Este debate quedó solapado durante años por la necesaria consolidación del Sistema Público de Servicios Sociales. Todos estábamos de acuerdo en que era preciso que las instituciones públicas tomaran consciencia de que era urgente el desarrollo de políticas de servicios sociales que abandonaran actitudes asistencialistas, para, en un segundo orden de prioridad establecer mecanismos conducentes a la entrada de las entidades privadas, del tipo que fuera, en el Sistema.

Pero, al mismo tiempo, hemos de ser conscientes de que durante los últimos años tanto el sector público como el sector privado han experimentado importantes transformaciones: algunas de ellas derivadas de los mismos procesos que se han producido en un marco más 
amplio que el Estado y, por tanto, comunes a lo que está pasando en otros países, y ha ocurrido en otras áreas institucionales, y todo ello, debido, entre otros argumentos, a:

- El fuerte crecimiento de los servicios personales.

- Estas transformaciones se han producido en el proceso de adaptación del país al modelo del Estado del Bienestar Social.

- Por un lado, el sector privado ha visto cómo se estructuraba, juntamente a otras realidades ya existentes, el hecho asociativo.

- Además, con el gran incremento de la gestión indirecta de los Servicios Personales se han comenzado nuevas dinámicas que obligan a los diferentes agentes a resituar sus espacios y dibujar un nuevo sistema de relaciones y de poderes que más adelante analizaremos.

Utilizando unos parámetros de finalidad y entorno, podríamos, de acuerdo con las propuestas de Intress (1991), definir diversas situaciones entre público y privado.

Desde el punto de vista de la finalidad, podemos identificar:

- El mundo de lo privado con lucro, con una finalidad definida de obtener beneficios como resultado de la gestión y con la posibilidad de excluir clientes.

- El mundo de lo privado no lucrativo, donde el beneficio es una condición de supervivencia pero no una finalidad. Sus criterios de gestión son más amplios que en lo privado lucrativo e incluyen finalidades de bien social, pero mantiene la posibilidad de excluir clientes.

- El mundo de lo público, con unos criterios de gestión que persiguen el interés común y sin la posibilidad de excluir clientes a voluntad, matizando este elemento en la definición de prioridades políticas.

Desde la perspectiva del entorno tenemos:

- Un entorno de mercado, definido por la posibilidad de escoger por parte de los clientes y por la competencia entre los productores, y

- un entorno de no mercado, donde no existe la competencia ni la posibilidad de escoger el producto por parte del cliente.

\subsection{El mercado en la provisión de servicios sociales}

A lo largo de la década de los 80 se ha alcanzado en Europa un amplio consenso acerca de la idoneidad y la necesidad de combinar adecuadamente Estado y mercado en la provisión de un número creciente de bienes y servicios públicos, y, muy especialmente, en aquellos más representativos del Estado del Bienestar: los servicios personales (sanidad, servicios sociales, educación). 
Desde el recurso directo al mercado (contratación externa) a la creación de un contexto que estimule la competencia entre las organizaciones públicas (y privadas) responsables de la prestación de servicios públicos; la incorporación del mercado responde siempre a una voluntad política de introducir en la actuación de las Administraciones públicas una mayor preocupación por la eficiencia en la utilización de los recursos y por el control del gasto público. En ocasiones, también se persigue una mayor eficacia en la satisfacción de las necesidades de los ciudadanos, considerados ahora como clientes de la Administración.

Como consecuencia, se sitúan en un primer plano valores y comportamientos que tradicionalmente habían tenido una importancia secundaria en la actuación de las Administraciones públicas, mucho más preocupadas por los aspectos de legalidad, regularidad procedimental, equidad e igualdad de oportunidades.

Teniendo como referente las diferentes experiencias de modernización emprendidas en Europa, en la actualidad, el debate teórico y práctico se plantea en términos de cuál debe ser la proporción entre Estado y mercado en la provisión de servicios públicos y de cómo articular la relación entre los sectores público y privado en dicha actividad (Mendoza, 1991).

\section{III. ¿UNA NUEVA IMAGEN DE LOS SERVICIOS PÚBLICOS EN EUROPA?}

Tanto los que defienden como los que abominan la ideología del servicio público, creen que se está produciendo al final del milenio un cambio radical. Este es casi el único pensamiento en común entre quienes creen que el servicio público ha muerto y los que piensan que nada hay en el horizonte que permita sostener semejante diagnóstico. Pero el servicio público es el corazón del Estado, de modo que una variación de sus reglas toca el centro de la organización de la convivencia. Se justifica, por ello, la alarma, cada vez que se mueve la tierra debajo de la clave de bóveda de los modernos sistemas políticos europeos (Mescheriakoff, 1991).

Lo cierto es que hay un fuerte movimiento que preconiza aires de cambio. Las causas del cambio son muchas. Las más generales, explicadas en el ámbito económico, se relacionan con los fenómenos de la globalización o la mundialización de la economía, que exige que las empresas se preparen en un nuevo ambiente de competitividad. La apelación a la iniciativa privada, que los desarrollos indicados hacen inevitable, ha requerido la fijación de un marco regulador distinto, 
que pivota sobre tres ideas fundamentales: primera, la privatización de sectores económicos que estaban integrados en el sector público o controlados y gestionados por administraciones y establecimientos públicos; segunda, la liberalización, que opera complementariamente, aunque con independencia de las medidas de privatización, y procura una reducción de las intervenciones públicas en los sectores económicos fundamentales para el desarrollo de la competitividad y el empleo; y tercera, la aplicación a las relaciones entre empresas del principio de igualdad y de las reglas del mercado, entre las cuales son fundamentales los principios de libre competencia, que tanto la Comisión Europea como las autoridades nacionales se ocupan de salvaguardar (Muñoz, 1998).

Como reconoce el documento de trabajo del Parlamento Europeo sobre empresas públicas y servicios públicos económicos en la Unión Europea (Entreprises publiques et services publics économiques dans l'Union Européenne, 1996), el lugar de las empresas públicas y su papel de servicio público fueron puestos en cuestión en los años ochenta. Existía al principio un movimiento de hostilidad hacia las empresas públicas en tanto que tales, procedente de la voluntad de reducir el papel de los poderes públicos en la economía y también en virtud de un principio liberal que postulaba la disminución general de dichas posiciones en nombre de la eficacia económica.

Los ideólogos del nuevo Estado mínimo imaginan una retirada progresiva de la acción del Estado sobre la sociedad, que empieza por una significativa transferencia hacia la empresa privada de la iniciativa y el control de los sectores económicos fundamentales, para continuar con la reducción drástica de los servicios de carácter social (Muñoz, 1998). La competencia y el mercado serían el lugar donde la sociedad autoabastecería sus necesidades de cualquier orden. En el contexto de una economía globalizada, el mundo entero quedaría convertido en un enorme mercado, en el que tendría difícil cabida cualquiera de los servicios públicos tradicionales, organizados, además, en ámbitos territoriales ridículamente pequeños, comparados con las magnitudes universales de los flujos económicos. A la postre, el adelgazamiento radical del Estado es una alternativa de organización de las sociedades que tiende a liquidar, incluso, alguno de los elementos básicos sobre los que el Estado se fundó.

Pero, suponiendo que la liberalización y la privatización alcancen los extremos máximos que los ideólogos del Estado mínimo pretenden, sería injustificada la conclusión de que la reforma incluye como precio la muerte de los servicios públicos. Esta valoración sobre la posición de los servicios públicos en el futuro está apoyada en un análisis erróneo de los cambios que se están produciendo, y en una des- 
mesurada exageración que Muñoz (1998), apoyado en su dilata experiencia como analista de servicios públicos, disecciona con precisión de cirujano, acotándolo en dos razonamientos.

En primer lugar, porque los únicos servicios públicos atacados por las reglas del mercado son los de carácter económico. No los servicios que requieren el empleo de autoridad, y remarca con énfasis: tampoco los servicios de carácter social. En segundo lugar, y sobre todo, porque quienes auguran la destrucción del servicio público no suelen preocuparse de establecer a qué servicio público se refieren. Es sabido que esta noción es de las más lábiles y cambiantes del Derecho público moderno. Existen servicios públicos monopolizados y otros que no lo están, servicios públicos atribuidos a la titularidad de la Administración y otros calificados como tales y gestionados directamente por privados. Los servicios públicos funcionan conforme a un régimen de Derecho público o de Derecho privado, según los casos.

La cuestión a resolver, por consiguiente, es si los procesos de privatización y liberalización que están afectando tan fuertemente a las economías europeas al final del milenio exigen un cambio radical de óptica para que sean las empresas privadas las que cumplan las misiones de servicio público que requiere el interés general y son imprescindibles para la convivencia. $\mathrm{O}$, por el contrario, si, pese a todos estos cambios, la tradición europea del servicio público como obligación del Estado, como actividad tutelada y dirigida por el Estado, se mantiene (Muñoz, 1998).

Abundan cada vez más en los últimos años las reivindicaciones de la idea europea de servicio público, formuladas algunas de ellas con la misma exageración con la que se pronostica su muerte.

Francia ha construido como ningún otro Estado europeo la ideología y la técnica del servicio público. La idea de servicio público que el ordenamiento comunitario pone en crisis se suele identificar como la «concepción francesa del servicio público». Y la calificación está hecha con toda justicia. Pero se comprende que sea también en Francia donde se están produciendo las defensas más ardorosas de la noción tradicional. Una resolución de la Asamblea Nacional, presentada por la delegación francesa en la Unión Europea, afirma de manera rotunda que "los principios del servicio público tocan a la organización misma de la sociedad francesa y no son negociables, en particular con las instancias comunitarias". Y añade que "sólo el pueblo francés está legítimamente habilitado para definir estos principios y sacar las consecuencias en términos de organización" (Kovar, 1996, pág. 205).

Kovar (1996) ha hecho un detenido análisis de la defensa francesa del servicio público tradicional. La justifica "en la importancia otorgada por el Derecho administrativo a la institución del servicio públi- 
co, pero igualmente a una tradición de intervencionismo estatal más afirmada que en la mayor parte de los demás Estados de la Unión Europea" (Kovar, 1996, pág. 215).

La verdad es que la Comunidad se ha rendido inmediatamente en este enfrentamiento. Su desconsideración inicial por el servicio público, cuando empezó a exigir la aplicación estricta de las reglas de competencia contenidas en los artículos 85 y siguientes del Tratado CEE, ha cedido ante algunas evidencias que se han acumulado ante los ojos de los responsables de los organismos comunitarios que, en opinión de Muñoz (1998) y a la vista de los nuevos documentos sobre Política de la Competencia en la Comunidad, se pueden concretar en tres aspectos:

El primero es la fuerza de las convicciones ideológicas de la mayor parte de los Estados miembros de la Comunidad. El Estado prestador de servicios, ocupado también de la solidaridad y el bienestar de los ciudadanos, es un activo cultural al que no se piensa renunciar.

El segundo es que la propia Comunidad ha tenido que llegar inmediatamente a la conclusión de que las regulaciones de los Tratados no son incompatibles con los servicios públicos. Postulan, en la mayor parte de los casos, adecuar a un entorno concurrencial las reglas de organización y funcionamiento de los servicios públicos, pero, en modo alguno, reclaman su desaparición.

Y el tercero, que la presión de los defensores del servicio público no sólo no se ha conformado con el cambio de actitudes de los agentes y autoridades europeos, sino que, además, ha propiciado la elaboración de un proyecto de Carta de los servicios públicos, fechada el 14 de febrero de 1994. Aunque referida principalmente a los servicios de carácter industrial y comercial, se apoya en que la idea de mercado no es indiferente a los objetivos de solidaridad, cohesión o equidad. También en que es necesario corregir el libre funcionamiento del mercado para que sean atendidos algunos intereses generales que resulta imposible satisfacer con el exclusivo juego de las fuerzas del mercado (Europe Concurrence et Service Public, 1995).

"La solidaridad y la igualdad de trato en el contexto de una economía de mercado abierta y dinámica, constituyen objetivos fundamentales de la Comunidad Europea. Los servicios de interés general contribuyen a la consecución de estos objetivos. Los europeos esperan servicios de calidad a precios asequibles. Para muchos de ellos, estos servicios de interés general suponen auténticos derechos sociales y participan en gran medida en la cohesión económica y social. Por ello, los servicios de interés general están en la base del modelo europeo de sociedad ..." (Los servicios de interés general en Europa. D.O.C.E., 26-IX-1996). 
Resulta, por tanto, que Europa no abomina del servicio público, sino que simplemente quiere ajustarlo a un entorno de competencia. Todo ello será un nuevo reto para el servicio público, pero no supondrá su liquidación. Ni siquiera será un reto nuevo.

\subsection{La naturaleza y los principios de lo privado}

Según lo visto hasta ahora, los presupuestos ideológicos de la actuación pública persiguen un fin determinado que consiste básicamente en el logro de la cohesión social. Este fin no se puede predicar del sector privado ya que su naturaleza se basa en el logro del beneficio particular frente a terceros, por mucho que el Estado del Bienestar haya suavizado el descarnamiento del fin de las empresas capitalistas. En definitiva, el sector privado antepone el interés particular, sin ningún tipo de intermediarios, sobre el interés general, aun entendiendo éste de una forma poco altruista, como ya se ha expuesto.

La regla fundamental por la que se rige la actuación privada es el beneficio. Este actúa como fin y como límite, ya que traspasar la línea en la que una actividad no es rentable, lo cual es debido a muchos factores y no todos ellos de carácter económico, puede suponer el cese de la actividad. También es cierto que el beneficio en nuestro Estado tiene una gran carga socializante al entender que la actividad privada transciende su ámbito al implicar derechos individuales y colectivos. En una visión menos teórica: la sociedad asume la expulsión o fracaso en el mercado de las empresas privadas mediante la socialización de pérdidas, bien a través de subvenciones y ayudas, bien mediante el sostenimiento de la mano de obra inactiva, Por ello, la exigencia de la eficiencia en el sector público es también una exigencia del mismo principio en el sector privado.

Siguiendo la línea argumental del apartado anterior, la utilización de los mismos procedimientos de gestión en una actividad determinada en el sector público y en una empresa privada no significa que los fines a conseguir sean los mismos, ya que el beneficio en el ámbito de lo público es un factor más a considerar. En cualquier caso, en el ámbito de los servicios públicos, y más en los sociales, no se puede hablar del principio de beneficio aplicado a los mismos si no se le adjetiva de social. Lo mismo cabe decir de otros conceptos como el de eficacia, eficiencia, productividad o coste-beneficio que veremos más adelante. 


\section{DIÁLOGO PÚBLICO-PRIVADO .}

Siguiendo la brillante contextualización realizada por Serra (1991), en torno a los múltiples escenarios en que podría darse un posible diálogo que no confrontación entre lo público y lo privado, mostramos los escenarios y los correspondientes niveles de diálogo que se pueden producir:

En primer lugar, el escenario ideológico. El que recoge y sintetiza principios y banderas: libertad, justicia, igualdad, progreso... Supuestamente el escenario fundamental y probablemente el escenario más empobrecido en los últimos tiempos como escenario principal del debate.

Un segundo escenario del debate es el escenario político, en el que lo que se discute es, fundamentalmente, el sistema de estructuración y de reparto del poder dentro de la estructura organizacional de la sociedad. Se trata aquí de dirimir qué cuota de poder sobre el conjunto de la sociedad se socializa a través de su cesión al Estado.

Un tercer escenario es el escenario competencial. La discusión se centra en este caso en encontrar la legitimidad que da soporte a la asignación de espacios de competencia. Quién tiene que hacer qué, cuáles son las competencias de cada cual, qué funciones debe cumplir, dónde están los límites de las distintas competencias.

Un cuarto escenario es el escenario productivo. En el que se discute no ya la competencia de cada cual acerca de garantizar una determinada función social, sino la idoneidad para garantizar el proceso de producción del bien o servicio de que se trate.

Un quinto escenario es el escenario gestionario. Cercano al escenario productivo pero distinto. Lo que se discute en él es cómo deben hacerse las cosas sean cuales sean las cosas a hacer. El debate intenta establecer qué reglas del juego garantizan una mayor economía, eficacia y eficiencia. Probablemente, el escenario de debate, diálogo y confrontación más popular, más inmediato, más reactivo y virulento y, en mi opinión, también el más engañoso, ya que parece contener una verdad que aparece como la verdad; a saber, que el sector público no es tan económico ni eficaz ni eficiente como el sector privado y que las cosas alcanzan su optimización, o bien cuando se dejan en manos de estructuras privadas, o bien, peligrosa apreciación, cuando el sector público mimetiza al privado en el ejercicio de sus responsabilidades. Es difícil en este escenario intentar reflexiones racionales, y, en cambio, es, en mi opinión, imprescindible hacerlo para acercarse a soluciones útiles. 


\section{LA EFICACIA EN LA ADMINISTRACIÓN PÚBLICA}

La Constitución Española, en su artículo 103.1, establece que la Administración sirve con objetividad los intereses generales de acuerdo a, entre otros, el principio de eficacia. Este principio, que todavía hasta hace poco era considerado una declaración programática sin expreso valor jurídico, cobra en nuestros días una importancia fundamental, descubriéndose como principio que, en gran medida, va a informar la entera actividad de la Administración Pública.

La importancia y trascendencia de este principio ha sido bien puesta de manifiesto en una obra colectiva que lo analiza y pone en relación con los procesos de privatización. Tal y como Parejo (1989) ha señalado:

«No basta ahora ya al Estado la legitimación que le presta el origen democrático del poder, ni la derivada de la efectividad (en términos tradicionales) de su mando sobre los ciudadanos: le es preciso justificarse permanentemente en la adecuada utilización de los medios puestos a su disposición y la obtención de resultados reales, es decir necesita la legitimación que proviene de la eficacia en la resolución de los problemas sociales». (pág. 162)

En todas las Administraciones se advierte la tendencia y el deseo de evolucionar desde el sistema burocrático al modelo operativo gerencial como camino seguro par mejorar la eficacia en la gestión de las políticas públicas. El principio de eficacia está en la base y origen de todos los procesos de modernización de las estructuras organizativas de las diferentes Administraciones Públicas. Se trata de hacer que la Administración sea menos costosa y más eficiente y que la burocracia abandone su filosofía de complacencia y derechos adquiridos por un enfoque de iniciativa y libertad para actuar. Se pretende rediseñar, reinventar y revitalizar toda la administración. La eficacia trasciende así de su carácter de principio y se convierte en fundamento no ya sólo de la actuación de la Administración, sino de la misma legitimación del ejercicio del gobierno.

La eficacia debe entenderse en relación con otros principios que rigen la actividad de la Administración. El debate sobre la compatibilidad del principio de eficacia con los de legalidad e igualdad viene de muy atrás, si bien forzoso es reconocer que se ha recrudecido tras la constitucionalización del principio. Aunque efectivamente la eficacia es un bien constitucionalmente protegido, este no tiene un carácter absoluto y debe ceder ante otros valores superiores, como, por ejemplo, el principio de igualdad (arts. 14 y 23.2. CE). No puede buscarse en la Administración la eficacia a toda costa si esta supone atentar contra el principio de los ciudadanos ante la ley. 
"Aunque la eficacia de la Administración es un bien constitucional protegido por el artículo 103.1., tal principio es de rango inferior a la igualdad, que es no sólo un derecho individual de los españoles protegible, incluso por vía de amparo (arts. 14 y 53.2. de la CE), sino un principio al que está sometido el legislador (arts. 14 y 9.1. de la $C E$ ), e incluso un valor superior del ordenamiento (art. 1.1 de la CE) ante el cual deben ceder otros de rango inferior, pues es indudable que no puede buscarse la eficacia de la Administración con medidas legislativas que atenten, como ahora ocurre con la enjuiciada, contra la igualdad» (Citado en Etxerraeta, 1995, pág. 48).

Los efectos de todo ello en la gestión de los servicios públicos son importantes ya que, en palabras de Villar (1993), las normas mercantiles no podrán afectar a la igualdad dentro del servicio en sus varias manifestaciones: igualdad en el acceso (universalidad) e igualdad en el funcionamiento (calidad y tarifas). Hablar de eficacia de las Administraciones Públicas implica tomar en consideración los resultados de la acción administrativa, y es bien cierto que el interés por esta cuestión es relativamente nuevo, ya que siempre ha preocupado más la regularidad formal o jurídica del procedimiento que el resultado o producto efectivamente obtenido.

La utilización de un término económico como es el de eficacia como concepto jurídico genera, fruto de la utilización no rigurosa de su contenido estricto, mucha confusión. En la doctrina jurídica, los términos, ambos económicos, de eficacia y eficiencia, son utilizados casi indistintamente, cuando, sin embargo, su contenido es diferente. Se dice incluso en ocasiones que un servicio es eficaz o eficiente porque no es caro y funciona bien ignorando que tal actuación pública puede ser ineficiente en sentido estricto a pesar de su economicidad y buen funcionamiento aparente (Etxerraeta, 1995).

El gestor de un determinado departamento público es eficaz en cuanto, haciendo uso de los medios o recursos que se le señalan, consigue alcanzar los objetivos que también se le especifican en el plan; su gestión será tanto más eficaz cuanto más se aproxime a los objetivos previamente señalados. La eficacia se refiere, pues, al grado de consecución de los objetivos dentro de las restricciones del plan, sin considerar la economía de medios para alcanzarlo. Si, además, y dentro del margen de libertad que le permiten las restricciones del propio plan o programa, consigue alcanzar los objetivos señalados para su área de responsabilidad con un mínimo coste la gestión eficaz sería asimismo eficiente. La eficiencia lleva pues aparejada la consecución de objetivos y la menor utilización de recursos necesario para ello, constituyendo, desde el punto de vista axiológico, un valor jerárquicamente superior al valor de eficacia. 
La eficiencia fue desde el origen el fin más sólido sobre el que los gobiernos conservadores fundaron la ola de privatizaciones. Es pues conveniente que detengamos en él nuestra mirada, siquiera un momento. La medida habitual de la eficiencia es el beneficio antes de impuestos e intereses; este es el beneficio operativo.

El tono de la década en la que nos encontramos viene dado por la cuestión del Estado. ¿Debe éste ampliar su tamaño y ejercer un liderazgo claro, imperioso, en la búsqueda de la prosperidad nacional? $\mathrm{O}$ debe, por el contrario, retirarse a un segundo plano cuidando, entre bambalinas, el establecimiento y cumplimiento de reglas de juego socialmente útiles?

El derrumbe de las economías de dirección central ha debilitado de tal modo los ánimos de quienes propiciaban el protagonismo del Estado en Occidente que se hace difícil no sólo conocer su pensamiento sino identificar a los partidarios claros de su expansión. Pervive, con todo, un puñado de defensores de un gran Estado de Bienestar. El debate más vivo y las polémicas más interesantes se están produciendo, sin embargo, entre los defensores de una vuelta fundamental a la iniciativa privada como hemos comprobado anteriormente. $Y$, en este campo, también el desmoronamiento de las economías planificadas ha tenido una incidencia profunda. ¿Cómo desestatificar con eficacia y mantenerse en los márgenes políticamente manejables? ¿Cuáles son las condiciones necesarias para una privatización sostenida sin traumatismos desestabilizadores? En este campo, las preguntas se enredan como racimos de cerezas.

Los argumentos más escépticos hacia las privatizaciones, fin primordial que persigue la eficiencia, son de distinto tipo. Sostienen unos que la competencia es de la más alta relevancia para que tengan las privatizaciones alguna probabilidad de éxito. Que se mantenga la libertad de entrada en el sector y la rivalidad, al menos potencial, entre los oferentes es crucial para maximizar los beneficios del consumidor, tanto como para garantizar una efectiva limitación del poder de monopolio de los nuevos dueños (Beesley, 1993). Opera, pues, el grado de competencia como indicador del nivel de éxito alcanzado por las privatizaciones. Es la competencia la condición necesaria de reducción de costes en los procesos de privatización. Bien lo habían detectado Millward y Parker (1983) en los comienzos de la década pasada .

Algunos autores han hallado, incluso, episodios y pronosticado privatizaciones en los que las empresas perceptoras de compañías privatizadas, operando en régimen de monopolio, parecen trabajar con menor eficiencia. Pero quien dice privatizaciones dice contratos externos. La contratación externa, aún admitiendo que la propiedad privada genera mayores incentivos para la eficiencia que otros sistemas 
de propiedad, puede suceder que no se disponga de información adecuada para detectar la oferta más barata. Pero existe la posibilidad de oferta temeraria, rebajando los precios a corto en la presentación de la oferta, con el fin de asegurar una posición de monopolio a largo plazo. Veamos algunas consideraciones sobre este fenómeno en los servicios sociales, especialmente en la tan utilizada contratación externa.

El incremento de la contratación externa como forma de gestión indirecta de Servicios Públicos en las áreas de Bienestar Social es un hecho evidente en determinadas áreas de la Administración y que aumenta cada día; pero, a pesar de su desarrollo, nos falta todavía aclarar muchos temas para poder argumentar empíricamente que de esta forma se mejora el servicio que recibe el ciudadano. Tanto las Administraciones como los contratistas han de profundizar en las vertientes jurídico-administrativa y conceptual para poder mejorar la calidad.

Una reflexión metodológica sobre la contratación externa de los servicios personales tendría que poder contestar a las siguientes cuestiones, que, no por clásicas, son menos necesarias de conocer en profundidad: ¿Qué razones llevan a optar por esta forma de gestión? ¿Para qué servicios en concreto, es decir, por qué para unos sí y no para otros? ¿Responder a un criterio de descentralización o de importancia territorial, aún en el mismo municipio, por ejemplo? ¿Quién decide si se realizará en todo el territorio o en una parte? ¿Qué porcentajes de la gestión se aplicará? ¿Se realiza con todo el servicio o solamente una parte? ¿Por qué, y en base a qué criterios? ¿Quién y cómo se definen los criterios temporales, ligados a la evaluación y los criterios ambientales, ligados a las posibilidades del entorno de crear una dinámica de mercado con capacidades de gestión? ¿Qué formas jurídicas se utilizarán y cuál ha de ser el contenido del contrato: qué cláusulas técnicas ha de tener para garantizar la calidad? ¿A quién de las diferentes posibilidades de contratistas, a cuáles se adjudicarán qué servicios? ¿Para quién serán los beneficios de la contrata directos e indirectos? y ¿Quiénes serán los beneficiarios del servicio?.

Como vemos, hay muchas preguntas que forman parte de un proceso metodológico que a veces los intereses políticos y las prisas y apremios administrativos dejan su respuesta en un segundo plano, lo que no quiere decir que se estigmatice la contratación externa, sino que simplemente necesita que deban ser, al menos desde nuestro punto de vista, debidamente contemplados. La contratación externa puede añadir determinados valores al servicio, derivados de la propia forma de gestión, que es importante tener presentes a la hora de optar por ella: determinados contratistas pueden tener un mayor conocimiento del terreno, lo cual puede revertir en un incremento de la eficacia; puede aportar una mayor capacidad de innovación; representa un incremento 
de la participación social, ya que se están implicando agentes diferentes a la Administración en la responsabilidad de su prestación; puede aportar una mayor eficiencia en la gestión del servicio y permite la comparación de la gestión y de los costes entre los diferentes contratistas.

\subsection{Empresa pública versus empresa priva}

Cuando se afirma que la empresa privada es más eficiente al reducir los costes de los servicios por concentrar más la responsabilidad en quien toma las decisiones (arriesga la propia riqueza, se somete a las presiones del mercado y soporta el riesgo de ser expulsado del mercado), lo que se está poniendo de manifiesto no es una ineficiencia natural de la empresa pública por razón de su propiedad, sino la ausencia de unos criterios de responsabilidad en la misma (o en los políticos que la controlan) que den lugar a unos resultados similares a los del mercado privado. La cuestión, por tanto, está más bien en determinar criterios de responsabilidad eficiente en los políticos, de tal forma que estos soporten también los «costes» de su gestión (Cainzos, 1991).

Bajo la oleada de argumentos que suscitaron los procesos privatizadores, se halla la comparación de eficiencias relativas y otros parámetros de empresas públicas y privadas. Un estudio muy conocido, que ha llegado a ser paradígmático de este tipo de equiparaciones, es el de David G. Davies, citado por Steve H. Hanke (1991) sobre los méritos relativos de compañías australianas, unas públicas y otras privada.

Al discutir los méritos relativos de uno y otro esquema institucional de empresa se ha subrayado diversos parámetros en los que la empresa privada ofrece ventaja notoria. El interesante artículo de Hanke hace un recuento de los principales trabajos comparativos de la eficacia relativa de la misma empresa en el sector público y en el privado. Sigámosle.

Refiere en primer lugar el estudio de Robert, W. Poole en el cual se han presentado notables ahorros en diversos servicios como ambulancias, controladores aéreos, protección contra incendios y las prisiones respectivamente gestionadas por el sector público o por manos privadas. Otros autores han hallado costes significativamente menores en empresas eléctricas, guarderías y otras empresas de servicios. Semejante hallazgo fue obtenido, por W. Clarkson y William Rushing, respecto a la superior eficacia de la administración hospilataria en establecimientos sanitarios y públicos. Cita Hanke un interesante estudio de W. Mark Crain y Ashar Zardhooki en el que los costes de una muestra de 24 empresas de aguas privadas y 88 públicas de suministro de aguas 
resultaron significativamente más altos (un 25 por cien más) en éstas últimas. ¿Diagnóstico?, menor productividad del factor trabajo e infrautilización del equipo en las empresas públicas. El propio Hanke halló una práctica de subvención a clientes determinados a cargo de precios más altos cobrados a otros en las públicas. Aunque los estudios citados por Hanke parecen apoyar la mayor eficacia de la empresa pública -eficacia económica, prescindiendo de objetivos sociales, naturalmente- no falta evidencia empírica en sentido contrario.

Los razonamientos relativos a la eficiencia actúan según dos puntos de vista, el de la prestación del bienestar y el del crecimiento. De acuerdo con el primero, se dice que el bienestar alienta el despilfarro tanto de los consumidores como de los productores. Los primeros no están sometidos a la disciplina del pago directo y los segundos no perciben el estímulo de la competencia. Sin embargo, los mercados privados del bienestar pueden adolocer de problemas parecidos. Los consumidores pueden verse sometidos a abusos, dada la importancia de disponer de conocimientos técnicos, problema que es especialmente grave en los campos de la medicina y la enseñanza. Los mercados competitivos pueden desembocar en monopolios. Los servicios públicos pueden ser más eficientes en el cumplimiento de sus objetivos al centrar sus recursos en cubrir necesidades, ya que no dependen de las pautas de los precios, en casos en los que el poder adquisitivo puede no estar distribuido adecuadamente. Por consiguiente, el argumento de la eficiciencia para la privatización supone la existencia de mecanismos para la redistribución de la renta o para garantizar el funcionamiento eficaz y no estigmatizante de un sistema de previsión pública muy selectivo.

Los estudios empíricos tampoco llegan a ninguna conclusión. Se dispone de escasas pruebas sobre la eficiencia en el ámbito del bienestar. Spann, por ejemplo, en un estudio sobre hospitales públicos, voluntarios y lucrativos en los Estados Unidos llega a la conclusión de que, aparentemente, entre los tres tipos hay poca diferencia de calidad. En el estudio de los datos disponibles realizado por Millward (1989), a principios de los ochenta, se llega a conclusiones contradictorias.

\subsection{Eficiencia y competencia.}

Existe una alta evidencia empírica de que la competencia es la forma más eficaz para fomentar la eficiencia productiva (Donahue, 1991). La competencia impulsa a los gestores a acercarse lo máximo a los límites de la producción. Además, les ofrece a los representantes del capital la información relevante que les sirve para controlar mejor sus 
actividades. Todo ello hace que la competencia favorezca asimismo la eficiencia en la asignación (Yarrow, 1989).

Si unos gestores no logran reducir los costes, aumentar la calidad, etc., en definitiva, la eficiencia, en una situación de competencia, la propia supervivencia de la empresa y de sus mismos puestos de trabajo están en peligro. Sin embargo, tampoco en todos los casos se puede defender la máxima de que cuanto más competencia haya, mayor es la eficiencia que se logra. Así, en determinados sectores, por las especiales características de la actividad a realizar, puede no ser la más conveniente la alternativa que ofrezca el máximo de competitividad.

Salvo esos casos particulares se puede sostener como cierto que la mejor forma de que coincidan los beneficios y el interés público es que el bien o servicio privatizado esté en un mercado competitivo. Hace falta la competencia de otras empresas para disciplinar el comportamiento de los gestores. Sin ella, será posiblemente continuamente necesaria la actuación pública (Goodman, 1994).

Ocurre que una organización privada que se mueve en un ámbito monopolístico pierde la tensión organizativa que el mundo competitivo conlleva decreciendo su capacidad innovadora y de búsqueda permanente de la reducción de costes y del aumento de la calidad como razón de supervivencia. Los resultados producidos por los monopolios de propiedad privada distan mucho de ser considerados como de alto rendimiento. Como explica Martín Mateo (1994), si la competencia es escasa, las empresas privadas sometidas a regulación no se comportan mejor que las públicas, quizás peor. En un contexto no competitivo, las privatizaciones probablemente serán netamente perjudiciales.

Pero ¿qué sucede si la empresa privatizable opera en condiciones de monopolio natural? Basta para conseguir evitar ambos daños de un solo golpe con que la subasta se realice sobre la base de los precios a cobrar y del servicio que se vaya a dar por parte del mejor postor. Se trataría, en otras palabras, de subastar el derecho, estipulando nítidamente la relación calidad-precio del output futuro. Esta subasta garantizaría, con toda probabilidad, un volumen de producción y un precio muy próximo, cuando no igual, al de la empresa precio aceptante en el mercado competitivo. Aunque mucho depende, es de reconocer, de la correcta estipulación del precio de venta y calidad exigido al futuro oferente victorioso en la puja. No consiste, pues, la subasta de la concesión en concedérselo al pretendiente que está dispuesto a pagar un precio más alto por la susodicha concesión. 


\section{LA IMPORTACIÓN DE TÉCNICAS DEL SECTOR PRIVADO}

Los dos problemas capitales con los que se encuentran las Administraciones Públicas son, por una parte, el llamado déficit de niveles de eficiencia y, por otra, la siempre difícil adaptación de los procesos de gestión importados de la empresa privada; pero, avanzando más en esta idea, hay que señalar que la importación de técnicas del sector privado al sector público debe contemplar los fines de las Administraciones Públicas y de las organizaciones a ellas vinculadas. La aplicación de una misma técnica de gestión en una empresa pública y en una privada vendrá condicionada por el fin que cada una de ellas tenga asignado. Además de esta limitación, hay que añadir la más transcendente y que se refiere a que la importación de técnicas privadas sólo se puede realizar en la zona operacional, lo cual resulta de gran interés para los servicios sociales. Las dos limitaciones anteriores, añadidas a los principios de la actuación de lo público, marcan los límites de actuación entre lo público y lo privado.

Con frecuencia, se afirma que la Administración pública es ineficiente por sí misma. Esto no es decir cosa alguna si nos estamos refiriendo a la zona decisional, puesto que su actividad no es equiparable a la actividad privada. Por eso, cuando se afirma que la política no utiliza criterios racionales, se está diciendo la verdad porque la lógica política es una lógica compleja en la que se implican a muchos actores de diversa naturaleza, lo que permite que se mantenga en equilibrio el Estado. Es claro que esto no es trasladable al sector privado.

Estas reflexiones hay que completarlas con el hecho de que el sector público realiza sus actividades en régimen monopólico en muchas ocasiones, debido precisamente a la naturaleza ya descrita de la actividad. Por ello, para evaluar los resultados en la prestación de los servicios, lo público frente a lo privado tiene su importancia, pero lo competitivo frente a lo no competitivo resulta habitualmente más importante. Y esto es perfectamente trasladable a las actividades monopólicas u oligopólicas del sector privado.

Otra limitación a la importación de técnicas a la Administración Pública proviene del hecho de que en la empresa privada, cuando se realizan tareas públicas, se traslada el mandato externo de producir bienes y servicios a un mandato interno de generar ingresos y limitar costos. Esto no es posible hacerlo con carácter general en la Administración pública, ya que persigue simultáneamente otros objetivos, por ello el producto social y político de dos organizaciones, una pública y otra privada, realizando las dos una misma actividad, debe ser, en principio, distinto. Si no lo es, especialmente en el caso de los servicios sociales, habrá que pensar que el interés general ha excluido de su 
atención a ciertas capas de la sociedad, precisamente las que no han conseguido que sus intereses se publifiquen y las que tampoco han sido merecedoras de que el Estado sea su valedor.

\section{LOS PROCESOS PRIVATIZADORES}

Un elemento esencial de una política eficaz sobre la competencia $y$, en definitiva, de una privatización en su concepto más estricto, es la regulación (Hemming y Mansoor, 1994), hasta el punto de que es posible afirmar que regulación y privatización van indisolublemente unidas. Debe esto ser asî so pena, en caso contrario, de pérdida de los grandes avances que las sociedades occidentales han logrado, reemplazando el monopolio jerárquico de la Administración pública por la mano invisible del mercado, en la versión más radical de las políticas que defienden el protagonismo del mercado.

Pues bien, no es concebible esa regulación sin la concreción y materialización del interés general en ámbitos concretos y sin la determinación de los derechos de los usuarios.

Esta concreción y materialización es además necesaria para incluso medir y ponderar la decisión de privatización e incluso su valoración una vez desarrollada. En palabras de Paul Starr (1995).

«La privatización tiene sus límites, no siempre da el mejor resultado»

«Mejor no puede significar solamente lo más barato o lo más eficaz, siendo necesario ponderar las cuestiones relacionadas con la justicia, la seguridad y la ciudadanía para una evaluación razonable de las alternativas». (pág. 231)

Así, encontramos que la privatización de los servicios públicos halla otra frontera derivada de la propia delimitación entre la sociedad y el Estado. Efectivamente, para amplias capas de la sociedad española, sólo el Estado, en sus diversos niveles organizativos, representa la garantía de hacer valer sus derechos. Por ello, sería una grave irresponsabilidad el pretender que el mercado regulase dichas capas, puesto que éstas se caracterizan por haber sido excluidas del mismo. Claro es que la privatización ha logrado poner en primer lugar la importancia de la gestión y la ha Ilenado de contenido político. Por ello, en los servicios públicos de la zona operativa es necesario la aplicación de técnicas de gestión que persigan la eficiencia, aunque con las cautelas anteriormente señaladas.

Pero el Estado no se puede desentender, ni siquiera en el caso de que se cumplan los requisitos señalados anteriormente, de una activi- 
dad que ahora pasa al sector privado. Ello es debido a las consecuencias sociales de toda actividad empresarial y, fundamentalmente, a que ahora ese sector privado realiza, en medida variable, funciones públicas. Por ello, no debe ser indiferente a los efectos del Estado que el logro de una mayor eficiencia en la prestación de un servicio privatizado se haga a costa de un significativo descenso del salario o de una reducción en los niveles de prestación. Podemos encontrar ejemplos periódicos en las huelgas de las contratas públicas en sectores como el de limpieza de los hospitales públicos, el de recogida de basuras y limpieza viaria, etc.

Por todo ello, se puede decir que la privatización exige un Estado fuerte. Una privatización extensa sólo podrá producirse si queda asegurado el fin esencial y ello pone el énfasis en el control que debe ejercer la Administración sobre las actividades privatizadas. En conclusión, la justificación de la privatización acaba remitiéndonos al criterio de la eficiencia y, preferiblemente, para aquellas actividades donde sea posible la competencia. Esto significa la transformación de una parte de la actividad estatal, en caso de que se produjera una privatización significativa del aparato administrativo, que pasaría de ser prestadora a garante de los fines políticos de los servicios públicos, gestionados ahora de forma privada.

\section{MODALIDADES DE RELACIÓN PÚBLICO-PRIVADO EN LA PRESTACIÓN DE SERVICIOS PÚBLICOS}

Es importante subrayar que las características definitorias del marco institucional y del tipo de incentivos a establecer variarán sensiblemente en función de: a) la importancia que se quiera atribuir a la gestión directa a cargo de la Administración en la prestación de un determinado servicio público, y b) del tipo de relación Administraciónentidades privadas que se quiera establecer.

De forma esquemática, podemos contemplar, bajo la orientación de Mendoza (1991), dos tipos de relación público-privado cualitativamente diferentes: la mercantil y la de cooperación. La relación mercantil es del tipo cliente-proveedor. El papel asignado a las organizaciones privadas (con ánimo de lucro o sin él) es el de la ejecución de una política cuyos objetivos habrán sido predeterminados por la Administración sin la intervención de dichas organizaciones. Lo único que se contrata a dichas entidades privadas es, pues, su capacidad de prestar un determinado servicio a cambio de una contrapartida económica.

Ante lo anterior es importante señalar dos aspectos. Primero, que la implicación de los agentes privados en la prestación de servicios 
públicos tiene aquí un carácter estrictamente instrumental y bajo una lógica muy próxima al control jerárquico «quien paga, manda»). Segundo, en este tipo de relación el riesgo y la responsabilidad no son asumidos por igual entre el sector público y el privado. Mientras el primero debe responder tanto de la idoneidad del diseño de la política como de su implementación, los agentes privados sólo responderán -lógicamente- de los aspectos materiales relacionados con la prestación de aquella parte del servicio público que les ha sido encomendada/contratada.

Por contra, la relación de cooperación plantea un escenario distinto. Aquí la Administración busca aprovechar los recursos, conocimientos y experiencias ya existentes de las organizaciones privadas a través de proyectos comunes, en donde el sector público y el privado participan en la detección de necesidades y/o en el diseño de los programas de actuación, asumiendo ambos la responsabilidad por los resultados.

La relación de cooperación constituye un mecanismo de participación directa y de implicación de la sociedad civil en la resolución de una serie de problemas sociales que le afectan. Ahora bien, este tipo de relación comporta retos tanto para el sector público como para el privado. Para el sector privado, porque el corolario de la co-responsabilidad es la co-financiación. No puede esperarse, en este contexto, que sea el sector público quien aporte la totalidad de los recursos monetarios necesarios.

Para el sector público, la relación de cooperación también comporta retos (Mendoza, 1991). Primero, porque supone abrir la discusión sobre los objetivos de las políticas y programas de actuación e incorporar en el proceso a estas organizaciones. Segundo, porque ello comporta que el «protagonismo» institucional pierda relieve y lo ganen, en cambio, los objetivos perseguidos. Lo importante ya no es el quién sino el qué se hace, y cuáles son las respuestas que se dan a un determinado problema social. Tercero, en una sociedad democrática y adulta, cooperación y crítica no son excluyentes. No por realizar proyectos conjuntos debe esperarse de las entidades privadas que renuncien a denunciar aquellas situaciones sociales menos gratas y que los poderes públicos y la propia sociedad prefieren ignorar (como el caso de la pobreza en las grandes ciudades españolas).

En resumen, Administración, sociedad civil y mercado son elementos que pueden articularse de diversas maneras en la prestación de servicios públicos. No existe, pues, una única modalidad de contratación externa de los servicios públicos, sino diferentes posibilidades en función del contexto (de concurrencia o no) y del tipo de relación público-privado (mercantil o de cooperación). 
La privatización es un proceso que se va a servir de múltiples técnicas. Existen bastantes guías, y cada una parte de un lugar para llegar a otro de su particular interés, con la consiguiente carga ideológica. Desde nuestra óptica, compartida con Etxezarreta (1995), seguimos las propuestas de Pirie (1990), por su amplitud, que sobrepasa con creces el objetivo de este artículo, pero únicamente señalamos aquellas técnicas más conocidas y de aplicación más efectiva en el ámbito de los servicios sociales.

1. Técnicas dirigidas a la privatización de la producción.

La Administración mediante la utilización de estas técnicas va a permanecer en la responsabilidad de la determinación de la prestación entregando a la iniciativa privada la elaboración de la misma.

a) Contratación del servicio a una empresa privada.

Se trata de la asignación de la producción del servicio a una empresa privada a la que se paga con recursos públicos. La Administración no elabora pero sí garantiza la oferta.

Con la producción a cargo del sector privado se reintroducen las leyes del mercado desapareciendo todas las prácticas restrictivas y de servicios controlados por los trabajadores y apareciendo un clima de competitividad. Las empresas se mantienen competitivas en precios y calidad mientras tratan de conseguir el contrato y mantenerlo. Los costes descienden porque recursos humanos y materiales son utilizados eficientemente.

Se debe asegurar un tratamiento preferente a los trabajadores existentes de forma previa a la aparición del gestor privado y que sobre éste no exista ninguna duda acerca de su capacidad para gestionar la producción correcta del servicio.

Los resultados que esta técnica viene continuamente ofreciendo son muy importantes.

b) Promoción de instituciones alternativas.

En un campo en el que, o no hay de por sí oferta privada o siempre ha dominado la pública, la opinión pública no ve la posibilidad de que exista una oferta privada válida. Encuentra difícil la concepción de alternativas.

La constitución de instituciones alternativas es capital por su carácter ejemplificador, debiendo la Administración limitarse a la promoción de estas instituciones al deber ser éstas de carácter privado.

El crecimiento de instituciones que representen una alternativa de oferta privada no sólo da capacidad de elección a los consumidores sino que también elimina el papel de la Administración como único empleador en ese campo. 
El éxito de instituciones de esta naturaleza proporciona poderosos apoyos a posteriores tendencias hacia la privatización.

2. Técnicas dirigidas a la privatización de la financiación.

Así como la producción de bienes y servicios puede estar en manos del sector público o del sector privado, así también la financiación de la producción puede estar en cualquiera de los dos sectores.

a) Cobro de los servicios.

El cobro de un precio por un servicio que anteriormente era gratuito es un ejemplo de traslación de la financiación al sector privado mientras continúa en el sector público la producción. El sistema de precios directos evita un exceso de demanda derivado de su carácter de libre, demanda que puede llegar a ser irracionalmente alta. La resistencia social y política a la introducción de precios allí donde no los había o incluso a su incremento introduce una dificultad operativa a esta técnica. Ejemplos los tenemos en el servicio de ayuda a domicilio o teleasistencia.

b) Fomento del abandono de la provisión pública.

La financiación pública hace que ciertos servicios permanezcan cerrados a la iniciativa privada como si de mercados monopolísticos se tratara. En ciertos de estos casos existen proyectos alternativos de carácter privado que son sólo alternativas para los que tienen un nivel de renta suficiente para pagar por esos servicios privados en campos en los que existe una provisión pública. La extensión de los servicios prestados por la oferta privada, con precios cada vez más atractivos para los potenciales clientes hará que paulatinamente la Administración pueda tomar medidas positivas para fomentar el abandono de la provisión pública.

3. Técnicas de privatización por la demanda

Consiste genéricamente en trasladar al usuario el poder de decisión de la elección.

a) Utilización de cheques y/o bonos.

En lugar de ofrecer al público servicios gratuitos que han sido financiados con ingresos impositivos, se trata de ofrecerles cheques, «Vouchers», con que pagar el servicio. La utilización de cheques en lugar de dinero está pensada para asegurar que los recursos se gastarán en el servicio y no se emplearán en otra cosa al arbitrio de sus beneficiarios.

La idea que late tras esta técnica es la de la capacidad de elección del consumidor. Las instituciones públicas que compitan en el mercado tendrían que orientarse hacia los consumidores si desean obtener suficientes cheques para su financiación, viéndose en definitiva envueltas en la dinámica del mercado. Los cheques sirven 
también como una forma de dirigir las subvenciones a los propios necesitados en lugar de hacia los productores del servicio mismo. Están así destinados a la demanda y no a la oferta. Así, la Administración puede además garantizar el poder de compra de personas que necesitan ayuda, pudiendo la oferta de servicios permanecer en manos privadas. Son ejemplos prácticos el bonotaxi para discapacitados con graves problemas de movilidad, cheques para residencias de tercera edad, tratamientos rehabilitadores o terapéuticos, prestaciones asistenciales en el hogar en el que asistan enfermos de Alzheimer u otro tipo de demencias. El 27 de noviembre ha tenido lugar en el IMSERSO una Jornadas relativa al estudio y análisis de los sistemas de utilización de cheques como pago de servicios, lo que pone de manifiesto el interés de la Administración por esta modalidad de cara al futuro de las relaciones con las empresas y la iniciativa social que presta servicios sociales finalistas.

b) Derecho a la opción privada.

Se trata de conceder al público el derecho a optar por la prestación privada del servicio, permaneciendo el pago del mismo en manos públicas. Ello ofrece un mayor campo de actuación a la competencia. La implementación de un derecho a la opción por una oferta privada es una de las nuevas armas en el arsenal de la privatización. También es una de las más prometedoras en tanto incrementa la capacidad de elección disponible para el público en general. La oposición a este procedimiento ha de basarse en el supuesto de que tal oportunidad de elección no ha de permitirse y que, por tanto, el público tiene que estar obligado a depender únicamente del sector público, a la calidad y velocidad que él impone. Políticamente esta es una posición débil, con la mayoría de los grupos de interés alineados por el lado de la extensión de la capacidad de elección.

Corrigiendo el borrador de este artículo se ha producido en nuestro país un importante debate en torno a una nueva modalidad de privatización, que no por conocida era menos esperada, nos referimos a la instauración de las fundaciones para gestionar los hospitales públicos. Y que, como cabría esperar, ha provocado una importante discusión sobre su implantación entre los que defienden que se trata de un mecanismo para favorecer la gestión y, por tanto, aumentar los niveles de eficacia y eficiencia de los hospitales y aquellos que denuncian esta operación como una privatización encubierta, señalando además que se ha producido sin debate público, quedando reflejada su implantación en la Ley de acompañamiento de los presupuestos para 1999, por la puerta falsa, dirían algunos otros. 
Para abordar adecuadamente el espinoso argumento de lo público y lo privado, y tras haber expuesto algunas consideraciones sobre una de las cuestiones en las que se deposita el debate: la eficiencia. Nos queda abordar dos aspectos tan significativos como éste: la modernización de la Administración y de todos sus procesos administrativos y de recursos humanos y el desarrollo de la cultura de la calidad en el contexto de la Administración Pública y, de una manera muy especial, en servicios sociales.

\section{LA MODERNIZACIÓN DE LA ADMINISTRACIÓN}

Las distintas Administraciones públicas de los países desarrollados están implicadas en una serie de profundos cambios y transformaciones con los que, en principio, tratan de mejorar la prestación de servicios públicos, así como adaptarse a los cambios de entorno existentes en las sociedades contemporáneas. El término modernización se utiliza en España y en algún otro país como paraguas conceptualizador bajo el que se acogen todo este conjunto de fenómenos de adaptación. Fenómenos que parecen intentar alumbrar un nuevo paradigma de gestión pública, una nueva forma de pensar sobre la acción de gobernar y sobre cómo ha de materializarse ésta.

Aquí defendemos que la modernización sólo se puede comprender en el marco de los grandes cambios políticos y sociales que nuestras sociedades están viviendo, pero, sin obviar, en el análisis, las peculiaridades de cada Estado implicado. Ello implica la aceptación de tres principios, utilizando las consideraciones de Alvarado (1998). Prime$r o$, que las variables que operan en el proceso de cambio no son sólo económicas; hay variables económicas y sociales en el entorno externo y, sin lugar a dudas, factores internos idiosincráticos, como la cultura política y cívica, el liderazgo o la estructura del sistema político (Huntington, 1971), que matizan o adaptan las influencias extemas al país y a cada circunstancia específica. Segundo, que la fuente principal de cambio son los cambios sociales y económicos que se producen fuera del sistema político. Dichos cambios impactan en la estabilidad del sistema y la consecución de un relativo equilibrio se produce en función de la participación social en la respuesta. Si dicha participación se logra institucionalizar, es decir, si el sistema consigue procesar de forma coherente la nueva estructura de demandas, se logrará la nueva y frágil estabilidad (Huntington, 1971). Tercero, que dado que las variables que actúan en el proceso son numerosas, cualquier reduccionismo es altamente peligroso para la adecuada respuesta final; de ahí que, desde una perspectiva científica, se tenga que intentar denun- 
ciar los reduccionismos ideológicos en la selección de las causas. Las causas que se estiman como influyentes e incluso determinantes del cambio son:

1. La radicalización de los rasgos de la modernidad, con la consiguiente fragilidad de las relaciones causa-efecto en un mundo cada vez más complejo e interdependiente y la dificultad para los gobiernos de controlar esta maquinaria tecnológica y sus efectos no deseados (Giddens, 1994).

2. Los procesos sociales y económicos como la globalización de los problemas y soluciones, el creciente peso de la opinión pública en el marco de la sociedad mediática y el imparable desarrollo de la sociedad del conocimiento, de la investigación y de la tecnología, con sus tremendas implicaciones sobre las organizaciones y sus empleados.

3. El desarrollo de las expectativas sociales frente a lo público, sobre todo en los países desarrollados, fenómeno que, unido a los procesos de elección democráticos y a su incapacidad para rechazar demandas, provoca un exceso de inputs sobre las maquinarias administrativas, las cuales se muestran incapaces de procesarlos en un entorno de conciencia de la escasez de recursos.

4. El cambio en el entorno económico, con unos mercados financieros internacionales con capacidad para condicionar las políticas económicas, provocando la pérdida de autonomía de las autoridades nacionales en la definición de las citadas políticas. Y un cambio en el pensamiento económico, con la progresiva retirada del cheque en blanco keynesiano a los gobiernos, los cuales tienen que, cada vez con mayor rigor, explicar en términos de eficacia sus actuaciones.

Como consecuencia de las causas a que antes hemos hecho referencia, se reflejan unos efectos que acertadamente nos señala Alvarado (1998): la Administración está, en primer lugar, fuertemente cuestionada como centro de definición del interés general de la sociedad. También está cuestionada como organización eficiente y como organización eficaz en la prestación de servicios de calidad a sus clientes. En segundo lugar, ha perdido sus límites tradicionales, siendo una organización difusa; así, se han desarrollado enormemente sus líneas de colaboración con las empresas privadas y las organizaciones no gubernamentales -privatizaciones, contracting out, desregulaciones, etc.-, lo cual hace difícil saber dónde empieza o acaba la Administración; al tiempo, continúa generando agencias autónomas o semiautónomas para la solución de problemas novedosos pero, también, hace desaparecer entes instrumentales propios de la época de apogeo del welfare state, como las empresas públicas; finalmente, se enfrenta a procesos de descentralización territorial e internacionaliza- 
ción, con la consiguiente creación de nuevos gobiernos intermedios hacia dentro, mientras, hacia afuera, pierde capacidad de toma de decisiones autónomas con el desarrollo de diferentes órganos internacionales o la revitalización de los anteriormente existentes. Tercero, se encuentra sometida a diversos debates sin que sea sencillo hallar soluciones a los mismos; así, no tiene claro si la gestión pública es un proceso técnico o político, si basta con generar respuestas de gestión importadas del sector privado o si es necesario reciclarlas con los valores propios de lo público, si es necesario desarrollar habilidades gerenciales o una mayor sensibilidad ética, si hay que dar empowerment a los empleados públicos o hay que desarrollar políticas neotayloristas centradas en medir rendimientos y en reducir plantillas, o bien, si es imprescindible hacer todo ello a la vez, intentando encontrar en cada caso el equilibrio preciso.

Pero en el fenómeno de la modernización, los empleados públicos tienen, desde nuestro particular e implicado punto de vista, un papel importante que no debemos ni queremos olvidar. Así que deseamos preguntar por el papel que pueden jugar los empleados públicos ante las demandas críticas de falta de eficiencia, eficacia y otras, a veces menos precisas andanadas, que lo único que persiguen es enmascarar el auténtico problema de la Administración que siempre se están poniendo parches y se proponen soluciones y remedios parciales. No se toma y se analiza el problema en su totalidad, abarcando todas las posibles salidas y con la colaboración de los interesados.

Se espera que los empleados públicos sean fieles cumplidores de los mandatos políticos. Su deber es cumplir los propósitos establecidos en los mandatos con la máxima eficacia y eficiencia. Se supone que los empleados públicos son grandes conocedores del campo en el que trabajan, es decir, que dominan los principales programas operativos que se pueden utilizar para conseguir los resultados deseados y que saben cuándo su actuación es de calidad y eficacia. También se espera de ellos que sean administrativamente competentes, que sean capaces de diseñar estructuras organizativas y realizar mejoras para que la organización tenga un rendimiento más eficaz y eficiente, y que administren los recursos financieros y humanos que les han confiado, para demostrar que no ha existido menoscabo, derroche o uso indebido de los recursos públicos.

Esta doctrina, criticada y estudiada con gran acierto por Moore (1998), genera una forma de pensar característica entre los empleados del sector público: la forma de pensar de administradores o burócratas y no de emprendedores, líderes o directivos. 'Su orientación es descendente, hacia el control fiable de las operaciones organizativas más que hacia afuera, hacia el logro de resultados; o ascendente, hacia la 
renegociación del mandato político. En lugar de contemplar su tarea como la iniciación o el impulso del cambio, la suelen concebir como el mantenimiento de una misión institucionalizada frente a los constantes cambios políticos. Su principal objetivo de gestión es perfeccionar las operaciones de sus organizaciones en su función tradicional, en lugar de innovar para cambiar dicha función o aumentar su valor para el Estado.

Reflejando los vientos de cambio en el pensamiento directivo que ahora invaden tanto el sector público corno el privado, la imaginación de bastantes empleados públicos con cargos directivos (especialmente significativo es este elemento entre los de servicios sociales que han tenido que levantar organizaciones sin ningún tipo de ayuda) va más allá de su mandato tradicional y de su instinto, poniendo de manifiesto un espíritu emprendedor. Abandonan las restricciones convencionales de su trabajo para imaginar qué puede hacer al respecto. En lugar de ver las nuevas demandas sociales como un problema, las consideran como una oportunidad. Tienen la sensación de que pueden crear algún valor para, al menos, algunos de los ciudadanos si se les permite trabajar a otro ritmo, y no necesariamente el que marcan las empresas privadas.

En este sentido, el empleado público, desde nuestra perspectiva, debe empezar a pensar tal y como la sociedad espera que piense un ejecutivo del sector privado, o sea, centrándose en la cuestión de si el conjunto de activos y capacidades de su institución se puede utilizar para crear un valor añadido para el contexto interventivo en que trabaja. No da por supuesto que sus recursos sean fijos, o que su misión esté restringida y sea inmutable, o que su organización sólo sea capaz de producir lo que está produciendo actualmente, sino que utiliza su imaginación para pensar cómo podría reposicionar y adaptar su organización para satisfacer las nuevas necesidades de los ciudadanos elegidos como población objetivo. En resumen, debe pensar como un líder emprendedor.

Reconciliar el deseo de que el proceso político determine lo que es valioso que el sector público produzca, reconociendo que el juego democrático es vulnerable a diferentes tipos de corrupción, ha constituido el reto persistente de quienes han querido ofrecer una teoría de la gestión pública en democracia. Con el tiempo, hemos confiado en diferentes conceptos como estándares para definir los propósitos directivos. De aquí, que sea de enorme interés conseguir objetivos de manera eficiente y eficaz. Durante la mayor parte de nuestra historia reciente, la concepción predominante ha consistido en que los empleados públicos deben trabajar para conseguir los objetivos marcados por los mandatos legislativos de la manera más eficaz y eficiente posible. 
Para aquellos que consideran que la política es una vía para crear la voluntad colectiva, y que ven en el sistema democrático la mejor respuesta al problema de reconciliar los intereses individuales y colectivos, no es sorprendente que dejen decidir al proceso político lo que es o no valioso producir con recursos públicos. Ningún otro procedimiento es coherente con los principios de la democracia.

Pero, para aquellos que desconfían de la integridad o utilidad de los procesos políticos, la idea de que el valor público se debe definir políticamente es difícil de aceptar. Han visto demasiada corrupción para confiar la determinación del valor público al proceso político. Como mínimo, dichos críticos quieren garantías de que el proceso político acepta los límites de la acción pública o cumple unos mínimos estándares de justicia y competencia en las deliberaciones que producen los mandatos. Alternativamente, preferirán procesos más objetivos para determinar el valor de la actividad pública y alguna plataforma para confrontar los procesos políticos con dicha información objetiva. (Moore, 1998)

Sin embargo, la política también genera desconfianza en nuestra cultura, y así han emergido plataformas para disciplinar y racionalizar el proceso democrático. Dicha plataforma fue establecida según un nuevo tipo de conocimiento. Mientras que la teoría tradicional de la administración pública reconoció el conocimiento sustantivo y administrativo de los profesionales (desarrollado a través de la experiencia profesional y la educación), la nueva formulación arguye que las técnicas analíticas procedentes de la economía, la estadística y la investigación operativa se pueden usar objetivamente para averiguar ex ante $\mathrm{o}$ aprender ex post si las actividades públicas son valiosas o no. Las nuevas técnicas incluyen el análisis de políticas, Ja evaluación de programas, el análisis coste-efectividad y el análisis coste-beneficio. Los reformadores confiaron en que el uso de dichas técnicas podía insuflar hechos objetivos en las deliberaciones políticas sobre el grado en que las iniciativas propuestas eran viables y el grado en que los costes del esfuerzo gubernamental podían ser justificados por los beneficios sociales.

Se puede discutir ampliamente sobre el grado en que dichas técnicas han cumplido sus promesas, lo cual es mucho más de lo que podemos decir aquí. Desde la perspectiva de alguien que analiza el impacto global en el proceso de elaboración de las políticas, se puede afirmar que las técnicas no se utilizan de manera rutinaria ni son invariablemente útiles cuando se emplean. 'A pesar de ello, han conseguido cambiar el discurso político sobre programas públicos. Han incrementado el apetito del proceso político por argumentos basados en datos sobre el grado en que los programas consiguen los objetivos explicitados o sirven al interés general. 
Puede ser también importante que, como se ha mencionado anteriormente, las organizaciones públicas tengan una especie de capital basado en las habilidades para adaptarse y definir nuevos retos. En la medida en que dicho capital existe, la evaluación de sus resultados en tareas presentes no capturará el beneficio global para la sociedad. En cualquier caso, el uso de dichas técnicas ha sido más común para evaluar programas que para analizar el valor producido por organizaciones públicas.

El sector privado parece disfrutar de una medida más fiable del valor de su producción que el sector público. Los ingresos y beneficios de la venta de productos y servicios - es decir, el famoso margenproveen una medida directa del éxito de la empresa privada. Sin embargo, lo interesante de la rentabilidad es que mide lo que pasó en el pasado. Dicha medida se toma muy seriamente en el sector privado, en parte porque se puede utilizar para controlar y estimular a los gestores, pero también porque da a los gestores privados una ventaja para pensar en el futuro. De hecho, se ha recomendado a muchos gestores privados reducir su confianza en la planificación estratégica diseñada para producir predicciones más precisas sobre el futuro y, en su lugar, confiar en su habilidad para reaccionar rápidamente ante las condiciones cambiantes del mercado.

Consiguientemente, la lección del sector privado parece ser que es extremadamente valioso desarrollar información precisa sobre los resultados pasados en lugar de concentrar todos los esfuerzos en adivinar el futuro. En la medida en que esto sea cierto, se deduce que las agencias públicas se deben centrar más en la evaluación de programas que en el análisis de políticas. Mi impresión, sin embargo, es que hacen lo contrario. Esto es desafortunado, porque la atención incoherente dada a la evaluación de programas impide al sector público disponer del tipo de responsabilidad, incentivos y capacidad de reacción rápida de que dispone el sector privado poniendo atención en el margen.

Y, desde otra perspectiva, necesitamos analizar qué tipo de preferencias intentan satisfacer las actividades públicas. A menudo, las técnicas analíticas se presentan como si fueran siempre herramientas útiles para que el gobierno sepa si sus esfuerzos son valiosos o no. Entre ellas, el análisis coste-beneficio se presenta como la técnica superior, la más general y relacionada con el valor. La única razón para no utilizar dicha técnica es que pertenece a las más difíciles de manejar. Consiguientemente, la evaluación de programas y el análisis costeefectividad se presentan como subóptimos respecto al análisis costebeneficio. 
En resumen, tanto la evaluación de programas como el análisis costeefectividad define el valor público en relación con los objetivos definidos colectivamente que emergen del proceso de decisión colectiva, mientras que el análisis coste-beneficio define el valor a partir de las preferencias de los individuos sin referencia al proceso de decisión colectiva. La confianza del análisis coste-beneficio en las preferencias puramente individuales es, sin lugar a dudas, lo que lo hace conceptualmente superior a los ojos de los economistas del bienestar Pero, para aquellos que creen en la capacidad del proceso político respecto a establecer una aspiración colectivamente articulada, y que creen que ésta es la mejor guía para la acción pública, la evaluación de programas y el análisis coste-efectividad parecen ser mejores técnicas precisamente porque van más allá de las preferencias individuales, hacia los propósitos establecidos colectivamente.

Recientemente, los gestores públicos han elaborado una nueva teoría para aumentar el valor de sus actividades. Basándose en el sector privado, ponen el acento en el servicio al cliente y se comprometen a valorar sus esfuerzos en la satisfacción de los usuarios y en la instauración de procesos de calidad. Habiendo convertido a la calidad en una especie de panacea que viene a solucionar todos los problemas que aquejan a la Administración Pública. Nada más lejos de la realidad, y quien esto afirma tiene la suficiente experiencia para atestiguarlo. La calidad no soluciona nada, únicamente refuerza y proporciona coherencia a los procesos que previamente estén establecidos. La calidad, sin embargo, sí que evidencia las malas políticas de gestión utilizadas en las Administraciones Públicas, por lo que resulta paradójico que la utilicemos como argumento favorecedor de las políticas privatizadoras. Se exige calidad en los contratos, a la empresa contratante, de aquellas prácticas en las que a la Administración le ha sido imposible efectuar ningún tipo de parametrización. Es, cuanto menos, una de las tantas paradojas de las que pervive la Administración Pública. No obstante, deseamos brindar unas cuantas reflexiones en torno a las grandes posibilidades que la calidad ofrece, tanto a la Administración Pública como a las empresas privadas o de iniciativa social que presten servicios sociales para la Administración Pública.

\section{$X$. LA CALIDAD DE LOS SERVICIOS SOCIALES ENTRE LO PÚBLICO Y LO PRIVADO.}

La preocupación por la calidad de los servicios sociales no es, obviamente, nada nuevo, aunque sí es escasa la bibliografía en la que apoyarnos (Medina, 1996;1997). Pese a ello, actualmente, parece existir 
un repentino y gran interés explícito por la cuestión de la calidad, lo que nos lleva a plantearnos algunas cuestiones: ¿por qué se ha intensificado este énfasis sobre la calidad?, ¿por una simple moda?, ¿o se trata de una forma más o menos encubierta de justificar las nuevas teorías del sistema de mercado, en la prestación de servicios sociales vinculados a la paulatina desaparición del Estado del Bienestar?. Pensamos, sin embargo, que el verdadero inicio de los estudios de calidad que se ha producido, tanto en otros países de nuestro entorno como en el nuestro, ha estado y está, en gran medida, unido a aspectos económicos, concretamente, a la restricción económica y a la búsqueda de la rentabilidad de los escasos recursos estatales. Pero también existen otras voces que vinculan el auge de la calidad, exclusivamente ligado a la rentabilidad, esté situado el elemento productor en la empresa pública o en la privada.

En este sentido, desde nuestra perspectiva, creemos que hay que tener en cuenta que las prestaciones que se realizan en el marco del Sistema Público de Servicios Sociales se consideran un derecho y deben proporcionarse independientemente de su mayor o menor rentabilidad. Sin que tengamos que abrir aquí un debate sobre lo que vamos a entender por rentabilidad, salvo que pongamos en el fiel de la balanza la rentabilidad de los procesos y la rentabilidad de los servicios que se prestan. Sin embargo, y esto sí es bueno, se debe reflexionar y cuestionar el discurso que sitúa la productividad por delante de otras cuestiones, alejándola de términos como eficacia y eficiencia, reduciendo las prestaciones sociales a meros listados de actividades o a específicas secuencias de datos, haciendo real lo que Kaplan y Merton (1992) denunciaban refiriéndose a las asociaciones, pretendidamente no lucrativas que prestan servicios sociales, señalando que la evaluación de resultados, aquella que demuestra los efectos producidos en los usuarios, es algo más que una memoria con datos y números y deben demostrar cómo la satisfacción del usuario, unida a la mejora de los procesos internos, las actividades de innovación organizativa y el interés por los clientes internos, serán los auténticos responsables de que podamos hablar de calidad que en definitiva debería ser la meta de una organización que se considere con perspectiva de futuro (Medina, 1998).

Es preciso, sin embargo, que seamos conscientes, y creemos que ya ha quedado explicitado la existencia de una fuerte tendencia a la gestión privada como un claro exponente de aumento de la competitividad y esta orientación actual hacia la calidad se ve acelerada, según López (1994), por el marketing; por las empresas que están orientando cada vez más su actividad y su gestión hacia la calidad y por la progresiva apertura de los sistemas sociales y económicos, que conlle- 
va un aumento de la competitividad y hace que se incluyan criterios de eficiencia económica en la realización de cualquier actividad. Para este autor, el sector público es pesado y cerrado. Además, estamos en tiempos de descrédito del Estado como administrador. Todo ello reclama la privatización, más que eso, se trata de implantar en el ámbito de lo público los procedimientos que se han revelado eficientes en la gestión de lo privado (aunque en la práctica no resulta nada fácil).

La calidad apenas forma parte de la cultura organizativa de los servicios sociales en España, considerados tanto, desde su perspectiva de comunitarios como de especializados, y así podemos comprobarlo al manejar la escasa bibliografía existente al respecto.

A modo de ejemplo, señalaremos algunas de las publicaciones que tímidamente van apareciendo y conformando un espacio que deseamos siga creciendo por el bien de los servicios sociales. Desde un posición global, aborda Porcel (1997) el difícil entorno de la calidad total en el trabajo social y su aplicación a diferentes ámbitos; la gestión de calidad en los servicios sociales es objeto de reflexión en Sacanell (1996; 1998) y, de forma práctica, en relación a la aportación de los círculos de calidad, Herrera (1996) presenta una experiencia de implantación en la administración local, en el área de servicios sociales del Ayuntamiento de Jaén.

La calidad asistencial de los servicios sociales, tal y como defendemos en este artículo, apenas tiene reflejo en las publicaciones revisadas (Fernández, Pérez, Medina et al., 1995; Medina, 1998) en el que se analiza la calidad del servicio de ayuda a domicilio; la evaluación de la calidad de los servicios sociales contemplada de forma integral (Medina, 1995); la garantía de calidad en la aplicación práctica de la evaluación de programas (Medina, 1996) o el marco teórico para la evaluación de la calidad asistencial en servicios sociales (Medina, 1996; 1997).

Sin embargo, en donde más se ha desarrollado el interés por la calidad ha sido en los servicios sociales especializados: la atención al cliente y su relación con la calidad del servicio (Elorriaga et al., 1997), la importancia de los recursos humanos y la calidad en las residencias de personas con retraso mental (Forteza, 1996); experiencias de gestión de calidad total (Aguiriano, 1998), la consideración de la calidad organizativa y su importancia en las instituciones para discapacitados psíquicos (Lacasta, 1998); en el amplio campo de las toxicomanías (SEIT, 1993); la evaluación de la calidad del servicio de teleasistencia (Rodríguez, 1996; IMSERSO, 1997); la evaluación de la calidad de Ios servicios del programa de termalismo social (INSERSO, 1992); la evaluación de la calidad en los centros residenciales y de acogida para menores (Fernández del Valle, 1998); la asistencia de la calidad de las 
personas mayores: desde una perspectiva general (Ruipérez, 1988), en las residencias (Suárez, Cifuentes y Merchán, 1992), en la elaboración de protocolos de evaluación (Medina, 1993b); en los centros de integración laboral (Fernández, 1996), la elaboración de estándares de calidad para la integración laboral de personas con discapacidad (MTAS y Fernández, 1997).

Fuera de nuestras fronteras, si bien es verdad que nos llevan algunos años de ventaja en relación a las propuestas metodológicas de evaluación de calidad, cuando se revisa la bibliografía, la distancia ya no es tan larga. Una reciente revisión (Alaszewski y Manyhorpe, 1993), actualizada posteriormente en 1997, señala que el nivel de producción sobre la calidad en el ámbito de los servicios sociales deja mucho que desear por su falta de cientificidad y abuso de metodologías puramente cualitativas. Algunas publicaciones señalan la importancia que para el futuro de los servicios sociales tiene el que se desarrollen evaluaciones de la calidad de las intervenciones (Greenley, Greeberg y Brown, 1997). Aprovechando los planteamientos reformistas que se están imponiendo en Estados Unidos, la calidad ha sido impulsada como requisito de puesta en marcha de programas de actuación y, al respecto, reflexionan (Stoker, Wilson-Gentry, Thomas y Clark, 1997); destacar la importancia de la calidad en gestión de calidad de los recursos humanos para el desarrollo de políticas de bienestar social (Wilding, 1994); las orientaciones respecto a la voz y a la importancia que debe tener el usuario o cliente de los servicios sociales y el papel que debe jugar en el proceso de calidad (Moore y Kelly, 1996); o la importancia de la medida de la satisfacción (Soliman y Poulin, 1997); la utilización de tecnologías o herramientas determinadas del ámbito de la calidad (Auslander, 1996); la calidad total en el campo de los servicios sociales, al menos en el contexto americano, tiene un determinado interés (Martin, 1993; Raynos, Gelsthorpe y Tisi, 1995), unido a la tecnología del TQM (Storr, 1996) y desde una perspectiva más asistencial, en relación al tratamiento de los ancianos y enfermos de larga duración que cada vez se aproximan más al campo de los servicios sociales, alejándose de lo sanitario, encontramos la aportación de Lyosn, La Valle y Grimwood (1995).

Sobre la función calidad, todos somos conscientes que es la traducción operacional, en herramientas y métodos de gestión, de la necesidad que tienen las empresas, para ser competitivas, de ofrecer a sus clientes los productos que satisfagan sus necesidades, cubran sus expectativas y respeten su estructura de preferencias. Sin embargo, siendo esto cierto en el ámbito empresarial, la ausencia de una referencia sistemática a un cuerpo teórico propio ha conducido, en el contexto de los servicios sociales, según nuestra experiencia, a conceptuar la cali- 
dad, desde un perspectiva muy reducida, como el conjunto de técnicas y actividades de carácter operativo destinado a comprobar que el servicio prestado cumple los requisitos relativos a la calidad y a actuar sobre las desviaciones. Esta confusión respecto a la calidad está muy extendida en organizaciones prestadoras de servicios sociales, ya que el fin de la calidad no ha sido comprendido ni aceptado, y únicamente se ha perseguido la certificación, la obtención de un diploma que avale los procesos y procedimientos.

En este artículo nos referimos a los servicios en los que las administraciones públicas adquieren un papel determinante en la decisión de suministrarlos, estableciendo la cobertura y condiciones bajo las cuales se ha de producir la prestación, así como su sistema de financiación: los servicios sociales, y a las prestaciones que desarrollan a través, por ejemplo, de los centros de servicios sociales. Indicando que uno de los problemas y, a su vez, beneficios de los servicios sociales es que se articulan a partir de los ayuntamientos, y esto tiene de positivo la cercanía y la proximidad del ciudadano a la hora del desempeño de las prestaciones, pero el inconveniente es de tipo presupuestario, ya que, en muchas ocasiones, los ayuntamientos realizan las prestaciones mediante convenio con los entes autonómicos que necesitan una formalización económica. También las estructuras municipales, en ocasiones están ancladas, no han desarrollado proyectos de modernización, desoyendo los argumentos que cada vez se van instalando en la Administración Pública española (Ayuntamiento de Murcia, 1993; MAP, 1996; López y Gadea, 1995 y VI Congreso Nacional de la Calidad, 1996). Pero también hemos de reconocer que $a$ lo largo de la última década se ha producido un progresivo cambio en la mentalidad, tanto de los políticos y gestores como de los ciudadanos, con respecto a sus expectativas, frente a los servicios públicos, de forma que, mientras anteriormente apenas existían reivindicaciones acerca del funcionamiento de los servicios colectivos, se ha pasado a una situación en la que cada vez es más patente la exigencia ciudadana de que se gestionen los servicios públicos con criterios de calidad. Por eso, tanto podríamos hablar de calidad de gestión como de gestión de calidad.

\subsection{Gestión de calidad}

Los fundamentos de la calidad son, en definitiva, el conjunto de principios, métodos y estrategias que intentan movilizar a toda la organización con el propósito de obtener la satisfacción del usuario al menor coste posible. La calidad es un sistema de pensamiento donde la excelencia rige las decisiones y actividades de todos y cada uno de 
los integrantes de la organización y en todos los niveles, incluida la Dirección, que debe formular la política de calidad y constituirse en impulsora del cambio y garante del sistema de calidad.

Los fundamentos de la gestión de la calidad, adaptados del mundo empresarial al ámbito de la Administración Pública, podrían resumirse en:

- El objetivo es la rentabilidad y la mejora continua.

- Pretende ayudar a satisfacer las necesidades del usuario.

- Los recursos humanos son su elemento más importante.

- Es preciso el trabajo en equipo para conseguirla.

- La comunicación, la información y la participación a todos los niveles son elementos imprescindibles.

- Se busca la disminución de costes mediante la prevención de las anomalías y fallos.

- Implica fijar objetivos de mejora permanente y la realización de un seguimiento periódico de resultados.

Los servicios sociales -entendidos en un sentido genérico-constituyen un tipo singular de organización que, a la alta especificidad propia del ámbito de la intervención social, suma las señas de identidad características de la función pública; de modo que aplicar a este sector los objetivos antes referidos es considerado, con frecuencia, por sus protagonistas, como inoportuno. Sin embargo, existe en la actualidad sobrada evidencia empírica como para reconocer que el modelo de gestión de los Centros públicos que opera en nuestro país, sean éstos del ámbito que sean, está sumido en una crisis cuya influencia sobre la concepción de gestión de calidad, aunque reclamada y conocida por los expertos su inexistencia, pasa a menudo inadvertida para la sociedad, entre otras razones, por la peculiar naturaleza del servicio que se proporciona -buena parte de cuyos efectos se advierten, principalmente, en el medio y largo plazo-y por la escasa referencia a los resultados - a la medida de la eficiencia- y a la comparación, con fines evaluativos, que dicho sector presenta.

Uno de los elementos definitorios de la eficiencia, junto a la calidad, es la medida de la satisfacción del usuario. Por esa razón, aquí nos queremos detener en este apartado, aunque no con la intensidad que se merece, sí con unas breves pinceladas que perfilen este tema para el futuro empírico tan necesario en los servicios sociales.

\subsection{Satisfacción del usuario}

La satisfacción ciudadana por la calidad de un servicio está relacionada con el conjunto de propiedades que debe tener ese servicio para atender, en primer lugar, las necesidades (explícitas e implícitas) 
de las personas a las cuales va destinado. Pero esto, aunque sea necesario, no es suficiente. Porque la satisfacción va ligada también a la percepción que el ciudadano tiene de cómo se presta el servicio y a la expectativa que tenía respecto al servicio esperado. Aunque, esta situación nos lleva a un lugar conflictivo como es la concepción del ciudadano como cliente de los servicios y esto sí significa un enorme cambio en las bases políticas de las administraciones y especialmente la municipal. Como bien indica García Roca (1992, pág. 31), el estado no se justifica por el respeto a las leyes, la división de poderes y los procedimientos de la toma de decisiones, sino por las prestaciones del estado que exigen los ciudadanos.

Corresponde que nos preguntemos en este momento. ¿Qué significa satisfacción del usuario?. Sobre este criterio se fundamenta gran parte de la filosofía de las organizaciones que tienen o muestran algún interés por la calidad. Es tan importante que se convierte en el núcleo de toda la actividad de la organización. Las instituciones que deciden trabajar con criterios de calidad utilizando alguno de los modelos existentes, planifican, generan procesos, diagnostican, se autoevalúan, toman decisiones, producen servicios, crean estructuras y mecanismos de comunicación para y en función del cliente. Por esta razón, es de gran importancia que podamos definir de forma operativa lo que significa satisfacción del usuario. Siguiendo algunas de las reflexiones de Álvarez (1998), destacamos los dos puntos que tienen gran utilidad para nuestro argumento: a) Identificar los factores críticos de éxito que constituyen el núcleo de las expectativas del usuario. Para ello es fundamental conocer (escuchar) las necesidades y demandas de los usuarios, y solicitar la opinión del usuario sobre la satisfacción del servicio que le estamos ofreciendo o le hemos ofrecido; $y$ b) destacar la importancia del personal de primera línea (trabajador social, psicólogo, educador), que son las personas claves en el proceso interventivo y, de manera especial, cuando surge una situación de conflicto o de insatisfacción con el usuario. Para ello, es necesario conocer el mayor número de aspectos de estos profesionales con el fin de calibrar el papel que auténticamente desempeñan en la prestación de los servicios. Por lo tanto, el objetivo de cualquier estudio que desee determinar la percepción de calidad de los usuarios de un centro de servicios sociales deberá contemplar, además de los ámbitos ya considerados de cultura organizacional y clima, aspectos y variables actitudinales como el nivel de satisfacción laboral, burnout y compromiso organizacional que presentan los profesionales, puesto que son los de mayor contacto con los usuarios y, como consecuencia, responsables de influir sobre la percepción de calidad asistencial que puedan tener los usuarios. 
Los dos grandes ejes de las organizaciones prestadoras de servicios públicos, tanto en el mundo de la empresa privada como en el sector público, son, sin duda, los clientes externos (receptores del servicio), clientes internos y proveedores, los que ejecutan y llevan a cabo el servicio. Sobre el primer eje ya hemos avanzado lo que la calidad asistencial contempla como importante: verificar el nivel de satisfacción; el segundo, consistiría en analizar el amplio espectro de posibilidades que los recursos humanos de las entidades prestadoras de servicios sociales tienen. Pero este es el problema, poco, o muy poco, existe sobre la contextualización profesional de los trabajadores de servicios sociales y, si existe alguna bibliografía (Luque, 1988; Rodríguez, 1996; Peiró y Medina, 1996, Torres Gómez et al., 1996), no está específicamente dirigida a ningún ámbito concreto sino estructurada de forma general. La bibliografía consultada al respecto, aunque relativa a campos próximos, como, por ejemplo, el sanitario, especialmente el de atención primaria, nos han permitido establecer algunas consideraciones sobre las actitudes hacia el trabajo, lo que también es fundamental para comprender en toda su dimensión las posibilidades de los centros de servicios sociales. Así, la satisfacción laboral, entendida como una actitud favorable, tanto hacia el trabajo en general, como hacia aspectos específicos de éste, suele aparecer relacionada de modo positivo con el compromiso organizacional y de modo negativo con el burnout. Y todas estas variables son esenciales para comprender la calidad asistencial.

\subsection{Medida de la satisfacción del usuario en servicios sociales}

La satisfacción de los usuarios con la atención recibida es concebida como una medida de control de calidad (Calero y Calero, 1991) por lo que su estudio y valoración es importante para la gestión y el trabajo de los profesionales de los servicios de salud y de servicios sociales en su conjunto, con la perspectiva de conseguir una mejor adaptación a las necesidades y deseos de los usuarios del sistema.

Autores como Howell (1976), Fleming (1981), Vuori (1982), Suñol (1987), Ware (1988), Medina (1994), Saturno (1997) y otros, además de organizaciones como la OMS y la Unesco, han señalado la importancia y pertinencia de introducir la satisfacción de los usuarios con los servicios como parte y complemento de otras actividades de control de calidad.

Desde nuestra perspectiva, compartida con Ana Delgado (1992), el objetivo principal de conocer la satisfacción de los usuarios es obtener información para llevar a acabo una intervención que permita mejorar las actuaciones profesionales. 
La satisfacción del usuario en relación al resultado de la asistencia, es decir, la opinión del mismo acerca de si el resultado obtenido era el mejor posible, no solía estar incluida en las medidas de satisfacción (Pallarés y García, 1996). En las evaluaciones de calidad asistencial sanitaria, tales juicios los realizan normalmente los profesionales, porque no es probable que los pacientes tengan los conocimientos técnicos que se necesitan para emitir un juicio sobre los máximos beneficios alcanzables por la asistencia sanitaria, esto ha cambiado lo suficiente, incluso con la creación de organizaciones de consumidores que asesoran a los pacientes, y otro tipo de organizaciones de defensa del consumidor, que reclaman la participación del paciente en todo lo que tiene que ver con el proceso asistencial (Martínez del Olmo, 1994; Gómez y Saturno, 1997); sin embargo, los usuarios del sistema de servicios sociales sí tienen criterio en muchas ocasiones, incluso los conocimientos necesarios para mantener una opinión definida (Medina, 1994; 1996a; 1997b).

Dos conceptos esenciales sobre la satisfacción del usuario surgen de la investigación de Ware: Los mecanismos de acceso, que incluyen los esfuerzos para buscar, concertar y recibir asistencia, y la actuación del profesional, que supone emitir juicios de valor sobre la calidad de la interacción con el profesional. Aparentemente, los entrevistados no distinguen entre la competencia técnica de los profesionales y su capacidad de relación interpersonal. Estos dos conceptos principales se corresponden con los conceptos de calidad de la asistencia, de accesibilidad y aceptabilidad. Dentro del concepto acceso, los usuarios diferencian una serie de subconceptos que, tomados de distintas disciplinas y debidamente adaptados, podemos aplicarlos a los servicios sociales, por ejemplo, en relación a los horarios de visita (Escalera et al., 1991) y ubicación de un centro (Mackesy, 1993); tiempo de demora para una citación (Gómez Calcerrada et al., 1996), la cita previa y los problemas de accesibilidad telefónica (Duarte y Godoy, 1997); accesibilidad telefónica (Pascual, et al., 1994), tiempo de espera en la consulta (Villanueva López et al., 1997), horarios y forma de pago; diferencias entre público y privado (Prieto, López y March, 1994), dificultades de la cita previa en general (Alastrué Loscos et al., 1992). También nos podemos encontrar con diversas consideraciones de accesibilidad, una de las más llamativas es la atención en los servicios de urgencias (Percerisa et al., 1997; Allende, Pacheco y Jürschik, 1998) son algunos de los ámbitos, como ejemplos específicos, para el desarrollo de encuestas de satisfacción.

Dentro de la actuación del profesional, los usuarios distinguen subconceptos tales como acogida (Maldonado y March, 1994; Madera et al., 1995), perfección, prudencia, recogida y facilitación de infor- 
mación (Estévez et al., 1995; Sánchez, Saturno et al., 1997; De la Calle Santisuste et al., 1997), atención a la asistencia preventiva (Espinosa et al., 1994), respeto (Gil Cebrián et al., 1993), preocupación (Mira, Valls, Velasco y Serra, 1997), amistad y cortesía (Doyle y Ware, 1977) y en relación con las características del profesional (Delgado et al., 1997).

Uno de los aspectos que cada vez se tiene en cuenta en la accesibilidad es el uso del teléfono que ha sido estudiado tanto desde la perspectiva sanitaria como teléfono de atención al paciente para el aumento de la calidad asistencial (Sánchez, Ortiz y Pineda, 1994), como en la cita previa (Angel y Vázquez, 1994); o en los teléfonos de urgencia (Curieses, Bermejo y Alvarez, 1991) y también con respecto a la cita previa en los servicios sociales (Duarte y Godoy, 1997).

\section{A MODO DE CONCLUSIÓN}

En España la privatización o el debate en torno a lo público-privado adquiere una serie de consecuencias territoriales muchas veces ignoradas. En España no existe el Estado del Bienestar, sino las Comunidades Autónomas del Bienestar y las Corporaciones Locales del Bienestar. Esta afirmación únicamente pretende señalar que el proceso de los servicios sociales está en diferentes manos políticas y administrativas que no siempre coinciden en sus planteamientos ni en sus intereses. Lo que para una Administración puede ser contratación externa, otra puede entenderlo como privatización, o aquella que ponga en marcha un sistema de gestión de calidad la otra puede entenderla como un proceso de control. La ausencia de una auténtico marco integrador de los servicios sociales hará que resulte difícil, aunque no imposible, la articulación de mecanismos más allá del denostado Plan Concertado que, a la postre, no es nada más que un mecanismo administrativo.

Las tendencias modemizadoras en los servicios sociales, y, en general, en los servicios públicos, van a girar, están girando ya, entorno a la privatización, unas veces clara y otras encubierta en modalidades variadas y entendiendo ésta en un sentido amplio, que va desde la importación de técnicas del sector privado hasta la prestación directa de determinados servicios por dicho sector. Ello no quiere decir que la salida a la situación actual sea la privatización, sino que ésta va a ser tomada como referencia, en su sentido positivo o negativo, en la prestación de los servicios sociales. Dicho de otra forma, la eventual incorporación al catálogo de servicios sociales públicos de una nueva prestación exigirá una reflexión sobre quién la va a realizar y cómo. 
De igual modo, la reconsideración del actual catálogo, a la luz de las disponibilidades presupuestarias, exigirá una reflexión análoga.

La cuestión de lo público y lo privado todavía no se ha planteado con el rigor de un debate científico, ni siquiera como debate político, es claro que los fenómenos privatizadores van a ser una constante inmediata en nuestro país, como lo están siendo en el resto de la Unión Europea. Con ello no nos referimos únicamente a los debates electorales que se avecinan, sino a la necesidad de plantear alternativas organizativas al insuficiente nivel de los servicios sociales por parte de los más directamente implicados que, sin duda, serán los empleados públicos.

Los fenómenos privatizadores no pueden olvidar el papel integrador que cumplen las prestaciones sociales. Por ello, se requiere un elaborado diseño de los límites entre lo público y lo privado logrado mediante el máximo consenso político, el estudio caso a caso de cada sector de la actividad susceptible de ser privatizado y la participación activa en el debate de los actores sociales. Una vez realizado el proceso privatizador, debe asegurarse firmemente el cumplimiento de los fines públicos que han sido delegados a una determinada entidad no pública. Esto significa el ejercicio de funciones de control político eficaces, ya que privatización no puede significar renuncia.

Una de las cuestiones de mayor debate ante los sistemas de gestión en la Administración ha sido la creencia de que la gestión indirecta reducía costes. En esta línea, se ha planteado la contratación como una forma sustitutoria de los convenios, donde hay una aportación de dos partes para llevar adelante un programa. La contratación externa no exime a la Administración de ser responsable de sus costes, ni ha de servir para utilizar el voluntariado de las asociaciones para los servicios que han de ser remunerados. Todo lo cual no quiere decir que determinados costes de estructura que se crean en la Administración al iniciar un servicio no sean menores o menos costosos en el seno de las estructuras privadas, pero la determinación de este tema con exactitud todavía está pendiente de estudio.

También debemos tener presente a la hora de enjuiciar los mecanismos privatizadores las dificultades para contratar personal derivadas del congelamiento del crecimiento del Capítulo 1 de los Presupuestos. De esta necesidad se derivaron contratos de prestación de servicios que en realidad fueron contrataciones laborales encubiertas donde al contratista sólo se le asignaba el papel de gestoría administrativa.

Igualmente los problemas de gestión administrativa también han sido la causa de muchos contratos de servicios, o bien por ser la única vía posible para determinados programas en específicos momentos, o 
bien como capitulación frente a las dificultades para realizar una reforma administrativa en profundidad.

La aparición y proliferación de entidades prestadoras de servicios puede provocar, y de hecho ya ocurre en torno a determinadas entidades, la formación de lobbys para defender sus intereses. Esto, que de hecho es una realidad en otros ámbitos, puede tener unas vertientes positivas, en el sentido de ayudar a la consolidación de estos sectores, pero puede provocar también situaciones de presión, más derivadas de los propios intereses de las entidades que de las necesidades sociales a que han de dar respuesta las Administraciones Públicas.

Desde un posicionamiento más positivo, es necesario que la Administración tome conciencia de que, si quiere evitar el permanente acoso crítico a la que le somete la iniciativa privada debido a sus procedimientos, erradique hábitos operativos malos que empañan la actuación administrativa, entre ellos, el vicio reglamentista y funcionarial, lo que algunos autores ya empiezan a denominar papelismo y tramitomanía. Es preciso racionalizar los procesos y simplificar las actuaciones, y esto es más urgente en el ámbito de los servicios sociales si de verdad existe un interés de aproximar las prestaciones sociales a los ciudadanos. El descrédito de la Administración es preciso combatirlo con eficacia. Es necesario fortalecer los mecanismos formativos elaborando buenos diseños que analicen las necesidades y luego dirijan sus intereses a fortalecer los conocimientos y las herramientas de los empleados públicos, tanto para dar coherencia a su trabajo como para hacer frente a las posiciones de análisis y control que los mecanismos de privatización o de contratación externa o de convenios les exige.

La calidad, tanto desde la perspectiva de su evaluación, como desde su implantación como herramienta útil de gestión, debe ser contemplada como inherente a los procesos de trabajo que proporciona rentabilidad, tras apoyarse en un trabajo bien hecho, sin defectos o, al menos, con un mecanismo capaz de detectar los fallos y eliminarlos. La calidad no es patrimonio de la empresa privada que se importa a la empresa pública. La calidad es patrimonio de aquellas organizaciones que quieran trabajar con un nivel de valor añadido que aumente la confianza de los usuarios en el servicio que se presta y de ésto los empleados públicos de servicios sociales entienden bastante más que otros. Y la calidad debe ir unida a una cultura que consiga instalar la satisfacción del usuario como componente imprescindible del sistema, sea la empresa privada o la pública la que efectúe la prestación social comprometida.

Por último, es preciso terminar con una llamada a la creación de un comportamiento del que estamos huérfanos en servicios sociales: la investigación. Tanto el sector público como el sector privado pueden 
ser observados como elementos diferenciados -o sea, como dos compartimentos estancos-, o bien como dos valores extremos de un continuum de categorías con situaciones intermedias; sin embargo, es importante que se pueda determinar cuáles son los ámbitos de gestión que definen lo que es público y lo que es privado: ¿Qué servicios y prestaciones son o tienen que ser exclusivos? ¿Cuáles pueden ser prestados por ambos? ¿Qué funciones son exclusivas de uno o de otro? ¿Qué tipologías y características de público y privado? ¿Qué interrelaciones se dan? Y estas preguntas deben responderse de forma empírica.

\section{BIBLIOGRAFÍA}

AGUIRIANO BEITIA, A. (1997): Experiencia práctica en la gestión para la calidad total. Siglo Cero, 29, 1, 15-22.

ALASTRÚE, J. et al. (1992): Evaluación del programa de cita previa en atención primaria a través de una encuesta de opinión de usuarios. Atención. Primaria, 9, 6, 299- 304.

ALASZEWSKI, A. y MANTHORPE, J. (1993): Quality and the Welfare Services: A literature Review. British Journal Social Work, 23, 653-665.

ALLENDE, P.; PACHECO, A. y JÜRSCHIK, P. (1998): Servicio de urgencias de un hospital. Perspectiva de los acompañantes del usuario. Todo Hospital, 145, 203-206.

ALVARADO, E. (Coord.) (1998): Retos del Estado del Bienestar en España a finales de los noventa. Madrid. Tecnos.

ALVAREZ, M. (1998): El liderazgo de la calidad total. Madrid. Editorial Escuela Española.

ASCOLI, U. (1996): I welfare mix in Europa. Assistenza Sociale, 1, 2134.

AUSLANDER, G.K. (1996): Outcome Evaluation in Host Organizations: A Research Agenda. Administration in Social Work, 20, 2, 15-27.

Ayuntamiento de Murcia (1993): Jornadas sobre modernización de la Administración Pública Local. Murcia.

BARINAGA, R. (1994): Opción política en la redefinición del Estado del Bienestar. Zerbitzuan, 25, 37- 39.

BEESLEY, M. (1993): Privatisation: Principles, Problems and Priorities. Lloyd Bank Review, 149, 1-20.

CAINZOS, J.J. (1991): Los componentes público-privado del Estado de Bienestar: Una perspectiva constitucional. En G. Rodríguez Cabrero: Estado, privatización y bienestar. Pág. 47-95. 
CALERO, M.J. y CALERO, M.D. (1991): Control de calidad asistencial. Revista ROL de Enfermería, 154, 33-40.

Círculo de Empresarios (1997): El Estado de bienestar a examen: un reto par el sector privado. Madrid.

Congreso Nacional de la Calidad (VI) (1995): Calidad por y para el hombre. Madrid. Ediciones Gestión 2000, S.A.

CREE, V.E. (1995): From Public Streets to Private Lives: The Changing Task of Social Work. Avebury. Aldershot.

CURIESES, A.; BERMEJO, R. y ALVAREZ, J.A. (1991): Encuesta de satisfacción de los usuarios con el teléfono 061 de urgencias sanitarias en la Comunidad de Madrid. En VI Jornadas de Salud Pública y Administración Sanitaria, pág. 203-204. Granada. Escuela Andaluza de Salud.

DE LA CALLE, A.; MORENO, E.; DE ALBA, V.; GARCÍA, M.J.; FLORES, M.C. y FERNÁNDEZX-MIRANDA, C. (1997): Calidad de información, comunicación y grado de comprensión en 590 pacientes quirúrgicos y familia. En XV Congreso de la Sociedad Española de Calidad Asistencial. Revista de Calidad Asistencial, 12, 338.

DELGADO, A.; HAZAÑA, M.P.; HERRERO, C.; MARÍN, I. y REYES, M.C. (1994): El perfil del médico y la calidad asistencial. En IX Jornadas de Salud Pública y Administración Sanitaria, pág. 48. Granada. Escuela Andaluza de Salud Pública.

DELGADO, A.; MARÍN, I., REYES, M.C.; HERRERO, C.; HAZAÑA, M.P. y BAILÓN, E. (1997): La calidad de la atención en relación con características del médico. En XV Congreso de la Sociedad Española de Calidad Asistencial. Revista de Calidad Asistencial, 12, 401-405.

DONAHUE, J.D. (1991): La decisión de privatizar, fines públicos y medios privados. Madrid. Paidos.

DONATI, P. (1996): Le politiche sociali in Italia oltre la crisi del welfare state: verso quali configurazioni. La Rivista di Servizio Sociale, I, 3.

DONATI, P. (1997): La crisis del estado Social y la emergencia del tercer sector: hacia una nueva configuración relacional. Revista del Ministerio de Trabajo y Asuntos Sociales, 5, 15-25.

DUARTE, A. y GODOY, S. (1997): La cita previa en un Centro de Servicios Sociales. En M.E. Medina, C. García y A. Romero. (Comps.): La psicología como profesión ( $2^{\circ}$ vol.). Universidad de Murcia y COP.

ELORRIAGA, J.; FERRER, R.; FUENTETAJA, A.; GARROFE, R.; REY, F. y RUEDA, P. (1997): Atención al cliente y calidad del servicio. Siglo Cero, $28,1,19-44$.

ESCALERA, M.; PÉREZ, R.; GONZÁLEZ, B.; MOYANO, G. y VARGAS, A. (1991). Análisis de la satisfacción del usuario con el horario actual de visitas en el Hospital regional de Málaga. En VI Jornadas de Salud Públi- 
ca y Administración Sanitaria, pág. 205. Granada. Escuela Andaluza de Salud Pública.

ESPINOSA, J.M.; ORTEGA, I.; HERNÁNDEZ, J.M.; MUÑOZ, F. y CARRASCO, A. (1994): Opinan nuestros clientes: ¿Hay que potenciar una nueva forma de atención en consulta médica?. En IX Jornadas de Salud Pública y Administración Sanitaria, pág. 108. Granada. Escuela Andaluza de Salud Pública.

ESPINOSA DE LOS MONTEROS, C. (1997): Crisis y reforma del Estado de bienestar. En Círculo de Empresarios (1997), pág. 101-119.

ESTÉVEZ, J.; HERNANDO, A.; ZABALA, E.; GONZÁLEZ, M. y VÁZQUEZ, M. (1995): Planificación e integración de los profesionales en la mejora de la información. En XIII Congreso de la Sociedad Española de Calidad Asistencial. Revista de Calidad Asistencial, 12.

ETXEZARRETA, J.C. (1995): La privatización en la Administración Local. Barcelona. Bayer Hermanos, S.A.

FERNÁNDEZ, S. (1996): Evaluación de programas y centros de integración laboral. Guía de estándares de calidad profesional. En II Escuela de Verano de Servicios Sociales de Almuñecar. (Documento fotocopiado). Diputación de Granada.

FERNÁNDEZ DEL VALLE, J. (1998): Los estándares de calidad de los servicios sociales a la infancia y familia. En $V$ Congreso Estatal de Intervención Social (en prensa). Madrid: Colegio Oficial de Psicólogos.

FERNÁNDEZ. J; PÉREZ, R. y MEDINA, M.E. (1995): Análisis de calidad del servivio de Ayuda a Domicilio. En I Jornadas de Trabajo Social de la Región de Murcia. Colegio Oficial de Diplomados en Trabajo Social, pág. 55-71.

FLEMING, G.V. (1981): Hospital structure and consumer satisfaction. Health. Sev. Res., 16, 43-63.

FORTEZA, S.; RAMÓN, M. y MOREY, E. (1996): Evaluación de las interacciones sociales entre los profesionales de atención directa y los usuarios de una residencia de personas con retraso mental. Siglo Cero, 27,5, 33-39.

GARCÍA ROCA, J. (1992): Público y privado en la acción social. Madrid. Editorial Popular.

GIDDENS, A. (1994): Consecuencias de la modernidad. Madrid. Alianza.

GIL, J.; RODRÍGUEZ, J.G.; DÍAZ-ALERSI, R.; MARTÍNEZ, P.; HUERTOS, M.J. y RUIZ, M.A. (1993): La comunicación con el usuario y sus familiares en una Unidad de Medicina Intensiva. Interés de la encuesta post-alta. Medicina Intensiva, 18, 2, 55-60.

GÓMEZ- CALCERRADA, D.; PÉREZ, D. y MARSET, P. (1996). La cita previa, perfil del consultante y accesibilidad. Atención Primaria, 17, 4, 288-291. 
GÓMEZ, P. y SATURNO, P.J. (1997): La calidad en atención primaria de salud según sus diferentes protagonistas. I Congreso Regional de Calidad Asistencial. Murcia.

GONZÁLEZ M.J. (1996): ¿A dónde va el sector público? Del Estado de Bienestar al bienestar con menos estado. Madrid: Instituto de Estudios y Anális Económicos.

GOODMAN, J.B. (1994): Privatización del sector público: ¿acierto o disparate?. Deusto Bussiness Review.

GREENLEY, J.R.; GREENBERG, J.S. y BROWN, R. (1997): Meauring Quality of Life: A new and practical Survey Instrument. Social Work, 42, 3, 244-254.

HANKE, S. (1991): Privatización del sector público. Revista de Estudios del Instituto de Estudios Económicos, 1, 137-171.

HEMMING, R. y MANSOOR, A.M. (1994): La privatización y las empresas públicas. Revista de Hacienda Pública, 128, 231-235.

HERRERA GARRIDO, F. (1996): Círculos de calidad. Proceso de implantación en la Administración Local. IV Jornadas de Intervención Social. Tomo 2, pág. 1235-1245. Madrid: Colegio oficial de Psicólogos de Madrid/ INSERSO.

HOWELL, J.R. (1976): Aproposed method for self-assessment in primary care organizations. Journal Commun Health, 4, 56-57.

HUNTIGTON, S.P. (1971): The Change to change; modernization, development and politics. Comparative Politics, 3, 3.

HUTTON, W. (1995): The State We're in. New York: Vintage Press.

IMSERSO (1997): Teleasistencia domiciliaria. Evaluación del programa INSERSO/FEMP. Madrid.

INSERSO (1992b): Evaluación de la calidad de los servicios del Programa de Termalismo Social. Madrid.

INTRESS (1991): Público-Privado y Bienestar social. Barcelona.

KAPLAN, R.S. y NORTON, D.P. (1992): Evaluación de resultados: algo más que números. Harvard Deusto Business Review, 24.

KEARNS, P.S. (1996): Privatization of human services: problems with contracting out theory. JHHSA SUMMER, 61-78.

KOVAR, S. (1996): Droit communautaire et service public: esprit dorthodoxie ou pensée larcisée, RTDE, 2, abril-junio, págs. 215 a 258.

LACASTA, J.J. (1997): Calidad organizacional: el cambio en las organizaciones no gubernamentales. Siglo Cero, 29, 1, 5-13.

LAPARRA, M. (1989): Privatización y servicios sociales. El caso de Navarra. Revista de Trabajo Social, 115, 57-81. 
LE GRAND, J. y ROBINSON, R. (1984): Privatisation and the Welfare State. London. George Allen \& Unwin.

LEONARDIS, O. (1996): I welfare mix e lêreditá difficile del welfare state. Assistenza Sociale, 1, 35-50.

LÓPEZ, J. y GADEA, A. (1995): Gestión de la calidad en la Administración Pública. Madrid. Gestión 2000.

LÓPEZ RUPÉREZ, F. (1994): La gestión de la calidad en educación. Madrid. La Muralla.

LUQUE, O. (1988): Intervención psicosocial en servicios sociales. Valencia. Nau Llibres.

LYOSN, K; LA VALLE, I. y GRIMWOOD, C. (1995): Career patterns of Qualified Social Workers: Discussion of a Recent Survey. British Journal Social Work, 25, 173-190.

MACKESY, R. (1993): Physician satisfaction with Rural Hospitals. Hospital \& health Services Administration, 38, 3, 375-386.

MADERA, M.V.; JURADO, M. y DE MIGUEL, M. (1995): Evaluación del protocolo de acogida para la mejora del trato al usuario en un servicio de medicina interna. En XII Congreso de la Sociedad Española de Calidad Asistencial. Revista de Calidad Asistencial, 12.

MALDONADO, A. y MARCH, J,C. (1994): Diseño de un plan de acogida de usuarios. En IX Jornadas de Salud Pública y Administración Sanitaria, pág. 127. Granada. Escuela Andaluza de Salud Pública.

MANN, K. (1991): Privatización del Bienestar, individualismo y Estado. En G. Rodríguez Cabrero: Estado, privatización y bienestar. Pág. 95-129.

MARTIN, L.L. (1993): Total Quality Management: The new Managerail Wave. Administration in Social Work, 17, 2, 1-15

MARTÍN MATEO, R. (1994): Liberalización de la economía (más Estado menos Administración ). Madrid. Trivium.

MARTÍN SANTOS, J.A. (1995): Sobre la privatización en servicios sociales. Documentos de Trabajo Social, 5, 89-93.

MARTÍNEZ DEL OLMO, M.T. (1994): La calidad de los servicios sanitarios y la participación de los usuarios. En IX Jornadas de Salud Pública y Administración Sanitaria, pág. 81. Granada. Escuela Andaluza de Salud Pública.

MAS, Ll; DEULOFEU, F.; SABÉ, A.; PAGÉS, A.; COLL, M. y RIU, Ll. (1997): Encuesta de satisfacción de los usuarios del servicio de urgencias. En XV Congreso de la Sociedad Española de Calidad Asistencial. Revista de Calidad Asistencial, 12, 347.

MEDINA TORNERO, M.E. (1993b): Análisis de calidad en los centros residenciales para mayores. En La Cristalera, 2, 41-49. Murcia: CARM. Dirección General de Bienestar Social. 
MEDINA TORNERO, M.E (1994): Consideraciones criticas a la vigencia u futuro del Plan Concertado. En I Congreso Nacional sobre el Sistema Público de Servicios Sociales en la Administración Local. Ayuntamiento de La Coruña, pág. 75-86.

MEDINA TORNERO, M.E. (1995): Organizar, Planificar y evaluar en las entidades asociativas. Murcia. Federación de Asociaciones Murcianas de Discapacitados Físicos (FAMDIF).

MEDINA TORNERO, M.E. (1996a): Gestión de Servicios Sociales. Murcia. PPU/Diego Marín.

MEDINA TORNERO, M.E. (1996b): La evaluación, garantía de calidad para los programas de intervención social. Simposio de Evaluación en la Intervención Socioeducativa. Fundació Pere Tarrés, Barcelona, Universitat Ramón Llull (Educación Social, 5, 46-69).

MEDINA TORNERO, M.E. (1996c): Evaluación de la calidad asistencial en Servicios Sociales. Intervención Psicosocial, 5, 14, 23-42.

MEDINA TORNERO, M.E. (1997a): La evaluación, de la calidad de los servicios sociales. II Congreso de Psicología Profesional. Murcia. Colegio Oficial de Psicólogos.

MEDINA TORNERO, M. E. (1997b): Utilidad de la evaluación en los servicios sociales comunitarios. Apuntes de Psicología, 49-50, 127-151.

MEDINA TORNERO, M.E. (1998): Evaluación de la calidad asistencial del servicio de ayuda a domicilio del Ayuntamiento de Murcia (1996-1997). Tesis Doctoral. Universidad de Murcia.

MENDOZA, X. (1991): Algunas reflexiones acerca de la transición al mercado de los servicios sociales. En INTRESS: Público-privado y Bienestar Social. Pág. 109.

MESCHERIAKOFF, S. (1991): Droit des services publics. París. PUF.

MILLWARD, R. y PARKER, D. (1983): Public and Private Enterprise: Comparative Behaviour and Relative Efficiency. En R. Millward (ed.): Public Sector Economic. New York. Longman.

Ministerio de Administraciones Públicas (MAP) (1996): Gestión y evaluación de la calidad en los servicios públicos. Madrid. MAP.

Ministerio de Trabajo y Asuntos Sociales y FERNÁNDEZ, S.(1997): Guía de integración laboral para personas con discapacidad. Estándares de calidad. Madrid.

MIRA, A.; VALLS, A.; VELASCO, J. y SERRA, M. (1997): Importancia de la opinión de los pacientes en la toma de decisiones. En XV Congreso de la Sociedad Española de Calidad Asistencial. Revista de Calidad Asistencial, $12,297$. 
MOORE, S. y KELLY, M.J. (1996): Quality Now: Moving Human Services Organizations toward a Consumer Orientation to Service quality. Social Work, 41, 1, 33-40.

MOORE, M.H. (1998): Gestión estratégica y creación de valor en el sector público. Madrid. Paidos.

MOTA, J. (1998): La gran expropiación. Madrid. Temas de Hoy.

MUÑOZ, S. (1998): Servicio público y mercado. Madrid. Civitas.

NAVARRO, V. (1998): Neoliberalismo y Estado del bienestar. Barcelona. Ariel.

ORTEGA, L. (1994): El reto dogmático del principio de eficacia, Revista de Administración Pública, 133.

PALLARÉS, L. y GARCÍA, M.J. (1996). Guía práctica para la evaluación. de la calidad en la atención enfermera. Madrid. Olalla Ediciones.

PAREJO ALFONSO, L. (1989): La eficacia como principio jurídico de la actuación de la Administración Pública, Documentación Administrativa, 218-219.

Parlement Européen, Direction Générale des Etudes (1996): Document de travail. Entreprises publiques et services publiques économiques dans l'Union Européenne, Luxemburgo.

PASCUAL, L.; AGUAS, J.M.; ALFONSO, D.; GARCÍA, E.; SANZ, R. y MARTÍNEZ, R. (1994): Análisis de la accesibilidad telefónica a un Centro de Salud. En XII Congreso de la Sociedad Española de Calidad Asistencial. Revista de Calidad Asistencial, 3, 127.

PEIRÓ, J.M. y MEDINA, M.E. (1996): Aspectos psicosociales de la gestión de servicios sociales. En IV Jornadas de Intervención Social, tomo 2, pág. 1147-1 183. Madrid: INSERSO/Colegio Oficial de Psicólogos.

PIRIE, M. (1990): Privatization: theory, practice and choice. London. Adam Smith Institute.

PORCEL MUNDO, A. (1997): La calidad total en el Trabajo Social. Revista de Servicios Sociales y Política Social, 59, 71-81.

PRIETO, M.A.; LÓPEZ, L.A. y MARCH, J.C. (1994): Percepción de usuarios sobre la calidad de los servicios de atención primaria y atención especializada. En IX Jornadas de Salud Pública y Administración Sanitaria, pág. 193-194. Granada. Escuela Andaluza de Salud Pública.

PUPPO, S. (1996): Patronato e welfare mix. Assistenza Sociale, 1, 63-70.

RANCI, C. (1996): Pubblico e privato nella transizione italiana verso il welfare mix. Assistenza Sociale, 1, 5-62.

RIPOLL, R. (1998): Libre competencia y ayudas a las empresas públicas. Valencia. Fundación Bancaixa.

RODRÍGUEZ CABRERO, G. (comp.) (1991): Estado, privatización y bienestar. Madrid. Icaria. 
RODRÍGUEZ RODRÍGUEZ, P. (1996): Analisis de la calidad de los servicios de teleasistencia en España: un estudio del INSERSO. En Jornadas Internacionales: Teleasistencia y Nuevas Tecnologias (documento fotocopiado).

RUIPÉREZ CANTERA, I. (1998): Calidad en la asistencia a las personas mayores. Revista Española de Geriatría y Gerontología, 33, 2, 63-66.

SACANELL , E. (1996): Aportaciones de la gestión de calidad en los servicios sociales. IV Jornadas de Intervención Social. Tomo 2, pág. 12611270. Madrid. Colegio Oficial de Psicólogos de Madrid/INSERSO.

SACANELL, E. (1998): Evaluación y calidad de la intervención social en el curriculum docente. En II Congreso de Escuelas Universitarias de Trabajo Social, pág. 352-355. Madrid. Escuela Universitaria de Trabajo Social. Universidad Complutense.

SÁNCHEZ, M.; ORTIZ, A. y PINEDA, A.I. (1994): Teléfono de atención al paciente: un aumento de la calidad asistencial. En IX Jornadas de Salud Pública y Administración Sanitaria, pág. 130. Granada. Escuela Andaluza de Salud Pública.

SÁNCHEZ, J.A.; SATURNO, P.J. y PORSPER-S. (1997): Evaluación de la calidad desde la perspectiva del paciente. Validación de un cuestionario tipo informe del usuario. En XV Congreso de la Sociedad Española de Calidad Asistencial. Revista de Calidad Asistencial, 12, 289-290.

SEIT (1993): Evaluación de la calidad del indicador tratamiento del Sistema estatal de Información sobre Toxicomanías (SEIT). Revista de Sanidad e Higiene Pública, 67, 385-399.

SERRA, A. (1991): La estructuración de la sociedad: el sector público y el sector privado. En INTRESS: Público-privado y Bienestar Social. Pág. 65-77.

SOLIMAN, H. y POULIN, J. ( 1997): Client Satisfaction with Crisis Outreach Services: The development of an Index. Journal of Social Service Research, 23, 2, 55-71.

STARR, P. (1995): The meaning of Privatization. Project on the Federal Social role. Working paper, 6, 231.

STORR, A. (1996): Total Quality Management: Organizational Transformation or passing Fancy?. Administration in Social Work, 20, 3, 75-94.

STOKER, R.; WILSON, L.; THOMAS, L. y CLARK, G. (1997): Paternalistic welfare reform: current perceptions and behavioral models. JHHSA SUMMER, 5, 62-82.

SUÁREZ, F.,CIFUENTES, R. y MERCHÁN, E. (1991): La calidad asistencial y los recursos humanos en las residencias de ancianos. Revista Española de Geriatría y Gerontología, 1 (suplemento). 
SUÑOL, R. (1987): El estudio de la opinión del usuario y su aplicación en los programas de control de calidad. Control de Calidad Asistencial, 2, 15-22.

TAYLOR-GOOBY. P. (1991): La privatización y el futuro del Estado de Bienestar británico. En G. Rodríguez Cabrero: Estado, privatización y bienestar. Barcelona. Icaria.

TORRES GÓMEZ, B. (1996): Principales razones y consecuencias del «burnout» en los profesionales de los servicios de bienestar social de la CAV: posibles vías de solución. Vitoria. Servicio Central de Publicaciones del Gobierno Vasco.

VILLANUEVA, S.; GARCÍA, M.; GOIKOETXEA, A.; CEREZO, M.; VALERO, M.A. y GUTIÉRREZ, G. (1997): Evaluación de tiempos de espera y satisfacción de pacientes en el servicio de urgencias de un hospital terciario. En XV Congreso de la Sociedad Española de Calidad Asistencial. Revista de Calidad Asistencial, 12, 349.

VILLAR ROJAS, F.J. (1993): Privatización de servicios públicos, la experiencia española a la luz del modelo británico. Madrid. Tecnos.

VUORI, H. (1988): El control de calidad en los servicios sanitarios. Madrid. Masson.

WARE, J. E. (1978): Effects of acquiescent response set on patient satisfaction ratings. Med. Care. 16, 327.

WILDING, P. (1994): Maintaining Quality in Human Services. Social Policy and Administration, 28, 1, 57-72.

YARROW, G. (1989): Privatization in Theory and Practice. Economic policy, 1. 



\section{TREBUNA LIBRE}





\title{
LA DELINCUENCIA JUVENIL COMO SÍNTOMA: PERSPECTIVAS DE INTERVENCIÓN PSICOSOCIAL'
}

\author{
AGUSTÍN BUENO BUENO \\ CONRADO MOYA MIRA \\ Área de Psicología Social. Universidad de Alicante.
}

\section{RESUMEN}

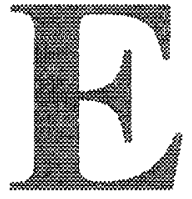

ste artículo presenta un análisis psicosocial del fenómeno de la delincuencia juvenil a propósito de los datos de incremento de la misma que aparecen recientemente en las revistas especializadas y de investigación. Se consideran los argumentos de carácter estrictamente personal y social, así como la interacción de ambos, pero se pone el acento en una explicación psicosocial del incremento del fenómeno que a juicio de los autores reside, en última instancia, en una inadecuación o disarmonía del proceso de socialización que se ofrece durante la infancia y adolescencia. Esta perspectiva no anula las anteriores y, sin embargo, permite una planificación y diseños de la intervención más completos y eficaces a todos los niveles.

\section{PALABRAS CLAVE}

Delincuencia juvenil. Socialización. Intervención social.

\section{INTRODUCCIÓN}

La delincuencia juvenil e infantil, o las infracciones de niños y adolescentes como formulación menos etiquetante, está resultando cada vez más un comportamiento preocupante. Hay una especial sensibilización hacia el tema que produce la alarma en los habitantes de ciudades grandes y pequeñas de nuestra civilización occidental cuando se

\footnotetext{
Este trabajo es fruto de los seminarios realizados dentro del Curso de Intervención Social con Jóvenes en Europa (EYST) subvencionado por el Programa Leonardo da Vinci del Fondo Social Europeo.
} 
ofrecen datos estadísticos de robos, agresiones, violaciones o asesinatos realizados por menores de edad penal cada año. Asusta la cantidad y evolución de los datos, pero asusta aún más, si ello es posible, el constatar crímenes crueles realizados por niños de 10-12 años, o incluso recientemente de 7 y 8 años.

El eco social de las infracciones juveniles tiene una preocupación añadida en los adultos que las contemplan impotentes. Es inevitable una proyección hacia el futuro y contemplar con la imaginación unos años venideros de caos y deterioro social con un tinte de impotencia o resignación por parte del adulto y una culpabilización de las nuevas generaciones, quizás sin ver otras facetas muy positivas de nuestra juventud.

Ante el impacto social de las noticias y estudios sobre delincuencia juvenil surge la necesidad de buscar explicaciones del fenómeno, y explicaciones preferentemente causales que determinen el origen del problema para poder atajarlo de raíz.

El análisis causal de un fenómeno social como la delincuencia juvenil admite dos polos de análisis casi equidistantes: el social y el personal.

\section{LA DELINCUENCIA JUVENIL COMO CONSECUENCIA DE LOS DESEQUILIBRIOS SOCIALES.}

Un análisis de las infracciones por regiones, países o comarcas, siempre arroja una mayor incidencia del fenómeno en aquellas zonas afectadas por fuertes desequilibrios sociales. La fácil atribución de causalidad a los datos correlacionales hace que se considere a estos desequilibrios sociales como causa última del incremento de la delincuencia juvenil y que se busquen soluciones a esa delincuencia con medidas de incremento de empleo, talleres de inserción sociolaboral, o contrataciones incentivadas para las empresas. El paro juvenil es un problema social en sí mismo y muy grave aunque no tuviera correlación ninguna con las infracciones juveniles de la ley.

Por otra parte, es fácil asociar al joven delincuente con juventud en paro. No quiere esto decir que los jóvenes de 16 a 20 años que trabajan o estudian no cometan actos delictivos, sino que su proporción es insignificante respecto de los que están en paro. Pero, como decía un compañero educador de jóvenes infractores en Holanda: «en mi país casi no hay paro y sigue aumentando la delincuencia juvenil».

Algo queda suelto en esta línea explicativa que nos impide generalizar el criterio. Lo mismo habría que decir respecto a los datos que relacionan delincuencia con población inmigrada de regiones menos 
desarrolladas. El hecho en sí de la inmigración no se puede considerar desencadenante de la conducta delictiva: ni todos ni sólo los jóvenes inmigrantes son los que delinquen. Ni siquiera nos sirve como fenómeno asociado a la falta de empleo comentada antes, aunque sin duda desempleo e inmigración son fenómenos íntimamente relacionados entre sí.

Si esta explicación no es concluyente es porque sin duda la delincuencia juvenil, en cuanto hecho social, es un fenómeno complejo que tiene asociaciones con el paro y con la inmigración, pero que también le encontraremos conexión con crisis de valores de la propia cultura, con rupturas familiares, con pobreza, con bajos niveles de escolarización...; pero sin que todo ese conjunto de factores explique totalmente el hecho delictivo.

\section{III.LA DELINCUENCIA JUVENIL COMO DESAJUSTE PERSO- NAL.}

Cuando en nuestros análisis de las infracciones juveniles y de su evolución vemos que los factores sociales, estando fuertemente relacionados con ellas, no llegan a una explicación completa del fenómeno, resulta inevitable volver la vista al polo personal del joven delincuente. Si el problema no está en la situación estará en la persona, o si no son las circunstancias será el yo.

Al pensar ahora en la problemática personal no nos referimos a los condicionantes genéticos de la conducta delictiva, que sin negarlos como posibles en casos muy específicos, no estaría justificada su generalización a todos los casos que queden fuera de la explicación por factores sociales.

La explicación de la delincuencia por desajustes personales se refiere a trastornos de la personalidad, más o menos leves, fruto de crisis afectivas, familiares, fracasos escolares, etc., que producen baja autoestima, impulsividad o bajo control, etc.

Estos elementos personales ciertamente se encuentran presentes en gran número de nuestros jóvenes infractores europeos; pero se encuentran también presentes en buen número de jóvenes europeos no infractores. Quizás, incluso, podríamos considerarlos como características frecuentes en los adolescentes y jóvenes de nuestros países de manera general. Más aún, difícilmente se van a encontrar estos elementos personales aislados de los factores sociales que veíamos antes.

Con frecuencia, en los análisis de la delincuencia juvenil en clave de desajuste personal aparece la drogadicción como factor desencadenante del desajuste personal. 
También ese dato es correcto en cierto porcentaje de sujetos. Pero esta explicación de la violencia juvenil como desajuste personal o inadaptación producida por la drogodependencia no nos resuelve el problema, sino que los desplaza de la delincuencia a la drogodependencia.

¿Por qué grandes grupos de jóvenes europeos caen en la dependencia de sustancias que alteran su personalidad hasta llevarles a delinquir? Si intentamos contestar con seriedad esa pregunta volveremos a estar otra vez buscando elementos sociales y/o elementos personales que nos diesen alguna luz sobre el fenómeno.

\section{IV.EL INCREMENTO DE LA DELINCUENCIA ES CONSECUEN- CIA DE LA INTERACCIÓN DE FACTORES PERSONALES Y SITUACIONALES.}

Vistas las explicaciones anteriores es inevitable pensar en una tercera vía interaccionista que en los fenómenos complejos de conducta siempre ha dado claves eficaces de interpretación de los fenómenos. En nuestro caso el interaccionismo vendría a explicar el incremento de las infracciones juveniles por una mayor confluencia de factores personales y factores situacionales.

En la medida, sería la argumentación, que en estos últimos tiempos la juventud vive más y mayores desequilibrios sociales, como los que hemos comentado, y éstos pueden producir desajustes personales al no ser capaces de superarlos, el joven genera unas conductas delictivas como protesta a lo que él considera una injusticia; o como respuesta, socialmente inadecuada pero para él satisfactoria, a sus necesidades. $Y$ a la inversa también cabe explicar que un joven con fuertes desajustes personales y familiares sea un fracasado en la escuela, caiga en la drogadicción, y en el desempleo crónico.

Cómo mecanismo armonizador de los factores de uno y otro signo esta postura es francamente sugerente. Si la cuestionamos no es como elemento explicador sino como atribución de causalidad al incremento de la delincuencia juvenil. De hecho el que unos factores influyan en los otros no justifica el incremento. Tal influencia es un mecanismo básico de la conducta humana que nos sirve muy bien para explicar la actuación y el proceso de un joven delincuente concreto. Nos sirve para ver cómo este chico ha llegado a cometer un delito de tal magnitud, pero no para explicar el incremento del fenómeno en un determinado colectivo de barrio, ciudad o nación.

La pregunta quedaría ahora formulado así ¿qué es lo que hace que actualmente haya aumentado la influencia recíproca de factores personales y situacionales conflictivos para nuestros jóvenes? 


\section{LA DELINCUENCIA JUVENIL COMO SÍNTOMA DEL FRA- CASO DEL PROCESO DE SOCIALIZACIÓN.}

Si queremos hacer un análisis de la delincuencia juvenil que nos permita desembocar, por una parte, en una comprensión amplia del fenómeno y, por otra, en una planificación de nuestra intervención psicosocial, resulta más operativo concebir las infracciones juveniles como un síntoma, entre varios posibles (la drogodependencia, por ejemplo), de que algo funciona mal tanto en el individuo como en la sociedad.

Mientras que el análisis del fenómeno de la delincuencia en términos de relación de causa/efecto nos va a llevar a entender e intervenir en un extremo del fenómeno, descuidando fácilmente el otro que queda exculpado, o por lo menos ignorado; el análisis de la delincuencia juvenil como síntoma, como señal de alerta de que un proceso de crecimiento, de integración, guiado por una gran pluralidad de factores y agentes determinantes, nos ha de llevar a una comprensión compleja del fenómeno y a una intervención multifrontera donde no tiene sentido una intervención en la persona si no va acompañada de una actuación en todas las ramificaciones del proceso que han conducido hasta allí.

Cuando nos enfrentamos con una serie de datos que nos dicen que nuestros jóvenes ahora presentan más conductas delictivas y de más gravedad que hace unos años, y que tales conductas empiezan a manifestarse a edades más tempranas, podemos afirmar, prescindiendo de causas inmediatas, que el proceso de socialización que estamos llevando ahora es menos eficaz o menos productivo que el que llevábamos hace unos años. Dicho esto no en términos nostálgicos de métodos, sino pensando en los resultados y en la educación de los instrumentos o recursos socializadores a las necesidades y exigencias del proceso en el momento actual.

Antes de seguir adelante en nuestra reflexión es importante que caigamos en la cuenta de lo que significa el proceso de socialización. No se trata de un fenómeno estrictamente social, ni tampoco estrictamente personal. Es un fenómeno de interacción, quizás uno de los más claros, de interacción entre individuo y sociedad.

La sociedad trasmite normas, valores, creencias, actitudes, con el fin de que los nuevos individuos que se incorporen a ella lo hagan de una manera constructiva y positiva para el conjunto social.

El individuo, por su parte, conforme va evolucionando su proceso de crecimiento y maduración, va desarrollando sus potencialidades en forma de habilidades, aptitudes, imaginación, fuerzas, etc., que han de 
tener su expresión y su repercusión en el contexto social que le rodea: la sociedad.

El proceso de socialización culmina de manera positiva cuando las cualidades desarrolladas por el individuo durante su infancia y adolescencia se convierten en instrumentos de actuación válida en la sociedad.

Como consecuencia de esa actuación el joven irá recibiendo de la sociedad reconocimientos, medios de subsistencia, de protección y de nuevo desarrollo.

Ahora bien, para que ese proceso culmine de manera positiva la sociedad ha de ir facilitando al niño y al adolescente los medios adecuados para su correcta evolución, en forma y medida que él pueda asimilarlos, como los alimentos.

Por el contrario, cuando la transmisión de normas, valores, creencias, actitudes, no se produce de manera adecuada es cuando ocurre la distorsión del proceso de socialización y la aparición de las conductas inadaptadas; y si éstas son de gravedad penal, y son detectadas por la autoridad competente, aparecerán las conductas delictivas.

El fracaso del proceso de socialización puede llegar por el deterioro de alguno de los agentes socializadores (familia, escuela, grupo de iguales, medios de comunicación), o bien por las contradicciones entre las transmisiones de unos agentes y otros, o también por los errores y contradicciones de los mecanismos de socialización que emplean cada uno de los agentes.

No vamos a entrar en un análisis de cada uno de estos agentes para detectar sus fallos. Caigamos en la cuenta, simplemente que familia, escuela, y amigos tienen sus períodos prioritarios de actuación a lo largo de la vida del niño, con lógicas superposiciones entre ellos.

Comienza la familia, sigue la escuela (concebida como enseñanza básica y como capacitación laboral), y culmina la pandilla. Mientras tanto los medios de comunicación intervienen con fuerza en la actualidad a lo largo de todo el proceso, pero mediados de alguna manera por los otros tres agentes.

También el grupo de iguales está de alguna forma mediado por la familia y la escuela, y al hablar de ese grupo de iguales o pandilla y su influencia hemos de considerar incluido todo lo que significa la calle de la ciudad, el vecindario, las ofertas de ocio y cultura, etc.

Es todo este entramado social, que tradicionalmente sintetizamos en los cuatro agentes, lo que determina que el proceso de socialización sea integrador o marginador e inadaptador.

El fracaso del proceso socializador puede venir porque alguno de los agentes no exista o esté muy deteriorado, y puede venir porque los 
contenidos que transmiten unos agentes estén en contradicción con los contenidos convivenciales, formas de resolución de conflictos, medios de obtener satisfacción, aspiraciones de futuro, etc. que transmiten los otros agentes.

Este cruce de contenidos de socialización es más frecuente de lo que parece, se extiende por todos los estratos sociales y su repercusión en el joven es de desorientación, ambivalencia y contradicción, optando él por el camino que le resulta más sencillo, o por el que tiene modelos más asequibles.

La otra vía de fracaso del proceso de socialización, paralela a la anterior, es relativa no ya a los agentes socializadores sino a los mecanismos o instrumentos que se emplean para la transmisión de los contenidos sociales y de convivencia.

Esta contradicción puede ser, y con frecuencia lo es, interna en cada agente socializador. Sea la familia, la escuela, la pandilla/calle, los medios de comunicación, tienen como instrumentos para socializar: la instrucción o consejo, los refuerzos positivos y negativos de las conductas deseables y no deseables respectivamente, y mediante la oferta de modelos de comportamiento. Con frecuencia, lo que el padre de familia aconseja que haga el hijo se contradice con lo que él hace y con las conductas que él refuerza en positivo o en negativo.

Estas contradicciones no son exclusivas del ámbito familiar. Se dan exactamente igual en la escuela, en la socialización de la calle con mensajes contradictorios y, por supuesto, en los medios de comunicación donde lo que se dice y analiza en los noticiarios está enfrentado con lo que hace el héroe de la película posterior, y con las conductas que se refuerzan en la publicidad del intermedio.

Es así como fracasa el proceso socializador en la infancia y adolescencia. Es aquí donde adquiere significado el paro juvenil (y los otros desequilibrios sociales) como elemento compañero de la delincuencia. Se le ha repetido mil veces al chico que será un hombre con trabajo, que será útil, que conseguirá medios para vivir dignamente; pero, luego, cuando llega el momento de la verdad, no hay trabajo para él o él no está preparado para ese trabajo, o se le desprecia en el puesto de trabajo por cualquier tipo de prejuicio. También puede ocurrir que el chico quiera trabajar pero sin esfuerzo, porque cansarse es malo; porque sus héroes de la televisión siempre consiguen la metas con facilidad y con las manos limpias.

Todo esto son ejemplos, aunque responden a auténticas realidades vividas por cualquiera de nosotros en nuestro trabajo con jóvenes infractores. Las situaciones en las que podríamos seguir poniendo ejemplos son infinitas, tantas como jóvenes. Todas tendrán un mismo denominador común: las experiencias, orientaciones, consejos, modelos, 
etc., que han ido acumulando hasta entonces resultan ineficaces para hallar una respuesta social integradora. En ellos han predominado, o han sido interiorizadas con más fuerza, aquellas otras que conducen a la inadaptación.

\section{CONSECUENCIAS DEL ANÁLISIS DE LA DELINCUENCIA JUVENIL COMO SÍNTOMA.}

Esta forma de explicar la delincuencia, sea en el plano individual sea en el plano colectivo, puede tener consecuencias muy importantes en la intervención. Esto se debe sencillamente a que nos lleva a entender que cuando falla el proceso de socialización nos hemos equivocado todos: el joven delincuente, por supuesto; pero con él, en diversa forma y medida, todos los agentes de socialización en diversa forma y medida.

\subsection{Consecuencias en la intervención sobre el individuo}

Las consecuencias a sacar en el plano individual cuando nos encontramos ante un joven con conductas delictivas y los procesos cognitivos que las sustentan no son atribuibles a una clara patología, son el resultado fallido de su socialización.

Por lo tanto, la intervención, o el tratamiento, a seguir tampoco ha de ser exclusivamente con él. Habrá que intervenir con él y con su familia en un esquema sistémico y de red social. Habrá que resocializar su capacitación laboral, sus posibilidades de ocio y tiempo libre, sus pautas de relación y convivencia. Habrá que ofrecerle modelos sanos de identificación y aprendizaje. Habrá que reforzarle adecuadamente las conductas deseables y las no deseables.

Resumiendo, ante un joven infractor hemos de ver lo que se puede hacer con el muchacho y lo que se puede hacer con todo su contexto socializador.

\subsection{Consecuencias en la intervención social}

Más importantes, por lo novedosas que pueden resultar, son las consecuencias que podemos sacar del mismo esquema de análisis en el nivel colectivo o social. Si los datos nos dicen que en nuestra ciudad, o en tal barrio de tal ciudad, han aumentado sensiblemente las conductas delictivas en los últimos cinco años, la conclusión a sacar será aceptar que los agentes y mecanismos de socialización de esa ciudad o barrio se han deteriorado. Eso es lo que nos dice el síntoma. Como el raquitis- 
mo respecto al desarrollo físico. El raquitismo en sí mismo no nos dice que hay mala alimentación, o que hay un problema de metabolismo o una infección intestinal u otra enfermedad concreta. El raquitismo, como podríamos decir de la fiebre o del dolor, directamente informa que hay un desajuste en el organismo y en la relación del organismo con su medio, y que éste manifiesta así el desequilibrio que vive.

Si queremos frenar y contrarrestar el deteriorado proceso socializador de ese colectivo, además de las medidas que se tomen con cada joven, habrá de tomarse medidas serias, tan serias como las del joven, con todos los agentes socializadores que actúan en esa zona.

Habrá que disponer de apoyos educativos y terapéuticos a las familias que los requieran. Habrá que revisar los modelos, pautas, niveles de las escuelas. Habrá que replantear el ocio y la capacitación laboral de los grupos juveniles. Habrá que fomentar la receptividad de las empresas facilitadoras de trabajo. Habrá que incidir en la publicidad, en los modelos de los medios de comunicación y en los valores que se trasmiten.

Todo esto es la sencilla conclusión de ver la socialización como un fenómeno de interacción entre individuo y sociedad.

Cuando la socialización lleva a una postura de integración, han triunfado individuo y sociedad. Cuando la socialización lleva a una postura de marginación e inadaptación han fracasado individuo y sociedad. En consecuencia, la reconstrucción de ese proceso de socialización ha de hacerse mediante la intervención en el individuo y en la sociedad. Hay que insertar la intervención de tipo clínico, exclusivamente dirigida al joven infractor, en una intervención de carácter psicosocial y comunitario.

Esto significa que si, en un determinado barrio o ciudad, durante un período de tiempo claro, se produce un incremento de la delincuencia juvenil, la autoridad judicial, igual que determina libertad vigilada para los jóvenes infractores o reparación en beneficio de la comunidad o ingreso en un centro, debería poder determinar también una vigilancia especial sobre los colegios, centros de ocio de la zona, o exigir una dotación especial de apoyo a la actividad escolar, o escuelas de padres, o dotación de educadores de calle. Dejar caer toda la intervención sobre las espaldas de los jóvenes nunca resolverá el problema. 



\section{LA ESCOLARIZACIÓN DE LOS NIÑOS GITANOS EN EL PAÍS VALENCIANO}

\section{JOSÉ CABANES HERNÁNDEZ}

Sociólogo. Servicios Sociales Municipales de Villena (Alicante). Monitor de minorías étnicas.

\section{INTRODUCCIÓN}

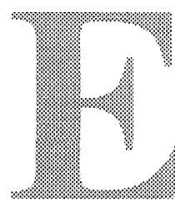

sta exposición es fruto de un estudio, no finalizado, que se realizó entre septiembre de 1996 y diciembre de 1997. El estudio fue encargado por la Consellería de Bienestar Social, por medio de una única beca de investigación, y en él participaron más tarde cerca de un centenar de voluntarias/os (estudiantes del último curso de Trabajo Social, y de Sociología, profesoras/es de la Escuela de Trabajo Social de Alicante, trabajadoras sociales, monitores de seguimiento escolar, etc.), sin cuyo trabajo hubiese resultado imposible llevar a cabo un estudio con tan amplia acotación geográfica.

El principal objetivo del estudio era el tener un acercamiento muy genérico a la situación gitana de todo el país valenciano (de cada una de sus localidades), y en diversas cuestiones (origen, barrios de residencia, tipo de viviendas, número aproximado de habitantes gitanos, situación escolar, migraciones y relaciones interétnicas), lo que suponía, de entrada, el no poder profundizar en ninguna de las cuestiones ni de las localidades.

En el apartado escolar, la información se ha obtenido por medio de entrevistas a los directores, jefes de estudios o claustros (según colegios) de 230 centros escolares de los distintos municipios valencianos, con un total de 5.000 niños y niñas gitanas, y complementada en las entrevistas a los centros sociales y familias gitanas (se han entrevistado a todos los equipos de Servicios Sociales Municipales, así como a distintas familias gitanas y asociaciones en los municipios).

\section{PROCESO HISTORICO, MIGRACIONES Y DISTRIBUCIÓN ACTUAL.}

El País Valenciano ha contado históricamente con un importante número de familias gitanas, debido especialmente a su riqueza agrícola, que permitía realizar trabajos como jornaleros en el campo y que también potenciaba un importante mercado de compraventa de caballerías. 
Con la industrialización de la agricultura en los años 60 , muchas familias gitanas en todo el Estado pierden su principal ocupación, la compraventa de caballerías, y se produce un importante flujo migratorio de familias gitanas (década de los 60 y primera mitad de los 70) de Andalucía (principalmente Jaén y Granada) y Castilla la Mancha, mayoritariamente, aunque también de otras muchas regiones. Estas migraciones buscan principalmente la posibilidad de encontrar trabajo como temporeros agrícolas, y en muchas localidades suplen la mano de obra abandonada por los trabajadores "payos" que habían pasado a trabajar en el sector industrial. Del mismo modo, muchos pequeños pueblos (especialmente de montaña) ven desaparecer a sus vecinos gitanos en busca de mejor fortuna en localidades más agrícolas (actualmente, hay unas 356 localidades donde no reside ninguna familia gitana).

Entre la segunda mitad de los años 70 y la primera de los 80 se da el fenómeno de la macro construcción de bloques viviendas sociales en distintos puntos de la Comunidad Valenciana, especialmente en aquellos donde ya existían problemas de vivienda precaria. Este nuevo fenómeno, en un principio dirigido a familias chabolistas, atrajo un nuevo flujo migratorio de familias que residían en otras localidades, en ocasiones de provincias muy alejadas, en busca de la oportunidad de acceder a una vivienda barata. Es el periodo en el que se consolidan los numerosos barrios ghetto que se distribuyen en las principales ciudades, y con ellos los principales colegios donde acabaran por concentrarse casi exclusivamente los niños gitanos. Aunque no los únicos colegios donde esto sucede.

Ya en los principios de los años 90 ha empezado a darse un proceso migratorio diferente, el cual es en dirección inversa a los anteriores, o sea, ciudad-campo. Se trata, por lo general, de familias que tratan de alejarse de las grandes concentraciones de población gitana (en especial por miedo a que sus hijos crezcan cerca del problema de la droga) y que buscan localidades cercanas a sus zonas de venta (si son vendedores ambulantes) o con recursos laborales (especialmente en el sector agrícola). Al mismo tiempo, se han sucedido nuevas migraciones desde Andalucía, que se instalan en localidades con trabajos agrícolas (en la mayoría de los casos sin población gitana anterior o con gitanos familiares de éstas) y que combinan su estancia en el municipio con las peonadas agrícolas en sus localidades de origen, a las que acuden durante unos meses al año. Por lo general, y con significativas excepciones de familias muy desestructuradas ya en su localidad de origen, estas nuevas migraciones están consiguiendo una buena integración sociolaboral y, paralelamente, los niños y niñas una mejor adaptación y resultados escolares. 
En la actualidad residen en el País Valenciano alrededor de 50.000 gitanos (estimación aproximada) en un total de 180 localidades (de las 536 existentes), de las cuales en más de la mitad residen menos de 100 personas gitanas, y sólo 8 municipios superan los 1.000 habitantes gitanos.

\section{III.DIFERENTES SITUACIONES SEGÚN LOCALIDADES.}

Como ya todos sabemos, la situación escolar no suele ser más que un reflejo de la situación social que se vive en la calle. En este sentido, creo que es interesante exponer las diferentes situaciones sociales en que los gitanos viven en el País Valenciano y como éstas les afectan.

Cuando comenzamos a realizar este estudio existía la tentación de limitarnos a estudiar las localidades que cuentan con un número muy importante de gitanos y que, en general, suelen ser famosas por la existencia de diversos problemas socioeconómicos. Sin embargo, se desechó esta idea porque, de alguna forma, ese tipo de estudios no nos están permitiendo ver que la realidad de la población gitana es mucho más diversa.

En la práctica totalidad de las localidades donde existe un alto número de población gitana suelen repetirse diferentes tipologías de barrios de residencia que llevan a la concentración espacial de la mayoría (cuando no de todas) las familias gitanas. Y que repercuten de forma importante en la situación escolar. La política de vivienda ha conllevado por activa y por pasiva la concentración de la población de menores recursos en los mismos barrios de estas ciudades y, entre esa población, principalmente, a los gitanos. Por activa, mediante la construcción de bloques de viviendas sociales en la periferia de la ciudad, o, en ocasiones, un poco más allá, en el extrarradio, condenándoles a una marginalidad social (están físicamente al margen de la sociedad) y económica. Por pasiva, mediante el mercado libre de vivienda, donde un piso o una casa cuesta una fortuna, y que relega a los estratos socioeconómicos más bajos a concentrarse en los barrios donde no quiere vivir ya nadie (especialmente cascos viejos muy deteriorados, situados en la ladera de alguna montaña o castillo, o en barrios que se sitúan en la periferia de la ciudad separados de ésta por una autovía o la vía férrea). Muchas de las familias que residen en estos barrios suelen padecer problemas de desestructuración, que son a la vez causa y efecto de las condiciones en que se han visto obligadas a vivir. Este tipo de habitat de concentración espacial conlleva una concentración también escolar, que al poco tiempo acaba por convertir al centro en un ghetto de donde huyen los alumnos no gitanos. (Creo que la situa- 
ción es bien conocida por todos/as ya que se repite en una infinidad de ciudades de todo el Estado). En estas ciudades las relaciones interétnicas (payos-gitanos) no suelen ser muy fluidas, y a los prejuicios y estereotipos existentes ya, sobre los gitanos en general, se suma la estigmatización de los barrios de residencia, lo que conlleva una situación en que los dos grupos étnicos se relacionan poco y mal.

En cualquier caso, suele haber en estas ciudades un número de familias, normalmente bastante pequeño, que ha conseguido instalarse en otros barrios, de forma más dispersa y que, en general, tienen una buena situación económica y social. Los hijos de estas familias suelen acceder a colegios con un bajo porcentaje de niños/as gitanos y, en general, están consiguiendo unos mejores resultados académicos (aunque en muchos de los casos el fracaso escolar siga siendo importante).

Por su parte, creo que es resaltable la situación que se da en un gran número de pueblos, más de la mitad, donde la población gitana no supera el centenar de personas. En muchos de estos pueblos la situación laboral y urbanística ha permitido una mejor situación de las familias gitanas, las cuales suelen dedicarse principalmente a realizar trabajos agrícolas (que es en muchos casos también el trabajo principal de la población no gitana). En estas localidades las familias gitanas suelen residir de forma dispersa en distintas calles del pueblo, lo que proporciona una mayor fluidez en las relaciones interétnicas y una mejor situación sociolaboral. Los niños, por su parte, se distribuyen en distintos colegios (cuando no, en el único colegio del municipio) y su situación escolar suele ser parecida a la de sus compañeros no gitanos, dependiendo de algunas variables añadidas (la familia a la que pertenece y la prioridad que le da a la escuela; la localidad donde residen y su actitud hacia los gitanos, etc.).

Evidentemente, esta situación de "normalidad" no se da en todas las pequeñas localidades, y se debe mencionar que muchas veces el hecho de que en un pueblo no resida ninguna familia gitana se debe al rechazo social que en ese municipio se tiene contra los gitanos. Por poner un ejemplo: cuando comencé con la investigación llamé a los ayuntamientos de los distintos municipios para establecer un primer contacto y conocer si residian familias gitanas. En un Ayuntamiento, la Sra. Alcaldesa, tras explicarle el objeto del estudio, me respondió; "en este pueblo, gracias a Dios, no vive ningún gitano".

A pesar de las múltiples excepciones, creo que en las localidades donde reside un número no muy alto de familias gitanas se está consiguiendo una aceptable situación socioeconómica y, paralelamente, también escolar. En este sentido me parece importante el tímido, pero significativo, flujo migratorio que en algunas comarcas se está dando de familias gitanas que emigran de las grandes ciudades con alta con- 
centración de población gitana, hacia municipios pequeños donde hasta ahora no había vecinos gitanos.

\section{IV.ESCOLARIZACIÓN ACTUAL}

En la actualidad, la práctica totalidad de los niños y niñas gitanas se encuentran escolarizados, aunque todavía existen algunos casos muy puntuales donde se constata la desescolarización de algunos niños, especialmente en barrios del extrarradio de las dos mayores ciudades (Valencia y Alicante), así como hijos de familias recién inmigradas que no habían escolarizado a sus hijos previamente, o que no los escolariza al llegar a la localidad, quizás por un planteamiento de que se trata sólo de una situación temporal (es muy frecuente cuando la inmigración responde a una situación de temporerismo agrícola que ahora trataremos).

En algunos barrios de la ciudad de Valencia los Servicios Sociales estiman en un $5 \%$ el número de niños gitanos desescolarizados. Sin embargo, y aunque la cifra es muy alta en comparación con la mayoría de las localidades donde el $100 \%$ están escolarizados, un estudio sociológico realizado en 1985 en la ciudad de Valencia estimaba en un $44 \%$ el número de niños desescolarizados. Aunque ese dato puede ser un poco exagerado, no cabe duda que ha habido un importantísimo cambio cuantitativo, durante la última década, en lo que se refiere a la escolarización.

Otro cambio importante que han podido constatar los colegios en los últimos años ha sido como en los alumnos gitanos se reducía drásticamente el número de niños que tenían una escolarización tardía (por encima de los 6 años). En las entrevistas realizadas, se comprueba que ya es algo casi anecdótico, y que sólo el $7 \%$ de los colegios cuentan con alumnos gitanos que se hayan escolarizado en cursos posteriores a primero. Es significativo que, de esos colegios, varios se concentren en las mismas localidades, lo que de alguna forma dice también mucho sobre el trabajo que desarrollan o no los profesionales de cada ayuntamiento a la hora de trabajar este tema con las familias.

Por el contrario, se aprecia una fuerte tendencia a escolarizar a los niños desde la Educación Infantil, e incluso en muchos de los barrios que cuentan con guarderías municipales se ha visto como este servicio ha pasado a ser masivamente utilizado por las familias de esos barrios. El $80 \%$ de los colegios manifiesta que actualmente todos o la mayoría de los niños gitanos inician su escolaridad en la Educación Infantil. Este hecho permite una mejor adaptación del alumno al sistema escolar, puede comenzar de cero con el resto de los compañeros (tengamos 
en cuenta que la incorporación tardía es una de las principales causas que aducen los colegios para justificar el fracaso escolar allí donde los niños gitanos no cursan Educación Infantil) al tiempo que es una edad en donde las familias (tanto payas como gitanas) mantienen un mayor interés por la marcha del niño en la escuela, y un mayor número de contactos con su profesor o profesora.

Si bien la escolarización temprana es un hecho ya consolidado en muchos colegios y ciudades, lo cierto es que no en todos, tratándose de un proceso todavía en expansión y que en la mayoría de los lugares ha empezado a ser generalizado desde hace unos cinco años, por lo que ninguno de los cursos donde todos los niños gitanos comenzaron a la par con sus compañeros ha llegado ya a los últimos cursos de primaria. Por otra parte, es una queja muy generalizada por parte de los centros escolares el altísimo absentismo escolar que se produce en la Educación Infantil, que en muchas ocasiones convierte la escolarización a esa edad en un puro espejismo. Muchas familias siguen teniendo un excesivo sobreproteccionismo con respecto a sus hijos más pequeños, y, aunque puede ser sólo anecdótico, en varias ocasiones me han comentado algunas familias gitanas que no llevan a sus hijos a Educación Infantil por la negativa de los abuelos, los cuales continúan teniendo un importante peso en las decisiones relativas a la educación de sus nietos.

\section{ABSENTISMO ESCOLAR}

La cuestión del absentismo continúa siendo uno de los temas que más preocupa a la Administración (especialmente a Servicios Sociales) sobre la situación escolar de los niños gitanos. Al tiempo que es la variable que más suelen aducir los centros escolares para justificar el retraso escolar.

En este sentido, la Dirección General de Servicios Sociales de Valencia lleva a cabo un Plan de absentismo escolar gitano desde hace años, por medio del cual financia la contratación de 38 monitores de seguimiento escolar. A esto se suma el Borrador de un Decreto de Ordenación del Plan Local de Absentismo Escolar de la Comunidad Valenciana, que en estos días están estudiando conjuntamente la Consellería de Bienestar social y la Consellería de Cultura, Educación y Ciencia, el cual pretende crear distintas comisiones en cada localidad encargadas de prevenir, detectar y erradicar los distintos casos de absentismo escolar.

Hay que decir que la cuestión del absentismo suele ser abordada casi exclusivamente por los Servicios Sociales, y que algunos cole- 
gios lo expresan así directamente, quizás porque muchas veces han catalogado a los niños gitanos desde un primer momento como "niños de Servicios Sociales".

A pesar de esta preocupación, el absentismo escolar sigue siendo la cuestión que menos parece haber mejorado durante los últimos años en lo relativo a los escolares gitanos.

\subsection{Absentismo severo}

En lo que respecta al absentismo severo, un $27 \%$ de los centros tiene algún alumno gitano que apenas aparece por el colegio, si bien reconocen que este tipo de absentismo ha disminuido bastante en comparación con años anteriores. Es significativo que el absentismo severo sea mucho más pronunciado en aquellas ciudades donde se da una mayor concentración de familias gitanas, y donde la segregación espacial es un hecho que afecta a casi todas ellas. En este sentido me comentaba un monitor de seguimiento escolar: "el absentismo escolar es como la gripe, muy contagioso; si sólo falta un niño se aburre y a los tres días vuelve a aparecer por el colegio; si faltan dos, juegan a las canicas; cuando ya faltan seis, echan partidos de fútbol en la calle, y esa imagen es muy atractiva para el resto de niños que sí van a la escuela". Puede que la explicación del "contagio" influya de alguna manera en que el absentismo casi total se produzca mayoritariamente en ese contexto determinado. Curiosamente, son varios los colegios de esos barrios que comentan que tienen alumnos payos con situaciones de desestructuración familiar con igual tipo de absentismo.

\subsection{Temporeros agrícolas}

El trabajo agrícola es la principal ocupación de muchas de las familias gitanas, especialmente en los pueblos y, en ocasiones, provoca migraciones temporales a otras comarcas o provincias (el Medio Vinalopó para la uva de mesa; Requena-Utiel para la vendimia; la naranja en diferentes puntos de Valencia y Castellón; fruta en Lérida; la aceituna en Jaén; etc.). Si bien no es algo generalizado, y quizás en retroceso en muchas localidades, lo cierto es que sigue habiendo muchas familias que se desplazan durante periodos de tiempo que van de dos semanas a dos meses aproximadamente. De la misma forma, hay muchas localidades que reciben la inmigración de familias gitanas durante los periodos de recolección.

Las familias suelen llevarse a los hijos, muchos de los cuales permanecen más de un mes al año desescolarizados por este motivo, ya que son muchos los que no se escolarizan durante el tiempo que per- 
manecen en la localidad de trabajo. Los Servicios Sociales alegan que es difícil conocer el número de familias que llegan, y los niños que llevan, por lo que el tema les desborda. Por su parte, los colegios de origen, a pesar de conocer la situación año tras año, no suelen ponerse en contacto con la localidad de destino para informarles de que van a llegar esos niños, y se limitan a quejarse del retraso escolar que provocan esas ausencias tan prolongadas.

También es cierto que un número cada vez mayor de niños sí se están escolarizando durante ese tiempo, y que en distintos municipios se están empezando a dar casos de familias que dejan a los niños a cargo de un familiar (normalmente la abuela) para que no pierdan clase por los desplazamientos. A esto ayuda la existencia de comedor escolar y, aunque puede estar influido por las ayudas económicas que algunas familias reciben de Servicios Sociales, lo cierto es que se trata de un indicador de cambio.

\subsection{Absentismo esporádico}

Por otra parte, el absentismo esporádico, el que se da sólo alguna vez a la semana (por quedarse durmiendo un día por la mañana, o porque han venido unos familiares a pasar unos días, o porque tienen a alguien en el hospital, o sencillamente porque hacía mal tiempo), sigue estando muy extendido y se da de forma similar en la mayoría de los colegios, aunque con grandes diferencias dependiendo de cada familia. Más del $80 \%$ de los colegios entrevistados comenta que al menos una parte de sus alumnos gitanos tienen este tipo de absentismo. Aún así, se constata que en muchos de estos centros ha disminuido mucho el número de faltas, muchas de las cuales se concentran en los hijos de determinadas familias más desestructuradas, al tiempo que los hijos de otras familias mejor situadas sólo faltan por causas más o menos justificadas (en este sentido, influye cuál es el concepto que se utilice para considerar qué puede justificar el que los niños no vayan un día al colegio, y parece bastante claro que los criterios escolares y los familiares no acaban de coincidir). A pesar de que el absentismo escolar sea más importante en familias con menos recursos, o más desestructuradas socialmente, en varios pueblos se dan casos de familias con buenos recursos económicos (vendedores de mercado con puestos fijos, e incluso propietarios de tiendas) y muy bien integradas socialmente, cuyos hijos presentan altas tasas de absentismo escolar. La explicación podría estar en que estas familias tienen ya muy claro cuál va a ser el futuro laboral de sus hijos, y consideran que para ese trabajo ya saben bastante, a lo que se suma el que la posible presión que puedan ejercer los Servicios Sociales es mucho menor que en aquellas familias que perciben ayudas económicas. 
Los comedores escolares han supuesto en muchos colegios un importante freno al absentismo de niños gitanos, viéndose disparado dicho absentismo durante los meses de septiembre y junio en que no hay comedor. Con este servicio, los padres pueden ir a trabajar sin la preocupación de tener que llevarse a los niños, o estar en casa al mediodía para prepararles la comida. A pesar de que los colegios reconocen la importancia de este recurso, hay algunos centros (ignoro el número, pero conozco varios casos) que siguen utilizando las expulsiones del comedor como forma de castigo para los niños. Considero que ese tipo de medida en realidad a quien está castigando es a los padres, y así me lo han expresado algunas familias gitanas, a la vez que aumenta aún más la distancia existente entre colegio y familias.

\subsection{Abandono escolar prematuro}

Otra cuestión relacionada con el absentismo es el abandono escolar prematuro. Al igual que comentábamos en el apartado anterior que ha habido un cambio importante en lo relativo a que los niños tienen cada vez una escolarización más temprana, también se ha dado una mayor permanencia escolar en los cursos posteriores, aunque no tanto como en la educación infantil. Lo cierto es que, en términos generales, cada vez se abandona los estudios con mayor edad existiendo un número cada vez más significativo de niños que terminaban la antigua enseñanza obligatoria.

En varios colegios me han hecho referencia al hecho de que, en la medida en que se ha visto mermada la posibilidad de colaborar con los padres en determinados trabajos, antes de cumplir los 16 años (principalmente en trabajos agrícolas), ha ido descendiendo el abandono escolar prematuro. Mientras que otros trabajos, como la recogida de chatarra, en algunos casos la venta ambulante y, desde luego, la ayuda en las tareas del hogar por parte de las niñas, hacen que en muchas ocasiones no se llegue a terminar la escolaridad al tener que colaborar con la familia. El aumento de la escolarización temprana, incluidas las guarderías, ha supuesto paralelamente una mayor libertad para que las hermanas mayores puedan acudir con regularidad al colegio, al quedar liberadas de sus obligaciones de cuidado de los hermanos pequeños en la casa.

El 50\% de los colegios entrevistados manifiestan que la mayoría de sus alumnos gitanos abandonaban el colegio antes de los 14 años. A esto hay añadir la nueva situación creada con la implantación de la E.S.O., de la cual hablaremos después.

Los resultados académicos de los niños gitanos continúan siendo, en términos generales, más bajos que los de sus compañeros, acumu- 
lando muchos de ellos un importante desfase entre sus conocimientos y el curso en el que están. Así, en muchos colegios, las Ilamadas "clases de apoyo" se ven ocupadas mayoritariamente por niños gitanos. Por ejemplo: en un colegio de la provincia de Alicante, donde sólo hay una decena de alumnos gitanos, el maestro "de apoyo" me comentaba que en su clase únicamente estaban los niños gitanos y los niños con sindrome de Down, y que cuando enviaba a alguno de los niños gitanos a su clase, el profesor no tardaba más de 10 minutos en devolverlo a la clase "de apoyo". En cualquier caso, existen grandes diferencias dependiendo de distintos colegios, profesores, familias y niños. Así, hay un número minoritario, pero significativo, de colegios donde los niños gitanos van en general al mismo nivel que sus compañeros. Estos centros suelen coincidir con aquellos donde el porcentaje de niños gitanos es menor, aunque no en todos los casos son colegios con pocos escolares gitanos, ni en todos lo colegios donde hay pocos niños gitanos se da esa circunstancia (en algunos, todo lo contrario).

Las causas que resaltan mayoritariamente los centros escolares para explicar el alto fracaso escolar de los niños gitanos son: el absentismo escolar y la falta de interés por parte de las familias en lo referente al colegio. Sólo en dos colegios plantearon la posibilidad de que el sistema escolar tuviese también alguna responsabilidad en esa situación. Sin embargo, al hablar con las familias gitanas, éstas no parecen vivir de la misma forma el fracaso escolar, el cual puede entenderse como un concepto payo, dado que los objetivos que un importante número de las familias tienen cuando escolarizan a sus hijos quedan sobradamente cubiertos cuando abandonan el colegio.

\section{TIPOS DE COLEGIOS}

La cuestión de la doble vía escolar, colegios públicos y colegios privados, también afecta de forma significativa a la escolarización de los niños gitanos, sirviendo, en un gran número de localidades, como filtro utilizado por familias de niños payos para que sus hijos no coincidan en un mismo colegio con "los gitanos".

En lo que respecta a los colegios privados no concertados, la ausencia de niños gitanos es total, como nos dejaba bien claro la directora de uno de estos centros: al establecer el primer contacto telefónico con los colegios de la ciudad de Valencia para conocer en qué colegios habia escolares gitanos, la directora del centro respondió de malos modos " ¿es que usted no sabe dónde ha llamado? jesto es un colegio privado!, jaqui no vienen gitanos!. 
Por su parte, los colegios privados-concertados apenas cuentan con población gitana; en un altísimo porcentaje de localidades no hay ningún niño gitano en los colegios concertados. En otras, encontramos colegios con un número muy pequeño de escolares gitanos, normalmente de familias con ciertos recursos económicos que están muy sensibilizadas por el futuro escolar de sus hijos y piensan (como muchos padres payos que llevan a sus hijos a esos centros) que allí van a recibir una enseñanza de más "calidad". Existiendo también algunos casos de colegios concertados, reconozco que pocos, que sólo escolarizan a algunos niños gitanos cuando tienen problemas en algún curso para poder cubrir el mínimo de alumnos por aula. Como en todo hay excepciones, y al menos cuatro colegios concertados tienen un alto porcentaje de alumnos gitanos, lo que les ha supuesto renunciar a la mayor parte de alumnos de clases medias y altas que alguno de ellos tuvo en otro tiempo. Estos colegios tienen claro que la asistencia de niños gitanos es una mala publicidad para el centro: al recoger la información en unas de las localidades preguntamos en uno de los colegios concertados y nos dijo que no tenían ningún alumno gitano. Pero más tarde, al hablar con una de las familias gitanas nos enteramos de que sí había un alumno gitano, por lo que volvimos a ir al colegio. La directora, con mucha discreción, nos dijo que no podía hacernos la entrevista, porque nadie en el colegio sabía que iba un niño gitano y no quería que se enterasen. En cualquier caso, el hecho de que los cursos de Educación Infantil no estén concertados, y haya, por tanto, que pagar importantes mensualidades, sumado a las normalmente altas cuotas de APAS y gastos de uniforme, está sirviendo de criba para que los gitanos no accedan de forma mayoritaria a este tipo de centros, incluso en algunos casos donde, por las políticas de vivienda, la población gitana reside actualmente junto al colegio concertado.

Algo parecido, aunque de distinta forma, está sucediendo con los colegios de línea en valenciano. Estos centros son poco elegidos por las familias gitanas, las cuales no suelen hablar en valenciano, y en algunas localidades se concentran en estos colegios los hijos de familias (no gitanas) más preocupadas por los resultados escolares de sus hijos. En varios colegios donde existe línea en valenciano y línea en castellano, nos comentaban los directores, que la diferencia de resultados escolares entre ambas era grandísima, y que en la línea en castellano era donde se matriculaban todos los gitanos, así como los hijos de las familias payas más desestructuradas.

Es en los colegios públicos donde se concentra la inmensa mayoría de alumnos gitanos, especialmente en aquellos situados más cerca de los barrios de residencia de sus familias. Ya comentábamos antes el fuerte proceso de ghettización que se ha dado en muchos de estos cen- 
tros, algunos de los cuales han pasado de contar con un $40 \%$ de alumnos gitanos a tener un 90\%, en apenas 10 años. Este hecho, muy generalizado en los barrios más desestructurados, ha llevado en algunas ciudades al cierre del centro escolar al quedarse con un bajísimo número de niños matriculados. Pero los niños han pasado al colegio más próximo (en muchas ocasiones con ya un importante porcentaje de escolares gitanos), el cual ha visto mermado el número de matrículas de niños payos de forma inmediata. Existen algunos casos donde se han cerrado en un corto plazo de tiempo dos colegios de forma consecutiva.

Al igual que comentábamos en el caso de los colegios concertados, los colegios públicos también conocen la mala publicidad que les aporta el tener alumnos gitanos. Es sorprendente ver como se repite en un gran número de localidades el que haya un colegio catalogado por todo el mundo como "el colegio de los gitanos". Muchos de estos directores reconocen que muchos padres payos optan por otros colegios para que sus hijos no vayan con "los gitanos" e incluso algunos trasladan a sus hijos a otros centros. Lo curioso es que en algunos de estos colegios tan "etiquetados" sólo hay un 5\% de escolares gitanos.

Existen entre muchos colegios unas fuertes tensiones a causa del número de alumnos gitanos. En unas ocasiones por parte de la dirección del centro, que se queja que un colegio cercano no quiere tener comedor, o que apenas tiene becas de comedor, para no tener niños gitanos y que a causa de eso ellos tienen que cargar con un alto número de éstos. Y, en otras, por la presión de la asociación de padres de algunos colegios que han solicitado enérgicamente a la dirección del centro y al ayuntamiento que se ponga numeros clausus a la matrícula de niños gitanos, para que se repartan de forma equitativa por todos los colegios.

\section{PREJUICIOS Y ESTEREOTIPOS: EN LAS ANTÍPODAS DE LA INTERCULTURALIDAD}

A pesar de que en algunas ocasiones he podido leer artículos que apuntaban al País Valenciano como "vanguardia" de la interculturalidad escolar, especialmente a partir de la publicación de diversos materiales en este sentido y de la creación de la figura del asesor de educación intercultural, la dura realidad demuestra que no sólo existe una sequía casi total en este aspecto (con una o dos excepciones escolares muy concretas, y la buena voluntad a nivel individual de algunos maestros y maestras), sino que nos seguimos encontrando en las antípodas del interculturalismo. En las entrevistas realizadas, donde a priori los dis- 
tintos directores y profesores tenían una gran cautela para no emitir determinadas opiniones que pudiesen ser catalogadas de prejuiciosas o racistas, han sido innumerables las anécdotas donde lo que se reflejaba era exactamente lo contrario.

Como hemos comentado anteriormente, los niños gitanos siguen siendo vistos en un gran número de colegios como una amenaza para su reputación, y la imagen que se tiene sobre ellos y sus familias está muy marcada por los prejuicios y los estereotipos. Abundan las frases del tipo: "en general los gitanos van muy retrasados, pero hay uno que va muy bien, no parece gitano"; "algunos valen para estudiar, aunque como buenos gitanos son muy gandules"; "los padres se dedican a vender muebles viejos y fruta que robarán por ahî"; "...no sé en qué trabajan los padres, no quiero generalizar, pero los gitanos son todos unos gandules"; etc. En este sentido, es curioso que en las entrevistas abunden de forma redundante las declaraciones de directores que ante la pregunta de: ¿qué tipo de profesiones suelen desarrollar los padres de los alumnos gitanos?, den como primera contestación, y en ocasiones como única contestación, "en la venta de droga", o el que respondan "en trabajos marginales como la venta ambulante".

Las etiquetas con las que muchos colegios catalogan lo que entienden por un alumno gitano lleva en ocasiones a situaciones extremas: en un colegio de la provincia de Alicante pude conversar con varias profesoras mientras esperaba a que llegase el director. Estas no se ponían de acuerdo sobre si los niños de un par de familias determinadas eran gitanos o no. Al llegar el director me aclaró que no eran gitanos, sino unas familias inmigradas de la provincia de Jaén. Unos minutos después, mientras consultaba la lista de alumnos para ver el número de gitanos que había en el centro me dijo que a los de Jaén también los incluía, "porque esos son como los gitanos". Algo parecido, pero a la inversa, me sucedía en otro colegio: el director me comentó al comenzar la entrevista que sólo tenía 4 alumnos gitanos, pero al rato recordó que en realidad eran 6, diciendo: "se me habian olvidado los otros dos porque esos niños están muy bien integrados", pero hasta el final de la entrevista siguió hablando de lo mal que se integraban los gitanos, obviando en todo momento a los dos que estaban tan bien integrados". Es algo así como si para algunos directores y profesores la imagen de lo que es un gitano estuviese perfectamente moldeada, y lo que cuadra con ese molde es un gitano (lo sea o no lo sea) y lo que no encaja no lo es.

$\mathrm{Al}$ mismo tiempo, el desconocimiento sobre la cultura del Pueblo Gitano es muy generalizado, tanto entre los profesionales de la enseñanza como entre otros profesionales que trabajan a menudo con gitanos, como son los/as trabajadores/as sociales. Así, encontramos algu- 
nas afirmaciones de directores según los cuales: "las niñas gitanas no pueden seguir estudiando a partir de los 12 años porque lo prohibe la ley gitana". O trabajadores/as sociales que te dicen "en este pueblo antes estaba la figura del rey de los gitanos, pero ahora ya se ha perdido".

\section{LA IMPLANTACIÓN DE LA E.S.O.}

Uno de los nuevos aspectos que ha empezado a afectar a los escolares de nuestro país es la implantación de la Enseñanza Secundaria Obligatoria. Cuando se realizaron las entrevistas de este estudio apenas se había comenzado a impartir el primer curso de la ESO, por lo que la repercusión de esta nueva situación no podía todavía conocerse. En el País Valenciano, la inmensa mayoría de los colegios públicos han asumido, al menos en principio, el primer ciclo de la ESO, por lo que no ha supuesto grandes cambios en los colegios al no tener que desplazarse a otros centros. Sin embargo, el curso 98/99 que ahora comienza, va a ser el primer año para el segundo ciclo de la ESO $\left(3^{\circ}\right.$ de ESO) y va a suponer el paso de un importante número de escolares gitanos de sus antiguos colegios de EGB (ahora de primaria) a los Institutos de Enseñanza Secundaria (IES). Este es un momento histórico de transición, donde se abren nuevas expectativas de futuro para aumentar la formación de los jóvenes gitanos, pero donde también surgen nuevos peligros, por ejemplo, que al acabar $2^{\circ}$ de ESO no continúen en el IES o, lo que sería peor, que cuando los dos ciclos de ESO estén en el IES muchos escolares gitanos finalicen su escolarización en $6^{\circ}$ de Primaria. En dos de los colegios donde se había puesto en práctica la incorporación de los alumnos al IES desde $1^{\circ}$ de ESO, los directores del colegio de primaria me comentaban que los niños gitanos no habían continuado, ni siquiera aquellos que iban muy bien en sus cursos y que según sus profesores de haber continuado con el anterior sistema habrían finalizado hasta $8^{\circ}$ sin ningún problema.

Existen diferentes factores que pueden hacer peligrar lo que en principio se puede considerar una excelente medida, como es el aumentar el tiempo de formación de los alumnos gitanos:

1. Los colegios de primaria suelen estar muy cerca de los barrios de residencia de los niños gitanos, facilita el acceso y la confianza de los padres hacia la escuela. Mientras que muchos de los IES están situados a más de $1 \mathrm{~km}$. de sus casas, en ocasiones en la periferia del municipio opuesta a donde se sitúan las viviendas sociales, etc.

2. El horario en los IES es diferente, y no incluye comedor escolar, lo que puede complicar a muchas familias su situación al mediodía. 
3. Muchos padres gitanos desconfían abiertamente de unos centros que desconocen por completo, pero que perciben como un riesgo para sus hijos, y especialmente para sus hijas (van chicos más mayores, miedo a las malas compañías, al tabaco u otras drogas, etc.).

4. Hasta ahora, una parte del éxito obtenido en la escolarización temprana de niños gitanos se ha basado en la responsabilidad delegada por los padres a los hermanos mayores para que los acompañen y los vigilen en los recreos. Si los hermanos cambian de colegio a los 12 años, algunos niños pequeños pueden aumentar su absentismo, o bien que los mayores no sigan en el IES por tener que acompañar a sus hermanos al colegio. En este sentido, en un colegio de primaria que cuenta con el primer ciclo de la ESO me comentaban que una niña gitana había estado faltando a clase por la mañana porque ella salía a las 13 horas, y sus hermanos pequeños a las 12, por lo que si iba a clase no podía acompañarlos a casa.

5. Los profesores de los IES (y es hacer una generalización un tanto arriesgada) no parecen ser muy conscientes, por el momento, del cambio de alumnado que van a tener, y puede que el cambio en la forma en que reciben la enseñanza los niños, posiblemente menos cercana e individualizada, haga que muchos de ellos abandonen el IES de forma prematura.

Existe un gran escepticismo en los centros de primaria sobre la repercusión que va a tener la implantación del segundo ciclo de la ESO. Muchos de ellos se limitan a afirmar que no va a cambiar nada "porque de todas formas van a dejar el colegio cuando ellos quieran", mientras que otros muchos consideran que va a suponer un retroceso en el camino recorrido hasta ahora, especialmente si se imparte el primer ciclo de la ESO directamente en los IES. Los únicos centros que consideran que la implantación de la ESO va a ser muy positiva son aquellos donde sus alumnos gitanos terminaban desde hace ya varios cursos hasta $8^{\circ}$, y sus resultados académicos son similares a los de sus compañeros no gitanos. También lo consideran como positivo aquellos centros que cuentan con el $2^{\circ}$ ciclo de la ESO en el mismo centro (especialmente concertados) ya que el no tener que cambiar de centro aumenta las posibilidades de que los niños terminen toda la escolarización obligatoria.

Comentando esta situación con varios inspectores escolares, se mostraban también muy preocupados por el futuro de la implantación del $2^{\circ}$ ciclo de ESO, especialmente por el choque que supone el cambio de centro. Estos inspectores me sugirieron que sería interesante que en determinados centros con alto número de escolares gitanos se pudiese impartir toda la ESO, tal y como se está dando en la inmensa mayoría de colegios concertados, lo cual quizás garantizase el que un 
mayor número de niños y niñas gitanos terminasen hasta los 16 años, al tiempo que podría ser un aliciente para que algunos padres payos no cambiasen a sus hijos de colegio por el mero hecho de que van gitanos.

\section{LA ENSEÑANZA NO OBLIGATORIA}

En términos generales, tanto la enseñanza secundaria no obligatoria (bachiller y FP) como la universitaria siguen desiertas de alumnos gitanos. Apenas se encuentran 1 ó 2 jóvenes en cada una de las ciudades medias que continúen sus estudios más allá de lo que fue la EGB, mayoritariamente en FP, y con unas altas tasas de abandono en los primeros cursos. En este aspecto, la presión social del resto de familias gitanas sobre aquellos jóvenes que continúan estudiando suele ser muy fuerte. Una mujer gitana cuyo hijo cursaba $5^{\circ}$ de FP administrativo en el curso 96/97 me decía : "mis primos me dicen que si no le da lache a mi hijo, tan mayor y en la escuela, en vez de estar ayudando a sus padres en el mercado. Pero yo le animo mucho para que siga". De la misma forma, el resto de compañeros payos, muchas veces no acostumbrados a compartir colegio con ningún gitano supone también una presión sobre estos alumnos, que se encuentran en ese sentido bastante solos: un gitano que realiza estudios de FP de electricidad me comentaba que, cuando llegó por primera vez al instituto todo el mundo se le quedaba mirando y se volvian por los pasillos, escuchando comentarios del tipo "mira ese es gitano". Así, se dan casos de algunos gitanos universitarios que prefieren mantener totalmente en secreto su identidad gitana ante el miedo de ser discriminados por sus compañeros: conozco el caso de una chica que estudia magisterio en la Universidad de Alicante, la cual tiene la piel muy oscura, y para que no la discriminen por ser gitana le dice a todo el mundo que es sudamericana.

Otro importante factor que parece influir en la menor motivación por parte de las familias y los alumnos a la hora de seguir estudiando es el hecho de que de los ejemplos que conocen de gitanos que han continuado con sus estudios muchos terminan finalmente trabajando en lo mismo que sus primos que no estudiaron. Son muchos los colegios que nos dicen que no existe ninguna diferencia laboral entre los niños que abandonaron el colegio a los 12 años, que los que terminaron su escolarización con graduado escolar, o algún curso de Bachiller. Algunos profesores me comentan, con respecto a la evolución en la escolarización de los niños gitanos, que cada vez salen más preparados y muchos con el graduado, pero que acaban en la misma situación 
económica que ya tenían sus padres. Los estudios no garantizan de por sí ningún futuro y, en muchos casos, el cambio estriba en la consecución de una pobreza más ilustrada.

También puede influir la existencia de una fuerte tendencia a trabajar en lo mismo que ya trabajan los padres, como si estuviese predeterminado su futuro, por lo que el planteamiento de continuar con otros estudios puede estar fuera de ese plan de vida en muchos casos casi inevitable.

A todo esto se suma el miedo al "apayamiento" que muchas familias gitanas siguen teniendo, y la presión que sufren los jóvenes que continúan estudiando para demostrar que, a pesar de eso, siguen siendo gitanos. El director de un colegio nos contaba que mantuvo una entrevista con un padre gitano para tratar de convencerlo de que permitiese que su hijo siguiese estudiando en secundaria, a lo que el padre contestó que su hijo no podía estudiar porque ellos eran personas normales. Ante esta afirmación el director le preguntó que qué entendía por ser personas normales, contestándole el padre: "pues hacer lo que hacen todos".

Al hilo de las declaraciones de este padre, sobre la influencia de lo que hacen "todos", me parece muy interesante resaltar la existencia de al menos 3 localidades (las 3 con menos de un centenar de vecinos gitanos), donde las familias gitanas han asumido la necesidad de que los jóvenes continúen estudiando más allá de los estudios primarios, existiendo en cada localidad un alto porcentaje (en comparación con la situación general del País Valenciano) de chicos y chicas que cursan estudios de FP y Bachiller, así como un par de casos de universitarios. Otro tanto pasa en determinados linajes que se extienden por distintos pueblos, muchas de las veces con origen en la provincia de Granada, donde en distintas localidades he podido comprobar que alguna de las personas que está estudiando se encuentra emparentada con otro estudiante de otro pueblo. En este sentido, es también significativo el caso de Castellón ciudad.

A pesar de todas las dificultades existentes, el número de estudiantes gitanos que continúan con sus estudios ha aumentado mucho, si bien no al ritmo que muchos hubiéramos deseado. En el País Valenciano hay actualmente alrededor de 150 jóvenes cursando enseñanza secundaria no obligatoria, y al menos una veintena en la Universidad.

Para terminar este tema, considero que es necesario y urgente la creación de un mayor número de programas que:

1. Fomenten el conocimiento entre estudiantes gitanos que cursan enseñanzas no obligatorias (FP, Bachiller y Universidad) para evitar la soledad y el desaliento que muchos de ellos sufren. 
2. Subvencionen suficientemente esos estudios, para que nadie deje de estudiar por problemas económicos, cosa que en algunos casos está sucediendo.

3. Sirvan para dar a conocer al resto de familias gitanas la existencia en múltiples ciudades de jóvenes gitanos que estudian, propiciando así un ambiente de "normalidad" de los estudios medios y universitarios.

4. Propicien una rápida incorporación laboral tras la finalización de esos estudios, con el fin de que puedan servir como referentes positivos, exactamente lo contrario que sucede cuando el paro y los trabajos no cualificados son el resultado final de esos estudios.

\section{BIBLIOGRAFÍA}

ABAJO ALCALDE, J. E.: La escolarización de los niños gitanos. Ministerio de Trabajo y Asuntos Sociales. Madrid, 1997.

FERNÁNDEZ ENGUITA, M.: Escuela y etnicidad: el caso del Pueblo Gitano. CIDE-MEC. Madrid, 1996.

FERNÁNDEZ JIMÉNEZ, D. L.: Situación y perspectivas de la juventud gitana en Europa. Instituto Romanó. Barcelona, 1996.

GAMELLA, J. F.: La población gitana en Andalucía. Junta de Andalucía. Sevilla, 1996.

GÓMEZ ALFARO, A.: La gran redada de gitanos. Presencia Gitana. Madrid, 1993.

LEBLOND, B.: Los gitanos de España. Gedisa. Barcelona, 1987.

LIÉGEOIS, J.-P.: Gitanos e itinerantes. Presencia Gitana. Madrid, 1987.

SAN ROMÁN ESPINOSA, T.: Vecinos gitanos. Akal. Madrid 1976.

SAN ROMÁN ESPINOSA, T.: La diferència inquietant: velles $i$ noves estratègies culturals dels gitanos. Alta Fulla. Barcelona, 1994.

VV.AA.: I Congreso Gitano de la Unión Europea. Instituto Romanó de Servicios Sociales y Culturales. Barcelona, 1996.

VV.AA. del Colectivo de Enseñantes con Gitanos de Valencia : Cultura Gitana: propuestas para un trabajo intercultural en la escuela. Conselleria de Cultura, Educación y Ciencia. Valencia, 1989.

VV.AA.: La comunidad gitana en Galicia. Xunta de Galicia. Santiago de Compostela, 1991.

VV.AA.: Los gitanos en la historia y la cultura: actas de un congreso. Junta de Andalucía. Granada, 1995. 


\title{
LOS GRUPOS DE AUTOAYUDA COMO ESTRATEGIA DE INTERVENCIÓN EN EL APOYO SOCIAL
}

\author{
YOLANDA DOMENECH LÓPEZ
}

Profesora titular de Trabajo Social. E.U.T.S. Universidad de Alicante.

\section{RESUMEN}

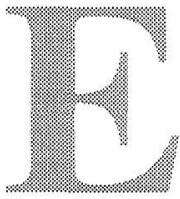

1 presente artículo pretende explicar qué son los grupos de autoayuda y cómo podemos, desde el trabajo social, crear y ayudar a que estos grupos se desarrollen.

En primer lugar, se analizan algunos aspectos teóricos del Apoyo social como teoría clave en los grupos de autoayuda (es decir, en un primer momento se trata de decir qué justifica la creación de grupos de autoayuda, entendidos estos como una de las estrategias fundamentales para conseguir apoyo). En segundo lugar, centrándonos en la falta de apoyo y en la necesidad de estructurar la red social de algunas personas, se explican los fundamentos teóricoprácticos de los grupos de autoayuda, como una forma especial de dar apoyo: darlo en grupo y con el grupo.

\section{PALABRAS CLAVE}

Apoyo social, grupos de autoayuda, red social

\section{CONSIDERACIONES PREVIAS: ASPECTOS TEÓRICOS DEL APOYO SOCIAL.}

El concepto de apoyo social surge alrededor de los años setenta cuando los resultados de diversas investigaciones acerca de problemáticas sociales comienzan a demostrar que la falta de apoyo es un elemento común a todas ellas. Esta falta de apoyo se hace evidente en la carencia de interacciones o en la ruptura de relaciones (como más tarde se ha venido llamando en la ausencia o ruptura de redes sociales).

No obstante, aunque en la práctica se operativiza, no es fácil definir qué es el apoyo social, ya que son numerosas las actividades que se incluyen bajo este término. Normalmente, se utiliza el concepto de red 
social para referirse a él, aunque, como se explica a continuación, son aspectos diferenciados ya que la red social podría definirse como la «socioestructura» donde tienen lugar las transacciones de apoyo.

Tres son las líneas que definen el apoyo social, haciendo hincapié en un aspecto u otro según nos situemos. A modo de síntesis, destacar algunas de las características de cada línea y explicar cómo, a través del grupo, puede operativizarse el apoyo social que, desde cada perspectiva, se plantea.

\subsection{Perspectivas del apoyo social}

1. La perspectiva estructural enfatiza la importancia de las características de las redes sociales y de las condiciones objetivas que rodean el proceso de ayuda. El interés se centra en los elementos más identificables y objetivos de la red de relaciones de una persona (Gracia, 1997:23). Desde esta perspectiva se define el apoyo social en términos del número de relaciones que mantiene el sujeto, la interconexión de las personas con las que se relaciona, el equilibrio o desequilibrio de sus intercambios y la semejanza o congruencia entre los miembros de la red.

La creación de grupos de autoayuda tiene sentido en el momento que se detecta que una persona a penas posee red social, no existe homogeneidad (por ejemplo, una joven madre soltera donde toda su red son personas de mayor edad), o los intercambios no se dan de forma recíproca, pudiendo aparecer conductas sobreprotectoras, excesivo control, abandonos, etc. Estos grupos ayudan a crear y/o ampliar una parte de red social que proporcione el apoyo necesario a las personas que forman parte del grupo.

2. La perspectiva funcional se centra en las funciones que cumplen las relaciones sociales. Desde esta perspectiva, Caplan (1974) define el apoyo social como guía y feedback proporcionado por otras personas que permite al sujeto manejar emocionalmente un evento estresante. Existe un acuerdo entre los investigadores en distinguir tres funciones fundamentales en el apoyo social, funciones que se dan en los grupos de autoayuda:

a) Función de apoyo emocional, a través de la cual las personas comparten experiencias y se sienten aceptadas por los demás.

b) Función de apoyo instrumental o material donde se intercambian ayudas que sirvan para resolver problemas prácticos y cotidia-

I En definitiva, el apoyo social se centra en el estudio de los cuatro elementos más importantes de la red y su relación con el sujeto. Estos son el tamaño, la densidad, la reciprocidad y la homogeneidad de la red. 
nos. En los grupos de autoayuda esta función suele darse en las fases avanzadas del grupo, ya que en las primeras fases las personas suelen ser reacias a pedir este tipo de ayuda. Además, suele darse fuera del contexto grupal.

c) Función de apoyo informacional, donde a través del proceso grupal las personas reciben información y guía.

Por tanto, desde la perspectiva funcional, el apoyo social se define como las transacciones en las que se intercambian recursos que permiten cumplir alguna de estas tres funciones (Barrón, 1996:17). A través de los grupos de autoayuda se ofrecen e intercambian diversos recursos, que permiten cumplir estas tres funciones.

3. La perspectiva contextual, enfatiza las características contextuales del apoyo social. Desde aquí, se debe adecuar el tipo de apoyo al tipo de problema en el que se trabaja. A veces, la propia familia no puede dar apoyo en una situación determinada y debemos recurrir a otras fuentes de apoyo como pueden ser los amigos o los grupos. Esta línea, la contextual, también considera importante la duración del apoyo en cada situación. Los grupos de ayuda, por ejemplo, ofrecen apoyo a largo plazo para aquellas personas que padecen situaciones crónicas.

Estas tres perspectivas ayudan a definir el concepto de apoyo social resaltando diferentes aspectos según nos situemos en una o otra. No obstante, el apoyo social puede operativizarse de múltiples formas, tal y como se señala en el cuadro $n^{\circ} 1$ que se presenta. Las intervenciones basadas en el apoyo social, independientemente de la estrategia que se adopte (en nuestro caso el grupo de autoayuda), implican la interacción

\section{CUADRO N. ${ }^{\circ} 1$}

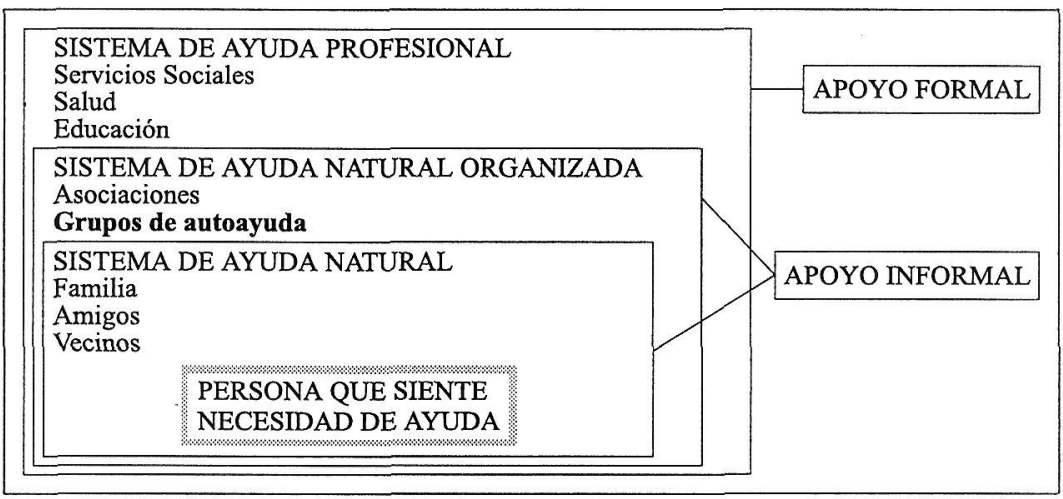

FUENTE: Adaptación de Villalba Quesada, C.: «Redes sociales: Un concepto con importantes implicaciones en la intervención comunitaria». Intervención Psicosocial, 4. 1993. Pág. 69-85. 
directa con el entorno social de la persona y sus efectos positivos son resultado de los recursos que se intercambian durante esa interacción (Gracia, 1997:39-40).

\section{APLICACIONES PRÁCTICAS: LOS GRUPOS DE AUTOAYUDA COMO ESTRATEGIA DE INTERVENCIÓN.}

Los grupos de autoayuda surgen como alternativa al sistema tradicional donde la dirección y la responsabilidad corre a cargo de un profesional. Este movimiento, el de la autoayuda, creció y se desarrolló de forma paralela al desarrollo de la profesión, a partir de los años 30 , con la creación de Alcohólicos Anónimos.

Tal y como veíamos en la primera parte, estos grupos suponen para el Trabajo Social una estrategia de intervención centrada en el apoyo social. Teniendo como objetivo consolidar, ampliar y complementar la red social del individuo que atraviesa alguna dificultad y/o problema no pudiendo recibir apoyo o no siendo adecuado el apoyo que recibe de otros sistemas de su red social. Estos grupos han surgido en campos tan diversos como la enfermedad mental y física, las adicciones, las crisis vitales, y diversas problemáticas sociales.

No obstante, abogar en defensa de la creación y el trabajo a través de estos grupos no supone olvidar todo el trabajo complementario que debemos hacer si queremos trabajar desde un enfoque que englobe al individuo y al conjunto de sus sistemas.

\subsection{Concepto}

Entre las numerosas definiciones que se han propuesto, destacamos a continuación la definición propuesta por Katz y Bender (1976), definición que ha adoptado la Organización Mundial de la Salud. Esta dice así: «los grupos de autoayuda son grupos pequeños y voluntarios estructurados para la ayuda mutua y la consecución de un propósito específico. Estos grupos están integrados habitualmente por iguales que se reúnen para ayudarse mutuamente en la satisfacción de una necesidad común, para superar un handicap común o problemas que trastornan la vida cotidiana, y conseguir cambios sociales y/o personales deseados. Los iniciadores y miembros de estos grupos perciben que sus necesidades no son o no pueden ser satisfechas por las instituciones sociales existentes. Los grupos de ayuda mutua enfatizan la interacción social cara a cara y la responsabilidad personal de sus miembros. Con frecuencia, proporcionan ayuda material así como apoyo emocional; están orientados a la causa del problema y promueven una 
ideología o conjunto de valores a través de los cuales los miembros del grupo pueden obtener e incrementar un sentimiento de identidad personal».

\subsection{Características}

Son numerosos los autores que identifican las características de los grupos de autoayuda (Killilea, 1976; Richardson,1983; Rogers, 1987; Orford,1992 ...). Siguiendo a Gracia (1997), destacamos, como características más relevantes de los grupos de autoayuda, las siguientes:

\subsubsection{Los miembros del grupo intercambian experiencias comunes}

El hecho de compartir un problema central define el estatus de miembro en los grupos de autoayuda, a pesar de las numerosas diferencias individuales. En este sentido, Silverman (1970) también considera que entre las principales características de los grupos de autoayuda se encuentra el hecho de que quien provee ayuda comparte el mismo problema con quien recibe esa ayuda. Para este autor, la experiencia común es el concepto fundamental que distingue la experiencia de la autoayuda de otros intercambios de ayuda.

Además, en estos grupos, la ayuda mutua no sólo surge de la experiencia común de un mismo problema sino de los sentimientos similares acerca de ese problema. Y de las experiencias comunes de resolución de conflictos aparecidos como consecuencia del malestar generado.

\subsubsection{El grupo proporciona apoyo emocional.}

Por apoyo emocional se entiende el hecho de saber acompañar y entender a otro miembro del grupo que padece un problema. El apoyo emocional que se transmite puede ayudar a la persona bien a ajustarse a la situación o bien a cambiar esa situación (Richardson,1883). Este apoyo se da durante las reuniones del grupo, pero a veces también puede darse fuera del grupo.

En el contexto de los grupos de autoayuda el apoyo emocional puede adoptar diversas formas. Entre otras conductas, los miembros del grupo proveen apoyo emocional cuando (Katz, $1983 \mathrm{cit}$. Gracia, 1997:65):

- Se manifiestan en el grupo los refuerzos positivos. En este sentido, el grupo aplaude o recompensa las conductas deseables.

- Cuando se comparten las experiencias, pensamientos y sentimien- 
tos cotidianos con otros miembros del grupo.

- Cuando se ofrece feed-back.

- Cuando los miembros del grupo se refuerzan mutuamente acerca de su capacidad para manejar sus problemas.

- Y cuando se justifican los sentimientos o acciones en respuesta a situaciones determinadas.

En el grupo, los miembros se refuerzan mutuamente acerca de su valía personal. Esto se manifiesta en la comprensión y aceptación de todos los miembros del grupo. Cuando un miembro del grupo describe sus acciones o emociones como raras o anormales, los otros miembros tratan de hacer ver que esa conducta es normal.

\subsubsection{Se intercambia información, consejo y educación}

En los grupos se da y se proporciona la información necesaria que ayuda a las personas a mejorar su capacidad de afrontamiento. Los grupos de autoayuda proporcionan esta información bien de forma directa entre los miembros del grupo, bien de forma indirecta indicándose dónde se puede acudir a recibir dicha información.

Una ventaja de estos grupos, respecto a la transmisión de información, es la composición del grupo. Al estar formados por personas en distintas fases del manejo de su problema, los miembros nuevos pueden beneficiarse y obtener información de otros miembros que han superado ya los primeros pasos.

También se puede recibir información invitando al grupo a técnicos o expertos sobre alguna cuestión que interese a los miembros del grupo, de modo que participen en algunas reuniones y aporten la información que el grupo necesite.

\subsubsection{En el grupo se favorece la reestructuración cognitiva.}

Por un lado, el grupo proporciona a sus miembros una razón y una lógica a sus problemas o fuentes de estrés, así como una forma para manejar esos problemas. En este sentido, en el grupo se amplía el rango de percepciones alternativas de los problemas y de las acciones disponibles para manejarlos.

Por otro lado, el grupo apoya el cambio. De esta forma, al considerar los problemas desde una perspectiva distinta, y al adoptar formas nuevas y más efectivas de afrontamiento, la persona comienza a percibirse como un individuo capaz de manejar las circunstancias que le rodean, incrementándose, así, los sentimientos de valía personal. 


\subsubsection{El grupo cumple funciones de socialización}

Aunque, no es su principal objetivo, numerosos grupos de autoayuda consideran la socialización de sus miembros como un aspecto importante. Como nos señala Katz (1993), la función de los grupos de autoayuda para ayudar a sus miembros a superar los sentimientos de aislamiento social es particularmente importante. La integración en un grupo, con las actividades que se llevan a cabo a través de él, puede ayudar a las personas que atraviesan situaciones problema, que les hayan llevado a estar solas, a participar en su comunidad.

\subsubsection{Las acciones se realizan conjuntamente}

La implicación personal en las actividades colectivas del grupo es una de las características más importantes de los grupos de autoayuda. En estos grupos se espera que cada miembro participe, según sus posibilidades, y no sea mero receptor tal y como ocurre en otros grupos.

\subsubsection{El grupo promueve sentimientos de control, autoconfianza y autoestima.}

Las distintas actividades que tienen lugar en los grupos de autoayuda ayudan a superar la pasividad y a mejorar la autoestima, así como a promover la responsabilidad personal.

Tal y como veíamos antes, la adquisición de información, el cambio en las percepciones, la utilización de la propia experiencia para ayudar a los miembros del grupo y las demás características que hemos nombrado ayudan a los miembros del grupo a reforzar la imagen que poseen de ellos mismos.

Como señalan diversos autores (Cameron 1992), los grupos de autoayuda al permitir no sólo la recepción de ayuda sino también su provisión, al promover la participación conjunta de sus miembros en el proceso de ayuda y al incrementar la red natural de apoyo de sus miembros son capaces de incrementar los sentimientos de control de sus miembros sobre su propia vida y de estimular el desarrollo de su autoestima.

\subsection{Tipos de grupos de autoayuda}

El desarrollo de un sistema de clasificación donde se describan los diferentes grupos de autoayuda es tarea imposible. La gran diversidad de grupos de autoayuda, así como la constante proliferación de grupos nuevos, hace que sea imposible poder ofrecer una clasificación. En 
España y más concretamente desde el Trabajo Social, aparecen tantos grupos como diversidad de problemas se traten, como objetivos se planteen o según las diferentes «formas» de entender estos grupos.

La mayoría de grupos que se potencian desde el Trabajo Social comienzan siendo grupos de apoyo donde la dirección corre a cuenta de un profesional para pasar, en un segundo momento y cuando el grupo esté preparado, a funcionar sin la dirección de ningún profesional, esto es, a regirse y funcionar como grupos de autoayuda.

No obstante, en el cuadro $\mathrm{n}^{\circ} 2$ se ofrecen algunas de las clasificaciones que sobre el tema se han propuesto, haciendo hincapié en cuatro de los criterios que consideramos importantes.

CUADRO N. ${ }^{\circ} 2$

\begin{tabular}{|c|c|c|}
\hline AUTOR & CRITERIO & TIPOS DE GRUPO \\
\hline $\begin{array}{l}\text { LEVY } \\
(1976)\end{array}$ & Composición y objetivos. & $\begin{array}{l}\text { - Grupos para la reorganización de la con- } \\
\text { ducta. } \\
\text { - Grupos de manejo del estrés. } \\
\text { - Grupos orientados a la acción social. } \\
\text { - Grupos de realización personal. }\end{array}$ \\
\hline $\begin{array}{l}\text { UFBERMAN } \\
(1978)\end{array}$ & Tipo de servicio. & $\begin{array}{l}\text { - Grupos que sirven a sus miembros. } \\
\text { - Grupos que sirven a la sociedad. }\end{array}$ \\
\hline $\begin{array}{l}\text { BARRÓN } \\
(1988)\end{array}$ & $\begin{array}{l}\text { Persona que padece el pro- } \\
\text { blema. }\end{array}$ & $\begin{array}{l}\text { - Los miembros del grupo padecen directa- } \\
\text { mente el problema. } \\
\text { - Los miembros del grupo no son afectados } \\
\text { de forma directa (familiares...). }\end{array}$ \\
\hline $\begin{array}{l}\text { VILLALBA } \\
(1996)\end{array}$ & Destinatarios prioritarios. & $\begin{array}{l}\text { - Aislamiento social. } \\
\text { - Adicciones } \\
\text { - Enfermedad física o mental. } \\
\text { - Supervivientes de catastrofes, atentados... }\end{array}$ \\
\hline
\end{tabular}

Una vez vistas y analizadas las características de los grupos de autoayuda, así como algunas de las clasificaciones que sobre el tema se han propuesto, vamos a exponer cómo puede formarse un grupo de autoayuda desde el Trabajo Social.

Para ello, retomamos la idea que exponíamos antes para recordar que la propuesta que presentamos supone un proceso gradual de creación de un grupo de autoayuda donde el Trabajador social estaría presente en las primeras fases del grupo para acabar fuera del grupo, siendo utilizado en algunas ocasiones a petición expresa del grupo.

Nuestra propuesta, siguiendo el análisis que plantea Barrón (apoyándose en Tylor y col. 1988), defiende que los grupos de apoyo y los de autoayuda pueden considerarse no como dos clases de grupos sino 
como fases en el desarrollo de los grupos basados en el apoyo social. De este modo, habrá grupos que toda su vida estén dirigidos por un profesional, esto es, grupos de apoyo o en fase de apoyo, y habrá grupos que, superado esta fase de apoyo, lleguen a dirigirse de forma autónoma, lo que hemos denominado grupos de autoayuda.

Desde estas premisas, tal y como hemos visto, dada la variedad de grupos y estilos de trabajo profesional, esta propuesta pretende ofrecer una de las posibles líneas de intervención y colaboración con los grupos de autoayuda englobados estos en la perspectiva del apoyo social de la que hablábamos en la primera parte de la exposición. La propuesta que presentamos recoge las ideas que al respecto se han propuesto por Roca y Villalbi (1993) y por Villalba (1996).

\subsection{Metodología del trabajo en grupo}

Centrándonos en la función del profesional en los grupos de autoayuda, estos quedan divididos en cuatro fases o etapas, que se resumen a continuación. Se trata de ver las características de cada fase, así como las funciones del trabajador social para con el grupo.

\section{I ${ }^{a}$ FASE: la creación de un grupo de autoayuda.}

La iniciativa de la puesta en marcha de un grupo de autoayuda puede venir del profesional que detecta la necesidad o problema y ve adecuado una intervención desde el nivel grupal, o puede venir a iniciativa de algunos futuros miembros del grupo.

Tanto si la idea parte del profesional como si no, se debe iniciar un período preparatorio donde todas las personas interesadas en formar parte del grupo tomen contacto unas con otras, comprendan el sentido y el funcionamiento del grupo, así como que se comprometan con y para trabajar en grupo.

Durante estas reuniones de carácter informal, como el grupo no está todavía formado, no se deben plantear objetivos específicos y actividades, ya que estas deben ser elaboradas por el conjunto de los miembros del grupo una vez ya formado. Lo que sí es importante es que los futuros miembros del grupo comprendan de manera general qué es la autoayuda y qué significa participar en un grupo de autoayuda.

A esta fase preparatoria del trabajo grupal, caracterizada por ser una fase de «captación» de los futuros miembros del grupo, le precede un paso previo dedicado a la difusión y propaganda de la creación del grupo.

Cada vez más, desde distintos ámbitos, se potencia el trabajo en grupos de autoayuda, donde previamente se ha avisado a todas las per- 
sonas que pueden trabajar en este tipo de grupo, preparándoles para el trabajo grupal.

La difusión puede realizarse por diversas vías, en algunas ocasiones se mandan cartas a familiares directamente implicados en distintas situaciones problema para los cuales el grupo de autoayuda puede ser un recurso adecuado. Por ejemplo, cuando desde el hospital se informa a los familiares de personas con problemas de anorexia, de la próxima creación de un grupo de autoayuda, o cuando desde una asociación de enfermos de Sida, se difunde a través de la propia revista de la asociación, la creación de un grupo de autoayuda para voluntarios que prestan su servicios en ella.

$2^{a}$ FASE: primeros contactos con el grupo.

En esta segunda fase, el objetivo fundamental es ir formando el clima grupal así como que el grupo vaya fijando algunos de los elementos más importantes.

El Trabajador social posee un rol activo, donde debe iniciar progresivamente el proceso de consolidación del grupo.

Durante esta fase, que puede durar 4 sesiones, los miembros del grupo deben conocerse entre sí, asî como conocer de manera más directa qué es la autoayuda y cuál va a ser la metodología de las sesiones, metodología que debe concretar el propio grupo en el transcurso de esta fase.

Los miembros del grupo han de elaborar objetivos, normas, concretar actividades, así como decidir el número de miembros que van a tener, cuáles van a ser las condiciones de ingreso, dónde y cuándo van a reunirse, etc.

Durante el transcurso de esta fase, el Trabajador Social debe dejar progresivamente que el grupo tome la iniciativa, delegando funciones en algunos miembros del grupo.

Entre los objetivos generales de estos grupos tenemos:

1. En primer lugar, conseguir que los miembros del grupo se autorresponsabilicen en sus propios procesos de cambios a través de compromisos cotidianos establecidos por ellos mismos de una sesión a otra.

2. Ayudar, a través de las sesiones, a tomar conciencia de los recursos y déficits individuales relacionados con el tema común del grupo.

3. Incrementar la calidad de apoyo emocional e instrumental a través de una estructura de sesiones que posibilite la expresión, la escucha y la posibilidad de dar y recibir feedback en todos los participantes del grupo. 
4. Y, por último, aumentar las redes sociales de los participantes del grupo a través de la periodicidad de los encuentros y la permanencia de los miembros en el grupo.

No obstante, además de estos objetivos generales, el grupo debe formular objetivos específicos y debe decidir qué tipo de actividades se llevarán a cabo para conseguir los objetivos propuestos.

Teniendo en cuenta que el grupo de autoayuda funciona como tal cuando consigue su propia autonomía, es necesario que el trabajador social desde estas primeras reuniones adopte el criterio de preparar las sesiones con algún miembro del grupo de forma rotativa, de modo que poco a poco sea esta la metodología que se utilice en el grupo y que el trabajador social vaya perdiendo protagonismo.

Este miembro del grupo, al que algunos autores llaman facilitador (Ródenas, 1996:197), posee dos funciones importantes: la de preparar y moderar las sesiones y la de servir de nexo de unión entre el interior y el exterior del grupo.

En algunos grupos de autoayuda esta persona que ejerce el papel de facilitador es siempre la misma, el grupo la elige democráticamente y puede recibir una formación previa por parte de la organización a la que pertenece o a través de cursos de formación para voluntarios. No obstante, consideramos más enriquecedora la experiencia cuando esta tarea es compartida de forma rotativa entre los miembros del grupo, de modo que no cargamos toda la responsabilidad en un sólo miembro del grupo, haciendo mucho más partícipes a estos en su propio grupo.

\section{$3^{a}$ FASE: fase de acompañamiento profesional.}

Una vez establecidos los aspectos formales del grupo así como consolidado el grupo, en esta tercera fase el objetivo fundamental consiste en enseñar al grupo a manejar adecuadamente los aspectos señalados en las sesiones anteriores. De forma más práctica, el grupo debe entrenarse en la práctica de la metodología de autoayuda, enseñando a cada miembro y al grupo en general a comunicarse.

Durante esta fase, que puede durar 12 sesiones, el profesional estará presente en el grupo, intentando no dirigir sino ejercer funciones de acompañamiento y apoyo en el grupo. El profesional preparará las sesiones con el miembro del grupo que le corresponda y será este quien coordine la sesión. Sólo cuando sea necesario, el profesional intervendrá intentando no dar soluciones sino generando la comunicación entre los miembros del grupo, apoyando al moderador en cuanto animar a algún miembro del grupo a hablar etc.

Es interesante la propuesta de Villalba (1996) en cuanto a la forma 
de dar apoyo a los miembros del grupo. Para ella, el profesional debe colocarse detrás de cada miembro del grupo que habla, poniendo o no las manos sobre sus hombros, dependiendo de si percibimos que esta actitud de cercanía física le puede o no ayudar en su comunicación. Esto se hace para apoyar a cada miembro del grupo y demostrar que el profesional que acompaña no es un miembro del grupo, ni un coordinador del mismo sino un asesor y colaborador.

Tanto si se adopta esta disposición física como si no, el profesional puede interrumpir a la persona y orientarle sobre su manera de comunicar al grupo. Por ejemplo, puede decirle que personalice más, que no hable de personas ausentes, que hable de lo que siente, que hable un poco más o bien que dé tiempo para hablar a los otros.

En el transcurso de una reunión, parece conveniente que se den tres momentos importantes:

1. Un primer momento donde cada miembro del grupo expresa al grupo cómo se encuentra, y destaca algún hecho importante que le haya ocurrido desde la anterior sesión. También, cada miembro del grupo comenta si ha realizado el compromiso o la tarea propuesta en la anterior reunión, si es que se ha propuesto alguna.

2. Un segundo momento donde el coordinador explica la preparación de la reunión, así como los temas que propone y los miembros del grupo eligen un tema de los expuestos o bien se puede trabajar acerca de un tema escogido en la anterior reunión donde se ha podido invitar a alguien de fuera.

3. Un tercer momento, donde se realiza una pequeña evaluación de la sesión, así como se proponen tareas o compromisos concretos para realizar hasta la próxima reunión. A la hora de la evaluación el profesional participa aportando ideas sobre el contenido y la metodología que ayuden al grupo en sus próximas sesiones.

$4^{a}$ FASE: fase de observación en el grupo.

En esta cuarta fase, el papel del profesional queda relegado al de observador pasivo del grupo. Es importante que el profesional permanezca en la misma sala del grupo, pero que no se siente con él en círculo, sino que se sitúe fuera del grupo. El Trabajador social actúa como observador, tomando algunas notas sobre cómo se desarrolla la sesión. Es importante que se fije en las tareas de liderazgo, que vea si algún miembro del grupo queda excluido, cómo se llevan a cabo las tareas propuestas, así como que observe de manera especial al miembro que coordina el grupo.

Durante esta fase, que puede durar 3 ó 4 sesiones, según se considere, el objetivo fundamental es que el grupo lleve a cabo la sesión sin la 
presencia cercana ni la participación del profesional. Al igual que en la fase anterior, el profesional, al finalizar la sesión, puede hacer algún comentario sobre lo observado prestando especial atención a la persona que ha coordinado la reunión.

$5^{a} F A S E$ : fase externa o de autodirección.

En esta quinta fase, que puede durar 3 ó 4 sesiones más, el grupo debe tener ya la suficiente autonomía para poder funcionar por sí solo, como un grupo de autoayuda.

Para ello, el profesional está en otra habitación distinta de donde se lleva a cabo el trabajo grupal, de modo que las reuniones se llevan a cabo sin su presencia.

Para la preparación de las sesiones cada coordinador debe tener en cuenta los aspectos planteados en el grupo, y cada vez menos se pide la ayuda del profesional. No obstante, en estas sesiones previas a la autonomía total, el profesional puede desempeñar el rol de supervisor externo y asesor. Tras cada reunión, el profesional puede reunirse con el coordinador del grupo si lo considera conveniente para ayudarle a realizar una evaluación.

Tras estas 5 fases (resumidas en el cuadro $\mathrm{n}^{\circ} 3$ ), el grupo puede funcionar ya como grupo de autoayuda, teniendo el apoyo del profesional, cuando el grupo lo necesite, ante alguna situación de crisis o conflicto o ante algún cambio importante que ocurra en el grupo.

Este proceso de acompañamiento profesional hacia los grupos permite aprender a trabajar en grupo de forma progresiva y gradual, de ahí que para formar un grupo de autoayuda sea importante que lo tengamos en cuenta. La duración de cada fase no tiene porqué ser fija, ya que depende del tipo de grupo y de las características de sus miembros. No obstante, Villalba propone como duración total del acompañamiento profesional el período comprendido entre seis meses y un año, aunque son fechas aproximadas que dependen, entre otros, de la frecuencia de las reuniones, de las características del grupo y de la participación de los miembros. De todas formas, es importante acordar con los miembros del grupo cuánto tiempo va a durar el acompañamiento profesional. 
CUADRO N. ${ }^{\circ} 3$

I. ${ }^{a}$ FASE: Creación del grupo de autoayuda
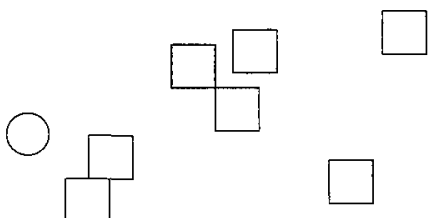

CARACTERÍSTICAS:

- Difusión y captación de los miembros del grupo.

- Información a través de contactos informales.

ROL DEL T.S.:

- Informativo.

2. ${ }^{a}$ FASE: Primeros contactos con el grupo

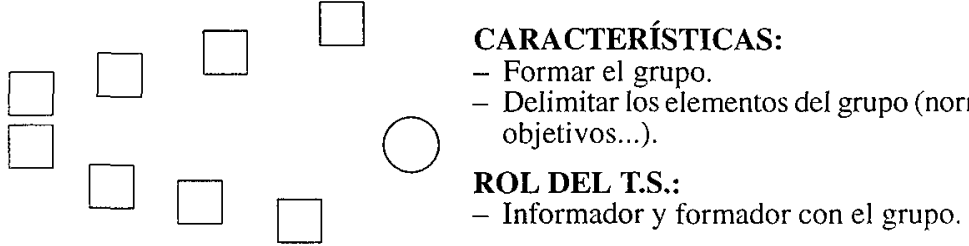

3. ${ }^{a}$ FASE: Fase de acompañamiento personal

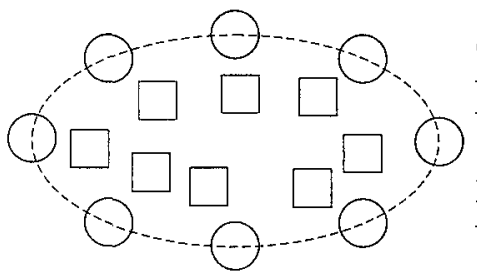

CARACTERÍSTICAS:

- Aprender la metodología de trabajo.

- Entrenar habilidades de comunicación en el grupo.

ROL DEL T.S.:

- Rol de apoyo.

4. FASE: Fase de observación en el grupo

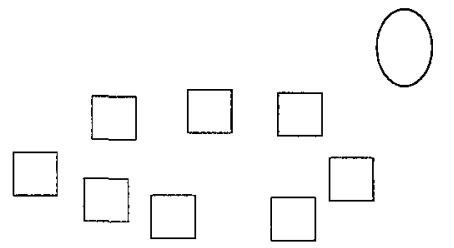

CARACTERÍSTICAS:

- El grupo se autogobierna.

- Independencia de los coordinadores de grupo.

ROL DEL T.S.:

- Observador pasivo.

5. ${ }^{\alpha}$ FASE: Fase externa o de autodirección

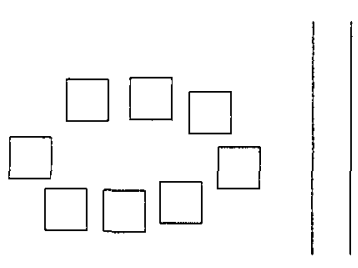

CARACTERÍSTICAS:

- El grupo se autogobierna.

ROL DEL T.S.:

- Supervisor externo y asesor. 


\section{III.CONCLUSIONES}

Los grupos de autoayuda suponen un recurso importante a utilizar desde el Trabajo Social. En ellos se crean vínculos sólidos y se amplían las redes sociales de sus miembros. En este sentido, está comprobada la eficacia de estos grupos para sus miembros. Tal y como señalan Roca y Villalbí (1989: 49), estudios sobre enfermos de cáncer demuestran que los que han asistido a un grupo de autoayuda han sido más capaces de afrontar su situación, asimismo, determinados grupos de autoayuda para ancianos muestran como se mejora la autoestima de sus participantes y la capacidad para realizar actividades.

Estos grupos generan nuevas perspectivas de futuro y capacitan para emprender acciones solidarias. Por ejemplo, muchos de los ex-participantes de un grupo de autoayuda se convierten en voluntarios sociales y siguen apoyando a personas que pasan por la misma situación que ellos pasaron. Esta es una de las características más relevantes de estos grupos. El poder no sólo compartir problemas sino también compartir cómo se pueden enfrentar desde la experiencia supone una fuente de recursos inagotables para los miembros del grupo ofrecidos desde el grupo.

Desde los distintos ámbitos del Trabajo social, el trabajo en grupo, y más concretamente en y con grupos de autoayuda, consolida el trabajo comunitario que desde la práctica se plantea. Estos grupos permiten la participación directa de nuestros clientes en sus problemas facilitando que, a la vez, estos participen en sus propios cambios y ayuden a otros a través del proceso del grupo.

El trabajo a través de grupos de autoayuda en el ámbito de los Servicios Sociales permite una mejora en la calidad de la ayuda, consiguiendo, a su vez, un aumento de la autoestima y una mayor participación en la comunidad de los grupos más desfavorecidos. Desde ellos, y en consecuencia con lo anterior, la dependencia institucional se reduce en el momento que la persona se responsabiliza y se le facilita un marco donde poder tomar decisiones acerca de su situación, situación que es compartida por otras personas.

El papel del profesional en estos grupos, tal y como hemos señalado, ha de ser de asesoramiento, formación y apoyo de líderes y no de liderazgo o coordinación de los mismos. Así pues, debe recordarse que una vez creado y apoyado, el profesional debe mantenerse al margen, porque, tal y como afirma Levin (1977), el beneficio real de los grupos de autoayuda está en su carácter no profesional, en su universalidad, en su accesibilidad, en su diversidad y en su aceptación. 


\section{BIBLIOGRAFÍA}

AYUNTAMIENTO DE MADRID, Área de Servicios Sociales: Trabajo Social con grupos. Teoría y práctica en los Servicios Sociales Municipales. Madrid. 1995.

AZNAR y otros: «Un año de grupo de autoayuda con familiares de enfermos mentales en Zaragoza». Trabajo Social y Salud, 20. Marzo 1995. Pág. 291-296.

BARRÓN, A. (1996): Apoyo social. Aspectos teóricos y aplicaciones. Siglo XXI. Madrid.

BORMAN, L.B. (1992): «Self-help/mutual aid groups in strategies for healt» en KATZ, A. y HEDRICK, H.L.: Self-help: Concepts and applications. The Carles Press. Filadelfia.

CAPLAN, G. y KILLILEA, M. (1976): Support Systems and mutual help. Grune \& Stratton. Nueva York.

ESPALLARGAS, A.: «Nuestra experiencia personal en un grupo de padres». Integración, 16. Octubre, 1994. Págs. 66-67.

FINN, J.: «Computer-Based Self-Help Groups: A new resource to supplement support groups». Social Work with groups, vol.18, 1. 1995.109-116.

GARCÉS TRULLENQUE, E. y otros.: «Grupos de aconsejamiento de padres de pacientes anoréxicos/as : una experiencia desde el Trabajo Social». Trabajo Social y Salud, 28. Diciembre, 1997. Págs. 129-139

GRACIA FUSTER, E. (1997): «Grupos de apoyo y atoayuda, una fuente de recursos para la intervención social» en El apoyo social en la intervención comunitaria. Paidós. Barcelona. Págs. 44-70.

GRACIA, E.; HERRERA, J.; MUSITU, G. (1995): El apoyo social. PPU. Barcelona.

KATZ, A.: «Self-help and mutual aid: An emerging social movement?». Anual Review of Sociology, 7. 1981. Págs. 129-145.

MIRANDA, M. y DE PEDRO, D.: «El concepto de red de apoyo y su importancia para el Trabajo Social». Trabajo Social y Salud, 20. Marzo, 1995.

RIESSMAN, F. (1995): Redefining Self-Help. Police and practice. JosseyBass Publishers. San Francisco.

ROCA, F. y VILLALBI, J.R. (1993): Manual para el funcionamiento de grupos de ayuda mutua. Fondo de Publicaciones del Gobierno de Navarra. Pamplona. Págs. 5-24.

ROCA, R. y VILLALBI, J.R.: «Los grupos de ayuda mutua en el campo de la salud». Revista de Trabajo Social, 114. 1989. Págs. 45-51. 
RÓDENAS PICARDAT, S.: «Grupos de Ayuda Mutua: Una práctica alternativa en la práctica del Trabajo Social».Alternativas, 4. Octubre 1996. Págs. 195-222.

SÁNCHEZ FERNÁNDEZ, C.: «Grupo de apoyo para madres adolescentes». Trabajo Social y Salud, 23. Marzo 1996. Págs. 49-57

SÁNCHEZ MARTÍNEZ, M.L.: «EL trabajo social en las actuaciones grupales con padres y madres ante el fenómeno de las drogodependencias: necesidad de una metodología participativa». Cuadernos de Trabajo Social, 8. Universidad Complutense. Madrid. 1995. Págs. 181-198.

SLUZKI, C. (1996): La red social: Frontera de la práctica sistémica. Gedisa. Barcelona.

TSCHORNE, P. (1995): Dinámica de grupo en Trabajo Social, atención primaria y salud comunitaria. Amarú. Barcelona.

VILLALBA QUESADA, C. (1993): «Redes sociales: un concepto con importantes implicaciones en la intervención comunitaria». Intervención psicosocial, Vol II, 4. Págs. 69-85.

VILLALBA QUESADA, C. (1996): «Los Grupos de Apoyo basados en la autoayuda: una propuesta para el inicio y acompañamiento profesional». Intervención psicosocial. Vol. V, 15. Págs. 23-41. 



\title{
CIENCIA POLÍTICA Y SERVICIOS SOCIALES. DEL ENTENDIMIENTO AL CONCUBINAGE
}

\author{
ALFREDO HIDALGO LAVIÉ \\ Doctor en Ciencias Políticas. Profesor de Servicios Sociales y Política Social. E.U.A. de \\ Trabajo Social de Jerez de la Frontera. Universidad de Cádiz.
}

\section{INTRODUCCIÓN}

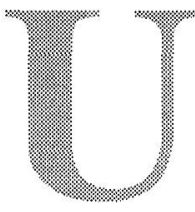

n título de estas características sin considerar al Estado de Bienestar como el epicentro de la obra no es muy corriente, sin embargo, no deja de ser una invitación bienvenida $y$, en lo que a mí respecta, un desafío seductor inevitable, por lo que agradezco enormemente a la dirección de esta publicación su atención al permitirme colaborar en estas páginas a modo de defensor del diablo en la unión de dos disciplinas que tantos aspectos comunes comparten y, no obstante, no suelen manifestar más abierta y frecuentemente sus confluencias.

Como politólogo, estoy en la obligación de decir que usualmente "lo político", además de la 'mala prensa' que hoy día parece tener esta expresión, no posee coloquialmente precisos contornos conceptuales, por esta razón, la primera tarea en una colaboración de estas características transcurre necesariamente, en primera instancia, por una aproximación conceptual que canalice todo el análisis posterior.

La Ciencia Política es una ciencia más en el seno de las Ciencias Sociales y, como tal, comparte un común punto de partida: el estudio del hombre como ser social, aunque, obviamente, focalizando su objeto en los procesos y conflictos relacionados con la autoridad y el poder que se desenvuelven dentro del mundo o realidad social. Como tal ciencia social, claro está, la apropiación de un ámbito exclusivamente autónomo es cuestionable, por lo que la necesidad de un enfoque inter y pluridisciplinar, la suma de sus resultados con los obtenidos por las otras ramas del saber social, se convierte en condición sine qua non para aspirar a constituirse en ciencia y de este modo ofrecer al conocimiento científico una comprensión racional y objetiva del ámbito de la realidad objeto del análisis. El binomio sujeto/objeto introduce serios problemas epistemológicos que van a determinar no sólo la utili- 
zación de ciertos procedimientos metodológicos, sino que además van a marcar también su finalidad como conocimiento científico. Todas estas consideraciones relevantes van a ser tratadas en la primera parte de esta exposición bajo el rótulo "la Política como Ciencia".

Realizada esta rápida endoscopia sobre los aspectos que más interesa conocer de la Ciencia Política en general, pasaré a presentar las confluencias que, a mi entender, comparten ambas disciplinas, las cuales servirán a su vez de 'rampa de lanzamiento' idónea desde la que subrayar las aportaciones sobresalientes que la Ciencia Política puede ofrecer para un conocimiento más exhaustivo de los Servicios Sociales, haciendo un especial hincapié en la unidad de análisis, por excelencia, de estas dos áreas del saber científico, el individuo-ciudadano.

Por último, he considerado necesario incluir una breve reflexión sobre una referencia que merece toda nuestra atención dada la actualidad y la curiosidad que hoy despierta, la necesidad de un nuevo estilo de hacer democracia, sin ningún interés mayor que el de trazar unas someras líneas a favor de nuestro modelo representativo sin que por ello se entienda, necesariamente, que nuestro sistema democrático, sostenido sobre la delegación, no requiere las suficientes reformas pertinentes para acercar, en la medida de lo posible, el poder político a los ciudadanos.

\section{LA POLÍTICA COMO CIENCIA}

\subsection{La idea de "lo político"}

Conocido es por todos el axioma aristotélico "el hombre es un zoon politikon", pero esta idea incipiente de "lo político" no describe conceptualmente, en absoluto, esta realidad. El animal político de Aristóteles, lejos de lo que puede parecer a simple vista, no es una descripción de la política, sino una concepción explícita de la vida, el modo helénico de entender la realidad vital del ser humano en el seno de la polis, donde la vida política no es una faceta más del quehacer humano, ni siquiera la más primordial, sino su esencia misma, vinculada estrechamente a la comunidad política primitiva. Tendrán que transcurrir bastante siglos para que la noción de lo político quede circunscrita a la esfera del poder, concepto siamés que, entendido en sentido lato, da forma y contenido a la idea común de esta realidad intangible que se manifiesta a través de actos y decisiones de naturaleza política. Este amplio paréntesis en el tiempo ha originado que la idea de lo político haya rodado de modelos sociales y de producción tan diferentes, con matices y acepciones tan diversas, que la locución acabó adop- 
tando incluso significados religiosos con los que deleitar a cualesquiera de las divinidades del hemisferio existencial. No es exagerada, pues, la apreciación de Eduardo Haro Tecglen (1995) al afirmar que todos los cientos de miles de libros que se han escrito en torno al tema no son siquiera suficientes para encerrar todos los conceptos de la palabra política.

Con Maquiavelo, al fin, la política se separa de los ámbitos moral y religioso, estableciendo su propia esfera autonómica, regida por racionales leyes particulares independientemente de lo éticamente descriptivo y originando, de este modo, una amoral idea de lo político que, como es sabido, no tiene por qué causar necesariamente reprochables comportamientos inmorales, fundamentalmente porque Maquiavelo no era indiferente a los efectos que producen la moral y la religión sobre la comunidad política; y, si bien es cierto, que, por un lado, condenaba a las virtudes cristianas, como la humildad, la abnegación y el desprecio de las cosas mundanas que causan, en su opinión, 'servilismo de carácter', por otro lado, como consecuencia de su estima hacia el gobierno liberal y sujeto a las leyes, sancionaba la utilización aleatoria e indiscriminada de medios poco dignos por parte de los gobernantes.

Sin embargo, y a pesar del importante paso realizado en el objeto propio que interesa a la política, es comúnmente aceptado que Maquiavelo no puede ser calificado correctamente de científico, ya que su empirismo procedía más del sentido común y sus indagaciones históricas que de la inducción promotora de elaboraciones teóricas y contrastadas. Hábil en la astucia, ni siquiera llegó a formular una teoría general del absolutismo político, aunque, ciertamente, sí fue el creador de un concepto clave para la Ciencia Política: el Estado.

Un paso más en la separación progresiva de lo moral/religioso de lo estrictamente político y, por ende, en la construcción de una esfera particularmente política de la actividad y pensamiento humanos, lo encontramos en la obra de Juan Bodino, no tanto por su elogiable recomendación política de la tolerancia religiosa, a pesar, paradójicamente, de su extremado fervor, como por extraer casi definitivamente la idea del poder soberano de la teoría del derecho divino.

No obstante, no será hasta 1651 cuando la serie de obras escritas por Thomas Hobbes, entre ellas el conocido Leviatán, colocan a lo político en estrecha relación con un sistema de pensamiento completamente moderno y, por ende, completamente autónomo. Si, con Maquiavelo, el Estado gobernaba aceptando las reglas de la política, con Hobbes el Estado gobierna creándolas. Su individualismo, su materialismo y su procedimiento deductivo y no empírico le condujo a considerar la política como parte de un cuerpo manipulable por el conocimiento científico. 
La autonomía de una esfera de lo político arrastrará más tarde una parcela similar en "lo social" con connotaciones económicas. De la mano de autores como David Ricardo o Adam Smith se fraguó la creencia fundada en que toda sociedad bien dirigida era capaz de regularse a sí misma, delegando en el gobierno sólo un papel de importancia muy limitada. Políticamente, la separación Estado/Sociedad-modelo económico debe ser interpretada como el nacimiento y consolidación de un nuevo pensamiento político caracterizado, fundamentalmente, por la libertad de la segunda frente al abstencionismo del primero. Su correspondiente traducción científica versará sobre una ciencia general de la sociedad en la línea del pensamiento filosófico de Comte. En otras palabras, el libre albedrío de las fuerzas ocultas de "una natural mano rectora" inherente a la sociedad de mercado proporcionará crecimiento económico y bienestar social. La injerencia política es considerada, pues, sinónimo de desorden y parcialidad ${ }^{1}$, de este modo, la autonomía de la sociedad es tal que ella misma puede ser objeto de un campo científico y, así pues, susceptible de normas y procedimientos metodológicos con los cuales descubrir realidades y principios sociales 'objetivos' y, evidentemente, contrastados. A este respecto, George Sabine (1987:519) ha argumentado que, "en cierto sentido, la filosofía de Comte fue una culminación de la especulación social que se había iniciado con la enigmática idea de Rousseau de la Voluntad General, el concepto de la sociedad como un ente colectivo con sus propios caracteres y valores y que supera los fines y voluntades de sus miembros", lo que implica, en gran medida, un apreciable y estimable esfuerzo por conducir los estudios sociales al sendero de la ciencia moderna, más aún, a la aparición de nuevas interrogantes que darán lugar al surgimiento de nuevas áreas de conocimiento como la psicología social y la antropología, entre otras.

La política, concebida, desde una perspectiva liberal, como el arte del buen gobierno que permite llegar a acuerdos entre posturas enfrentadas e intereses diametralmente opuestos gracias al poder compartido y fragmentado, hará frente a una nueva concepción de la misma, si se me permite, más "combativa": la conquista y el ejercicio del poder no permiten procedimiento pacífico alguno, la fuerza impulsora del cam-

No obstante, es preciso recordar que las conclusiones de los estudios realizados por Adam Smith sobre la naturaleza humana y el modelo ideal de comunidad político-económica, será distinto del apuntado por la doctrina liberal al enfatizar los injustos desequilibrios que el modelo de producción causa sobre la distribución de la riqueza. En esta línea, Adam Smith (1978:31) afirmará que "por más egoísta que quiera suponerse al hombre, evidentemente, hay algunos elementos en su naturaleza que lo hacen interesarse en la suerte de los otros, de tal modo que la felicidad de éstos le es necesaria, aunque de ello nada obtenga, a no ser el placer de presenciarla". 
bio social no es la negociación, sino la revolución, dado que la naturaleza del poder no es política. Para el marxismo, las fuerzas que impulsan el desarrollo y el devenir de la historia son económicas. La cultura y los modelos políticos encuentran su razón de ser en el modelo de producción; es la teoría del determinismo económico que, aplicado a lo político, explica el materialismo dialéctico en la línea del pensamiento de Hegel.

El breve pero aberrante y cruel periodo de los totalitarismos fascista y nazi, productos de la profunda desmoralización originada por las consecuencias de la Primera Guerra Mundial, eliminó de lo político un elemento consustancial a su trayectoria, enunciado sólo a grandes rasgos en estas primeras páginas, la inteligencia. Un peligroso intento de retroceso hacia un primitivismo originario que, afortunadamente, y a pesar de sus desagradables secuelas, no ha causado daños irreparables en el paulatino desarrollo de identificar lo político con un poder cuyo ejercicio, sobre unas básicas premisas éticas, pero fundamentales, continúa correspondiéndose con la armonía y el consenso desde los que aprehender un modelo racional de convivencia humana, independientemente de si el análisis es de naturaleza liberal, conservadora, socialdemócrata o comunista. Un modelo de convivencia que tras el hundimiento del imperio ubicado tras los Urales es hoy en día el único paradigma exportable, aunque continuamente perfectible, la democracia.

\subsection{La presunción de Ciencia}

La Ciencias Sociales se han enfrentado desde siempre a problemas metodológicos, por lo que, si tuviéramos que prescindir de un intento de definición más amplio, podríamos comenzar afirmando que toda ciencia, o la Ciencia en sentido genérico, es sólo método con el que y desde el cual ser capaces de formular leyes válidas para todos. Por consiguiente, y a modo de primer enunciado, se podría argüir que no hay ciencia propiamente dicha sin método científico, aunque, evidentemente, éste pueda ser múltiple. Asimismo, y a pesar del lógico énfasis realizado sobre el procedimiento, tampoco un saber científico es tal sin hipótesis y generalizaciones, a través de las cuales formular enunciados verdaderos, independientemente del tiempo y del espacio, que comúnmente denominamos leyes.

En lo que concierne a la política y a la ciencia misma, el punto de arranque para un camino conjunto nos obliga a indagar en los escritos de la epistemología y de la filosofía, del mismo modo que toda teoría al respecto no puede prescindir en absoluto de la idea de ciencia que en cada momento histórico se ha compartido. El primer paso dado en esta línea, como hemos visto, se produce con el proceso de demarcación de 
ciertas esferas, tales como la moral o la economía, en pro de un ámbito propio, aunque difícilmente exclusivo, de lo político. Especial atención merece la separación de la filosofía que hizo posible el surgimiento de una Ciencia Política, en el sentido correcto de la expresión, dado que el método, los objetivos y los criterios del politólogo son diferentes. Un ejemplo ilustrativo de esta diferencia deriva de los procedimientos metodológicos entre los que el politólogo utiliza, en un elevadísimo número de casos, el control histórico y comparado, muy en menor medida el estadístico, iy qué decir del experimental!. Precisamente, la imposibilidad de recurrir a este último nos recuerda el difícil inconveniente al que tiene que hacer frente la política en su aspiración a configurarse como saber científico: la imprevisibilidad simbólica del sujeto y del objeto, piedra clave sobre la que Giovanni Sartori (1984) ha afirmado que la causalidad propia de las ciencias naturales no es posible encontrarla en las ciencias sociales, puesto que el hombre escapa al modelo fisicalista de explicación causal.

La imposibilidad de enunciados a modo de "a tal estímulo, tal reacción" vuelve a la política inaprensible, sin olvidar, además, que lo que llamamos generalmente político, como sucede igualmente en toda la realidad social, tampoco posee claros contornos nítidamente delimitados. El poder, como ya ha sido señalado, es intangible, por lo que resulta más oportuno hablar de relaciones de poder o de actos y decisiones concretas de naturaleza política, cuestión que nos trae a colación otro ingrediente imprescindible para toda presunción creativa de conocimiento científico: la formación de conceptos, es decir, la delimitación conceptual de ciertos términos útiles que ha de manejarse con precisión en nuestro campo, en definitiva, la importante tarea de sistematizar el lenguaje. ¿Quién no ha alertado alguna vez la utilización indiscriminada de la locución "Estado", por ejemplo, para hacer referencia a aquellas comunidades políticas organizadas con anterioridad a la Edad Moderna?.

Como ya ha sido apuntado, el proceso histórico de demarcación de un ámbito puramente político en el seno de las Ciencias Sociales ha sido largo, ni siquiera el tratamiento de la constitución de la Ciencias Sociales, con precisión histórica, es fácil de evaluar. La literatura sobre la necesidad de validar los enunciados de la realidad social en general mediante una metodología científica es muy abundante, con ejemplos tan ilustrativos como "la crisis de la conciencia europea" de Paul Hazard. La fragmentación del saber en distintos y separados campos formalizados o institucionalizados, impulsados por un deseo permanente de verificación y especialización (la astrología es reemplazada por la astronomía, por ejemplo) es paulatina, proceso durante el cual destacaron figuras brillantes como Descartes y Bacon que también ilustran la confrontación entre el racionalismo y el empirismo, respectivamente. 
Habrá que esperar, no obstante, a toda una serie de autores como Dilthey o Rickert, conocidos bajo el calificativo de "neokantianos", para distinguir, al fin, entre ciencias naturales y ciencias sociales, los cuales, como es sabido, romperán con la unidad metodológica esgrimida por los positivistas ${ }^{2}$, dada la naturaleza tan diferente del objeto de estudio en cuestión, la realidad social subjetiva. Así pues, realizada la bifurcación del pensamiento científico, la unidad de la ciencia quedará confirmada, no siendo incompatible con aplicaciones metodológicas tan dispares como la utilización de datos cuantitativos y empíricos por un lado, y el uso de información simbólica y significativa por otro. Dicho esto, y una vez ubicado el ámbito de lo político en el seno de las ciencias sociales, la cuestión inevitable a resolver es la siguiente: ¿en qué consiste, en definitiva, la Ciencia Política?.

\subsection{Origen y Objeto de la Ciencia Política}

La institucionalización de la Ciencia Política como disciplina científica es de muy reciente aparición en el seno de lo que venimos llamando ciencias sociales, por más que, ciertamente, muchos autores estiman que el primer enfoque científico-político se encuentra ya en la obra de Maquiavelo. Pero ¿participa el análisis de la realidad políticosocial de Maquiavelo de propuestas y enunciados racionales, resultado de la observación y sometidos a su verificación científica?. Ya hemos visto que no y cuán discutible es el procedimiento por él utilizado.

Una opinión más consensuada merece el análisis de Saint Simon y Fourier, aunque será Tocqueville el artífice de la consolidación de la observación y deducción racional de aquello que hemos llamado político.

En un sentido amplio, el objeto de la Ciencia Política está inexorablemente vinculado a la sociedad, a la colectividad, entendida ésta como un agregado de individuos relacionados entre ellos en torno a la columna vertebral de toda comunidad humana: el poder. Desde la antigüedad, el estudio del poder ha inquietado tanto a pensadores y filósofos que la literatura sobre este punto es prolífica, pero esta preocupación, sin embargo, no ha sido analizada a lo largo de los siglos bajo una misma perspectiva. Por ejemplo, con el surgimiento, expansión y posterior consolidación del cristianismo, el poder, procedente o transmitido por dios, era susceptible del mal o buen uso, pero el proceso paula-

2 El enunciado común de los positivistas, como es sabido, afirmaba que el conocimiento científico era único, pero esta unidad se manifestaba igualmente en los procedimientos utilizados, por lo que las ciencias experimentales y las no experimentales, según este argumento, debían utilizar una análoga metodología. 
tino de secularización experimentado a lo largo y ancho del Renacimiento modificó substancialmente la preocupación por el mismo, hasta el punto que las interrogantes que giraban alrededor del poder ya no respondían tanto al fundamento moral como al conocimiento de la propia naturaleza del poder, lo que supuso, lógicamente, un extraordinario salto cualitativo dada la pretensión científica del estudio, justificando, en cierta medida, la partida de bautismo de lo político como área de conocimiento especializada.

Aunque sobre el objeto de la Ciencia Política existe un consenso generalizado, éste no está exento de perfiles matizados de relevantes consideraciones. Así, por ejemplo, para Javier Pérez Royo (1980), el objeto verdadero de la Ciencia Política es el Estado. Estimando la opinión genérica como la más utilizada, podemos concluir, pues, afirmando que el objeto de la Ciencia Política abarca todos los procesos sociales mediados por las relaciones de poder, pero el estudio de estos procesos deben ser no sólo analizados desde un enfoque descriptivo y explicativo, sino también, interpretativo. ¿Por qué?. Porque la finalidad del conocimiento científico en la esfera política no consiste meramente en entender, no se conforma simplemente con la comprensión del fenómeno del poder, también pretende formular previsiones sobre las consecuencias de la aplicación de ciertas medidas propias de su habitual ejercicio.

Ya en la Teoría Política clásica, de Aristóteles a Tocqueville, encontramos una preocupación próxima, aunque no similar, en torno a la política, concretamente la búsqueda de una forma de gobierno óptima. La ausencia de una finalidad en el conocimiento científico de lo político es, en mi opinión, similar a la avitaminosis, por citar un caso muy actual; esto es, una carencia precisa que no permite el buen funcionamiento de nuestro organismo. Así pues, no existe Ciencia Política sin finalidad y ésta, en términos concretos, implica y se corresponde con una búsqueda permanente, cuya piedra angular y razón de ser consiste en la aprehensión de toda una serie de elementos de juicio que permitan edificar una comunidad humana apta "para todo género de público", una convivencia pacífica que garantice el libre desarrollo de nuestras potencialidades como seres autónomos y propietarios exclusivos de nuestra particular empresa, un proyecto vital. Sin esta expresa finalidad, los conocimientos de nuestro medio serían inocuos.

Nuestra finalidad, similar en su general premisa al conjunto de las áreas que constituyen las Ciencias Sociales, es, por consiguiente, y para concluir, influir sobre la realidad para mejorarla, un proceso circular, ya que el sujeto y el objeto se entremezclan, muy diferente del proceso lineal propio de las ciencias naturales. 


\section{CIENCIA POLÍTICA Y SERVICIOS SOCIALES. UN DENOMI- NADOR COMÚN}

\subsection{La imprescindible necesidad de un enfoque pluridisciplinar.}

La Ciencia Política es considerada normalmente un saber de segundo orden porque versa sobre realidades complejas cuya crucial interpretación exige necesariamente conocimientos de otros saberes, tales como el Derecho, la Historia, la Economía, etc. Es, pues, un saber científico de naturaleza enciclopédica dada su necesidad imprescindible de aplicar un enfoque pluri e interdisciplinar. Este reciente convencimiento, generalizado en toda nuestra comunidad científica, no ha sido siempre fielmente compartido $y$, por tanto, no exento de perspectivas alternativas con las que construir y cultivar, como apunta Ramón Cotarelo (1986), una Ciencia Política sin el auxilio de otras ramas del conocimiento. Así, del Derecho son utilizados los aspectos normativos, y de la Sociología el interaccionismo simbólico, por ejemplo.

Este requisito multidimensional no debe ser entendido como una "impureza" que imposibilita la construcción y delimitación de un área de conocimiento autónomo. Más aún, la consideración de esta necesidad puede y debe ser interpretada positivamente, pues la fusión de elementos de naturaleza diversa produce una serie de resultados útiles para el enriquecimiento de todas las otras áreas. Numerosos son los ejemplos de esta confluencia, tales como la relación entre la Economía y la Estructura Social, el Derecho Constitucional y los Sistemas Políticos, por citar algunos. Esta línea fronteriza difusa es, en los modelos sociales complejos de la actualidad, más patente aún, dada la globalización de la naturaleza de los problemas acuciantes de nuestro tiempo presente.

Lógicamente, este enfoque pluridisciplinar se configura igualmente como un denominador común entre la Ciencia Política y los Servicios Sociales. No podría ser de otro modo. Por definición, los Servicios Sociales son, en pocas palabras, instrumentos de política social y la política social es ya un ámbito de actuación gubernamental enmarcada en un modelo específico de organización política, el Estado de Bienestar. No es de extrañar, a este respecto, el acertado enunciado de Carmen Alemán (1996:36) al afirmar que "los servicios sociales guardan una estrecha vinculación con la Ciencia Política, y no sólo porque estos servicios se insertan dentro de un contexto político determinado, sino porque, en su propio fundamento, son manifestaciones de decisiones políticas", de lo que puede deducirse, por consiguiente, que todo estudio acerca de los servicios sociales no puede prescindir de la comprensión del móvil y de los resultados de las decisiones y actuaciones 
gubernamentales que, sin duda alguna, corresponde a la Ciencia Política describir, valorar e interpretar. Sobre este punto específico, y como suele decirse coloquialmente, "se puede rizar aún más el rizo" ante la irremediable necesidad de tener en cuenta además: a) el modelo de organización territorial de un Estado; b) el proceso paulatino de construcción de la Unión Europea con la consiguiente coordinación de las políticas sociales que conlleva este proceso; c) el corporatismo, pronunciado o no, característico de los modelos políticos democráticos que conlleva a reconocer un papel también central a los grupos de presión de toda índole en el quehacer cotidiano de las propuestas políticas. La descentralización/centralización territorial, por ejemplo, incrementa o disminuye el número de actores políticos que estarán obligados a coordinar planes y programas, entre otros asuntos. La existencia misma de un sistema público de servicios sociales responde a una concepción específica del rol que debe corresponder al Estado en aras de una finalidad también muy concreta, el bienestar social, recordándonos una vez más esta finalidad el leimotiv de la Ciencia Política: "conocer para mejorar".

Asimismo, el conocimiento de los servicios sociales exige necesariamente tener en cuenta el complejo entramado de interacciones entre actores que deciden o influyen notablemente en el ejercicio de una intervención positiva, negativa o abstencionista, según los modelos establecidos por Demetrio Casado (1991), del protagonista político número uno, para cuya comprensión las aportaciones del análisis sistémico de David Easton, como veremos un poco más adelante, son de gran consideración.

Todas estas observaciones, en torno a las áreas de actuación sobre las que versan, y comparten, los objetos de estudio de los Servicios Sociales y la Ciencia Política, nos conducen, a su vez, e irremediablemente, a otro aspecto científico relevante: la sistematización del lenguaje con la consiguiente delimitación conceptual de las locuciones y voces que tan común y frecuentemente son utilizadas por nuestras disciplinas. Para la Ciencia Política, como para todas las ciencias sociales, es indispensable construir un lenguaje comprensible desde el que utilizar las categorías propias de nuestro objeto de estudio y con el que y para el cual el politólogo describe, analiza, interpreta y predice. Muchas de estas categorías distan mucho de esa difusa línea fronteriza anteriormente señalada, tales como el poder, la autoridad, la obediencia, el conflicto, etc. Pero otras, sin embargo, sí comparten el denominador común de lo que vamos a llamar confluencia conceptual. Por esta razón, las locuciones bienestar social, mercado o democracia desarrollada, entre otras, no pueden ser monopolio ni de la Economía, ni de la Sociología, ni del Trabajo Social. Estas realidades conceptuales, a modo de "espacio aéreo y marítimo internacional", también deben 
tener en cuenta las importantes aportaciones procedentes de la Ciencia Política, dada, fundamentalmente, su vinculación con el poder y el modo de organizarse las comunidades humanas. Una relación interdisciplinaria, en definitiva, que tal y como se ha indicado a comienzos de este apartado, debe ser considerada positiva y sin la cual, según indican Jorge Garcés y Carmen Alemán (1996) en el prólogo de su nueva obra, "no puede prosperar intelectualmente si se basa en fronteras y exclusivismos estériles, sino en el trabajo común y en el esfuerzo solidario".

\subsection{Aportaciones específicas de la Ciencia Política a los Servicios Sociales}

Llegado a este punto, los vínculos que parecían entrelazar tímidamente los Servicios Sociales con la Ciencia Política se tornan ahora más estrechos. El objeto y la finalidad de la Ciencia Política, junto a la también esencial contribución que ésta realiza en la paulatina y cambiante delimitación conceptual de ciertas realidades entrecruzadas y, por ende, ligadas fuertemente a la esfera de los Servicios Sociales, constituyen un sólido puente que refuerza el permanente entendimiento común. No obstante, las aportaciones que la Ciencia Política puede ofertar a la disciplina de los Servicios Sociales no se agotan aquí, por lo que es preciso enumerar otras de similar relevancia que paso a señalar a continuación.

\subsubsection{El concepto de ciudadanía y la participación en asuntos comu- nitarios}

Aquello que entendemos por político utiliza como elemental unidad de análisis, especialmente desde el enfoque característico del individualismo metodológico, al individuo, cuya suma y agregado configura lo colectivo, que da lugar, a su vez, y en última instancia, a toda una comunidad política. Es, por consiguiente, obvio que el sujeto destinatario del elenco de servicios sociales, y el sujeto que participa en el proceso de las relaciones de poder, se configura, ya en principio, en vértice común. Pero, simultánemante, el concepto de ciudadano está estrechamente ligado a los derechos que a éste le corresponden por ser miembro de una comunidad política específica, por lo que su significado no se puede entender sin hacer irremediablemente referencia al origen, naturaleza, protección y consiguiente ejercicio y desarrollo de los mismos.

Sobre este punto, tanto el constitucionalismo moderno como la Ciencia Política han recurrido indistintamente al emblemático momento histórico de las revoluciones burguesas que dan inicio al apasionante 
período de nuestra historia contemporánea. El disparo de salida procede de la proclamación de la Declaración de los Derechos del Hombre y del Ciudadano, aprobada por la Asamblea Nacional francesa en 1789, materializando en su documento escrito la libertad y la igualdad en los derechos de todos los hombres, consagrando una de las más importantes victorias del ciudadano sobre el poder político.

Como es sabido, el resultado feliz de la universal Declaración francesa ha sido de tal magnitud que ha eclipsado otras declaraciones semejantes de también suma importancia política. Así, los Bills of Rights de las colonias americanas, que se sublevaron contra el imperialismo de Inglaterra en 1776, y el Bill of Rights puramente inglés, tras la denominada "Revolución Gloriosa" de 1689, son considerados, sin lugar a dudas, como sus dos principales precedentes. Aunque el matiz ${ }^{3}$ que distingue a los dos primeros del Bill of Rights inglés es relevante, se puede afirmar en ambos casos, y seguir sosteniendo, que el concepto de ciudadanía está vinculado, pues, a toda una serie de derechos que lo delimitan conceptualmente y éstos, a su vez, a un concepción abstracta del individuo, para lo que la Teoría Política cuenta con útiles herramientas de análisis y comprensión. Qué duda cabe, por ejemplo, que la naturaleza humana del individuo abstracto de Thomas Hobbes no se corresponde con la realizada por Rousseau.

La paulatina evolución de este concepto va unida al desarrollo paralelo de otras dos nociones estrechamente ligadas también a la Ciencia Política y a los Servicios Sociales: la libertad y la igualdad, cuya expansión semántica ha redundado en la aparición de una tercera clasificación de los derechos junto a los iniciales derechos civiles y políticos. Estoy haciendo referencia, evidentemente, a los derechos sociales.

Llegado a este punto, estamos listos para realizar, al fin, la siguiente afirmación a modo de primer enunciado concluyente: la extraordinaria contribución que la Ciencia Política puede aportar a la esfera cognitiva de los Servicios Sociales es, en primer término, conceptual y explicativa. En la configuración y establecimiento de todo saber científico es necesario, y más aún en la realidad mutante en la que éste se desenvuelve, la conformación de un marco conceptual apropiado y, dado que el destinatario último de los servicios sociales, más allá de ciertos colectivos o grupos más o menos específicos, es el ciudadano, es admisible considerar que la aportación de la Ciencia y Teoría Políticas a este respecto, es, cuando menos, indispensable. Un requisito que

En el Bill inglés no son reconocidos los derechos del hombre, propio de las elucubraciones del Jusnaturalismo y del Contractualismo característico de la época, sino los derechos tradicionales del ciudadano inglés, cuya fuente de inspiración fue la Common Law. 
no abarca sólo la delimitación conceptual de esta elemental unidad de análisis, sino que debe incluir además una explicación acertada de los porqués que circunscriben la noción política de ciudadano en cada momento histórico.

Un segundo elemento clave estrechamente unido al concepto de ciudadano es el de la participación, también igualmente importante para los Servicios Sociales. Como un racimo de cerezas, los conceptos en las ciencias sociales se entrelazan e interrelacionan complementándose, aportando nuevos espacios conceptuales. Así, toda participación bien entendida inexorablemente se constituye, a su vez, en un elemento primordial de una realidad, la cual, aunque normalmente equívoca y pluriforme, delimita un modelo político central para la Ciencia Políti$\mathrm{ca}$, y en cuyo seno se desenvuelve actualmente el sistema público de servicios sociales, la democracia.

El boom asociativo, el fenómeno actual del voluntariado, las influencias ejercidas por los grupos de presión de toda índole, la mayor o menor intensidad del corporatismo, la canalización de las demandas ciudadanas por medio de los partidos políticos, la paulatina descentralización territorial, orgánica y funcional..., no son objetos que deban ser considerados aleatoriamente, sino medidos y analizados en su justa importancia como fenómenos de dos significados interrelacionados, incluso etimológicamente hablando, la democracia v.s. participación. Asimismo, la huida de la colectividad, las tendencias abstencionistas, el desencanto político generalizado, el inquietante desinterés por lo comunitario..., son manifestaciones patológicas del mal endémico originado por una concepción mal entendida tanto de la participación como de la democracia y las cuales son analizadas por la Sociología Política, explicadas en cierta medida por la Cultura Política, pero cuya comprensión global y formulación de soluciones requiere necesariamente un enfoque politológico. La articulación de la participación, la democratización interna de la administración local, la modernización de los procedimientos burocráticos, las posibilidades sin desarrollar aún de nuestra Constitución, tales como la iniciativa legislativa y el referéndum, ¿acaso no son aspectos relevantes de nuestra presente realidad socio-política aptos para una investigación profunda desde un enfoque necesariamente interdisciplinar, pero, por consiguiente, también irremediablemente politológico?.

La participación es un componente de la noción de democracia, pero ésta, incluso sólo aplicando procedimientos indirectos, no puede prescindir de la participación. Como ya he indicado, la Ciencia Política no sólo pretende describir y explicar, sino, además, interpretar, evaluar y predecir. Según Juan Amézaga (1994), no se han concretado ni garantizado suficientemente los mecanismos para la participación. La 
falta de movilización y dinamismo social es un rasgo característico de la presente situación socio-política, una manifestación concreta, entre otras, de un contexto político, social, económico y cultural que reclama una solución. En este punto, la Ciencia Política puede aportar sus amplios conocimientos sobre el proceso político de adopción de decisiones, así como promocionar soluciones en común esfuerzo con los profesionales de las otras ramas involucradas. ¿Cómo canalizar, por ejemplo, la tan "cacareada" participación de los ciudadanos en la gestión de los servicios sociales, especialmente, en el ámbito de la administración local?. El saber de lo político puede y debe contribuir en el encuentro de soluciones, porque su colaboración, dicho sea de paso, una vez más, es indispensable para entender el entramado de interacciones de procedencias diversas que participan de los porqués de una específica decisión política adoptada en un momento dado.

Estaremos de acuerdo que, tal y como han comenzado a concebirse actualmente los servicios sociales, su significado incluye conceptualmente la participación de sus principales protagonistas, los usuarios, pero, por encima de esta consideración, ya relevante, se encuentra un principio más importante, pilar de todo sistema democrático: la participación es necesaria porque sin ella no hay un real ejercicio democrático del poder, por lo que sin participación política y ciudadana los miembros de una comunidad no encuentran el medio indispensable para pasar de su condición como individuo/persona, que ostenta ciertos derechos, a la de auténtico ciudadano.

\subsubsection{La finalidad del Estado en proyección histórica}

Tanto para el Trabajo Social, en general, como para los Servicios Sociales, desde un enfoque más específico, hablar de ciudadano/usuario es hacer mención obligatoriamente a necesidades y modos de satisfacción de las mismas. Es hacer referencia, asimismo, a fines tan compremetedores como la cohesión y bienestar sociales a través de la participación de agentes públicos y/o privados. Y, además, generar expectativas desde las que aprehender modelos comunitarios de convivencia en los que los individuos/ciudadanos puedan desarrollar óptimamente sus potencialidades y capacidades a fin de alcanzar su pleno desarrollo personal. Es, pues, y en definitiva, vincular al ciudadano necesaria y forzosamente con el Estado, porque su naturaleza, recursos, objetivos y más excelsa finalidad son, desde hace centurias, condición de la existencia humana.

Como es generalmente admitido, el Estado es sólo una forma histórica de unidad política, por lo que su especifidad original le vuelve diferente tanto de los modelos precedentes como de cualesquiera otras 
alternativas posibles de futuro, por más que, en sentido amplio, aunque incorrectamente, es utilizado coloquialmente para designar todo modelo de convivencia política, siempre existente, sea ya por la naturaleza sociable del ser humano, según el criterio aristotélico, ya por las inseguridades a las que le arrastra su naturaleza pasional y egoísta, pese a su condición antisocial, según Hobbes, razones que llevan a los individuos aislados hacia el artificio de lo colectivo y comunitario para garantizar su integridad física y su propiedad. Independientemente del criterio utilizado con el que explicar el origen de toda comunidad política en función de una concepción abstracta de la naturaleza humana, la finalidad genérica del Estado, satisfacción de necesidades, nos recuerda, como he pretendido señalar a comienzos de este párrafo, cómo éstas devienen denominador común de un análogo objeto de estudio y preocupación de estas áreas de conocimiento. No en vano, las distintas modalidades de satisfacción de las necesidades que en el área de los Servicios Sociales suelen ser clasificadas como antecedentes históricos, tales como "la ayuda mutua", "el reparto medieval", "la irrupción de la beneficencia", "el pauperismo y la seguridad social" 4 , se corresponden, como no podía ser de otro modo, con un modelo específico de Estado o, más concretamente, con una concepción concreta de la finalidad de la comunidad política y sus inevitables e intrínsecas relaciones de poder, según el período histórico objeto de atención.

Así pues, junto a los fines permanentes o consustanciales del Estado, tales como el mantenimiento de su propia conservación como organización ${ }^{5}$, su permanencia como entidad soberana en el marco internacional y la convivencia pacífica en el seno de su delimitación territorial, encontramos otras finalidades más estimables, estrechamente vinculadas a la relación súbdito/ciudadano-poder político en aras del desarrollo integral de los componentes de ese modelo de comunidades específica. De este modo, durante el Despotismo Ilustrado, por ejemplo, ciertos Estados absolutistas se propusieron hacer de la felicidad de sus súbditos el leimotiv de sus intervenciones políticas, para lo que desarrollaron una extensa actividad administrativa. Para el Estado Liberal, por el contrario, la felicidad es un asunto personal, una cuestión privada reservada a la esfera íntima del individuo a la que el Estado no le está permitido interferir, postulando simultáneamente la libertad como supremo valor de la comunidad política, para lo que será necesario la sujeción del poder político a los contenidos de la ley, garantía de las

4 Sobre este apartado, las referencias bibliográficas son, afortunadamente, copiosas. A modo de sugerencia, ver "Los servicios sociales en perspectiva histórica", Documentación Social, n. ${ }^{\circ} 64$, julio/septiembre, 1986.

5 Conviene recordar sobre este punto que el Estado ha sido la primera gran organización, propiamente hablando, después de la Iglesia, su gran fuente de inspiración. 
libertades y derechos individuales. Posteriormente, como todos sabemos, el Estado Social o Estado Distribuidor sumará a la finalidad del Estado Liberal precedente los medios necesarios o "procura existencial" con los que los ciudadanos podrán hacer efectiva la utilización de la libertad para su personal proyecto existencial una vez satisfechas sus perentorias necesidades más elementales. Esta confluencia de procesos diversos para la satisfacción de las necesidades humanas ofrecerá, qué duda cabe, una contextualización más enriquecedora de lo que han sido los servicios sociales en el transcurso de los años.

Sin embargo, la importancia de las posibles aportaciones de la Ciencia Política al conocimiento científico de los Servicios Sociales es hoy día mayor, dado el carácter público de los servicios sociales ofertados actualmente y la finalidad del modelo de Estado, cuestionada por la expansión de los principios clásicos del liberalismo-conservador.

Por un lado, la finalidad del Estado de Bienestar, según Ramón Cotarelo (1986), consiste en garantizar el bienestar social pasando a ser ahora la legitimidad del nuevo modelo de organización política la preocupación estatal por canalizar los conflictos sociales pacíficamente y por intervenir en "toda suerte de relaciones privadas", y, por otro lado, los Servicios Sociales se definen como sistema público para la garantía universal de los derechos sociales "dentro de las nuevas estrategias del bienestar social", en opinión de Gustavo García y José Manuel Ramírez (1992). Esta repetida confluencia dado a) el bienestar social como objeto compartido de estudio; b) "el carácter público" de todo el sistema de servicios sociales y, por ende, procedente de las pertinentes instituciones del poder político, independientemente de su mayor o menor descentralización territorial, orgánica y funcional, y c) la condición de los servicios sociales como instrumentos de política social, nos conducen, nuevamente, al punto de inflexión de este artículo: la naturaleza pluridisciplinar característica de la disciplina de los servicios sociales no es una mera invitación a la Ciencia Política en función de ciertos aspectos comunes, objeto de estudio, e intereses de ambas disciplinas, sino que su colaboración es imprescindible dada la naturaleza política de los mismos servicios sociales, so pena, claro está, de convertir el campo científico de los Servicios Sociales en una simple gestión empresarial de ciertos recursos, según los baremos conocidos de la eficiencia y la utilidad.

La crisis del Estado Benefactor, las consecuencias de la globalización económica mundial y, particularmente, el proceso paulatino, pero aparentemente firme, de integración europea presentan día tras día nuevos desafíos a la permanencia de los servicios sociales y a la continuidad de ciertos contenidos de política social. La colaboración interdisciplinar no tiene por qué sustentarse sólo en suplir la compleja falta de autono- 
mía, también podría ser utilizada para reinventar, conjuntamente, nuevos argumentos que consoliden sólidamente la noción de bienestar social en el futuro.

\section{3:2.3. Elementos de un sistema político y sus interacciones}

Si hemos aceptado con convicción el enunciado ligeramente esbozado en la página anterior, según el cual la red de servicios sociales procede de las pertinentes instancias del poder político, no será difícil admitir ahora que éstos son un componente vertebral y definitorio que da contenido al modelo político que denominamos Welfare State, el cual es, a su vez, un modelo teórico de sistema político, y, por ende, los servicios sociales, independientemente que su materialización práctica evidentemente pueda adoptar diversas y numerosas formas de intensidad, se constituyen, pues, como elemento de un sistema político.

La locución "sistema político", como todas las nociones que pretenden sistematizar el lenguaje de las ciencias sociales en general, es equívoca. Propongo utilizarla según una acepción concreta que hace referencia a la vida política de toda la sociedad, así, todo sistema político puede ser identificado con el conjunto de interacciones sociales e institucionales, las cuales asignan valores a una determinada sociedad.

Como término con implicaciones analíticas específicas fue introducido y conocido popularmente por medio de la obra "El sistema político" de David Easton (1953). Paulatinamente, primero en los Estados Unidos y más tarde en Europa, la expresión "sistema político" ha desplazado a la idea de Estado, el cual proporciona una descripción más acertada y completa del dominio del campo de estudio de la Ciencia Política. Como recordarán, la Teoría de Sistemas en su aplicación a las Ciencias Sociales ha sido criticada desde diversas perspectivas, las cuales acaban confluyendo en un vértice común: no existe una Teoría General de sistemas, sino toda una gran familia de sistemas que constituye un bloque teórico cohesionado.

En cuanto a la Ciencia Política se refiere, un enfoque crítico ya conocido es el introducido por el profesor Cotarelo (1979), según el cual, mientras no se produzca una distinción nítida entre el sistema y el medio, siempre estará ausente un factor fundamental para estructurar una verdadera Teoría de sistemas, porque los poderes públicos cuando actúan sobre los ciudadanos sus efectos no sólo recaen sobre el medio, sino también sobre el propio sistema. Pero, por encima de las acertadas críticas y observaciones realizadas sobre la Teoría de sistemas, es honesto reconocer que este enfoque metodológico ha abierto un amplio sendero en nuestra disciplina con el que contrastar, observar y analizar las materias afines a la Ciencia Política, logrando, ciertamente, un 
amplio reconocimiento colectivo nada desdeñable en pro de su virtuosa utilidad. No en vano, esta mencionada utilidad, junto a su vocación integradora y claridad, ha llevado al mismo profesor Cotarelo a enumerar sus ventajas y a concluir que "no es preciso que el paradigma dé respuestas satisfactorias a todos los problemas que se planteen. Será suficiente si redefine el campo científico, orienta a la investigación y permite el ejercicio práctico de la Ciencia como una actividad de resolver rompecabezas" (Ramón Cotarelo, 1979:98/99).

La noción "sistema político" presupone tres supuestos: 1.- toda sociedad se compone de toda una variedad de sistemas de distinta naturaleza; 2.- el sistema político puede abstraerse o diferenciarse para su estudio de los no políticos ${ }^{6} \mathrm{y}$, más importante aún, 3.- todos los subsistemas y elementos que constituyen una sociedad están en permanente interacción e influyéndose constantemente. Este tercer elemento es absolutamente imprescindible a la hora de demostrar, una vez más, la estrecha vinculación que une los Servicios Sociales con la Ciencia Política.

En primer lugar, y en consonancia con lo ya enunciado en párrafos anteriores, si consideramos que los individuos, como afirma David Easton (1969), que intervienen en esas interacciones, y más concretamente los que actúan en roles políticos, son llamados genéricamente miembros del sistema, los procedimientos que éstos utilizan, incluyendo los indirectos, para intervenir en los procesos que en sentido amplio podemos catalogar con la acepción genérica de "sociales" deben ser, pues, considerados igualmente elementos del sistema. Dicho esto, ¿Cómo no vamos a considerar los servicios sociales como un elemento del sistema de bienestar cuando la contracción v.s. expansión de estos instrumentos de política social dependen, primordialmente, de los sujetos o actores centrales que detentan el poder político?. Y, en segundo lugar, y más importante aún, es el enfoque que hace referencia al complejo entramado que conlleva el proceso de adopción de decisiones políticas e implementación de las mismas. Si seguimos sosteniendo que el bienestar social es una finalidad que nos une en cierta medida, no pudiendo obviar que los profesionales más inmersos en estas áreas

" Obsérvese que en la línea de este procedimiento, aunque ciñéndonos a lo que podríamos denominar puramente "social", Salvador Giner (1996:22) también ha señalado a este respecto, en relación a la dificultad de conocimiento en el proceso sociológico, que mientras que "el economista puede hacer abstracción de ciertas dimensiones de la realidad social... y estudiar al hombre como homo oeconomicus (y) lo mismo puede hacer la ciencia política, y entenderlo como homo politicus... en la concepción de homo sociologicus nos vamos a encontrar con que éste será siempre sujeto simultáneo de diversas redes de interrelaciones y de creencias y valores... y es que la multiplicidad de las dimensiones sociales se hace sentir siempre en el estudio de la sociedad". 
como son los trabajadores sociales, encargados de aplicar las políticas sociales ya diseñadas, también en opinión de Natividad de la Red (1996), proporcionan indicadores y argumentos para cambiar estas políticas; el objeto de estudio de los Servicios Sociales tiene que contar necesariamente con los útiles conocimientos necesarios sobre estas instancias de poder que también influyen en el proceso de adopción de decisiones y confluyen así con otros protagonistas copartícipes de las mismas. De este modo, habrá que tenerse en cuenta, igualmente, el papel que desempeñan ciertas administraciones y organismos políticos y entidades tuteladas, así como aquellas entidades que canalizan las demandas sociales, como los partidos políticos y los grupos de presión, cuya naturaleza diversa incluye desde las tradicionales organizaciones sindicales y empresariales hasta la propia comunidad de vecinos en una administración local.

Este complicado compendio de interacciones exige un conocimiento más global y completo de la ya compleja realidad socio-política, lo que justifica, a mi entender, las oportunas observaciones que desde la Ciencia Política se puede aportar al campo y a los contenidos más específicos de los Servicios Sociales.

Una cuestión última a añadir, aunque brevemente expuesta en un par de líneas y cuya brevedad, admito, no se corresponde en absoluto con la crucial importancia que ésta tiene: ¿cómo va a prescindir la disciplina de los Servicios Sociales de las convicciones políticas, del protagonismo subyacente que desempeñan las ideologías, expresamente en estos tiempos de "crisis" del Estado de Bienestar, cuando son éstas las que pueden poner en situación de "jaque-mate" la persistencia misma de la naturaleza pública de todo el conjunto del sistema de servicios sociales??

\section{IV.LA NECESIDAD DE UN NUEVO ESTILO DE HACER DEMO- CRACIA}

Tras la caída del muro de Berlín y la rápida sucesión de acontecimientos que han superado las barreras de todas las previsiones imaginables, la democracia parece disfrutar de un aura de legitimidad, desconocida hasta hace relativamente poco, cimentando, más sólida-

7 Para aquellos 'escépticos' que se han forjado el convencimiento de que los contenidos de las políticas sociales no tienen nada que ver con las orientaciones ideológicas de las fuerzas políticas, es recomendable seguir difundiendo los acertados y oportunos argumentos que Norberto Bobbio (Derecha e Izquierda, Taurus, Madrid, 1995) recoge en su reciente libro sobre las razones y significados que aún, "en los tiempos que corren", dan contenido a una distinción política. 
mente aún, su universal criterio paradigmático exportable a todos los confines del planeta.

Sin embargo, simultáneamente, el descontento, la apatía y un cada vez mayor número de voces críticas manifiestan abiertamente, de diversas formas, su descontento hacia este modelo de organización política, exhibiendo aquellos aspectos que consideran puramente formales de la misma o al menos políticamente poco desarrollados, especialmente en todo lo que respecta a la participación. Así, David Held (1991:360) sostiene que "no muy por debajo de la superficie del triunfo de la democracia existe una paradoja manifiesta: mientras que se defiende de nuevo la idea del "gobierno del pueblo", la eficacia misma de la democracia como una forma nacional de organización política se ve puesta en duda". Pero, aunque el análisis que sigue a este enunciado es de suma importancia, ya que trata fundamentalmente sobre la interconexión y sistemas mundiales, la superación política de las fronteras estatales y el establecimiento de instituciones decisorias de naturaleza supranacional, en cuanto concierne a los servicios sociales, las críticas a la democracia representativa se ciernen más sobre los factores que obstaculizan una mayor profundización en los aspectos participativos del sistema político. Un ejemplo ilustrativo de esta realidad en nuestro país es el artículo de Manuel Montañés (y otros; 1996:23) en el que denuncia explícitamente que mientras "unos apelamos porque la sociedad civil asuma su protagonismo y sea copartícipe de las decisiones públicas, otros, sin embargo, quieren una sociedad civil domesticada y como servicio complementario para tapar los agujeros que van surgiendo en el proceso de desmantelamiento del Estado de Bienestar".

En mi opinión, este sano inconformismo crítico manifestado contra las instituciones, y no estoy aludiendo al autor, puede correr, no obstante, un riesgo de lamentables tintes "demagógicos", esto es, la ausencia de verdaderas alternativas susceptibles de ser llevadas a la práctica, en otras palabras, "pecar" de excesivo celo al enarbolar la participación ciudadana como un banderín progresista sin presentar, al mismo tiempo, procedimientos y argumentos sólidos que hagan viable, ciertamente, la materialización de estas opciones. En esta línea, Ramón Cotarelo (1990:71) ha expresado que "a veces da incluso la impresión de que quienes insisten en proponer un aumento de la participación, desconocen los cauces reales para llevarla a cabo, con lo cual hacen legítima la duda sobre sus auténticas intenciones. Y, en el peor de los casos, las mencionadas instituciones, como la iniciativa popular, el referéndum, la petición, la revocación, las únicas viables en régimen de compatibilidad con la democracia representativa (ya... que nadie parece reclamar hoy de verdad una democracia directa) también son consideradas como informales e insuficientes por los críticos izquierdistas". 
No obstante, es justo admitir que ciertas medidas están siendo estudiadas seriamente, incluso aplicadas algunas de ellas, en otros Estados muy en consonancia con la noción de "autonomía democrática", introducida por David Held (1991:347), según el cual "la aplicación del principio de autonomía, en torno a un proceso de doble democratización, produce un modelo de Estado y de sociedad civil,... el modelo comprende un número de propuestas que en conjunto podrían crear las condiciones para la defensa y desarrollo de la democracia en las condiciones contemporáneas (en donde) el Estado garantizaría los recursos y los servicios para el cuidado de los niños, las clínicas de salud y los colegios, al tiempo que dejaría el gobierno de esas organizaciones a comunidades locales". Propuestas de esta naturaleza proceden de los gobiernos escandinavos acerca de cómo conseguir una ampliación gradual de la propiedad social productiva, las cuales encuentran su razón de ser, lógicamente, tanto en el desarrollo como en las adversidades que tiene que hacer frente el Estado de Bienestar.

No es de extrañar, pues, como se ha comentado ya desde distintos foros, que los municipios se están convirtiendo, dada la proximidad ciudadano/poder político/asuntos comunitarios, en los laboratorios más afines a estos intentos de cambios democratizadores. Por otro lado, y a mi modo de ver, la corriente alternativa al Estado de Bienestar, conocida bajo la rúbrica de "pluralismo de bienestar", por ejemplo, presenta una oferta peculiar caracterizada por la participación de los usuarios en el proceso de adopción de decisiones en materia de servicios sociales a nivel local, por más que también esta opción plausible introduce serios inconvenientes que indudablemente, sin la adopción previa de garantías necesarias, cuestionarían seriamente su efectividad, tales como, y en opinión de Garcés Ferrer (1996:49), la delimitación de la iniciativa para la gestión de los recursos de servicios sociales (administración pública v.s. iniciativa social) o, más concretamente, y en lo que concierne a nuestro país, la ausencia de a) una autonomía económica y administrativa, b) una conciencia de autogestión de servicios y c) una estructuración del voluntariado, indispensable para lograr este cometido ${ }^{8}$. Interrogantes importantes del tipo de qué legitimidad dis-

A este respecto, a modo de aportación personal, una profunda reestructuración de los Consejos de Servicios Sociales o Bienestar Social, desde los cuales potenciar una mayor partícipación de los grupos sociales en todos los niveles de la administración del Estado, cuyas posibles funciones más determinantes (lejos del mero asesoramiento consultivo presente), amplia representación (no reducida sólo a ciertos colectivos establecidos por el marco jurídico actual) y legitimidad democrática (condición sine que non para participar a un mismo nivel de igualdad con el poder político) permitirían una mayor efectividad y aceptación de la que escasamente gozan hoy día estas instituciones complementarias en el proceso de adopción de decisiones. En definitiva, una vía participativa más acorde con los principios representativos que caracterizan nuestros modelos democráticos actuales. 
pondrían los grupos ciudadanos-copartícipes en el proceso de adopción de decisiones en la esfera local, deben ser resueltas con suma prudencia y reflexión. Quizás, sería más conveniente, a pesar de la aparente paradoja, girar nuevamente hacia la delegación característica del sistema representativo con base electoral para, por ejemplo, componer futuros órganos, abiertos a todos los colectivos de ciudadanos y desde los cuales coparticipar en la gestión de los asuntos comunitarios, en lugar de criticar sin fundamentos ni alternativas verosímiles nuestro presente modelo de organización política que, aunque no es perfecto y difícilmente lograremos uno, dicho sea de paso, se presenta actualmente como el único modelo válido susceptible de exportación universal.

\section{CONCLUSIONES}

La Ciencia Política aspira ser una ciencia más en el seno de las denominadas Ciencias Sociales, para cuyo objetivo se dota de a) un objeto (el poder: su naturaleza, legitimidad, ejercicio e interacciones) que, aunque difícilmente autónomo, sí circunscribe, por el contrario, una esfera específica del comportamiento humano como ser social, y b) un método científico apto para la investigación de su objeto de estudio, desafiando los complejos problemas epistemológicos que retan a nuestra área del saber a la hora de formular enunciados con rango de leyes científicas.

Por su parte, los Servicios Sociales, reconocidos como instrumentos de política social, confluyen con la Ciencia Política en a) los actores protagonistas que detentan el poder y deciden políticamente, b) la participación ciudadana, columna vertebral del sistema democrático desde un punto de vista teórico, c) evolución paralela de los modelos de satisfacción de las necesidades junto a los rasgos específicos que caracterizan la finalidad del Estado en cada momento histórico, d) la naturaleza pública del sistema de servicios sociales que define el modelo de organización política presente, el Estado de Bienestar y e) la necesidad de conocer los otros actores políticos (partidos políticos y administraciones públicas) y agentes sociales (grupos de presión de naturaleza diversa) que intervienen directa e indirectamente en el proceso de adopción de decisiones y de los cuales depende el futuro de la permanencia pública de toda la red de servicios sociales.

Finalmente, las insuficiencias del modelo democrático actualmente exigen medidas reformadoras capaces de hacernos superar los obstáculos que imposibilitan en la actualidad una participación más activa de la ciudadanía. Por esta razón, deben ser bien recibidos los modelos 
alternativos al presente sistema participativo que tan abiertamente está mostrando sus insuficiencias y, como era de esperar, sus desagradables consecuencias manifestadas en la apatía, el desinterés e, incluso, la desidia, que un número cada vez mayor de ciudadanos muestra, en general, hacia todo "lo político" y, más concretamente, hacia la colaboración ciudadana en asuntos de su comunidad. Modelos alternativos como el elaborado por Garcés Ferrer (1997) en su ponencia de GuadixGranada sobre los servicios sociales y las políticas de igualdad, que invita, no sólo a una seria reflexión sobre las insuficiencias tantas veces mencionadas, sino también, y más relevante aún, a expresar este saludable conformismo hacia un sistema, si se me permite, ortopédico, que malentiende lo que debe ser entendido por una participación ágil, activa e ilusionada". Pero las críticas y alternativas hacia nuestro sistema representativo requieren igualmente prudencia, reflexión y desapasionamiento, so pena de caer rápidamente en la mera demagogia propagandística, falsamente progresista y desafortunadamente útil sólo para minar un modelo de organización política que garantiza, como mínimo, el acceso, ejercicio y alternativa en el poder por medios pacíficos. Los sucesos históricos son irrepetibles, pero sus lecciones, que no debemos olvidar, son magistrales.

\section{BIBLIOGRAFÍA}

ALEMÁN BRACHO, M. ${ }^{\circ}$ del C. y GARCÉS FERRER, J. (dir.): Administración Social: servicios de bienestar social. Siglo XXI. Madrid, 1996.

AMÉZAGA, J.: «Democracia y participación» en Revista de Trabajo Social, n. 133 (marzo). Ed. Colegio Oficial de Diplomados en Trabajo Social y Asistentes Sociales de Cataluña. 1994.

DE LA RED, N.: «El Trabajo Social en los servicios de bienestar social». Citado por ZAMANILLO, T. «Bienestar y Trabajo Social» en Pros y Contras del Estado de Bienestar, CASILDA, R. y TORTOSA, J.M." (ed.). Tecnos. Madrid, 1996.

EASTON, D.: Esquema para el análisis político. Amorrortu. Buenos Aires, 1969.

GARCÉS FERRER, J.: Sistema político y administrativo de los servicios sociales. Tirant lo Blanch. Valencia, 1996.

' En opinión de Garcés Ferrer (1997), su peculiar modelo de 'empresa social comprometida' es "una nueva forma de organización económica y social capaz de erigirse como instrumento creativo para un nuevo compromiso social e ideológico... que trasciende lo meramente societal así como el modelo de gestión privada de recursos públicos de bienestar, y en su lugar, la sociedad entra a gestionar espacios conflictivos... a los que por razones políticas o económicas el Estado y el mercado ya no pueden dar una respuesta efectiva y se baten en retirada". 
GARCÉS FERRER, J.: «Los servicios sociales y las políticas de igualdad» (ponencia), Guadix-Granada, 14/15 de marzo de 1997.

GARCÍA COTARELO, R.: Introducción a la Teoría del Estado. (comp.) Teide (3. ${ }^{a}$ ed.). Barcelona, 1986.

GARCÍA COTARELO, R.: Del Estado del Bienestar al Estado del Malestar. Centro de Estudios Constitucionales. Madrid, 1986.

GARCÍA COTARELO, R.: Crítica a la Teoría de Sistemas. C.I.S., 1979.

GARCÍA COTARELO, R.: En torno a la Teoría de la Democracia. Cuadernos y Debates 23. Centro de Estudios Constitucionales. Madrid, 1990.

GARCÍA HERRERO, G. y RAMÍREZ NAVARRO, J.M.: Los nuevos servicios sociales. (2. ${ }^{a}$ ed.) Certeza. Zaragoza, 1992.

GINER, S.: Sociología. (nueva ed. revisada). Península. Barcelona, 1996.

HARO TECGLEN, E.: Diccionario Político. Planeta. Barcelona, 1995.

HELD, D.: Modelos de democracia. Alianza Universidad. Madrid, 1991.

MONTAÑÉS, M. (y otros): «¿Asociaciones de voluntarios?. Lo que se dice y lo que se quiere decir cuando hablamos de voluntariado», en Voluntariado, Documentación Social. Cáritas Española, n. ${ }^{\circ}$ 104, julio/septiembre, 1996.

PÉREZ ROYO, J.: Introducción a la Teoría del Estado. Blume. Barcelona, 1980.

SABINE, G.: Historia de la Teoría Política. Fondo de Cultura Económica. (16. ${ }^{\mathrm{a}}$ reed.). México, 1987.

SARTORI, G.: La Política, lógica y método en las Ciencias Sociales. Fondo de Cultura Económica. México, 1984.

SMITH, A.: Teoría de los sentimientos morales. Fondo de Cultura Económica. México, 1978. 


\section{LA ACCIÓN SOCIAL EN LA UNIÓN EUROPEA: EVOLUCIÓN HISTÓRICA}

\section{SILVIA QUESADA DÍEZ}

Licenciada en Ciencias Empresariales y Derecho. Universidad Pontificia de Comillas. ICADE.

\section{RESUMEN}

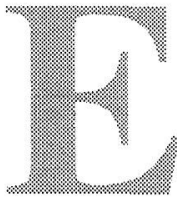

n el presente artículo se va a desarrollar brevemente cuál ha sido la evolución de la Política de Acción Social Europea en los últimos tiempos. Son muchos los esfuerzos que desde la Unión Europea se están llevando a cabo para desarrollar y consolidar una Política Social que busque el mayor beneficio para todos los ciudadanos. Algunos de los principales objetivos han sido, entre otros, mejorar la situación del empleo, el desarrollo de recursos humanos, fomentar la solidaridad y la integración, la lucha contra la pobreza y la exclusión, fomento de la igualdad de oportunidades entre hombres y mujeres en una sociedad europea en curso de transformación, reforzamiento del diálogo social y el mercado único y la libre circulación de las personas.

\section{SUMMARY}

In this article the most important points and the evolution of the Social Policy in Europe it is going to be explained and summarized. A lot of effort is being developing in order to create and consolidate the social profits for the European people. The European Social Policy have specific and important objectives and some of these essential objectives are: to improve the employment situation, to fight against the poverty, to develop the equal opportunities between both, men and women, and to get a global trade in Europe where products and people are able to circulate without any kind of barriers. 


\section{ANTECEDENTES}

Quienes piensan que la Unión Europea es algo distante de la vida del ciudadano de a pie deberían examinar más de cerca su Política Social y los esfuerzos que realiza en materia social. El modelo europeo de acción social ha hecho mucho para mantener la armonía social y la paz durante los cincuenta últimos años. Su mantenimiento continúa siendo una de las prioridades de la Unión y de sus Estados miembros. Todo ello a pesar de las presiones para reducir los gastos sociales que impone, en parte, la competencia mundial y que se han intensificado en un momento en que el aumento del desempleo y el envejecimiento de la población lastran cada vez más el presupuesto de la Unión.

El desarrollo de una política de acción social a escala comunitaria no figuró entre las grandes prioridades de los seis Estados miembros durante los doce primeros años de la Comunidad Europea. El único sector de actividad real era la coordinación de los regímenes de seguridad social para los trabajadores emigrantes que ejercían el derecho de libre circulación que les confería el Tratado.

Las disposiciones de política social, que ya figuraban en el Tratado constitutivo de la Comunidad Europea del Carbón y del Acero (1951), se vieron confirmadas más tarde en el Tratado constitutivo de la CEE con la inclusión de la mejora de las condiciones de vida y de trabajo entre los objetivos de la integración europea. Para ello se contaba, sobre todo, con la contribución del Fondo Social Europeo y con la coordinación y cooperación entre los Estados miembros. Ya antes de 1970, y como parte de la realización de la libre circulación de los trabajadores, uno de los objetivos fundamentales del mercado interior, se creó un sistema para garantizar las prestaciones de seguridad social a los trabajadores que ejercieran su actividad laboral en otro Estado miembro.

Para poder comprender mejor todo el esfuerzo desarrollado por la Unión Europea en materia de Acción Social, creemos necesario que el lector conozca una breve historia sobre lo que ha ido sucediendo en materia social durante las últimas décadas.

\section{PRIMEROS TIEMPOS (1960): FONDO SOCIAL}

«Para mejorar las posibilidades de empleo de los trabajadores en el mercado interior y contribuir así a la elevación del nivel de vida, se crea, en el marco de las disposiciones siguientes, un Fondo Social Europeo destinado a fomentar, dentro de la Comunidad, las oportunidades de empleo y la movilidad geográfica y profesional de los trabaja- 
dores, así como a facilitar su adaptación a las transformaciones industriales y a los cambios de los sistemas de producción, especialmente mediante la formación y la reconversión profesionales», según se explica en el art. 123 TCE. La administración del Fondo corresponde a la Comisión.

El Fondo fue creado en el Tratado de Roma y empezó sirviendo principalmente para financiar medidas de reinstalación y de reconversión profesional y beneficiando en mayor medida a los Estados miembros más «ricos» que poseían un mayor experiencia en la presentación de solicitudes. A lo largo de los años ha sido objeto de varias revisiones y modificaciones desde su instauración hasta nuestros días.

El FSE se concentra, esencialmente, en ayudas al empleo y en formación profesional continua de los trabajadores a través de acciones de formación, tal y como establecen los art. 125 y $130 \mathrm{E}$ del TCE. Así, los principales objetivos del FSE son conseguir:

- La integración a la vida laboral de personas desempleadas durante un largo período.

- Integración a la vida laboral de los jóvenes en busca de empleo.

- Integración de personas expuestas a la exclusión del mercado de trabajo.

- Promoción de la igualdad de oportunidades entre ambos sexos en el mercado laboral.

- Anticiparse al desempleo adaptando a los trabajadores al cambio laboral.

- Estabilidad y crecimiento del empleo, impulsando la creación de puestos de trabajo.

- Fortalecimiento de los sistemas de educación y formación.

Entre 1994 y 1999 el FSE transferirá 47.000 millones de ecus del presupuesto de la Unión Europea para cofinanciar acciones emprendidas por los Estados miembros.

\section{III.PRIMER PROGRAMA (1974)}

Hasta la adopción del primer Programa de Acción Social en 1974, que marcó el verdadero comienzo de la política social comunitaria, ésta estuvo limitada a las actividades del Fondo Social Europeo. A partir de mediados de los años setenta, la política de acción social se centró en programas de objetivos específicos como, por ejemplo, los dedicados a la seguridad y salud en el lugar de trabajo, al fomento de la igualdad de oportunidades para las mujeres y a la inserción en la vida laboral de los grupos desfavorecidos. Sólo pocas de estas actividades podían apoyarse en un fundamento jurídico específico y los programas 
de Política de Acción Social se basaban en las normas generales de competencia, así y todo, desde 1974 se aceptó básicamente la competencia de la CE para promulgar disposiciones en materia de Política Social.

\section{ACTA ÚNICA (1987)}

El Acta Única Europea fue firmada en 1986 y entró en vigor el I de julio de 1987. Apenas supuso una ampliación de las competencias comunitarias en el terreno de la Política de Acción Social: el nuevo artículo 118 A del Tratado CEE sólo preveía las medidas para salvaguardar la salud y la seguridad en el lugar de trabajo que pudieran ser adoptadas por el Consejo por mayoría cualificada y en cooperación con el Parlamento Europeo.

El Acta Única corrobora en más de un aspecto la evolución durante los años anteriores en materia de desarrollo de políticas comunes y confirma el objetivo de completar el mercado único europeo en 1992 según el calendario fijado en el Libro blanco de 1986. El Tratado constitutivo de la CEE queda enriquecido con la aportación que hace el Acta Única Europea de nuevos artículos que dan un nuevo impulso a la Política de Acción Social, sugieren la importancia de estimular el diálogo entre los interlocutores sociales y hacen hincapié en la necesidad de la cohesión económica y social de los doce Estados miembros.

\section{LA CARTA SOCIAL (1989)}

La Carta Comunitaria de los Derechos Sociales Fundamentales de los Trabajadores fue adoptada por el Consejo Europeo en diciembre de 1989, pese al voto contrario del Reino Unido. Esta Carta pretende contribuir a la realización de la dimensión social del mercado interior. Sin embargo, a raíz de los debates a que ésta fue sometida en el Consejo y a la postura negativa del Reino Unido, el ambicioso objetivo inicial de una "Carta que estableciera unos derechos fundamentales vinculantes y reclamables" quedó convertido en una mera declaración de intenciones políticas de carácter no vinculante sobre una serie de derechos sociales fundamentales.

Los derechos fundamentales que se contienen en ella, como por ejemplo la formación profesional y la libertad de asociación, el derecho de los trabajadores y a la información, etc., no pueden reclamarse, sino que sirven de directrices para la política en los Estados miembros de la Unión Europea, salvo en Gran Bretaña. La Carta Social recoge doce principios: 
1. El derecho a elegir el Estado miembro en que se desea trabajar.

2. El derecho a una remuneración justa.

3. El derecho a mejores condiciones de vida y trabajo.

4. El derecho a la protección social con arreglo a la realidad de cada Estado miembro.

5. La libertad de asociación sindical y el derecho a la negociación colectiva.

6. El derecho a la formación profesional.

7. El derecho a la igualdad de trato de hombres y mujeres.

8. El derecho de información, consulta y colaboración de los trabajadores.

9. El derecho a la protección de la salud y a la seguridad en el puesto de trabajo.

10. La protección de la infancia y la juventud.

11. El derecho de las personas mayores a disfrutar de un nivel de vida adecuado.

12. La promoción de la integración social y profesional de los minusválidos.

\section{SEGUNDO PROGRAMA DE ACCIÓN SOCIAL (1989)}

A pesar de lo acontecido con la Carta Social, y a fin de poder llevar adelante la política social, la Comisión presentó aún en diciembre de 1989 un programa de acción para la aplicación de la Carta a través de cuarenta y siete medidas concretas. Las iniciativas propuestas, que deben contar con la aprobación del Consejo, se han llevado a la práctica en gran parte. Entre ellas, figuran, por ejemplo, directivas sobre los despidos colectivos, sobre la prueba de la relación laboral, sobre la protección de la maternidad, sobre la protección del trabajo juvenil y sobre la jornada laboral. La realización de las medidas restantes se llevará a cabo probablemente, en parte, sin el Reino Unido, en el marco del Protocolo Social.

\section{MAASTRICHT Y EL PROTOCOLO SOBRE LA POLÍTICA SOCIAL (1991)}

En el transcurso de las negociaciones para el Tratado de la Unión Europea el Gobierno británico sostuvo la no ampliación de las competencias comunitarias. Por ello, se temió que la Política Social fuera a 
convertirse en el obstáculo para la llegada a un acuerdo. El Consejo Europeo de Maastricht (diciembre de 1991) acabó encontrando un compromiso consistente en dejar intactas las disposiciones del Tratado CEE en materia de Política Social y en añadirle un «Protocolo sobre la política social». En dicho Protocolo, firmado por los doce Estados miembros y anexo al Tratado de Unión Europea, se declara la voluntad de once Estados miembros de lograr avances significativos en materia de política social.

Mediante este Protocolo se facultaba a los demás Estados miembros a recurrir a los órganos, procedimientos y mecanismos de los Tratados para llevar adelante una política social común de mayor alcance sin el Reino Unido. Lo expuesto anteriormente llevó consigo que la aplicación del Protocolo Social diera lugar, por primera vez en la historia de la Comunidad, a un acto de legislación comunitaria derivada destinado solamente a una parte de los Estados miembros, pudiendo crear con ello una posible ventaja competitiva para el Reino Unido. Sin embargo, en mayo de 1997, el Reino Unido anunció su intención de renunciar a su cláusula de excepción en materia social.

Los objetivos de la Política de Acción Social son el fomento del empleo, la mejora de las condiciones de vida y de trabajo, una protección social adecuada, el diálogo social, el desarrollo de los recursos humanos para conseguir un empleo elevado y duradero y la lucha contra las exclusiones.

Por último, sitúa explícitamente fuera del ámbito de las competencias comunitarias las remuneraciones, el derecho de asociación y sindicación, el derecho de huelga y el derecho de cierre patronal.

\section{LIBRO VERDE (1993)}

En noviembre de 1993, la Comisión publicó el Libro Verde sobre el futuro de la Política Social europea en el marco de un extenso proceso de consulta. Parecía claramente necesario que los ciudadanos europeos debían sentir que la Unión y la Europa social les afectaba más que en el pasado. Los mensajes clave resultantes del proceso de consulta y recogidos en el Libro verde eran que existe un modelo social europeo claro, basado en la democracia y los derechos individuales, la libertad de negociación colectiva, la economía de mercado, la necesidad de igualdad de oportunidades para todos y la importancia de la protección social y de la solidaridad.

Europa atravesaba un período de cambios profundos a nivel social y económico, como muestra la mundialización creciente, la difusión de nuevas tecnologías, los nuevos métodos de organización del traba- 
jo, la evolución de las estructuras de la población en Europa y el aumento del coste de la asistencia sanitaria de las pensiones. El Libro Verde concluye que el desempleo en Europa es un problema estructural y no cíclico y debe tratarse como tal. No basta con que el PIB aumente; es necesario que el empleo se desarrolle paralelamente.

\section{Resumen de las principales cuestiones}

1. En materia de mercado de trabajo:

- la oferta de un empleo o de una formación a todos aquellos que buscan trabajo,

- un nuevo equilibrio entre los gastos dedicados, por una parte, a las medidas activas y, por otra, al mantenimiento de los ingresos.

2. En materia de protección social y de exclusión:

- establecimiento de un nivel mínimo de ingresos,

- plan de integración para todos los excluidos.

3. En materia de igualdad de oportunidades:

- objetivos (trabajo compartido, reparto de los ingresos, toma de decisiones) en favor de grupos específicos tales como las mujeres,

- medidas que permitan combinar las responsabilidades familiares y el trabajo,

- en cuanto a los jóvenes, la «garantía» del empleo o de una formación útil,

- medidas que permitan fomentar el fin de la segregación vertical y horizontal del mercado de trabajo.

4. En materia de formación:

- objetivos en materia de producción de cualificaciones en diferentes niveles, de forma que se movilice a los diferentes actores;

- supresión de los obstáculos jurídicos todavía existentes a la libre circulación de los trabajadores (reagrupación familiar, igualdad de trato, derecho de residencia, etc.);

- desarrollo de la red EURES a fin de proporcionar asesoramiento e información sobre las ofertas de empleo y las condiciones de vida y de trabajo a escala comunitaria;

- igualdad de trato para todos los ciudadanos de la UE que residan en un Estado miembro, en particular en lo que se refiere a las ventajas sociales y fiscales (estudiantes, jubilados, etc.);

- garantía de una mejor protección social de los trabajadores que se trasladan a otro país comunitario, especialmente facilitando la adquisición, la conservación y la transferencia de los derechos de jubilación;

- ampliación de la población cubierta por la coordinación de los regímenes de seguridad social, simplificación de las normas, mo- 
dernización de los procedimientos y mejor información del público en general.

\section{LIBRO BLANCO (1994)}

En julio de 1994, la Comisión publicó el Libro Blanco sobre la Política de Acción Social europea, que contenía sus propuestas sobre el camino a seguir. El Libro Blanco aboga por una nueva amalgama de Políticas Sociales y Económicas y hace hincapié en el hecho de que la competitividad y el progreso social pueden ir unidos. Indica que Europa tiene sobre todo necesidad de una mano de obra adaptable, cualificada y motivada, que solamente una política social puede generar. Los grandes temas del Libro Blanco son: el empleo, las modalidades de desarrollo del fundamento jurídico y de la necesidad vital de una sociedad que exija la colaboración activa de todos.

El Libro Blanco es el resultado del procedimiento de consulta iniciado por el Libro Verde sobre la Política Social europea que ha implicado a las instituciones de la Unión, a los Estados miembros, a los empresarios, a los sindicatos, a las instituciones públicas y a los particulares. Se esfuerza por determinar las principales líneas de acción de la Unión para los próximos años y las principales propuestas son relativas al empleo y a la formación.

Este Libro pretende consolidar y desarrollar todo lo que se ha ido realizando anteriormente, en particular lo que respecta al derecho laboral, la salud y seguridad, la libre circulación y la igualdad de trato a mujeres y hombres. Se hacen nuevas propuestas en los sectores de la protección social, la igualdad de oportunidades para todos y la salud pública.

\subsection{Resumen de las principales cuestiones.}

1. Empleos: la primera prioridad. La Comisión propone en el ámbito del empleo, entre otras muchas:

- reforzar su cooperación existente con las autoridades de los Estados miembros;

- desarrollar la cooperación en la Unión entre todos los directores generales con responsabilidades en materia de empleo, incluidos los ministerios de Empleo, Protección social, Educación y Formación;

Las PYMES son creadoras de empleo, y la Comisión, en el marco de su programa integrado en favor de las PYMES concede una atención particular al estímulo de las mejoras del entorno administrativo y legal de las PYMES. 


\section{Invertir en una mano de obra de primer orden.}

La inversión en educación y formación es una de las condiciones esenciales de la competitividad de la Unión y de la cohesión de nuestras sociedades. Las principales propuestas vinculadas al plan global de acción para el empleo, concentrándose en las prioridades fijadas en el Libro Blanco sobre crecimiento, competitividad y empleo y con la voluntad, en el marco de las estructuras nacionales, fueron, entre otras:

- garantizar en toda la Unión que ningún joven esté en el paro antes de la edad de 18 años;

- fijar objetivos escalonados hasta el año 2000 para la eliminación del analfabetismo y de la falta de cualificaciones de base entre los jóvenes que dejan la escuela;

- mejorar el estatuto de la formación y de la enseñanza profesionales iniciales y fomentar, gracias a una experiencia profesional conveniente, el desarrollo del espíritu de empresa en los jóvenes, así como sus capacidades de explotar las nuevas tecnologías;

Los Fondos Estructurales, gracias a un presupuesto de más de 141.000 millones de ecus para el período 1994-1999, han contribuido de manera importante a la inversión en recursos humanos, a la lucha contra el desempleo y al buen funcionamiento del mercado del empleo. En cuanto al Fondo Social Europeo, su dotación ha sido de más de 40.000 millones de ecus para el mismo período. El FSE en el conjunto de la Unión tiene por tarea luchar contra el desempleo de larga duración y la exclusión del mercado del empleo, intentar dar a todos los jóvenes las cualificaciones necesarias y la posibilidad de trabajar, promover la igualdad de oportunidades y, en el marco del objetivo n. ${ }^{\circ} 4$, ayudar a la mano de obra a adaptarse a los cambios industriales.

3. Promover mejores normas de empleo para una Europa competitiva

Los Estados miembros siguen divididos sobre si es oportuno adoptar nuevas medidas legislativas sobre las normas de empleo a nivel europeo. Se ha propuesto una serie de sectores para la acción legislativa de la Unión, como la protección contra los despidos individuales, la protección de la vida privada de los trabajadores, en particular, en cuanto al tratamiento de los datos personales, incluidas su recogida y su difusión, etc.

4. La seguridad social.

Se realizaría un examen y una reestructuración técnica de gran envergadura de las reglas de coordinación de las disposiciones de la seguridad social para adaptarlas a los cambios y necesidades de los particulares y para simplificarlas. La principal cuestión ha sido y es, la necesidad de mantener una protección adecuada de las per- 
sonas que circulan de un país a otro por lo que respecta a los regímenes profesionales o a cualquier otro régimen complementario de seguridad social que se añada o que sustituya a lo establecido por ley.

5. Igualdad de oportunidades entre los hombres y las mujeres

Suprimir la segregación que existe en el mercado del empleo y valorar el trabajo de las mujeres. Así, la Comisión:

- introducirá códigos de buena práctica en materia de igualdad de remuneraciones por un trabajo de igual valor, de formación y de eliminación de la segregación vertical;

- adoptará medidas tendentes a fomentar la adquisición de competencias y el perfeccionamiento profesional de las mujeres;

- presentará propuestas con vistas a la eliminación de políticas discriminatorias en materia de fiscalidad y de protección social y con vistas a la individualización de los derechos;

- emprenderá una evaluación económica de la creación de empleos y del potencial de reanudación de las infraestructuras y de los servicios para niños y personas dependientes;

- continuará sus trabajos de investigación, información y formación sobre una mayor participación de las mujeres en las tomas de decisión en los todos los sectores.

6. Acción en el sector de la salud pública.

La Comisión ha aprobado propuestas de decisión para tres de estos programas, que son los relativos al cáncer, la promoción, la información, la educación y la formación en materia de salud y la prevención de las toxicomanías.

La Comisión propone prioritariamente otros programas sobre el SIDA y otras enfermedades transmisibles, así como sobre los datos sanitarios y los indicadores de salud, incluida la vigilancia de las enfermedades. Se prevén otros programas en sectores como los accidentes y las heridas, las enfermedades vinculadas a la contaminación y las enfermedades raras.

7. Los sindicatos, las organizaciones patronales y las organizaciones de voluntarios como socios del cambio.

8. Cooperación internacional: el papel de la política social europea.

La Comisión tiene la intención de:

- dar un carácter sistemático a los intercambios y a los contactos con otros países industrializados;

- proseguir su larga tradición de cooperación con la organización internacional del trabajo. La Comisión, hasta la ampliación de la UE en 1995, seguirá contribuyendo activamente a la cooperación en materia de política social en el marco del acuerdo del Espacio Económico Europeo; 
- ayudar a los países de Europa central y oriental a encontrar respuestas a sus problemas (consecuencias sociales de las reestructuraciones industriales, aplicación de las políticas de empleo, lucha contra la pobreza y la exclusión social, instauración de regímenes de seguridad social, etc.) y organizar la cooperación, con la ayuda y el apoyo de los Estados miembros.

\section{TERCER PROGRAMA DE ACCIÓN SOCIAL (1995-...)}

Este programa es la tercera y última fase de un proceso que comenzó en 1993 con la publicación del Libro Verde sobre el futuro de la Política Social europea y que prosiguió en 1994 con el Libro Blanco. Los puntos fundamentales del programa son:

- Utilización más eficaz del FSE para promover el empleo.

- Fomento de la formación general y profesional.

- Facilitar la libre circulación dentro de la Unión Europea.

- Creación de una estructura de normas mínimas en todos los ámbitos de la política social.

- Regulación de la compatibilidad de la vida familiar y profesional.

- Aplicación del principio de igualdad de oportunidades en todos los ámbitos.

- Asistencia para los pobres, minusválidos y ancianos.

- Actuación conjunta para luchar contra el racismo y la xenofobia en la sociedad.

- Profundizar en el diálogo social.

- Intensificar la colaboración con organizaciones no gubernamentales.

- Analizar las repercusiones sociales de la sociedad de la información.

En un informe del Parlamento Europeo sobre este programa de medidas, los diputados exigen una mayor perspectiva social de Europa, que debe expresarse sobre todo a través de los interlocutores sociales. Los cambios estructurales que comporta el mercado interior deben afrontarse a través del diálogo entre empresarios y trabajadores. De ahí debe surgir la legislación europea, como en el caso del permiso parental o del debate sobre el trabajo a tiempo parcial, para que puedan protegerse con plena eficacia los derechos de los trabajadores.

El gráfico que se muestra a continuación expresa el reparto de los fondos del FSE durante el año 1997. 


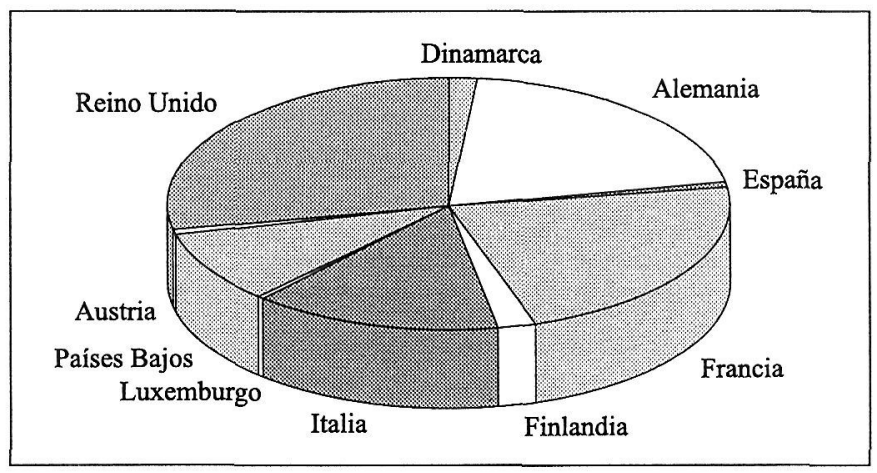

\section{CONCLUSIÓN}

Todo lo expuesto en el presente artículo ha sido, principalmente, la evolución histórica y los objetivos y metas a alcanzar por la Política de Acción Social Europea en los últimos años. Habrá que constatar que en los años venideros todas estas iniciativas y proposiciones han seguido dado fruto incrementando y mejorando la calidad de vida de todo ciudadano europeo.

Creemos que los ciudadanos de la Unión Europea deben poseer un mayor conocimiento de todos los esfuerzos que desde Europa se están llevando a cabo en materia de Política Social. Es algo que nos concierne a todos y que se está desarrollando para nuestro beneficio. La Política de Acción Social es fundamental en toda sociedad que busque el beneficio de sus ciudadanos y este es un objetivo primordial de la Unión Europea.

\section{BIBLIOGRAFÍA}

ALONSO GARCÍA, R. (1996): Tratado de la Unión Europea. Civitas. $4^{\text {a }}$ edición. Colegio de Economistas de Madrid. (1996) «Política de Empleo en Europa».

WERNER WEIDENSELD, W. (1997): Europa de la A a la Z. Guía de la integración europea. Oficina de Publicaciones Oficiales de las Comunidades Europeas. Luxemburgo.

Economic Commission for Europe United Nation «Economic Survey of Europe 1996-1997». Ginebra. NN.UU. 1997. 


\section{REFLEXIONES SOBRE LA INTERVENCIÓN DEL TRABAJADOR SOCIAL EN EL CONTEXTO EDUCATIVO}

\section{ELENA ROSELLÓ NADAL}

Profesora Ayudante del Departamento de Trabajo Social y Servicios Sociales. Universidad de Alicante.

\section{RESUMEN}

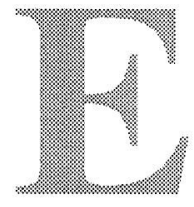

1 artículo que voy a desarrollar a continuación quiere difundir la labor que están realizando un grupo de profesionales, $y$, en concreto, de trabajadores sociales, en un ámbito de intervención poco conocido como es el contexto educativo.

En el ámbito educativo hay una importante confusión en cuanto a las funciones que realiza el trabajador social como miembro de los equipos interdisciplinares que actúan en los centros escolares, también se carece de una definición normativa que aclare nuestra situación. Y, como consecuencia de esto, la figura del trabajador social en el campo educativo tiene muy poco reconocimiento.

El artículo recoge las reflexiones que he realizado en mis años de ejercicio profesional como trabajadora social en los Servicios Psicopedagógicos Escolares (S.P.E.) de la Consellería de Educación y Ciencia, así como las aportaciones realizadas por otros compañeros que trabajan en este ámbito.

Por eso, creo importante aportar un poco de claridad en algunos aspectos: contextualizar la figura del trabajador social dentro del marco educativo y, en concreto, dentro de los equipos interdisciplinares que actúan en los centros escolares; intentar delimitar cuáles serían las funciones específicas que podrían desarrollar los trabajadores sociales; reflexionar sobre la metodología de trabajo que debería utilizarse para que nuestra intervención fuera realmente eficaz y eficiente y presentar algunas propuestas de intervención a nivel operativo que podrían darse en la práctica cotidiana.

Considero fundamental la divulgación de materiales, documentos, programas e investigaciones con los que se esté trabajando en la práctica profesional para contribuir al afianzamiento de la disciplina del 
Trabajo Social en el ámbito educativo y para dejar abierto un campo profesional en el que considero necesario e imprescindible la figura del trabajador social.

\section{PALABRAS CLAVE}

Trabajo social escolar; orientación educativa y sociolaboral; diversidad del alumnado; valoración sociopsicopedagógica; asesoramiento a padres; modelo ecológico-sistémico.

\section{INTRODUCCIÓN}

El sistema educativo no ha sido capaz de absorber y modificar toda la problemática que el alumnado lleva de forma individual y que está dificultando la consecución de los objetivos que la institución escolar se plantea para con los alumnos.

Si concebimos el proceso educativo como un todo en el que se pretende conseguir que el alumno tenga una situación tal que posibilite su desarrollo libre y armónico, tendremos en cuenta que son necesarias acciones, no sólo por parte de los educadores, sino también por parte de otros profesionales (psicólogos, pedagogos, trabajadores sociales, logopedas, etc.). Estos profesionales tienen su razón de ser porque vienen a cubrir lagunas existentes en el propio sistema educativo, tanto en el desarrollo en sí, mediante la superación de las dificultades individuales y colectivas que encierran, como en su acción preventiva.

La actividad del trabajador social no es sino un eslabón en la cadena; su grado de eficacia será mayor cuando más se realice dentro del trabajo y actividades del equipo educativo.

El modelo de intervención en un centro debe tener en cuenta el carácter sistemático del contexto en el que se desarrolla el acto educativo. Somos conscientes de que para que "los árboles no nos impidan ver el bosque", nuestra perspectiva tiene que dejar de centrarse en los alumnos o en las situaciones problema, considerándolas de forma aislada.

Este punto de vista reduccionista sólo nos permite salir del paso momentáneamente, suprimir unos síntomas, mostrar una respuesta a una demanda poco clarificada. Pero a la larga nos crea un sentimiento de insatisfacción o frustración por su exigua operatividad. Debemos entender el acto educativo como una serie de procesos que suceden inscritos en un sistema más amplio, sobre él hay que actuar de forma 
global, o al menos teniendo en cuenta las posibles interacciones de las partes. Este cambio de perspectiva pasa necesariamente por establecer un puente o una unión entre educadores y profesionales de los equipos de apoyo a los centros, que permita contextualizar las situaciones en el marco global en el que se encuentran. Y, al mismo tiempo, conlleva una actitud de evaluación crítica y de investigación sobre nuestro propio trabajo, modificando el mismo en función de su operatividad.

En este artículo se pretende difundir un trabajo "silencioso" que vienen desarrollando un grupo de profesionales, trabajadores sociales, dentro del contexto educativo y, digo silencioso, porque, a pesar de los años que llevan ejerciendo su profesión dentro de este contexto (más de 15 años desde los primeros pioneros) y del inestimable valor de sus aportaciones profesionales (aspecto éste que intentaré demostrar a lo largo de este artículo), siguen siendo unos profesionales muy poco conocidos dentro de este contexto y apenas imperceptibles si nos referimos a ámbitos ajenos a donde estos trabajadores sociales realizan su labor, siendo, en general, una profesión poco conocida por la sociedad.

\section{FUNDAMENTACIÓN TEÓRICA}

La Federación Internacional de Trabajadores Sociales (F.I.T.S.) afirma que el medio escolar es el primero en el que se pueden detectar problemas familiares y sociales. Considera a la institución escolar como uno de los pilares de prevención, ya que en ella se pueden detectar posibles anomalías antes que en otras instituciones, de forma globalizada, y que facilitaría una intervención temprana para modificar, en la medida de lo posible, la situación que está influyendo negativamente.

En el contexto educativo, el niño está integrado básicamente en tres subsistemas: la escuela, el grupo-clase y la familia. Dentro de cada uno de ellos, establece una serie de relaciones; estas relaciones y las interacciones que mantienen los diferentes sistemas entre sí determinarán el papel que el niño desempeñe tanto en la escuela como en casa; de ahí que nuestra intervención profesional, cuyo objetivo último es favorecer el desarrollo integral del alumno, tenga que incidir en los diferentes contextos en los que el niño se desenvuelve.

Si el medio familiar y comunitario en el que se desenvuelve el niño es un medio "normalizado" y el centro escolar responde a las expectativas e intereses del niño, entonces no surgirán problemas, pero en el momento en que alguna de estas áreas sea deficitaria o cuando las relaciones que se establecen entre ellas sea disfuncional seguramente será 
justificada nuestra intervención como trabajadores sociales para intentar corregir los desajustes personales, familiares, sociales y/o escolares que se manifiesten en el niño.

Toda situación educativa afecta al niño en su unidad como persona: lo biológico, lo afectivo, lo intelectual y lo social forman parte del niño en una realidad interactiva, de modo que no cabe aislar en comportamientos separados cada una de las dimensiones constitutivas de la personalidad.

El Trabajo Social en el ámbito educativo y dentro de un equipo interdisciplinar, como es el Servicio de Orientación Educativa, Psicopedagógica y Profesional, tiene su razón de ser en la necesidad de abordar la realidad en la que se interviene desde una perspectiva globalizadora, que tenga en cuenta todos los factores y elementos que interactúan en el proceso educativo, tanto en el sistema escolar como en su relación con otros sistemas e instituciones.

Podría definirse el Trabajo Social Escolar como la ayuda técnica que favorece el establecimiento y fortalecimiento de las relaciones entre el medio escolar, el familiar y el comunitario, la integración escolar y social de los niños que tienen dificultades de adaptación al contexto educativo por sus circunstancias personales, familiares o sociales y la intervención sobre todos aquellos obstáculos que impiden el desarrollo integral del menor.

En la adaptación al medio escolar del alumno influyen enormemente factores vinculados a la familia, como el clima cultural, las motivaciones hacia el estudio, la valoración del trabajo escolar, el clima afectivo y el apoyo y seguimiento de los progresos y esfuerzos del niño.

Numerosos estudios han demostrado que la incidencia negativa de los factores ambientales se detecta en mayor proporción en las familias de ambientes socioculturales desfavorecidos, pero no de forma exclusiva; cada vez más, en las familias que podríamos considerar normalizadas, se aprecia la carencia de elementos básicos para el desarrollo adecuado del niño, como la motivación y la ayuda para las tareas escolares, un clima afectivo apropiado, unas normas y valores claramente establecidos y respetados, unos mecanismos de refuerzo y recompensa ajustados, etc.

Así pues, la intervención del trabajador social en este ámbito no puede tener otro objetivo que el de contribuir a que el alumno, independientemente de su pertenencia a un entorno sociofamiliar u otro, tenga las mismas oportunidades educativas que los demás, procurando que el entorno más inmediato del alumno sea lo más motivador y estimulante posible, de cara a su adaptación y rendimiento escolar, trabajando conjuntamente con las familias e implicándolas al máximo en el proceso educativo. 
Los trabajadores sociales realizarán su intervención socioeducativa en y con la comunidad educativa, y para el desarrollo de su trabajo estarán en constante coordinación con tutores, familias, centros y profesionales de otros servicios con el fin de garantizar el máximo aprovechamiento de los recursos sociales disponibles.

\section{FUNDAMENTACIÓN LEGISLATIVA}

La legislación básica internacional sobre la que se basa la atención a las necesidades socioeducativas de los niños es la Convención sobre los Derechos del Niño. Este documento reconoce el derecho del niño a la educación, determinando que los estados firmantes, a fin de que se pueda ejercer progresivamente y en condiciones de igualdad de oportunidades ese derecho, deberán en particular:

"Hacer que todos los niños dispongan de información y orientación en cuestiones educacionales y tengan acceso a ellas». «Adoptar medidas para fomentar la asistencia regular a las escuelas y reducir las tasas de deserción escolar».

Por otro lado, la actuación de los trabajadores sociales en el ámbito escolar queda contextualizada en la Ley Orgánica 1/1990, de 3 de octubre de Ordenación General del Sistema Educativo (a la que nos referiremos a partir de ahora como LOGSE), en el preámbulo de dicha ley se señala "el objetivo primero y fundamental de la educación es el de proporcionar a los niños y niñas, a los jóvenes de uno y otro sexo una formación plena que les permita conformar su propia y esencial identidad... Tal formación plena ha de ir dirigida al desarrollo de su capacidad para ejercer, de manera crítica y en una sociedad axiológicamente plural, la libertad, la tolerancia y la solidaridad."

En el Título Preliminar, artículo 2, se señalan los principios que guiarán la actividad educativa y, entre ellos, señalo, como más significativos, los siguientes:

c) la efectiva igualdad de derechos entre los sexos y el rechazo a todo tipo de discriminación, y el respeto a todas las culturas,

d) la atención psicopedagógica y la orientación educativa y profesional,

j) La relación con el entorno social, económico y cultural

Cuando habla de la Educación Especial (Título primero, Capítulo quinto) en el artículo 36, punto 2, dispone que "la identificación y valoración de las necesidades educativas especiales se realizará por equipos integrados por profesionales de distintas cualificaciones, que establecerán en cada caso planes de actuación en relación con las necesidades educativas específicas de los alumnos". 
En el Título Cuarto, referido a la Calidad de la Enseñanza, se recoge, en el artículo 60, punto 2, lo siguiente: "Las Administraciones educativas garantizarán la orientación académica, psicopedagógica y profesional de los alumnos, especialmente en lo que se refiere a las distintas opciones educativas y a la transición del sistema educativo al mundo laboral, prestando singular atención a la superación de hábitos sociales discriminatorios que condicionan el acceso a los diferentes estudios y profesiones. La coordinación de las actividades de orientación se llevará a cabo por profesionales con la debida preparación."

Hay que remarcar, dentro de esta ley, el Título quinto, de la Compensación de las Desigualdades en la Educación, que, en su artículo 63, establece que "las políticas de educación compensatoria reforzarán la acción del sistema educativo de forma que se eviten las desigualdades derivadas de factores sociales, económicos, culturales, geográficos, étnicos o de otra indole" y, posteriormente (artículo 64), añade: "Las Administraciones educativas asegurarán una actuación preventiva y compensatoria garantizando, en su caso, las condiciones más favorables para la escolarización, durante la educación infantil, de todos los niños cuyas condiciones personales, por la procedencia de un medio familiar de bajo nivel de renta, por su origen geográfico o por cualquier otra circunstancia, supongan una desigualdad inicial para acceder a la educación obligatoria y para progresar en los niveles posteriores."

Con el fin, pues, de asegurar la necesaria calidad de la enseñanza, la citada ley ordena en su disposición adicional tercera, 3 e), que "en el proceso de su aplicación las administraciones educativas crearán servicios especializados de orientación educativa, psicopedagógica y profesional que atiendan a los centros que impartan enseñanzas de régimen general."

Habiendo hecho ya un análisis exhaustivo del marco legal genérico que supone la LOGSE para la actuación de los equipos multiprofesionales en el ámbito educativo, pasaré ahora a hacer una revisión de la normativa autonómica más concreta que regula la creación y funcionamiento de estos equipos dentro del ámbito de nuestra Comunidad Valenciana.

El Decreto 136/1984, de 10 de diciembre, del Gobierno Valenciano, creó los Servicios Psicopedagógicos Escolares (S.P.E.), integrando en éstos a los equipos multiprofesionales establecidos por la Ley 13/ 1982, de 7 de abril, de Integración Social de los Minusválidos (L.I.S.M.I.) y definiendo un modelo de intervención propio de la Comunidad Valenciana. 
Posteriormente, el Decreto 53/1989, de 18 de abril, del Gobierno Valenciano, definió un nuevo marco jurídico de los servicios psicopedagógicos escolares y de los gabinetes psicopedagógicos municipales. Por otra parte, el Real Decreto 986/1991, de 14 de junio, por el que se aprueba el calendario de aplicación de la nueva ordenación del sistema educativo, en su artículo 18, establece que "las administraciones educativas procederán a la creación progresiva de servicios especializados de orientación educativa, psicopedagógica y profesional para atender a los centros docentes de manera que el proceso quede completado en el momento de la implantación total de los respectivos niveles y etapas del nuevo sistema."

Y, así, el Decreto 13/1994, de 5 de julio, del Gobierno Valenciano, regula los servicios especializados de orientación educativa, psicopedagógica y profesional de la Conselleria de Educación y Ciencia y los define como "equipos integrados por distintos profesionales que se constituyen para favorecer el ejercicio de funciones especializadas de orientación, evaluación e intervención educativa y, en general, de apoyo al sistema escolar en sus distintos niveles educativos y su vinculación al mundo del trabajo."

\section{FUNCIONES GENERALES}

El Decreto 131/1994 establece, como funciones generales de los servicios especializados de orientación educativa, psicopedagógica y profesional, las siguientes:

a) Participar en el apoyo y asesoramiento a los centros educativos.

b) Elaborar y difundir materiales e instrumentos de orientación educativa y de intervención sociopsicopedagógica y logopédica en las dos lenguas oficiales de la Comunidad Valenciana.

c) Coordinar las actividades de orientación educativa y sociofamiliar que se realicen en los centros docentes de su ámbito de actuación.

d) Asesorar al profesorado en el tratamiento de la diversidad del alumnado.

e) Asesorar al profesorado en el diseño de procedimientos e instrumentos de evaluación, tanto de los aprendizajes del alumnado, como del mismo proceso de enseñanza.

f) Detectar aquellas condiciones personales y sociales que faciliten o dificulten el proceso de enseñanza y aprendizaje del alumnado y su adaptación al ámbito escolar.

g) Realizar la evaluación y la valoración sociopsicopedagógica y logopédica del alumnado, para la determinación de su escolarización más adecuada y, si procede, elaborar la propuesta de diversifica- 
ción curricular o de adaptación curricular significativa y, en su caso, realizar el tratamiento logopédico y rehabilitador.

h) Colaborar en la orientación académica, para favorecer en el alumnado la toma de decisiones.

i) Colaborar en la orientación del alumnado en los procesos de transición a otras etapas e itinerarios educativos y al mundo del trabajo.

j) Llevar a cabo la orientación psicopedagógica sobre el proceso de enseñanza y aprendizaje y sobre la adaptación personal y social en el ámbito educativo.

k) Asesorar a las familias o a los representantes legales del alumnado, participando, en su caso, en el desarrollo de programas formativos de padres y madres de alumnos.

1) Cualquier otra que se determine reglamentariamente.

El artículo quinto, punto 4, referido a la organización, recoge un aspecto muy importante que es el de la coordinación con los profesionales de los recursos y servicios sociocomunitarios, en la línea de elaborar acciones conjuntas adecuadas a las demandas planteadas, con el objeto de proporcionar respuestas globalizadas.

En el artículo sexto, punto 2, del citado Decreto, referido a la composición de estos equipos, establece que "los profesionales que compondrán los servicios psicopedagógicos escolares podrán ser... C) Trabajadores sociales".

\section{FUNCIONES PRIORITARIAS}

La Orden de 10 de marzo de 1995 por la que se determinan las funciones de cada profesional dentro de los equipos, señala como funciones prioritarias del trabajador social las siguientes:

a) Asesorar a la comunidad educativa sobre aspectos familiares y sociales del alumnado y sobre los recursos socioeducativos de la zona.

b) Realizar el estudio y la valoración sociofamiliar de los casos detectados, bien elaborando la propuesta de intervención socioeducativa o bien derivándolo hacia el recurso pertinente, con el posterior seguimiento y evaluación del caso.

c) Participar en el desarrollo de programas de garantía social, de orientación escolar o profesional y en programas formativos para padres y madres de alumnos.

Partiendo de esta determinación normativa y desarrollándola, voy a intentar señalar las funciones, actividades y programas que podrían desarrollar los trabajadores sociales en el ámbito educativo, intentando abrir un amplio abanico de posibilidades, que en cada realidad con- 
creta deberán ser valorados y priorizados adecuadamente, atendiendo al contexto particular en el que se interviene.

Las condiciones y elementos de trabajo con los que se encuentre cada profesional determinarán el énfasis en unas líneas de actuación u otras, el carácter de la intervención y el nivel de implicación en las tareas, asumiendo una mayor o menor responsabilidad en su realización.

\section{FUNCIONES ESPECÍFICAS DEL TRABAJADOR SOCIAL}

Sus funciones específicas serán las siguientes:

a) Participar en la elaboración y desarrollo de programas de prevención y detección dirigidos a la comunidad educativa.

b) Asesorar al profesorado en la elaboración, seguimiento y evaluación de los programas de acción tutorial (P.A.T.) y en la atención a la diversidad.

c) Realizar el estudio y la valoración sociofamiliar de los casos detectados. Elaborar la propuesta de intervención socioeducativa directa o canalizar hacia el recurso pertinente, con el posterior seguimiento y evaluación del caso.

d) Participar en la elaboración y realización de actividades de orientación educativa y sociolaboral.

e) Colaborar con los distintos órganos de representación del centro, según necesidades.

f) Asesorar a las familias y participar, en su caso, en el desarrollo de programas formativos de padres y madres de alumnos.

g) Elaborar documentos y materiales propios de la intervención socioeducativa.

\section{ALGUNAS CONSIDERACIONES PREVIAS A LA INTER- VENCIÓN}

Antes de pasar a describir las actividades y programas que pueden desarrollar los trabajadores sociales en este ámbito, quisiera presentar unas reflexiones que considero deberíamos hacernos previamente a nuestra intervención.

\subsection{Modelo ecológico-sistémico}

Personalmente parto de la idea de que debe haber una transformación (que yo denominaría evolución) de lo que tradicionalmente ha 
sido la intervención habitual de los trabajadores sociales en este campo. Con esto, me refiero a que si hasta ahora el nivel de intervención que se ha venido utilizando ha sido el nivel individual y, en algunos aspectos, el familiar, es necesario ir introduciendo también el nivel de intervención comunitario y, más que eso, superando esta tradicional fragmentación de nuestra intervención en diferentes niveles apuesto por un modelo de intervención integral e integrado, que asuma el enfoque de la intervención desde un modelo teórico-metodológico como el ecológico-sistémico.

Este modelo puede considerar al menor como miembro de una familia, que, a su vez, está inmersa en su entorno, con el cual establece una serie de relaciones interpersonales e intergrupales, en donde ambos sistemas (familiar- comunitario) están interconectados constantemente; pero, a su vez, también puede considerar al menor como un alumno dentro de otro sistema, el escolar, y las interrelaciones que se establecen entre ese sistema escolar y el sistema familiar.

Este enfoque de la intervención resulta difícil por varias razones:

- Es necesaria la clarificación de roles para no "perder los papeles" en esa intervención conjunta de profesionales de diferentes disciplinas. Cada profesional tiene que tener claramente diferenciada su área competencial, dejándola explícita desde un principio, de modo que no conlleve dificultades de entendimiento, pero tampoco se interprete como un distanciamiento o una barrera para no querer trabajar en equipo.

- Hay una necesidad de formación de carácter metodológico en algunas profesiones que posibilite el crear una infraestructura de intervención que permita el trabajo en equipo y actúe contextualizando las situaciones, es decir, una metodología que potencie el enriquecimiento y la aportación mutua de diferentes disciplinas y ayude a ver más allá de lo evidente.

- Los problemas del sistema educativo están interrelacionados. Sin embargo, conviene delimitar qué situaciones están bajo el efecto de nuestra intervención y cuáles no. A veces, una postura cómoda es culpar a agentes externos sobre los que no tenemos capacidad ni responsabilidad de intervención. Con ello, justificamos la inoperancia de nuestro trabajo cuando el cambio nos supone un gran esfuerzo o, simplemente, cuando no somos capaces de asumir nuestra parte de responsabilidades de la situación, ante lo cual nos sentimos angustiados e impotentes.

- La Administración Educativa (en nuestro caso, la Consellería de Educación y Ciencia) asigna una determinada zona de intervención a cada S.P.E., y, así, cada equipo se ve obligado, por distintas razones, a intervenir en muchos centros; además, a esto se añade que 
normalmente hay un solo trabajador social en cada equipo con lo cual la ratio de centros y demandas a atender por el trabajador social se ve ampliamente sobrepasada. Esto provocará que en muchas situaciones sólo se pueda intervenir sobre demandas superficiales (aquellas referidas a los síntomas, los aspectos individuales y que no se cuestionan el contexto en el que se sitúan los problemas), lo que a la larga resulta poco útil y operativo, y, lo que es peor, desmotivador para el profesional.

\subsection{Modelo de investigación-acción}

La investigación-acción es un método de trabajo por el que un grupo de profesionales, conscientes de unas necesidades, ponen en práctica un proceso de cambio para satisfacer las mismas. La actuación profesional de los miembros del equipo es diferenciada, pero basando esta diferencia exclusivamente en sus distintos roles profesionales y en su distinta área de competencias. La deben realizar los profesionales de los S.P.E., el profesorado del centro, así como otros profesionales que puedan intervenir en la situación, en un ambiente de participación y compromiso. Esto evitará la actitud pasiva por parte del profesorado, cuando expone su demanda y espera que el S.P.E. le dé la solución y también evita, por otra parte, la actitud descomprometida de los profesionales del S.P.E. que terminan su intervención con la devolución del informe o la derivación de la demanda a otro servicio.

El proceso de investigación-acción comprendería los siguientes pasos:

1. Identificar o clarificar una relación de problemas. Es imprescindible hacer explícito un listado de situaciones-problema y realizar una jerarquización del mismo. Esta priorización de problemas debe ser revisada constantemente en el transcurso del proceso.

2. Exploración. Supone indagar unos hechos acerca de las circunstancias que concurren en la idea general susceptible de cambio. Requiere:

a) Describir del modo más completo posible la naturaleza de la situación que se desea cambiar o mejorar.

b) Explicar los hechos de la situación, analizando el contexto en el que surgen. Comprende:

- Generar hipótesis explicativas.

- Comprobación de las hipótesis, si se puede establecer alguna relación entre la situación y algún otro factor que opere en el contexto.

c) Construcción del Plan General de Acción. Debería contener:

a) Una descripción revisada de la idea general, clarificada. 
b) Descripción de los factores que se ha de modificar o cambiar y las acciones que se ha de emprender en este sentido.

c) Descripción de los recursos con los que se cuenta.

d) Descripción del compromiso establecido entre las personas que intervienen.

4. Desarrollo de los pasos siguientes del Plan. Especificar la temporalización de las medidas previstas en el Plan general y cómo han de ser verificados los procesos de puesta en marcha, su efectividad.

5. Puesta en marcha de los pasos siguientes del Plan, en el caso de que haya consecuencias sobre las que deba tratarse. Implica una revisión constante del Plan General de Acción.

\subsection{Modelo de intervención por programas}

Un tercer aspecto a considerar, y relacionado con los anteriores, es que debemos ir transformando nuestro esquema tradicional de intervención (intervención sobre casos detectados) por un modelo de intervención por programas.

Este modelo debe partir de un análisis de necesidades y demandas de la comunidad educativa y, a partir de ahí, el trabajador social, como miembro integrante de un equipo interdisciplinar, elaborará, junto con el resto del equipo y tras una negociación con cada centro escolar (a través de la Comisión de Coordinación Pedagógica de cada centro), un plan de actuación general que se estructurará en diferentes programas adaptados a cada contexto específico. Habrá que lograr implicar a un grupo de profesores que sean capaces de dinamizar un determinado programa desde el propio centro, dándoles la información y formación necesaria que les capacite para poder desarrollar las diferentes actividades del programa, pero contando siempre con el asesoramiento técnico y profesional necesario por parte de uno o varios especialistas que coordinen dichas actividades.

Esto supondría una reestructuración de la atención a los centros, una priorización de funciones y actividades en detrimento de otras, una mayor coordinación con otros profesionales para lograr una cierta unidad y coherencia en las acciones a desarrollar y renunciar a ciertos comportamientos y conceptualizaciones (paternalistas o asistencialistas) para trabajar por programas de forma progresiva y secuenciada.

Este proceso de transición hacia un modelo de actuación por programas no es nada fácil puesto que supone un cambio de actitud personal y profesional del trabajador social e implicaría, a su vez, un nuevo modelo organizativo que afectaría a los centros y al propio equipo, cambios estos para los cuales no todos pueden estar mentalizados. Este es el nuevo planteamiento que tendremos que asumir para adaptarnos a 
los principios y los cambios que plantea la LOGSE, tendremos que intentar superar las intervenciones de tipo puntual e individualizado para dar paso a una concepción más globalizadora e integradora.

Otro de los grandes retos que se le plantean al trabajador social en este campo es convencer a la institución escolar, y a la comunidad educativa, en general, de que resulta mucho más rentable (tanto cuantitativa como cualitativamente) invertir todo tipo de medios (materiales, técnicos, económicos, humanos, etc.) en actividades y programas de prevención que en intervenciones puntuales de parcheo cuando la situación está ya bastante deteriorada.

Para poder actuar desde este punto de vista más preventivo y globalizador es necesario que se den unas premisas básicas:

1. Compromiso por parte del centro de potenciar actividades secuenciadas en programas para todos los alumnos, a pesar de la falta de habituación para trabajar por programas.

2. Implicación y disponibilidad de tiempo del personal que interviene. Puesto que se ha de partir de un diagnóstico de necesidades, éstas se han de priorizar y concretar en el diseño de un programa que hay que elaborar; posteriormente, tendremos que ejecutar lo diseñado $y$, finalmente, evaluar lo ejecutado (esto supone un esfuerzo de tiempo y de preparación que ha de ser reconocido por todos).

3. Disponibilidad de recursos humanos, materiales, económicos y técnicos para llevar a cabo este plan de actuación general.

4. La unidad de intervención puede ser el grupo-clase, un determinado nivel educativo o el centro, en general, e irá dirigido a todos los alumnos, no sólo a los que presenten algún tipo de problemática específica.

Resulta obvio señalar que para que pueda darse esta intervención por programas es necesaria la colaboración de otros profesionales, organismos e instituciones en todas las fases del mismo (diagnóstico, diseño, implementación, ejecución y evaluación), así como de todos los agentes sociales y educativos implicados en la situación (profesores, padres, tutores, alumnos, profesionales, etc.).

\section{ACTIVIDADES Y PROGRAMAS QUE PUEDEN DESARRO- LLAR LOS TRABAJADORES SOCIALES EN EL ÁMBITO ESCOLAR.}

Intentar delimitar las líneas de intervención que pueden realizar los trabajadores sociales en el ámbito educativo es un objetivo un tanto utópico, y digo esto por varios motivos: 
1. Cada trabajador social realizará su intervención dentro de un contexto determinado, de una realidad concreta, que va a ir marcando y delimitando mucho su intervención profesional. Y no se puede (o no debemos) coger un programa que nos parece interesante y aplicarlo sin más a nuestro contexto concreto sin haber valorado previamente la adecuación e idoneidad del mismo a nuestra realidad concreta. Habrá que tener en cuenta una serie de aspectos tales como: necesidad real o sentida de ese programa, características de los usuarios a los que va dirigido, recursos y medios con los que se cuenta, grado de implicación del equipo o de otros profesionales, etc.

2. Cada profesional, por una serie de condicionantes propios a nivel personal, académico, formativo, institucional, etc., va a desarrollar su trabajo desde una determinada perspectiva y puede considerar que el que se quiera delimitar su actuación desde un modelo determinado o con la utilización de una determinada metodología pueda suponer para él un desafío (si lo ve como un reto personal y profesional), una imposición (si las órdenes vienen desde arriba o la institución le obliga a ello), o, incluso, como una amenaza (si no está capacitado para responder de determinada manera, puede ver amenazado su puesto de trabajo).

3. Uno de los principales rasgos que caracterizan a nuestra profesión es la constante adaptación a los cambios que se van produciendo en todos los órdenes (económico, social, legislativo, etc.). Es por esta razón que el trabajador social tiene que estar constantemente adaptándose a todas estas transformaciones para ser capaz de dar respuestas a las nuevas necesidades sociales que puedan ir surgiendo en esta sociedad dinámica que es la nuestra. Como consecuencia de esto, lo que podemos proponer en un momento determinado, como una alternativa eficaz de intervención, puede quedar desfasado en un tiempo relativamente corto o puede ya no ser el centro de interés al año siguiente. Esto supone un riesgo en el sentido de que podemos programar actuaciones para un período de tiempo determinado $y$, cuando nos vamos a sentar a evaluar lo programado (etapa del método que pocas veces realizamos) nos encontramos que es casi inoperativo porque al año siguiente ya no se va a continuar con ese programa y lo que se nos está pidiendo es que nos pongamos ya a diseñar el programa del año siguiente que puede estar relacionado o no con el anterior.

Una vez que hemos reflexionado un poco sobre este tipo de consideraciones y otras que seguro han quedado en el tintero, puedo pasar a presentar algunos programas que considero pueden resultar interesantes para aquellas personas que trabajen en este campo o para aquellos que quieran conocer algo más sobre él. 
Es importante recordar, de nuevo, que no son programas diseñados, ejecutados y evaluados única y exclusivamente por trabajadores sociales, creemos que el trabajador social debe participar en ellos como un miembro más dentro de un equipo interdisciplinar. Es el equipo en su conjunto el que tiene que planificar estos programas. Lo que sí que habrá que definir con claridad es el grado de implicación y de responsabilidad de cada uno de los miembros del equipo y debe ser esta una decisión que comparta y asuma todo el equipo para evitar problemas posteriores cuando el programa se esté ejecutando.

Los programas y actividades a realizar van a ser presentados siguiendo la clasificación establecida en el apartado anterior de funciones específicas como una manera coherente de desarrollo de estas funciones.

\subsection{Participar en la elaboración y desarrollo de programas de pre-} vención y detección dirigidos a la comunidad educativa.

El Decreto 131/1994 señala, como una de las funciones de los Servicio de Orientación Educativa, Psicopedagógica y Profesional, la de "detectar aquellas condiciones personales y sociales que faciliten o dificulten los procesos de aprendizaje del alumnado y su adaptación al ámbito escolar". Entendemos que el desarrollo de esta función tiene una finalidad preventiva, de especial relevancia en toda intervención social y, particularmente, en el ámbito de la educación.

Anteriormente, hicimos referencia a la prevención como uno de los principios que debe regir nuestra intervención, convencidos de que las actuaciones preventivas son, sin duda, de mayor eficacia y, en última instancia, de menor coste social que las medidas paliativas. Si bien, a menudo sólo se emplea el esfuerzo y el tiempo en estas últimas, por falta de medios o por carecer de perspectivas a largo plazo, tanto en la programación como en la valoración de resultados, siendo las posibilidades de éxito infinitamente menores.

En el desarrollo de esta función, el trabajador social debe desempeñar una importante labor de coordinación, tanto con el resto de los profesionales del servicio, profesores, padres y alumnos, como con otros servicios socio-comunitarios, colaborando en la prevención y detección de indicadores que puedan incidir en el proceso evolutivo y adaptativo del alumno.

\subsubsection{Estudio de la zona de actuación.}

Es imprescindible, antes de plantearse cualquier actividad preventiva, conocer la realidad concreta, las necesidades de la comunidad 
educativa, del centro al que irán dirigidas. Este conocimiento determinará tanto los contenidos, los temas a abordar, como los medios y la metodología más apropiada. De no actuar así, se corre el riesgo de aplicar actividades o programas preventivos muy bien diseñados pero que no responden a las características y las necesidades de la población a la que se dirigen.

\subsubsection{Participar en programas de prevención inespecífica en el área socioeducativa.}

Esta actividad se refiere a actuaciones preventivas que se lleven a cabo sólo en el ámbito escolar, con alumnos, padres o profesores o en coordinación con otras instituciones (del ámbito sanitario, social...) y en contextos más amplios. Y abarcaría programas de prevención del absentismo escolar, de prevención de drogodependencias o, en términos más amplios, de educación para la salud; o bien de desarrollo personal, de habilidades y actitudes, etc., siempre dependiendo de las características y necesidades del contexto y la población a la que se dirigen.

\subsubsection{Colaborar en programas de detección, previa a la escolarización, de niños con necesidades educativas especiales.}

Diferentes investigaciones han puesto de manifiesto que los esfuerzos educativos de mayor eficiencia son aquellos realizados antes de los tres años de edad, período de especial importancia en el desarrollo del niño.

En el Servicio de Atención Ambulatoria Previo a la Escolarización (S.A.A.P.E) ubicado en centros específicos de Educación Especial, se atienden las necesidades específicas de los casos detectados a través de la coordinación con los servicios de salud, servicios sociales, escuelas infantiles y guarderías, asociaciones, etc.; arbitrando, lo antes posible, los recursos necesarios para que se normalice su proceso de escolarización.

Por otra parte, el trabajador social aportará la información relevante sobre el contexto socio-familiar del niño al dictamen de escolarización, cuya finalidad es determinar las necesidades educativas especiales, la modalidad de escolarización adecuada y los tratamientos y apoyos específicos. Así, se podrá realizar un trabajo preventivo desde su integración en el centro. 
8.1.4. Detección inicial, en educación infantil y primer ciclo de primaria, de situaciones de riesgo social, en colaboración con el profesor-tutor.

El desarrollo de esta actividad exige la elaboración de instrumentos para la recogida de información, o completar los que ya existen (añadir nuevos ítems al cuestionario para la historia personal del alumno...) para que los tutores registren todo aquello que pueda informar de situaciones de riesgo social en el entorno socio-familiar del alumno. Y, posteriormente, la realización de entrevistas con tutores, familias y otros profesionales, para completar la información y arbitrar las medidas necesarias para introducir modificaciones y evitar el deterioro de las situaciones detectadas.

\subsubsection{Intervención inicial en las problemáticas socioeducativas que se presenten, especialmente en Educación infantil y primer ci- clo de Primaria.}

Es enormemente importante la intervención temprana de los diferentes profesionales que trabajamos en este ámbito en el momento en que aparece algún problema en la vida escolar del alumno (absentismo, dificultades de relación con profesores o compañeros, etc.) a fin de poder atajar las causas que lo ocasionan y evitar que esa situación continúe a lo largo de la escolaridad.

\subsubsection{Establecer o potenciar mecanismos de coordinación y trasvase de información formales, con los diferentes servicios de la zona.}

Esto permitirá que, frente a situaciones o problemáticas detectadas en cualquier ámbito de intervención, sea posible una respuesta rápida y coordinada y la previsión de recursos en el área educativa o en cualquier otra.

A este respecto, son necesarios programas de coordinación interinstitucional de cara a la prevención e intervención rápida en problemáticas del menor, con el fin de optimizar la actuación de los diferentes servicios e incrementar su eficacia preventiva, con un sistema de registro de información, seguimiento y evaluación común. 
8.2. Asesorar al profesorado en la elaboración, seguimiento y evaluación de los programas de acción tutorial (P.A.T.) y en la atención a la diversidad.

Si en todas las funciones el trabajo en equipo es fundamental, aquí es cuando cobra su mayor sentido, ya que ningún profesional de la escuela (ni de ningún otro campo) puede tener conocimientos ni habilidades suficientes para dar respuesta adecuada a dos tareas que son dos de los pilares fundamentales de la educación actual. El trabajador social, como profesional que forma parte de un equipo, tiene una aportación específica, pero su trabajo, al igual que el de los demás profesionales, no tiene sentido si se realiza en solitario, ya que debe coordinarse siempre estrechamente tanto con los demás profesionales del equipo como con los profesores de los centros.

\subsubsection{Colaborar en el programa de acción tutorial.}

Las actividades que puede llevar a cabo el trabajador social en los tres niveles en los que se desarrolla la acción son las siguientes:

a) A nivel del profesorado:

- Colaborar en la elaboración, seguimiento y evaluación del PAT a nivel del centro.

- Apoyar al tutor en el desarrollo del PAT, según sus necesidades.

- Promover y facilitar la coordinación de todos los profesores que intervienen en una misma aula para la realización de las actividades del PAT.

- Favorecer la disposición hacia el intercambio de ideas y experiencias y hacia la ayuda y la colaboración.

- Potenciar actividades encaminadas a la actualización y renovación profesional.

b) A nivel del alumnado:

- Aconsejar al tutor para su mejor conocimiento del alumnado, tanto a nivel individual como de grupo.

- Guiar al tutor en la creación de un clima social positivo dentro del grupo-clase.

- Orientar al tutor en su labor de fomento de actitudes participativas en los alumnos.

- Asistir al tutor en el desarrollo de determinados valores, actitudes y habilidades en el alumnado, encaminados a favorecer su realización personal y social.

- Colaborar en el proceso de orientación (se desarrolla en el apartado referido a las actividades de orientación educativa y sociolaboral). 
c) A nivel de la familia:

- Proponer actividades al tutor para el mejor conocimiento de las familias, informándole de los aspectos relevantes del entorno sociofamiliar de sus alumnos y de cómo influye éste en el proceso de enseñanza-aprendizaje.

- Aconsejar al tutor acerca de las estrategias que faciliten su relación con las familias y el acercamiento de éstas al centro.

- Cuando no exista una relación positiva, o siempre que se considere necesario, se realizará una labor mediadora.

- Colaborar con el tutor en las actividades encaminadas a conseguir una mayor implicación de las familias en el proceso educativo de sus hijos a través de reuniones periódicas con los padres del grupo-clase, escuela de padres, entrevistas, mayor participación de las familias, etc.

\subsubsection{Colaborar en la atención a la diversidad}

Para conseguir avanzar en una adecuada atención a la diversidad, es fundamental que se tengan en cuenta dos exigencias básicas: la coordinación de todo el equipo educativo para determinar las líneas de actuación a seguir y la utilización de metodologías que primen la actividad del alumno sobre la del profesor para llegar al mayor número posible de alumnos. Esto contribuirá a la construcción de un currículum lo más flexible posible para tener que elaborar el mínimo de adaptaciones curriculares.

En lo referido a la atención a la diversidad, las actividades que puede llevar a cabo el trabajador social son las siguientes:

- Participar en el análisis de las necesidades educativas especiales y de las características del aula.

- Potenciar la coordinación de todo el equipo educativo, que actúa en un nivel o ciclo.

- Ayudar a un cambio en el papel del profesor: de emisor a dinamizador.

- Ayudar a un cambio en el papel del alumnado: de receptor a sujeto activo de su propio aprendizaje.

- Inducir a un cambio en las relaciones de los diversos subgrupos (profesor-profesor, alumno-alumno, profesor-alumno, escuela-familia, profesor-equipo de apoyo) con el objetivo de crear un clima en clase y en el centro que favorezca el tratamiento a la diversidad.

- Colaborar en la elaboración, seguimiento y evaluación de las adaptaciones curriculares. 
8.3. Realizar el estudio y la valoracion sociofamiliar de los casos detectados. Elaborar la propuesta de intervencion socioeducativa directa o canalizar hacia el recurso pertinente, con el posterior seguimiento y evaluación del caso.

La valoración sociofamiliar que se realice ha de atender a la globalidad del alumno, es decir, estudiar todos aquellos factores que le rodean y afecten como persona. Las valoraciones están insertas en un proceso, en un conjunto de actuaciones dirigidas a dar respuesta a las necesidades educativas y socio-familiares que rodean al alumno.

Las aportaciones del trabajador social a esta función se concretan en las siguientes actividades:

1. Estudio del entorno social y familiar del alumno empleando los instrumentos propios del trabajo social (entrevistas estructuradas/no estructuradas, cuestionarios, informes sociales, etc.) como parte de la evaluación diagnóstica.

2. Análisis y síntesis de la información recogida sobre las características del ambiente sociofamiliar del alumno, su entorno comunitario y su historial educativo.

3. Diseño de la intervención que consistirá en realizar un trabajo directo con la familia o se canalizará hacia el recurso pertinente.

4. Elaboración de informes técnicos cuando se requiera y sea necesario motivados por: cambios de escolarización, de centro ordinario a centro específico y viceversa; cambio del alumno a un grupo distinto de enseñanza-aprendizaje; gestión de determinados recursos (becas de comedor, de libros o de transporte, ayudas técnicas o instrumentales, etc.); a petición de otros organismos o servicios que intervengan en el caso; etc.

5. Colaborar en la elaboración, seguimiento y evaluación de las adaptaciones curriculares, incidiendo especialmente en los apartados de autonomía personal y socialización.

8.4. Participar en la elaboración y realización de actividades de orientación educativa y sociolaboral.

Cabe entender por orientación, en sentido amplio, la ayuda sistemática ofrecida a una persona para que llegue a un mejor conocimiento de sus características y potencialidades, a la aceptación de su propia realidad y al logro de su capacidad de autodirigirse. Todo ello, enfocado al desarrollo integral de su personalidad y a una contribución eficaz a la sociedad en que vive.

La orientación, si bien es para todos los sujetos, debe prestar particular atención a aquellos que presentan problemas de integración o 
adaptación al sistema educativo ordinario o a los recursos normalizados. Debe atender a todas las facetas de la personalidad del sujeto e intentar un desarrollo armónico y equilibrado de las mismas. Ha de basarse en las diferencias inter e intraindividuales. Ha de ser cooperativa, comprometiendo no sólo a los expertos, sino también al propio sujeto, a la familia, al profesorado y dirección del centro. Debe utilizar los recursos de la comunidad y coordinarlos con los de la escuela y la familia.

El trabajador social colaborará con el equipo interdisciplinar en la elaboración del programa de orientación educativa y sociolaboral que se oferta a los centros. Los programas de orientación sociolaboral que tradicionalmente se llevan a cabo en los centros escolares dan respuesta a los alumnos sobre la oferta educativa ordinaria, sin ofrecer demasiadas alternativas para aquellos alumnos que, por sus características personales, sociales, educativas, etc., no pueden acogerse a esta oferta. Corresponde al trabajador social llevar a cabo una serie de actividades para potenciar la orientación a todos y cada uno de estos alumnos, en especial a los alumnos con necesidades educativas especiales.

Las aportaciones del trabajador social a esta función se concretan en las siguientes actividades:

1. Estudio y valoración de aquellas condiciones sociofamiliares que influyan en la evolución y la continuidad del proceso de enseñanza-aprendizaje del alumno y su incorporación a la comunidad y al mundo laboral.

2. Participar junto con el psicopedagogo y los tutores en el diseño, ejecución y puesta en marcha del programa de orientación escolar, profesional y vocacional del centro.

3. Coordinación con otros Servicios e Instituciones hacia los que se puedan dirigir alumnos/as al acabar la escolaridad obligatoria que no puedan acogerse a la oferta educativa ordinaria.

4. Participar en la evaluación del Programa de orientación educativa y sociolaboral, y llevar a cabo un seguimiento para valorar la idoneidad del recurso propuesto al alumno.

\subsection{Colaborar con los distintos órganos de representación del centro escolar, según las necesidades.}

Como trabajadores sociales, nuestra intervención en los diferentes órganos de participación, relacionados con la escuela, vendrá dada, por un lado, por la demanda expresa del propio órgano y, por otro, por nuestra propia demanda de participación, derivada del estudio del centro, características y necesidades.

Nuestro trabajo se podrá realizar en los diferentes órganos con las siguientes actividades: 


\section{Equipo Directivo.}

- Informar al equipo directivo sobre aquellos aspectos relevantes relacionados con la comunidad educativa: interrelaciones entre sus diversos miembros, problemáticas que surgen, experiencias innovadoras y de interés para la comunidad, etc.

- Asesorar al equipo directivo en todas aquellas situaciones que surjan en el centro cuando sea necesario: actuación con determinados alumnos o familias cuya problemática sobrepasa al tutor, actuación en ámbitos más generales como puede ser la elaboración de un plan de prevención o actuación sobre la disciplina, etc.

- Información sobre recursos de la comunidad, legislación de interés, ayudas, etc.

\section{Comisión de Coordinación Pedagógica}

- Participar en dicha comisión en todos los temas que sean de su competencia: temas transversales, análisis del contexto, atención a la diversidad, acción tutorial, etc.

3. Claustro.

- Aportar aquellas informaciones generales y específicas sobre el entorno sociofamiliar del alumnado que sean relevantes para mejorar su comprensión de la situación y la atención al alumnado.

- Colaborar con el Claustro en las propuestas de programas para el centro y en la elaboración de estrategias generales de actuación a nivel del centro: programas de educación para la salud, de educación para la paz, escuelas de padres, desarrollo del Plan de Acción Tutorial, etc.

4. Consejo Escolar.

- Asesorar y orientar para la toma de decisiones en aquellas funciones que son propias del Consejo Escolar: admisión de alumnado, gestión de becas, programas concretos de actuación, reglamento de régimen interno, instrucciones de expedientes disciplinarios, etc.

5. Asociaciones de Padres de Alumnos (A.P.A.S.)

- Haremos referencia a las posibilidades de intervención con las A.P.A.S cuando hablemos de la función específica de asesoramiento a las familias.

6. Asociaciones de alumnos, Cámaras de delegados o Consejos de alumnos.

Nuestra participación en estos órganos estará encaminada a :

- Promover y estimular la constitución de estas asociaciones y consejos, ya que estos facilitan la representatividad y participación del alumnado en la vida del centro, favoreciendo también el aprendizaje de las formas democráticas de convivencia. 
- Asesorar en el proceso de elección de delegados y cargos.

- Participar, como asesores del alumnado, en la puesta en marcha de los mismos y en sus posteriores planes de actividad.

8.6. Asesorar a las familias y participar, en su caso, en el desarrollo de programas formativos de padres y madres de alumnos.

Los padres pueden proporcionar información relevante sobre sus hijos que sirva para dar contenido y sentido al trabajo que con ellos se desarrolla en el centro escolar. Del mismo modo, los profesores pueden colaborar con los padres en la búsqueda de respuestas a las necesidades que presenten los hijos en su desarrollo. Planteada de este modo, la participación de los padres en la escuela constituye un aspecto más e ineludible de su función educativa.

Desde el punto de vista legal, los padres tienen derecho constitucional a intervenir en la gestión y control de los centros escolares sostenidos con fondos públicos. Ahora bien, para que este reconocimiento legal se traduzca en acciones concretas y eficaces, es preciso que los padres conozcan y participen activamente en dichos cauces y creen canales propios de comunicación en el convencimiento de que sus puntos de vista y sus valores enriquecen extraordinariamente la vida de la escuela.

Las acciones para desarrollar la función de asesoramiento a las familias y a la Asociación de Padres de Alumnos, en su caso, pueden tener un enfoque individual o colectivo, según los objetivos específicos que se pretendan.

a) A nivel individual

1. Orientación y trabajo con las familias para procurar modificar las causas de origen familiar que puedan generar problemas de desarrollo personal, adaptación escolar y/o social en los alumnos.

2. Desarrollar programas de intervención familiar referidos a aspectos como autonomía personal, hábitos básicos, relaciones familiares, relaciones familia-escuela, etc.

3. Apoyo, atención y orientación a las familias de alumnos con necesidades educativas especiales.

4. Elaboración de programas de intervención educativa familiar para llevar a cabo las Adaptaciones Curriculares Individualizadas (ACIs).

b) A nivel colectivo

1. Promover la constitución de seminarios operativos de padres, profesores y/o alumnos, en los que se trabajen conjuntamente diversos aspectos que se desee potenciar o eliminar en la comu- 
nidad educativa, aspectos concretos sobre la participación en la gestión del centro, etc.

2. Colaboración con los tutores en la preparación y desarrollo de las reuniones que a lo largo del curso realizan con las familias de su grupo de alumnos.

3. Facilitar la formación de grupos operativos de padres y profesores que traten los diferentes problemas que pueden afectarles: problemas de disciplina, relacionales, interétnicos, etc.

4. Asesoramiento a las Asociaciones o Federaciones de Padres de Alumnos:

- Asesorar en la puesta en marcha y en el funcionamiento de la Asociación, proponiendo ideas y orientándoles en su acción.

- Si fuese necesario, servir de enlace entre el APA y otros órganos de gestión y representación del centro.

- Fomentar la participación de los padres en todo tipo de programas y acciones que se estén llevando a cabo en el centro.

- Participar en las reuniones de la Junta Directiva y asambleas del A.P.A., cuando se nos solicite.

- Aportarles datos para el conocimiento de la escuela y la comunidad educativa utilizando el análisis del contexto realizado desde el Proyecto Educativo del centro u otros estudios elaborados anteriormente.

- Colaborar en campañas de sensibilización organizadas por APAS o Federaciones de APAS dirigidas a promover actitudes positivas hacia la integración escolar y/o sociolaboral de los alumnos con necesidades educativas especiales, de minorías étnicas, actividades para fomentar la participación de padres, etc.

- Participar en la organización de actividades culturales y formativas, tanto para los alumnos como para las familias: semana cultural, actividades extraescolares, ciclos de charlas y conferencias, encuentros padres-profesores, jornadas de puertas abiertas, etc.

5. Promoción y participación de actividades formativas dirigidas a familias a través de escuelas de padres, charlas, conferencias y otro tipo de actividades.

El trabajador social podrá participar como colaborador en la organización de las actividades, intentando responder a las necesidades planteadas por los padres y a las detectadas a través del análisis del contexto medioambiental, el organizativo-institucional y las interacciones personales. También podrá asesorar en el diseño del programa de formación dirigido a los padres en todas sus fases. 
8.7. Elaborar y difundir materiales e instrumentos propios de la intervención socioeducativa.

El trabajador social elaborará documentos y materiales propios del Trabajo Social en el ámbito socioeducativo y lo adoptará instrumentos y materiales utilizados en la intervención social en otros campos adecuándolos a la especificidad de este ámbito.

1. Recopilar materiales e instrumentos existentes en la actualidad referidos a la intervención del trabajador social en el campo educativo.

2. Elaborar materiales específicos para programas o actividades concretas, tales como cuestionario de detección, catálogo de recursos socioeducativos, guía de alternativas al acabar la escolaridad, materiales para el asesoramiento y la formación de padres, etc.

3. Elaborar y divulgar materiales informativos para padres, profesores y alumnos sobre recursos socioeducativos del entorno.

4. Proporcionar a los profesores materiales de apoyo para su acción tutorial (cuestionarios de detección de indicadores de riesgo social, cuestionario de detección de alumnos con necesidades educativas especiales, etc.).

5. Contribuir a la renovación de enfoques y técnicas de innovación educativa e intervención sociofamiliar.

6. Realizar investigaciones sobre cuestiones que son objeto de su intervención profesional, así como sobre distintos aspectos de la comunidad educativa con la que trabaja, que sirvan, al mismo tiempo, para contribuir al desarrollo teórico-práctico del Trabajo Social en este campo.

\section{BIBLIOGRAFÍA}

ÁLVAREZ, M. y FERNÁNDEZ, R. (1989): Programa de orientación de estudios y vocacional al término de la escolaridad obligatoria. Promociones y Publicaciones Universitarias, S.A. Barcelona.

CAMPO, M. a A. y LASMARIAS, M. (1993): El trabajador social en los equipos interdisciplinares. Programa de intervención en el contexto sociofamiliar. Documento de Orientación Educativa e Intervención Psicopedagógica (M. ${ }^{\circ}$ de Educación y Ciencia).

DECRETO 136/1984, sobre creación y funcionamiento de los Servicios Psicopedagógicos Escolares.

DECRETO 13/1994, por el que se regulan los Servicios Especializados de Orientación Educativa, Psicopedagógica y Profesional ( DOGV n ${ }^{\circ} 2.320$, de 28-7-94). 
ESTRADA LORCA, M. y MOLINA SÁNCHEZ, M." V. (1991): “La interdisciplinariedad en la orientación educativa: respuesta a la diversidad" en Respuesta educativa ante la diversidad. Amarú Ediciones. Salamanca.

HERRANZ HERRANZ, C. (1991): "La investigación-acción como modelo de intervención psicopedagógica" en Respuesta educativa ante la diversidad. Amarú Ediciones. Salamanca.

IFAPLAN (1988): Nuevos temas y lugares educativos. Editorial Popular. Ministerio de Educación y Ciencia. Madrid.

JIMÉNEZ PUADO, C. (1990): Trabajo Social en el sistema educativo. Revista "Documentación Social", n79, pp. 145-159. Madrid. Cáritas Española.

LEY ORGÁNICA 1/1990, de Ordenación General del Sistema Educativo (LOGSE) ( BOE,4-11-90).

MINISTERIO DE EDUCACIÓN Y CIENCIA (1989): Libro Blanco para la Reforma del Sistema Educativo. Madrid.

ORDEN 10 de Marzo de 1995, por la que se determinan las funciones de cada profesional dentro de estos equipos.

PÉREZ SERRANO, G. (1990): Investigación-acción: aplicaciones al campo social y educativo. Dykinson. Madrid.

ROSELLÓ NADAL, E. y SAAVEDRA MUÑOZ, M. (1995): La intervención del trabajador social en los Servicios Psicopedagógicos Escolares. Conselleria de Educación y Ciencia. Generalitat Valenciana. 


\title{
MARCO LEGISLATIVO DEL ACOGIMIENTO FAMILIAR
}

\author{
ANA ROSSER LIMIÑNA \\ Psicóloga de la Unidad de Adopción de la Conselleria de Bienestar Social. Alicante.
}

\section{RESUMEN}

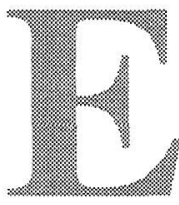

1 presente artículo hace un recorrido sobre la legislación existente en los ámbitos internacional, nacional y autonómico (Comunidad Valenciana) respecto al acogimiento familiar, su evolución, avances y aspectos pendientes de acometer.

\section{PALABRAS CLAVE}

Acogimiento familiar, Legislación.

\section{INTRODUCCIÓN}

La adopción y el acogimiento familiar se enmarcan dentro de las medidas de protección a la infancia que se vienen desarrollando tanto a nivel internacional como nacional cuando se detectan casos de problemática socio-familiar y en los que se plantea la conveniencia de que el niño sea acogido por una determinada familia de forma transitoria o permanente, dado que su familia no puede o no quiere hacerse cargo de las obligaciones que conlleva ser padres.

Aunque existen antecedentes históricos importantes sobre la figura del acogimiento de menores, la preocupación por regular esta medida de protección infantil se instaura con fuerza en Europa a partir de la segunda mitad del siglo XX, y especialmente en sus últimas décadas, reflejándose en el desarrollo normativo de los distintos países, aunque a ritmos diferentes y con matices.

En general, la normativa sobre el acogimiento familiar, así como la promoción e intensificación de dicha figura se dieron como consecuencia de los numerosos estudios que evidenciaban los efectos negativos que producía la institucionalización de menores en su desarrollo personal y adaptación social. 
En España, como veremos más adelante, el marco legal del recurso empieza a vislumbrarse a finales de los años 80 , si bien habrá que esperar hasta 1996, con la publicación de la Ley Orgánica De Protección Jurídica Del Menor, para poder contar con un instrumento que reconozca plenamente y regule los aspectos legales del acogimiento familiar en todas sus formas.

\section{NORMATIVA LEGAL SOBRE ACOGIMIENTO FAMILIAR A NIVEL INTERNACIONAL.}

El hito principal, a nivel internacional, referente a la protección infantil lo encontramos con la Declaración De Los Derechos Del Niño que proclamó Naciones Unidas en su Resolución 1386 de 20 de noviembre de 1959, particularmente sus principios 2, 4 y, especialmente, el 6, que establece que, siempre que sea posible, el niño deberá crecer al amparo y bajo la responsabilidad de sus padres y, en todo caso, en un ambiente de afecto y seguridad moral y material.

Destaca, posteriormente, la Resolución (77) 33 de 3 de noviembre de 1977 del Consejo de Europa sobre Acogimiento de Menores, que viene a recoger los principios por los que debe regirse este recurso.

Por otra parte, en la Convención de las Naciones Unidas sobre los Derechos del Niño del 20 de septiembre de 1989, cuyo instrumento de ratificación por parte de España fue publicado en el B.O.E. de 30 de diciembre de 1990, se recogerá nuevamente el derecho de los menores a no ser maltratados y a ser protegidos por las entidades públicas del estado.

Finalmente, el Convenio de la Haya, relativo a la protección del niño y a la cooperación en materia de adopción internacional de 20 de mayo de 1993, cuyo instrumento de ratificación por parte de España fue publicado en el B.O.E. de 1 de agosto de 1995, vendrá a regular la colaboración entre los distintos estados contratantes y la normativa en materia de adopción internacional, garantizando que se preservará en las mismas el interés del menor y previniendo la sustracción, venta y tráfico de niños.

\section{NORMATIVA LEGAL SOBRE ACOGIMIENTO FAMILIAR A NIVEL ESTATAL.}

La constitución española de 1978 recoge, fundamentalmente en el artículo 39 la protección que dispensa tanto a la familia como al me- 
nor, siguiendo la línea de interés que con respecto a esta materia viene reflejándose en los distintos acuerdos internacionales.

La norma constitucional obliga a los poderes públicos a asegurar una protección a la familia, como marco idóneo donde se desarrolla el individuo y donde debe ser atendido.

El apartado 2 del artículo 39 del texto constitucional establece la necesidad por parte de los poderes públicos de asegurar una protección al menor mas allá del deber asistencial que tienen los padres con respecto a sus hijos. En consecuencia, los niños deben gozar de una protección, no sólo por parte de sus padres, sino también a través de los distintos mecanismos que establezcan los organismos públicos competentes en materia de asistencia y defensa del menor.

A nivel legislativo, en el ámbito estatal, no será hasta noviembre de 1987 , con la ley $21 / 87$, por la que se modifican determinados artículos del Código Civil y de la ley de Enjuiciamiento Civil en materia de adopción, cuando se regulen las medidas de protección infantil y en concreto el acogimiento y la adopción, si bien estas ya contaban con un abordaje jurídico desde 1937.

Las metas claves de la ley 21/87 fueron:

- La desjudicializacion de las primeras etapas de protección, agilizando su aplicación.

- La potenciación del papel de las entidades públicas a través de los servicios sociales.

- La profundización de la idea de un Ministerio Fiscal, defensor real del menor.

- La prioridad del tratamiento del menor en su propia familia.

A partir de estos principios, la ley 21/87 introdujo grandes cambios en el ámbito de la protección del menor:

- Permitiendo la asunción automática por parte de la entidad publica de la tutela de los menores que se encontraran en situación de desamparo (posibilidad que, hasta entonces, sólo era potestad del juez).

- Considerando la adopción como un elemento de plena integración familiar.

- Configurando el acogimiento familiar como una nueva institución de protección.

- Regularizando y simplificando el procedimiento, para lo que se modificaron los artículos 172 y siguientes del Código Civil.

La ley orgánica 1/96 De Protección Jurídica Del Menor vendrá a cubrir algunas lagunas de aquella ley, a la vez que pretende dar respuesta a las nuevas necesidades y demandas que han ido surgiendo desde la publicación de la anterior. 
En este sentido, en el tema que nos ocupa, aporta las siguientes novedades:

- Diferencia explícitamente el acogimiento familiar y el acogimiento residencial como distintas formas de ejercer la guarda de los menores.

- Flexibiliza la acogida familiar para dar respuesta a las distintas circunstancias que concurran sobre el menor y a la finalidad del acogimiento, distinguiendo tres modalidades:

- Simple, cuando se establece una medida transitoria.

- Permanente, para dotar de estabilidad familiar a los menores que no pueden acceder a la adopción ni es posible su retorno a la familia de origen.

- Preadoptivo, con vistas a su adopción.

- Permite a la entidad pública acordar un acogimiento provisional en la familia, aun cuando los padres no consientan o se opongan y en tanto se produzca resolución judicial.

- En materia de adopción, internacional, introduce la exigencia del requisito de idoneidad de los adoptantes y regula el papel de las entidades mediadoras en el ámbito de la adopción internacional.

\section{IV.NORMATIVA LEGAL SOBRE ACOGIMIENTO FAMILIAR EN LA COMUNIDAD VALENCIANA.}

En el ámbito autonómico, el acogimiento familiar ha sido regulado por la siguiente normativa legal:

4.1. La orden del 20 de marzo de 1986 de la Conselleria de Treball i Afers Socials, por la que se establece el recurso de familias educadoras en la Comunidad Valenciana; surge con carácter pionero a nivel nacional, tras las experiencias catalanas, para regular los acogimientos familiares.

Observamos en esta orden que:

- Ya delimita las características del recurso de acogimiento familiar como medida de protección temporal en situaciones de riesgo.

- Tiene como principios rectores:

- la voluntariedad de las partes.

- la cercanía entre las familias de origen y educadora.

- la temporalidad.

- Hace pivotar el recurso sobre las Secciones de Familia, Infancia y Juventud de las Direcciones Territoriales de la Conselleria de Treball i Afers Socials. 
4.2. El Decreto $23 / 1988$ de 8 de febrero del Consell de la Generalitat Valenciana, de medidas de protección de menores en situación de desamparo en la Comunidad Valenciana, desarrolló más ampliamente el recurso dentro del ámbito de las medidas de protección, pudiéndose destacar del mismo los siguientes aspectos:

- Se atiene a los términos marcados por la ley 21/87.

- Asume la orientación, principios, reglamentación y gestión de la orden de 1986.

- Procura la municipalización de la gestión, en aras a su descentralización.

- Señala como requisitos para su aplicación:

- la jerarquización de los recursos, agotando previamente las mediadas que permitan mantener al menor en su medio natural.

- valorar la idoneidad de las personas acogedoras.

- Añade, respecto a la orden anterior:

- una organización funcional y competencial en la aplicación de las medidas.

- la colaboración de las instituciones de integración familiar.

- la determinación en la resolución del tiempo y de la cuantía económica.

- la atribución de poder resolutivo a las Comisiones Mixtas.

4.3. El Decreto $31 / 1991$ de 18 de febrero, que modifica el Decreto 23/88 de Medidas De Protección De Menores En Situación De Desamparo En La C.V., pasará a atribuir a las Comisiones Mixtas de familias Educadoras la emisión de la propuesta técnica al Jefe de Area de Servicios Sociales.

4.4. La ley 7/1994 de 5 de diciembre de la Infancia, de la Generalitat Valenciana, se va a caracterizar porque:

- Pretende consolidar la política que desde los distintos sistemas con responsabilidad en materia de menores vienen implantándose en la Comunidad Valenciana, de forma integral y coordinada, indicando la necesidad y sentando las bases para la elaboración del Plan Integral de Atención a la Infancia.

- Contempla los cinco grandes programas de intervención según los cuales se articula el Plan de Ordenación de los servicios sociales en la C. Valenciana:

- Información.

- Accesibilidad.

- Cooperación.

- Convivencia.

- Reinserción. 
- Diferencia distintas modalidades de intervención, niveles primarios y especializados, en cada uno de los programas.

- Incluye el acogimiento familiar en el programa de convivencia, y diferencia el acogimiento familiar primario y el especializado, en función de que el mismo se realice en ámbitos próximos al entorno del menor (familia extensa, vecindario, etc.) o alejados del mismo, y de su finalidad (retorno o adopción).

\section{NORMATIVA DE SOPORTE.}

Existe, además, todo un cuerpo de normativa legal, tanto a nivel estatal como autonómico, que, sin referirse específicamente a la protección de la infancia, sí le sirve de soporte para poder llevar a cabo con éxito la misma, y que, fundamentalmente, engloba las siguientes leyes:

- La ley 8/1985 de Derecho a la Educación, que generaliza el principio de integración escolar.

- La ley 7/1985, reglamentada en Real Decreto $155 / 1996$ sobre derechos y deberes en España, que recoge los derechos de los extranjeros residentes en el país.

- La ley 14/1986 General de Sanidad, que propicia la universalizaron de la sanidad.

- La Ley 5/1989 de Servicios Sociales de la Comunidad Valenciana, que desarrolla el principio de normalización de la asistencia social.

- La ley 5/1997, que modifica la anterior en lo que respecta a la regulación del Sistema de Servicios Sociales en la Comunidad Valenciana.

\section{CONCLUSIONES.}

A la vista del recorrido realizado por la normativa legal que sustenta el recurso del acogimiento familiar como medida de protección infantil, podríamos aventurar las siguientes conclusiones:

1. No se han producido cambios relevantes en los principios y parámetros de actuación. Sorprende comprobar cómo las recomendaciones realizadas por el Consejo de Europa, en 1977, hace más de 20 años, siguen teniendo vigencia en la actualidad. Muchos de los aspectos allí recogidos no se han implementado en su totalidad hasta la fecha en los diferentes programas de protección infantil existentes, o no son tenidos en cuenta a la hora de aplicar el recurso del acogimiento familiar a las situaciones concretas, posiblemente 
no por desconocimiento de estos principios sino por la falta de recursos disponibles y/o la urgencia de las situaciones.

2. La ley de Protección Jurídica del Menor ha supuesto un avance tardío pero eficaz en cuanto al soporte legal que requerían diferentes aspectos de la puesta en práctica del acogimiento familiar, especialmente cuando no se contaba con el consentimiento de los padres y respecto a sus modalidades de aplicación en función de la finalidad del mismo.

3. A nivel autonómico, en la Comunidad Valenciana se ha producido, a partir de la ausencia de desarrollo de la Ley de la Infancia (Ley $7 /$ 94 de la G.V.) y su falta de concordancia con la ley $1 / 96$, un estancamiento legal que se ha ido supliendo con instrucciones y circulares que no han llegado a cobrar cuerpo normativo hasta la fecha. En consecuencia, siguen estando sin regular aspectos tan importantes como:

- La adecuada coordinación entre las diferentes instancias cuyo centro de interés es el menor: educativas, sanitarias, etc.

- La implantación de programas integrales a nivel preventivo y de actuación en el medio donde se detectan las situaciones de riesgo.

- La creación de Equipos de Atención Especializada a nivel municipal o comarcal que permitieran el abordaje de las problemáticas de mayor complejidad técnica, desde el propio entorno en el que se producen.

4. Por otra parte, parece estarse produciendo un giro en cuanto al marco competencial que apunta hacia un intento de «recentralización» del control y la puesta en marcha de las medidas de protección, cuyo peso específico vuelve a recaer en las entidades de carácter autonómico o provincial, en detrimento de las municipales.

5. Finalmente, la reciente separación de los programas referidos a menores, a nivel competencial en la Comunidad Valenciana, entre las Direcciones Generales de Servicios Sociales y Familia y Adopciones respectivamente, parece estar dificultando todavía más la realización de planes de actuación sobre los menores que les permitan alcanzar una estabilidad familiar definitiva y lo menos traumática posible.

\section{BIBLIOGRAFÍA}

AGUILAR VENTURA, A., COGOLLOS RUBIO, Y. y CALERO JAÉN, C. (1992): Acogimiento familiar y familias educadoras en la Comunidad Valenciana. Generalitat valenciana. Conselleria de Treball i Seguretat Social. 
DE PAUL OCHOTORENA, J. y ARRUABARENA MADARIAGA, M.J. (1996): Manual de protección infantil. Masson. Barcelona.

IGLESIAS REDONDO (1996): Guarda asistencial, tutela ex lege y acogimiento de menores. CEDES editorial. Barcelona.

MARÍN GARCÍA DE LEONARDO, M.T. (1991): La tutela ex lege. La guarda y el acogimiento de menores en la Comunidad Valenciana. Generalitat Valenciana. Conselleria de Treball i Seguretat Social.

PÉREZ MARTÍN (1995): Derecho de familia. Adopción, acogimiento, tutela y otras instituciones de protección de menores. Lex Nova. Valladolid. 
MARCO LEGAL DEL ACOGIMIENTO FAMILIAR.

\begin{tabular}{|c|c|c|}
\hline Ambito Internacional & Ambito Nacional & Ambito Autonómico \\
\hline $\begin{array}{l}\text { - Declaración De Los } \\
\text { Derechos Del Niño de } \\
\text { las Naciones Unidas, de } \\
20 \text { de noviembre de } \\
\text { 1959. } \\
\text { - Resolución (77) } 33 \text { del } \\
\text { Consejo de Europa so- } \\
\text { bre acogimiento de me- } \\
\text { nores. } \\
\text { - La Convención de las } \\
\text { naciones Unidas sobre } \\
\text { los Derechos del Niño } \\
\text { de 20/9/89, ratificada } \\
\text { por España el 30/12/90. } \\
\text { - CONVENIO DE LA } \\
\text { HAYA, relativo a la } \\
\text { Protección del Niño y } \\
\text { la Cooperación en ma- } \\
\text { teria de Adopción Inter- } \\
\text { nacional de 29 de mayo } \\
\text { de 1993, ratificado por } \\
\text { España el 30-6-1995 } \\
\text { (BOE de 1/8/95). }\end{array}$ & $\begin{array}{l}\text { - Ley } 21 / 87 \text { de } 11 \text { de no- } \\
\text { viembre de } 1987 \text {, por la } \\
\text { que se modifican deter- } \\
\text { minados artículos del } \\
\text { Código Civil y de la } \\
\text { Ley de Enjuiciamiento } \\
\text { Civil, en materia de } \\
\text { Adopción. } \\
\text { - Ley O. 1/96 de } 15 \text { de } \\
\text { enero. De Protección } \\
\text { Jurídica del Menor, y } \\
\text { de modificación parcial } \\
\text { del C. Civil y de la } \\
\text { L.E.C. }\end{array}$ & $\begin{array}{l}\text { - Orden de } 20 / 3 / 86 \text { por la } \\
\text { que se establece el re- } \\
\text { curso de familias edu- } \\
\text { cadoras en la C. Valen- } \\
\text { ciana. } \\
\text { - Decreto 23/88 de medi- } \\
\text { das de protección de } \\
\text { menores en situación } \\
\text { de desamparo en la C. } \\
\text { Valenciana. } \\
\text { - Decreto } 31 / 91 \text { que mo- } \\
\text { difica algunos artículos } \\
\text { del Decreto } 23 / 88 . \\
\text { - Ley } 7 / 94 \text { de } \\
\text { Generatilat Valenciana } \\
\text { de la Infancia. } \\
\text { - Decreto } 130 / 96 \text { de } 4 \text { de } \\
\text { Julio por el que se re- } \\
\text { gula el Consejo de } \\
\text { Adopción de Menores } \\
\text { de la Generalitat Valen- } \\
\text { ciana. } \\
\text { modifica el anterior en } \\
\text { ción del Consejo de } \\
\text { adopción. }\end{array}$ \\
\hline
\end{tabular}





\section{PENSAR LA EPISTEMOLOGÍA DEL TRABAJO SOCIAL}

\section{OCTAVIO VÁZQUEZ AGUADO}

Trabajador Social. Antropólogo.

Profesor Titular de Escuela Universitaria. Departamento de Sociología y Trabajo Social. Universidad de Huelva.

\section{ABSTRACT}

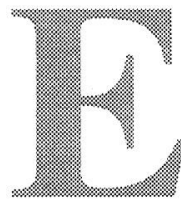

n el presente trabajo realizamos una reflexión a cerca de la epistemología del trabajo social. Partimos de considerar la epistemología como una reflexión de "segundo orden" frente a las producciones de la disciplina y profesión, siendo importante analizar qué relaciones mantiene con los contextos sociales donde se producen. En nuestro caso, vemos cuáles son los marcadores que más influyeron en el nacimiento del trabajo social y sus repercusiones en la consideración social de la disciplina. Creemos que la epistemología del trabajo social ha de hacerse teniendo en cuenta las aportaciones de este debate en el conjunto de las ciencias sociales, del cual nos interesa destacar lo que se denomina la concepción ampliada o nueva de las ciencias humanas, donde las características particulares del trabajo social encuentran la justificación para poder generar conocimiento. Establecido ya lo que nos aportan las ciencias sociales, abordamos el análisis de nuestra disciplina centrándonos en su concepto, objeto y método. Creemos que es posible la construcción de conocimientos puesto que, en las intervenciones del trabajo social, están presentes los grandes problemas teóricos de las ciencias sociales. Establezcamos una mínima distancia sobre las mismas para poder reflexionar sobre ellas.

\section{INTRODUCCIÓN}

El ser humano vive inserto en un medio físico y social determinado. A lo largo del espacio y del tiempo, ha intentado conocer ese medio de diversas formas y utilizando diferentes procedimientos, cada uno de los cuales le ha proporcionado una explicación concreta sobre la realidad. Esta explicación ha nutrido el capital de conocimientos que ha ido acumulando. A veces, sumativamente; otras veces, una explicación ha sustituido a la anterior. El conocimiento es pues unạ́ posibilidad y ne- 
cesidad que todas las sociedades han desarrollado de una u otra forma. En nuestro contexto, en el que se ubica el trabajo social, el conocimiento científico es el instrumento que nos hemos dado para señalar la diferencia entre lo cierto y lo falso

Nadie puede dudar de la importancia de la ciencia en nuestra sociedad. El desarrollo de la misma está en la base de la organización y de la vida social. Hay pues que interrogarse por sus repercusiones en todos los ámbitos de la sociedad. El trabajo social, en cuanto que está presente en una sociedad donde la ciencia es el criterio dominante para el establecimiento de lo verdadero y de lo falso, tiene que preguntarse por su carácter científico o no. La epistemología será un medio para ello. La concepción que tenemos sobre la misma vendría determinada por considerar que consiste en un análisis de las estructuras conceptuales de una ciencia en particular y de la ciencia en general. Este análisis se ubica en un nivel de segundo orden con respecto a la reflexión científica misma. Su objeto de trabajo vendría determinado no por entidades acotadas espacio-temporales..., sino por los conceptos que manejan los especialistas de esta ciencia para el desarrollo de la misma (Ulises Moulines, 1988). La epistemología no quiere imponer un sistema a priori, dogmático, que dicte autoritariamente lo que debe ser conocimiento científico, sino estudiar la génesis y la estructura de los conocimientos científicos, es decir, estudiar la producción científica desde todos sus aspectos, sin obviar que los conceptos empleados, y la misma ciencia, se producen en un contexto determinado por lo que habría que analizar la relación entre ciencia y sociedad (Mardones y Ursúa, 1982: 41-44).

\section{POR QUÉ UNA EPISTEMOLOGÍA DEL TRABAJO SOCIAL}

Para contestar esta pregunta creemos necesario remontarnos al contexto en el que surge el trabajo social. El mismo está condicionado por tres aspectos principales.

$1^{\circ}$. A lo largo de los siglos XIX y XX tiene lugar la expansión de las ciencias sociales. Como sabemos, a partir de la Revolución Francesa, las explicaciones dadas hasta ese momento sobre el funcionamiento de la sociedad fueron sustituidas por otras. Estas nuevas respuestas iniciaron el incipiente desarrollo de las ciencias sociales que hubieron de seguir el camino, el método y el modelo de las ciencias naturales para ser consideradas como ciencias. Creemos importante señalar que la noción de ciencia dominante (y única por aquellos momentos) gozaba de un lugar destacado en la sociedad como fuente de verdad. El conocimiento sólo se podía obtener a través de un procedimiento que pone 
el énfasis en lo objetivo, lo cuantitativo, lo experimental, la observación, la verificación y la generación de leyes de orden mecanicista (Naredo, 1987). La ciencia puesta al servicio del hombre y con la finalidad de dominar la realidad, social o natural. Si las ciencias sociales trataban de convertirse en ciencias y, para ello, se desarrollaron líneas de pensamiento por los precursores de las mismas, el trabajo social, por contra, nació como un saber empírico, como una actividad filantrópica (Zamanillo, 1991), centrado en la atención a los pobres en una mezcla de asistencia, control y represión. Sus preocupaciones «científicas» eran limitadas y se ceñían a cómo mejorar la organización de la caridad. Posteriormente, aparecería la necesidad del conocimiento de la realidad social, la profesionalización de la asistencia y su formación.

$2^{\circ}$. Las consecuencias sociales provocadas por la industrialización fueron muy importantes: no sólo porque motivaran la identificación del trabajador como pobre, sino porque fueron el motivo directo tanto del inicio de una tímida reformulación del liberalismo económico desde dentro como de propuestas más radicales desde el socialismo. Nos señala Rubio Lara (1991: 27-31) que en el siglo XIX se inició una revisión del orden socioeconómico implantado por el capitalismo liberal dada su patente injusticia. Revisiones que o bien se hacen desde el propio liberalismo de acuerdo a principios humanitarios y morales, o bien desde posturas más radicales que pretendían no reformar el sistema para asegurar su supervivencia, sino cambiarlo radicalmente (Marx). La sociedad no es vivida como un espacio de tranquilidad, seguridad y prosperidad, sino como un lugar de conflicto y tensión (Cotarelo, 1987). Desde las filas más conservadoras se desarrollaron acciones encaminadas a mejorar las condiciones de vida de los trabajadores y de los pobres (beneficencia, caridad). Con este deseo de mejorar las condiciones de vida y hacer aceptable el sistema (esto es, no cuestionarlo), se procederá a una revisión y expansión de las organizaciones de caridad, donde encontrará su origen el propio trabajo social. Las primeras visitadoras amigables, educadoras de la clase obrera, serán mujeres de la burguesía que pretenden mejorar su vida, guiada por el espíritu del utilitarismo (Moix: 1991, 57), que perseguía el mayor bien del mayor número. Quedaron en saco roto, de momento, las indicaciones emanadas de la Revolución Francesa que afirmará que la asistencia es una ciencia política que debe ser cuidadosamente estudiada (Álvarez Uría, 1986).

Si el impulso de las organizaciones de la caridad provino de las clases pudientes, no podemos obviar (por contraposición) que, en el siglo XIX, y gracias a la presión del movimiento obrero y de los partidos socialistas, comenzó también el desarrollado del Estado de Bie- 
nestar. Se podrá discutir si los logros alcanzados en este período, tanto en el orden político como social, son verdaderas conquistas de los trabajadores o, simplemente, cesiones del Estado y de la burguesía necesarias para el mantenimiento del sistema capitalista. En cualquier caso, lo que parece innegable es que la vida de los obreros empezó a mejorar, una redistribución incipiente de la riqueza se realizó y, sobre todo, se abrió definitivamente la puerta a la intervención del Estado en la regulación de la vida económica y en la protección y mejora de las condiciones de vida de los trabajadores. Esta intervención fue aceptada por los liberales como una manera de mantener el sistema y, por parte de los socialistas (al menos los lasellanos - Cotarelo, 1987-), fue el inicio de poner el Estado al servicio de la clase trabajadora. El incipiente Estado social nace a partir del reconocimiento de derechos a la clase obrera, el trabajo social nace con la finalidad de contribuir a mejorar las condiciones de vida de la misma, pero sin cuestionar la lógica que generaba las situaciones de enorme desigualdad: el objetivo era intervenir con medidas de previsión y protección social en el seno de la clase trabajadora, y ello no tanto en nombre del sacrosanto principio de la igualdad cuanto en nombre de la solidaridad, es decir, sin conceder a los asistidos derechos sobre el espacio político, espacio de soberanía (Álvarez Uría, 1995: 10-11). Si la clase obrera recibió bien el desarrollo de los primeros seguros sociales, recelaba frente a los primeros trabajadores sociales: unos eran vistos, aunque con discusiones, como conquistas de los trabajadores; otros eran percibidos como agentes de control.

$3^{\circ}$. El papel de la mujer en el siglo XIX también nos parece una referencia importante para conocer el contexto en el que nace el trabajo social. Su rol en la sociedad, la distribución de poderes, los espacios propios de los dos sexos, configurarán una presencia de la mujer en la sociedad subsidiaria del hombre, expulsada de la vida pública y cuya importancia, tanto en la producción como en la reproducción social, no es valorada suficientemente. Farge (1991: 90-96) nos señala que la mujer se caracteriza en este período, por estar sometida al hombre: el producto de su trabajo recae en su tutor legal y la procreación está sometida al control de la comunidad. Es considerada como un ser débil (y, por ello, quizás las primeras legislaciones de las condiciones de trabajo se dirigen a ellas y a los niños), lo que no impide que su trabajo siga siendo duro. Se les ve como irresponsables. Su ámbito de poder se limita a lo doméstico, donde se vive como una intrusión la presencia del hombre. En este espacio, tendrá lugar la socialización de hijos e hijas y, por tanto, la reproducción social. Lo único que cambia, según Farge, es que las mujeres (determinadas mujeres) comienzan a desarrollar una presencia pública que antes era de dominio exclusivo de los 
hombres. Veamos cómo lo dice la autora: las Iglesias, la República, exaltan "el poder social de las mujeres», considerado como fundamental en el desarrollo del Welfare Estate. En Alemania adopta la forma de una verdadera «maternidad social». En ese caso, las mujeres burguesas socorren, educan y controlan a las mujeres pobres y obreras. A impulso de asociaciones, pasan, de ser «visitantes de pobres» según la vieja expresión filantrópica, a inspectoras benévolas, de damas protectoras a asistentes sociales, precursoras de los trabajadores sociales... De la misma manera, los médicos hacen de las mujeres sus aliadas en la lucha por la higiene, que es también un modo de moralizar la miseria que se oculta tras la mugre. Muchas mujeres encontraban ahí un exutorio a sus energías y a la mala conciencia que los valores de utilidad y trabajo, crecientes en la sociedad, transmitían a su ociosidad (1991: 91).

Las mujeres se incorporan a la vida social progresivamente, siendo la asistencia social uno de los campos privilegiados para ello. Su presencia, su labor, es una prolongación de los roles expresivos que juegan en el ámbito doméstico y que reproducen en el ámbito público. Observamos también cómo el movimiento precursor del trabajo social nace en el seno de la clase alta y, a parte de servir para justificar a las mujeres frente a la sociedad, es empleado como un mecanismo de control respecto del cual la clase trabajadora recela, como había recelado con anterioridad de otros mecanismos de ayuda desarrollados por la sociedad (Fernando Díez, 1992: 116). La asistencia social, como precursora del trabajo social, nace pues de un deseo reformador desde las élites sociales, alejada del incipiente Estado social y sin participación en el debate sobre las ciencias sociales.

Entonces, ¿para qué una epistemología del trabajo social? ¿Puede mejorar la vida de la gente con las que intervienen los trabajadores sociales una construcción científica del trabajo social? Creemos que sí. Que el sujeto sea protagonista de su propio cambio, desarrolle una acción reflexiva, exige no sólo reconocerle un espacio en la relación, una influencia en el profesional, una capacidad en la toma de decisiones, requiere, por parte del profesional, de un conocimiento de la realidad y de su complejidad, que evite el interés técnico y se sitúe en las claves del interés emancipatorio.

\section{III.EN QUÉ CONSISTIRÍA ESTA EPISTEMOLOGÍA: CIENCIAS SOCIALES Y TRABAJO SOCIAL}

Las referencias interdisciplinares siempre han estado presentes en la profesión. Esta recurrencia ha sido conflictiva por dos razones prin- 
cipalmente: la obtención de los referentes teóricos en otras materias ha podido ser causa que explique el no desarrollo de la propia reflexión teórica y, en segundo lugar, por los criterios por los que dichos conocimientos se aplicaban al trabajo social: importaba más la orientación empírica, la resolución de un problema a partir del conocimiento tomado, que el ajuste del mismo al objeto, la naturaleza o los valores de la profesión. Esta adaptación de conocimientos supone una reducción del trabajo social a algunos de sus elementos fundamentales: su atención en lo psicológico, en lo individual, buscando la causa y la solución de los problemas en la propia persona. La atención principal en lo estructural, buscando, en este caso, la explicación y resolución de los conflictos únicamente en la sociedad, tensionada dialécticamente (Zamanillo, 1991: 37-43).

No obstante, recurrir a las ciencias sociales es una de las vías posibles para construir la disciplina: encontramos tanto elementos que nos ayudan a una justificación epistemológica del trabajo social como bases para el desarrollo de la disciplina. Quien piense que dicha relación es unidireccional, es decir, desde las ciencias sociales al trabajo social, se equivoca puesto que, tal y como demuestra Kam-Fong (1990), existen también aportaciones de nuestra profesión hacia ese ámbito más general que constituyen las ciencias sociales.

\section{1. ¿Qué podemos aprender de las ciencias sociales?}

$1^{\circ}$. Los modelos o paradigmas dominantes. Mardones y Ursúa (1982:15-35) nos plantean que, en el fondo del debate respecto a la consideración epistémica de las ciencias sociales, se encuentran dos tradiciones filosóficas sobre el método científico. La polémica entre ambas ha atravesado la historia de las ciencias sociales. La tradición aristotélica sostiene que en el principio de la investigación está la observación pero, que la explicación científica, no se logra hasta que no se dan razones de los hechos y fenómenos que son observados por el investigador. Por tanto, no es suficiente la observación. El investigador tiene que lograr una explicación de los hechos observados puesto que, sin tal explicación, no existiría conocimiento científico. El rasgo último y definitorio de esta corriente es la búsqueda de explicaciones teleológicas que aclaren las «causas finales»: se trata de buscar las razones que explican la existencia de los fenómenos. La tradición galileana defiende que las preocupaciones de la ciencia no son ya de orden metafísico sino funcional y mecanicista. Lo que interesa es buscar las leyes que explican el comportamiento de los fenómenos. El objetivo del conocimiento no se centra en saber el para qué o por qué de los hechos sino el cómo funcionan. Sólo así será posible establecer leyes científicas, expresadas matemáticamente, que expliquen los he- 
chos. Estas explicaciones funcionarán a modo de hipótesis causales que deberán experimentarse, ponerse a prueba.

$2^{\circ}$. Los condicionantes del conocimiento científico social. El objeto de conocimiento: lo social, el conjunto de relaciones interacciones, actuaciones e influencia de los hombres entre sí y con la sociedad institucional, la cultura y la naturaleza. Esta definición englobaría a un conjunto importante de campos de investigación: hechos externos al propio individuo que le influyen en su comportamiento, y hechos internos, motivados en el interior del individuo y que influyen también en su comportamiento (Sierra Bravo, 1984).

$3^{\circ}$. Las características peculiares de la realidad social. Vista bien desde el punto de vista de los sujetos que interaccionan o bien en su globalidad, se caracteriza por ser compleja, sutil y cambiante. Los fenómenos sociales se presentan a veces «tal como son» (realidad real) y, en otras ocasiones, su dimensión real está oculta, escondida (realidad aparente, que, a veces, puede ser real en la medida que existe como tal y, otras veces, esconde la realidad tal cual es) (Beltrán, 1982). Sin embargo, esta aproximación a la realidad no es compleja sólo por las características de la realidad social, sino también porque los objetos que en ella están no se presentan al investigador de manera inmediata, sino mediata, es decir, dicha aproximación está atravesada tanto por el todo social como por la experiencia previa del que se aproxima. Este conjunto de circunstancias determina un hecho fundamental: en la realidad social, objeto y sujeto forman parte de la misma al tratarse, como decía Ibáñez, de un sistema hiperreflexivo.

$4^{\circ}$. La relación objeto-sujeto y su incidencia en la objetividad. En el ámbito de las ciencias sociales ocurre que el sujeto que conoce ocupa, respecto al objeto conocido, una posición particular, puesto que el cognoscente forma parte de lo conocido. En cuanto que afecta a la objetividad, afecta a la validez del conocimiento científico social. Según Sierra Bravo (1984: 65), la objetividad la vamos a entender como la correspondencia del resultado del conocimiento con lo conocido. Como se trata de dos «productos» de naturaleza diferente -lo conocido es real mientras que el conocimiento es ideal-, la correspondencia no consiste en una reproducción de la realidad tal cual, sino que se concreta en términos y expresiones lingüísticas que designan los aspectos del fenómeno, sus propiedades y relaciones. Inciden en ella: el objeto sobre el que se conoce. En este caso, la realidad social, que es sensible, cambiante, múltiple, compleja. Este conjunto de rasgos determinan que los hechos sociales sean únicos. El sujeto, forma parte del objeto de conocimiento y, como ya hemos indiciado, puede ser causa o consecuencia de cambios en relación al objeto. Sobre la relación que el sujeto mantiene con el objeto se han desarrollado en las ciencias sociales 
diversas corrientes que enfatizan bien la objetividad, partiendo de parámetros positivistas y realistas, o bien la subjetividad, que se sostiene sobre el énfasis en el sujeto y en las representaciones mentales de éstos. Al respecto, Gualda Caballero (1996: 46-49) nos recuerda que tal polémica está superada por la reflexividad en la cibernética de segundo orden, que nos pone de manifiesto cómo el sujeto forma parte del objeto y está dotado de reflexividad: el sujeto observa al objeto, se observa a sí mismo y es observado por los objetos. El proceso de conocimiento que está influenciado por el sujeto y el objeto y la relación que mantienen entre sí.

$5^{\circ}$. La influencia de los valores en el conocimiento. Como parte del objeto, el sujeto que conoce puede poseer no sólo una experiencia previa o un conocimiento superficial, sino que puede valorar o apreciar los rasgos de los fenómenos sociales de acuerdo a su particular escala, puesto que toda persona posee valores que tienden a permanecer a lo largo del tiempo, lo que influye en su capacidad de conocer. Todos los fenómenos sociales pueden ser objeto de valoración por parte de las personas, aunque las jerarquías de valores varíen entre los grupos existentes en el seno de una sociedad (Duverger, 1981) y entre sociedades o culturas diferentes (Dumont, 1987).

$6^{\circ}$. El método en las ciencias sociales. ¿O los métodos? El seguir un método es condición imprescindible para que el conocimiento pueda ser científico. No obstante, como nos señala Bernal (1991), el método no ha sido algo fijo que no puede ser analizado sin tener en cuenta sus conexiones con el carácter social de la ciencia. Pensamos, con Feyerabend (1974), que los procedimientos utilizados por los científicos han sido diversos y que, por tanto, la práctica de los mismos no ha sido unánime en el uso del método científico. Al respecto, García Ferrando (1979: 50) nos pone de manifiesto que sí hay un acuerdo básico en cuanto a los principios de tal concepto: el pluralismo teórico, la dependencia contextual y teórica de la práctica científica, el recurso a la lógica y a la experiencia empírica, la metodología entendida como una actividad crítica y teóricamente dependiente... el acuerdo no va más allá de estos principios:... de aquí que... haya que escuchar con escepticismo las apelaciones, tan enfáticas como ruidosas, a un método científico riguroso, detallado, universal y «manualizable»: tal cosa, ciertamente, no existe. (Beltrán, 1991: 97-98).

En lo que afecta a las ciencias sociales, Beltrán (1991: 98) nos afirma que no deben mirarse en el espejo de las ciencias naturales por la peculiaridad de su objeto, completamente diferente puesto que es $s u b$ jetivo, en el sentido de que posee subjetividad y reflexividad propias, volición y libertad..., reactivo a la observación y al conocimiento... un objeto de una complejidad inimaginable. Este conjunto de caracterís- 
ticas determina necesariamente una pluralidad de metodologías para su conocimiento.

Los métodos que empleemos nos ponen de manifiesto una realidad, pero no la realidad tal y como es: nos permiten una aproximación a la misma pero mediatizada. Los métodos, como construcciones teóricas, están atravesados por concepciones previas que inciden en la realidad que ponen de manifiesto: seleccionan la realidad de alguna forma. Se impone un uso relativista de los mismos, siendo válidos en la medida que sean capaces de describir y explicar los hechos a los que se enfrentan. Más que una oposición de métodos, optamos por una complementariedad entre los mismos de acuerdo a la naturaleza de lo que se quiere estudiar.

$7^{\circ}$. Lo cuantitativo y lo cualitativo en las ciencias sociales. ¿Son incompatibles? Creemos que no. El debate entre ambos enfoques, siguiendo a Pérez Serrano (1994: 53), se produce en dos niveles diferentes: el primero de ellos, será el nivel epistemológico, donde se encuentran las mayores incompatibilidades entre ambos enfoques puesto que parten de concepciones diferentes acerca de la realidad social y de cómo abordarla. El encuadre en un paradigma u otro no supone necesariamente la elección en exclusiva de los métodos coherentes con el mismo. Es posible la combinación de métodos diferentes en función siempre de la naturaleza de lo que se quiere estudiar, de las exigencias planteadas en el estudio. El segundo nivel en el que se produce el debate es el nivel metodológico y técnico donde, a tenor de lo dicho hasta ahora, la incompatibilidad a priori es menor puesto que los problemas a resolver en este nivel aluden tanto a la rigurosidad del conocimiento obtenido como al empleo conjunto de ambos.

$8^{\circ}$. La concepción ampliada de las ciencias sociales y los intereses del conocimiento. Según Pourtois y Desmet (1992), la concepción ampliada podría ser el [camino] de la epistemología y de la metodología nuevas, a saber, aquél que favoreciera el análisis de las interacciones entre los individuos, el examen de la subjetividad del observado y del observador, la investigación de lo particular y del sentido, el tener en cuenta la dinámica de los acontecimientos, la historia de los individuos y la complejidad de los fenómenos

La concepción ampliada la contemplamos a partir de las orientaciones metodológicas resumidas en los siguientes puntos: subjetivi$d a d$, la importancia del material cualitativo que permite rescatar las actitudes, los valores, las opiniones, las percepciones, las creencias, las preferencias de los sujetos. La participación del observador: tener en cuenta la existencia del observador, sacar partido de la subjetividad inherente al acto de la observación y estudiar la reciprocidad de esta actividad. Significancia: la importancia de conocer los significados 
que los sujetos otorgan a los hechos que viven. Tiempo subjetivo: el tiempo de lo vivido. Los significados que los actores atribuyen a sus actos pueden variar, modificarse en función de la influencia de otros actores y/o acontecimientos.

Coherente con estas orientaciones metodológicas es la concepción del sujeto que se deriva de las siguientes características: Sujeto en interacción. La comprensión del sujeto no puede hacerse al margen del contexto en el que se ubica. Rasgos particulares: lo que pretende poner de manifiesto es la peculiaridad. Prevalece en esta concepción la singularidad. Diferencia: nos destaca la importancia de los contextos, de los entornos inmediatos a los sujetos a la hora de establecer los rasgos distintivos de los mismos. Complejidad. Los hechos sociales no tienen una única causa ni un solo determinante. Ambos son históricos y dinámicos. Se trata de comprender esta complejidad en la que cada elemento depende de los demás y sólo existe en ellos y por la relación de ellos. Comprender desde dentro, lo que nos remite de nuevo a tener en cuenta a los sujetos, a los significados que otorgan a los fenómenos sociales.

La construcción de las ciencias sociales no es ni objetiva ni neutra. Responde siempre a unos intereses que es necesario tener en cuenta para mantener una actitud crítica respecto al conocimiento. De los tipos de interés que identifica Habermas (1988)-interés técnico del conocimiento, interés práctico del conocimiento e interés de emancipación-, al trabajo social creemos que le corresponde este último, que está basado en la lógica de la comunicación, pero con una orientación «yo-yo», es decir, donde se potencia la capacidad de autorreflexión del sujeto. El investigador no domina, facilita que el sujeto sea capaz de autodeterminarse, de potenciar su autonomía propia. El objetivo, por tanto, se centra en la liberación del sujeto de las relaciones de dependencia que existen en su entorno. Es el interés propio de las ciencias sociales críticamente orientadas.

\subsection{El trabajo social como disciplina}

Para desarrollar este epígrafe consideramos importante hacernos tres preguntas: ¿cuál es la naturaleza del trabajo social (concepto). ¿De qué se ocupa? (objeto). ¿Cómo conoce dicho objeto (métodos)?

\subsubsection{Concepto de trabajo social}

Sobre la naturaleza de la disciplina se ha producido a lo largo de la historia un debate que todos conocemos. De las tres posturas mantenidas, arte, tecnología y ciencia, nos interesa destacar esta última. Klein 
y Bloom (1990) sostienen que la definición científica del trabajo social se apoya en cinco elementos: empirismo, que reúne tres tipos de datos: (1) la colección de datos cuantitativos primarios usando métodos empíricos estándares, como la investigación descriptiva y el análisis bivariante y multivariante; (2) la manipulación de los datos secundarios ya existentes, y (3) la investigación cualitativa, que incluiría los estudios de casos o la explicación de casos comunitarios, como un análisis de los datos secundarios o primarios, y los métodos etnográficos. Tecnología. Se refiere a la aplicación de los contactos empíricos a través de una amplia variedad de mecanismos. Conceptualización. Modo de pensar que se mueve de los acontecimientos específicos en el mundo cotidiano a un campo lógico y abstracto en donde las características seleccionadas se extraen y generalizan de manera que, esas entidades, se convierten en el objeto de nuestras consideraciones. Valoración. Toda actividad humana conlleva algún grado de elección preferencial (aunque sólo sea dedicarse a esa actividad y nada más). Con todo, como componente de una ciencia aplicada, la valoración tiene que ver con la presentación de una posición particular de estimación. Comentario. Se refiere a los estados que describen, critican o comentan las actividades empíricas, tecnológicas, conceptuales o de valoración.

Han sido necesarios muchos años y el avance epistemológico de las ciencias sociales para que las características del trabajo social que, vistas desde una perspectiva positivista no eran sino impedimentos en la construcción como ciencia de la disciplina, se revelaran como fortalezas (Méndez-Bonito, 1996), como amarras a las que asirnos en la construcción científica de la disciplina. Si estas características son la complejidad, unicidad, sensibilidad, el cambio..., la reflexión sobre las mismas en una perspectiva científica sólo era posible desde la concepción nueva o ampliada de las ciencias que, como ya vimos, nos proporcionan tanto orientaciones metodológicas que ponen el acento en la subjetividad, participación del observador, la significancia y el tiempo subjetivo, como una concepción del sujeto que es definido en interacción, en base a sus rasgos particulares, la diferencia y la complejidad. Se trata pues de construir conocimiento a partir de lo particular, de profundizar en algo concreto más que buscar la generalización.

\subsubsection{Objeto del trabajo social}

El objeto del trabajo social se localiza en la realidad social donde interaccionan los individuos entre sí y con los elementos presentes en la misma. Esta interacción determina la existencia de carencias, problemas, necesidades que requieren ser abordadas con un apoyo profesional, experto, para ser superadas. La cuestión es delimitar qué parte 
de esta realidad social y, más concretamente, qué espacio de la necesidad o problema corresponde al trabajo social. Al igual que ocurre con el todo social, creemos que el objeto de nuestra disciplina es complejo, dinámico y cambiante, que adquiere diversas manifestaciones y que, en consecuencia, debe ser abordado desde una pluralidad cognitiva y metodológica, siendo conscientes de que los diversos enfoques teóricos dirigen su conocimiento en una sentido poniendo de manifiesto un aspecto concreto de la realidad y no toda ella.

Creemos, con García Salord, que es necesario pensar y definir el objeto del trabajo social porque significaría deslindar analíticamente el objeto de intervención de los sujetos involucrados en la problemáti$\mathrm{ca}$, es decir, no nos corresponde como objeto toda la persona sino una de las dimensiones de la misma, lo que no significa que, para abordar la problemática concreta, no haya que tener en cuenta la multidimensionalidad del individuo. Ello supone identificar qué dimensión del problema social es la propia y específica del trabajo social para, posteriormente, distinguir la estructura del objeto a través de reconocer los elementos que lo componen y las interrelaciones establecidos entre ellos. Para ello, será fundamental considerar al trabajo social no desde una perspectiva práctica sino conceptual, aprehender nuestro objeto de trabajo y reflexionar sobre el mismo.

De la reflexión que hacemos sobre el objeto destacamos que la disciplina localiza su centro gravitatorio en la persona, ubicada siempre dentro de un contexto, interesándoles los aspectos subjetivos, desde el momento en el que se trabaja con individuos con autonomía para pensar y actuar, y los aspectos objetivos, ya que en la realidad social se dan situaciones sociales que tienen un carácter externo, "objetivo" y coercitivo con respecto al sujeto. Entre sujeto y contexto, entre las dimensiones objetivas y subjetivas, hay una continua influencia, pues si bien el contexto limita la posibilidad de acción de los sujetos, éstos modifican a aquél por medio de sus acciones (Hierro, 1996). Abordar estas dos dimensiones requiere de varias reflexiones: cómo es la realidad social y qué parte de la misma nos corresponde como disciplina, participamos de la que identifica el objeto como malestar psicosocial ordenado según su génesis estructural y su vivencia personal (Zamanillo,1992). Pensamos que se trata de una definición general, que se abstrae de lo inmediato, y que permite un abordaje conceptual del objeto. La definición del malestar viene establecida no sólo por la vivencia de una carencia, sino por la distancia que se establece entre la misma y la posibilidad de superarla obteniendo así una situación de bienestar. Al trabajo social le interesa conocer las situaciones de malestar en cuanto que los individuos pretenden mejorarla. La ayuda que se puede prestar en ese tránsito es lo específico de la profesión. Ahora 
bien, la definición del malestar necesita tener en cuenta el juego que se establece entre los individuos y entre éstos y la estructura social, es decir, necesita preguntarse cómo se genera y cómo se concibe este malestar. El malestar lo entendemos como una construcción históricosocial, fruto de la interrelación de los hombres, que genera situaciones de desigualdad, de desequilibrio interno en la propia interactuación y con la estructura social. Como producto social, la consideración de lo que se entiende por malestar está sujeta a cambios de acuerdo a coordenadas espacio temporales. No se entiende lo mismo por malestar psicosocial según el momento histórico y según la ubicación espacial. Igualmente, con la especialización del trabajo, con la movilidad estructural funcional (Zapatero, 1989) de bienes y personas que se produce en la ruptura del antiguo régimen y con la Revolución Industrial, la forma de hacer frente a ese malestar definido socialmente ha variado. Preguntarse por cómo se genera el malestar implica interrogarse cómo se le hace frente. Y es aquí donde aparece el trabajo social, como una forma especializada de ayuda (o control) a/de las personas que padecen dichas situaciones de malestar.

¿Cómo se construye el malestar? Nos dice Pelegrí (1995) que el objeto del trabajo social no es enteramente objetivo. Nosotros consideramos que es fundamentalmente ideológico en cuanto que subjetivo. La aproximación que hacemos al objeto está mediatizada por dos instancias:

- El todo social y los poderes públicos. Corresponde al conjunto de individuos en su interacción definir qué situaciones son conceptualizadas, son objetivadas, como malestar. Sin esta definición, no se legitima la intervención profesional que se realiza con ellas, es decir, no hay un espacio social para la misma. Desde esta consideración, la definición de una situación de malestar se convierte en un medio poderoso de control social puesto que determina quién puede recibir o no la ayuda, quién forma parte o no de la normalidad: seguimos posicionándonos ya haciendo juicios de valor ante eventos, circunstancias, hechos y situaciones, mediante pensamientos que no siempre hacemos explícitos pero que emergen... (Garcés Ferrer y Durá, 1998:52). Cuando existe el consenso en el seno de la sociedad, la intervención de los poderes públicos refrenda al mismo disponiendo y organizando una política de atención hacia el conjunto de personas que sufren la situación de malestar. En esta política encuentran los profesionales, entre ellos los trabajadores sociales, el paraguas que da sentido a su actuación. Ahora bien, como ya señalamos en la relación entre política social y trabajo social, las instituciones imponen a los profesionales objetivos, medios y fines pudiéndose originar conflictos entre estos y los de la 
profesión. Corresponde al trabajo social interrogarse cómo es esa definición social de malestar y las repercusiones que tiene para su ejercicio profesional.

- La segunda instancia es el propio trabajo social y los trabajadores sociales. Como miembros de la sociedad, los profesionales también interactúan con otros sujetos, con el todo social y con la estructura. Intercambian y comparten significados que contribuyen a crear los conceptos objetivados, entre ellos el de malestar social. Los trabajadores sociales se localizan en la parte normalizada, mayoritaria en la sociedad, en la que reside el poder de objetivación. Como consecuencia de ello, tiene una visión sobre los problemas y las manifestaciones materiales del objeto, del malestar. Esa visión, obtenida como miembro de la sociedad, es consustancial a su persona, a su ciudadanía, y de la que difícilmente se desprenden cuando intervienen como profesionales.

Si doble es el procedimiento de definición del objeto (en cuanto que construcción social y definición profesional), doble tiene que ser la devolución que se haga desde el propio trabajo social: hacia la sociedad a la que pertenece, influyendo en la configuración social del malestar, y hacia la propia profesión y disciplina, ayudando a establecer distancia sobre las opciones personales y reflexionando sobre la intervención en claves de subjetividad. Pensar sobre las mediaciones para ser conscientes de cómo construimos el malestar y cómo concebimos a quien lo padece. Pensar sobre las distancias para poder alejarnos de la racionalidad técnico instrumental y entrar en otra comunicativa y emancipadora.

\subsubsection{Los métodos en trabajo social}

Plantear la construcción de los métodos en trabajo social desde una perspectiva científica requiere de varias reflexiones, unas en el ámbito de las ciencias sociales y otras propias de nuestra disciplina. En primer lugar, ser conscientes del debate presente en el seno de las ciencias sociales sobre la existencia de un sólo método científico, que el mismo sea el de las ciencias naturales y que éste se pueda aplicar al conjunto de las ciencias sociales. Se trata de elegir un método, de acuerdo a la naturaleza propia de la parcela de la realidad que vayamos a estudiar, de los objetivos que persigamos con nuestra investigación y de las capacidades y medios del investigador. Sea cual sea el método elegido, no podemos renunciar a su carácter parcial, premeditado, en la medida que no nos pondrá de manifiesto toda la realidad social sino sólo una parte de la misma y desde unos planteamientos determinados. En segundo lugar, para la construcción científica del método en la discipli- 
na, es necesario tener en cuenta tanto las características peculiares de nuestro objeto como la relación objeto-sujeto que se da en trabajo social. En tercer lugar, el objeto de la disciplina participa de las características propias de la realidad social pero, al identificarse con el malestar psicosocial de los individuos, sobre su definición pesan mediaciones sobre las que es necesario establecer distancias para un abordaje conceptual de las manifestaciones materiales del mismo. En cuarto lugar, la construcción de los métodos en trabajo social requiere de un desde dónde se plantea tal construcción. Esta pregunta también ha quedado meridianamente respondida en nuestro trabajo. Las claves desde las que nos situamos nos remiten, por un lado, a la concepción ampliada de las ciencias sociales, desde la cual, las características del trabajo social se revelan como adecuadas y apropiadas para una construcción científica que respete la subjetividad, la participación del otro y la significancia como orientaciones metodológicas, y que concibe al sujeto en interacción, complejo, con rasgos particulares. El interés de emancipación de Habermas, con base en la lógica de la comunicación pero orientada hacia la autonomía y autorreflexión del sujeto.

Por estos condicionamientos epistemológicos, a la hora de abordar el método en trabajo social, tenemos que ser flexibles, respetando el carácter holístico de los fenómenos que giran en torno al malestar. Los métodos tendrán un carácter integral y globalizador, que contemple lo objetivo y subjetivo del objeto. Se trata de una metodología adaptada al objeto de estudio y de actuación, a los sujetos y a las circunstancias en que éstos se encuentran, que permita el conocimiento de los procesos de interacción social y de los comportamientos humanos. Entendemos pues que la pluralidad en los métodos debe ser la característica del trabajo social, dada la naturaleza de su objeto. La pregunta a plantear ahora es si el trabajo social tiene que crear métodos propios o puede realizar su construcción científica a partir de los métodos ya existentes. Ambas cuestiones creemos que no son incompatibles, pero, mientras llega la definición de los métodos propios, es decir, aquellos generados en el seno de la disciplina, el trabajo social debe trabajar con los métodos ya existentes, adaptándolos a su realidad y a sus peculiaridades.

La aproximación al conocimiento del objeto necesita de una doble estrategia que permita captar el contexto en el que se desarrolla y se manifiesta en una persona concreta. Las formas de acceder al conocimiento de ambas dimensiones apuntan a la necesidad de métodos y procedimientos cuantitativos y cualitativos. Los primeros, porque nos proporcionan un conocimiento del contexto, del entorno en el que se ubica la persona, aunque no son la única manera de acceder al conocimiento de lo contextual. En cuanto a los procedimientos cualitativos, 
su orientación más evidente se dirige hacia el conocimiento de la vivencia personal, a saber cómo la persona vive la situación concreta de malestar, qué significa y qué representa para ella. Los métodos cualitativos exigen una proximidad mayor entre trabajador social y cliente, entre profesional y lo que se ha definido como objeto de trabajo. No obstante, con estos procedimientos también podemos acceder al conocimiento de lo contextual en la medida que el discurso individual es también un producto social.

La conclusión general que podemos establecer es la necesidad de realizar investigaciones dentro del área de conocimiento que generen la teoría del trabajo social. Teoría que oriente tanto la práctica profesional propia de la disciplina como que constituya la aportación general al ámbito de las ciencias sociales. Investigaciones que mejoren la práctica profesional e investigaciones que versen sobre la propia disciplina. De acuerdo a las dos dimensiones del objeto, el sujeto y el contexto, los procesos de investigación a seguir se basarán tanto en la metodología cualitativa como la cuantitativa. Se trata de incorporar la investigación al campo de actuación del trabajo social. Campo de actuación que no se limita a la mera intervención profesional, sino que se extiende por la búsqueda de referentes teóricos que aludan a la propia disciplina y al contexto social donde ésta se desarrolla. No mejorar únicamente la práctica sino la presencia del trabajo social en el ámbito de las ciencias sociales. Esta práctica de la investigación requiere de la definición del objeto, de la selección de un o unos métodos y de su posterior desarrollo: un diseño, su implementación, una presentación de resultados y un sometimiento al juego de la contrastación, tanto de los resultados como de los procesos.

Pero la construcción del trabajo social no puede hacerse al margen de los nuevos vientos que corren en las ciencias sociales. Ya hemos dicho que nuestra profesión encuentra su lugar en la nueva concepción de las ciencias sociales y humanas. Una concepción dominada por una ruptura epistemológica con el paradigma positivista, lo que no supone un rechazo de los métodos cuantitativos. Creemos que esta construcción teórica pasa por la definición de una descripción densa (como la entiende Geertz -1992-) para el trabajo social. Un esfuerzo intelectual que nos permita ver, en las interactuaciones cara a cara con los individuos, distintos niveles de significación: desde aquél que se sitúa en lo más evidente, superficial, hasta el que se localiza en la estructura profunda y que dota de significado a los comportamientos individuales. En una intervención directa, los trabajadores sociales se enfrentan a gran parte de los problemas que abordan las ciencias sociales. Basta con que tengamos la posibilidad de traspasar lo evidente para descubrir todo un mundo de significados complejos que necesitan de un en- 
tendimiento y de una confrontación para poder ser comprendidos. Interrogarnos sobre por qué el otro se comporta de una determinada manera, qué significa para él dicha actuación, qué significa para nosotros..., nos coloca en la tesitura de estructurar un conocimiento autónomo.

\section{BIBLIOGRAFÍA}

ÁLVAREZ URÍA, F.: «Los visitadores del pobre. Caridad, economía social y asistencia en la España del siglo XIX», en VARIOS AUTORES: De la beneficencia al bienestar social. Cuatro siglos de historia de la acción social. Siglo XXI. Madrid, 1986.

ÁVAREZ URÍA, F.: «En torno a la crisis de los modelos de intervención social», en VARIOS AUTORES: Desigualdad y pobreza hoy. Talasa. Madrid, 1995.

BELTRÁN, M .: «La realidad social como realidad y apariencia». En REIS, $\mathrm{n}^{\circ}$ 37, 1982, pp. 25-53.

BELTRÁN, M.: La realidad social. Tecnos. Madrid, 1991.

BERNAL, J.D.: Historia social de la ciencia. Península. Barcelona, 1991.

FARGE, A.: «La historia de las mujeres. Cultura y poder de las mujeres: ensayo de historiografía». En Historia Social $n^{\circ}$ 9: historia de las mujeres, historia del género, 1991, pp. 79-101.

FERNANDO DÍEZ, R.: «Estructura social y sistema benéfico-asistencial en la ciudad preindustrial». En Historia Social $n^{\circ}$ 13: Pobreza y asistencia social, 1992, pp. 101-121.

FEYERABEND, P.: Contra el método. Ariel. Barcelona, 1974.

GARCÍA COTARELO, R.: «Origen y desarrollo del Estado de Bienestar». En Sistemas n ${ }^{\circ}$ 80/81. 1987, pp. 5-22.

GARCÉS FERRER, J. y DURÁ, E.: «Ideología y política social». En GARCÉS FERRER, J. y ALEMÁN BRACHO, C. (Coord.):Politica social. Mc Graw Hill. Madrid, 1998, pp. 51-77.

GARCÍA FERRANDO, M.: «La Sociología, ¿una ciencia multiparadigmática?, en JIMÉNEZ BLANCO, J. y otros (comps.): Teoría sociológica contemporánea. Tecnos. Madrid, 1978.

GARCÍA SALORD, S.: Especifidad y rol en trabajo social: curriculum, saber, formación. Humanitas. Buenos Aires, 1991.

GEERTZ, C.: La interpretación de las culturas. Gedisa. Barcelona, 1992.

GUALDA , E.: «Pluralismo metodológico y cognitivo y articulación de técnicas». En CRUZ, F. y GUALDA, E. (Coord.): Métodos y técnicas de investigación social. Asociación Miguel Ángel Caro. Huelva, 1996. 
HABERMAS, J.: Conocimiento e interés. Taurus. Madrid, 1988.

HIERRO, M.: Proyecto Docente para concursar a una plaza de profesora titular de escuela universitaria. Área de trabajo social y servicios sociales. Material inédito, 1996.

KAN-FONG MOINT CHEUNG: «Interdisciplinary relationships between social work and other disciplines: a citation study». En Social Work Research and Abstracts, volumen 26, $\mathrm{n}^{\circ} 3,1990$, pp. 23-29.

KLEIN, W \& BLOOM, M. (1990): «Social work as applied social science: A historical analysis. En Social Work, volumen 39, n 4, 1990, pp. 421-431.

MARDONES, J.M. y URSÚA, N.: Filosofía de las ciencias humanas y sociales. Fontamara. Colección Logos. Barcelona, 1982.

MÉNDEZ-BONITO ZORITA, P.: «El trabajo social en sociedades complejas en el contexto de una modernidad en crisis». En Ponencias y comunicaciones oficiales al VIII Congreso Estatal de diplomados en Trabajo Social y asistentes sociales. Consejo General de Diplomados en Trabajo Social y asistentes sociales. Sevilla, 1996, pp. 139-148.

MOIX MARTÍNEZ, M.: Manual de Trabajo Social. Trivium. Madrid,1991.

NAREDO, J.M.: La economía en evolución. Historia y perspectivas de las categorías básicas del pensamiento económico. Siglo XXI. Madrid, 1987.

PELEGRÍ, X.: «La relación de los profesionales del trabajo social con su objeto de trabajo». En RTS n 137, 1995, pp. 87-100.

PÉREZ SERRANO, G.: Investigación cualitativa. Retos e interrogantes. I. Métodos. La Muralla. Madrid, 1994.

POURTOIS, J.P. y DESMET, H.: Epistemología e instrumentación en ciencias humanas. Herder. Barcelona, 1992.

RUBIO LARA, M.J.: La formación del Estado Social. Ministerio de Trabajo y Seguridad Social. Madrid, 1991.

SIERRA BRAVO, R.: Ciencias sociales. Epistemología, lógica y metodología. Teoría y ejercicios. Paraninfo. Madrid, 1984.

ULISES MOULINES, C.: «Epistemología». En REYES, R (ed.):Terminología Cientifico social. Anthropos, pp. 347-350. Barcelona, 1988.

ZAMANILLO PERAL, T.: «La evidencia empírica». En ZAMANILLO, T. y GAITÁN, L.: Para comprender el trabajo social. Verbo Divino. Navarra, 1991.

ZAMANILLO PERAL, T.: «La intervención profesional». En VII Congreso Estatal de diplomados en Trabajo Social y asistentes sociales. Barcelona, 3, 4 y 5 de diciembre de 1992. 


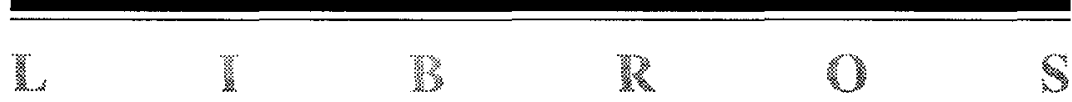





\section{Título: Trabajo Social Experimental}

Autora: Rosario Conde Megías.

Edita: Tirant lo Blanch. Valencia, 1998

No me resulta fácil hacer una recensión de un libro como éste. De entrada, porque no es mi campo habitual de trabajo, por más que mantenga relaciones estrechas con él incluso cotidianamente. En cualquier caso, estoy clasificado en lo que, en vocabulario administrativo-universitario, se llaman «áreas afines». Pero, sobre todo, y esa es una buena razón para leerlo, no es fácil precisamente por su originalidad. Aunque la bibliografía no es excesivamente heterodoxa, su enfoque es particularmente operativo y se aborda con rigor conceptual y estrecha correspondencia con la práctica profesional deseable desde un punto de vista científico.

El libro parte de los «aspectos epistemológicos generales del Trabajo Social Experimental», para lo cual, después de describir los antecedentes históricos, define el objeto y método. Inmediatamente, detalla, desde esa perspectiva epistemológica, la práctica profesional y la práctica educativa dentro de la Universidad. Probablemente debido a este interés por la enseñanza universitaria, el libro se suma a los que defienden las «fronteras» con otras ciencias sociales. Es comprensible: la organización universitaria en (pretendidas) Areas de conocimiento, Departamentos, Facultades y Escuelas que marcan «etológicamente» su territorio (que es territorio de poder) lleva a esta defensa de las «fronteras». Pertenezco, sin embargo, a la corriente minoritaria de los que creen, por el contrario, que lo que hace falta en la actualidad es, siguiendo el título del informe para la Comisión Gulbenkian coordinado por Immanuel Wallerstein, «abrir las ciencias sociales», pero es cuestión de opciones personales y no es argumento que pueda utilizarse para una crítica de «juego limpio». De todas maneras, mantengo mi opinión: todos ganaríamos más si intentáramos 
pasar de la multidisciplinaridad o la interdisciplinaridad a la «unidisciplinaridad» de unas ciencias sociales reunificadas a partir de los fragmentos construidos en el siglo XIX y principios del XX y que creo que habría que reconstruir de cara el XXI. En cualquier caso, sea bienvenida la reflexión sobre los aspectos epistemológicos, puente para ulteriores encuentros.

Desde mi punto de vista por lo menos, la parte más interesante es la segunda, dedicada a la evaluación científica de casuísticas sociales y es ahí donde sí hay profundas coincidencias con el esquema que a mí también me parece particularmente útil en la actualidad, que está tomado de la medicina clínica y que defienden y practican, dentro de la bibliografía que manejo habitualmente, autores tan diversos como Etzioni y Galtung. Me refiero a la visión tripartita «diagnóstico-pronóstico-terapia» que la autora prolonga a la enseñanza universitaria como lo ha hecho en la primera parte y que tiene paralelos en la socioeconomía y en la investigación para la paz.

Puestos a aplicar metodología experimental, un mayor énfasis en la metodología comparada (con una tradición formalizada por lo menos desde Stuart Mill) hubiera sido deseable, pero el libro será de utilidad tanto para los profesionales como, sobre todo, para los docentes. En especial, obviamente, será útil y es recomendable para los dedicados a la metodología, campo en el que los estudiantes deben aprender todas las «recetas» posibles, pero hacerlo con la profundidad y rigor de un libro como éste para no caer en el «recetismo».

José Maria Tortosa

Catedrático de Sociología

Universidad de Alicante 
NUMEROS PUBLTCADOS 



\section{NUMERO 1 (1992)}

Jesús Daza Martínez, director. Presentación

María José Escartín Caparrós. Profesora de Trabajo Social. E.U.T.S. Alicante Consideraciones preliminares

\section{Estudios sobre la familia}

Isabel Ramírez de Mingo. Titular de Trabajo Social. Universidad Complutense. Madrid.

El Trabajo Social con familias

María Asunción Martínez Román, María Teresa Mira-Perceval Pastor, Hortensia Redero Bellido. E.U.T.S. de Alicante.

Función especifica de la Familia en la atención social comunitaria: su valor como recurso para la sociedad

María José Escartín Caparrós. Profesora E.U.T.S. Alicante.

El Sistema familiar y el Trabajo Social

Dr. D. Agustín Bueno Bueno. Profesor del Departamento de Psicología de la Salud. Universidad de Alicante.

Estilos de vida familiar y riesgo social infantil

María Asunción Martínez Román. Profesora de Servicios Sociales. E.U.T.S. Alicante.

Participación de la Familia en el proceso de rehabilitación de los enfermos crónicos: Los Insuficientes Respiratorios Crónicos Graves (I.R.C.G.) y el Bienestar Social

Josefa Lorenzo García, Manuela Palomar Villena, Esperanza Suárez Soto. Trabajadoras sociales. Profesoras de la E.U.T.S. Alicante.

Mujer y Familia. Reflexiones críticas desde nuestra experiencia profesional

Dr. Don Francisco Ortega Beviá. Director Master Terapia Familiar y Profesor Terapia Familiar, Curso Superior Psicosociológico. Da Elisa Pérez de Ayala Morenos Santa Maria. Profesora de Trabajo Social Familiar. Universidad de Sevilla.

La ilasión de las alternativas: vivir en pareja

Antonio Bellido Alonso, Esther Villegas Castrillo. Profesores del Area de Trabajo Social y Servicios Sociales. E.U.T.S., Alicante.

Influencia de la Familia en el desarrollo de pautas inadecuadas de conducta

Josep-Lluís Orts Molines. Profesor de Valencià a I'E.U.T.S. Universitat d'Alacant.

Idees sobre la familia a la tardor medieval a través de Lo Libre de les dones de Francesc Eiximenis (1327-1490)

M. ${ }^{a}$ Dolores Vargas Llovera. Profesora del Area de Antropología. Universidad de Alicante.

La función familiar en el actual pluralismo religioso: El caso de Los Testigos de Jehová

Jesús Daza Martínez. Catedrático de Derecho Romano.

La ley de Divorcio de 1932. Presupuestos ideológicos y significación política 
II. Tribuna Libre

Manuel Moix Martínez. Catedrático de Trabajo Social y Servicios Sociales. Problematismo del Bienestar Social

Esther Villegas Castrillo, Antonio Bellido Alonso. Profesores de Trabajo Social. E.U.T.S. Alicante.

La Teoría Sistémica en Trabajo Social. Criterios de apli-cación y observaciones criticas

Ana M. ${ }^{a}$ Herthogue. Trabajadora Social jubilada de la «Family Welfare Association» de Londres.

Relevancia de algunos conceptos y arquetipos de C. Jung para la labor profesional de los trabajadores sociales

Jorge Garcés Ferrer, M. ${ }^{a}$ José Lahoz Campos, Fco. José Ródenas Riga, Estrella Durá Ferrandis. Profesores de SS.SS, en la Escuela de Trabajo Social. U. de Valencia.

Valores y características de personalidad en estudiantes de Trabajo Social de la Comunidad Valenciana

\section{Actualidad bibliográfica}

María Asunción Martínez Román, María Teresa Mira-Perceval, Hortensia Redero Bellido. E.U.T.S. de Alicante. Jorge Garcés Ferrer. Escola Universitària de Treball Social. Universitat de València.

La fumilia

\section{Apéndice documental}

Decreto 23/1988 de 8 de febrero, del Consell de la Generalitat Valenciana, de medidas de protección de menores en situación de desamparo en la Comunidad Valenciana

Orden de 20 de marzo de 1986, de la Conselleria de Trabajo y Seguridad Social, por la que se establece el recurso de familias Educadoras en la Comunidad Valenciana

Ley $21 / 1987$, de 11 de noviembre, por la que se modifican determinados artículos del Código Civil y de la Ley de Enjuiciamiento Civil en materia de adopción

Decret 23/1988, de 8 de febrer, del Consell de la Generalitat Valenciana, de mesures de protecció de menors en situació de desamparament a la Comunitat Valenciana

Ordie de 20 de març de 1986, de la Conselleria de Treball i Seguretat Social, per la qual s'estableix el recurs de Famílies Educadores de la Comunitat Valenciana 


\section{NUMERO 2 (1993)}

Jesús Daza Martínez.

Presentación

\section{Algunas claves del Estado social contemporáneo}

Jorge Hurtado Jordá. Profesor del Departamento de Ciencias Sociales y de la Educación. Universidad de Alicante.

Sociedad, Estado, tal vez mercado

Fermín Aliaga Aliaga. Profesor del Departamento de Economía Aplicada y Politica Económica. Universidad de Alicante.

Política económica y calidad de vida

Ramón Martín Mateo. Catedrático de Derecho Administrativo.

La cultura del ocio

II. Cuestiones teórico-prácticas sobre el Trabajo Social

M. José Escartín Caparrós. Profesora titular de Trabajo Social de la EUTSA de Alicante

Influencia de las diferencias culturales en la relación de ayuda

Esperanza Suárez Soto, Manuela Palomar Villena. Profesoras titulares de Trabajo Social en la EUTSA de Alicante.

El cliente en Trabajo social. Cuestiones conceptuales y análisis tipológico...

Esther Villegas Castrillo. Profesora titular de Trabajo Social en la EUTSA de Alicante.

El Trabajador Social en el trabajo de grupo

Antonio José Bellido Alonso. Profesor titular de Trabajo Social en la EUTSA de Alicante.

La primera entrevista en la relación de ayuda del Trabajo Social Individualizado

Josefa Lorenzo García. Profesora Titular de Trabajo Social en la EUTSA de Alicante.

La intervención profesional con familias multiproblema desde los Servicios. Sociales Municipales

Manuela Palomar Villena y Esperanza Suárez Soto. Profesoras Titulares de Trabajo Social en la EUTSA de Alicante.

El modelo sistémico en el Trabajo Social familiar. Claves teoricas e intervención práctica

\section{Problemas y perspectivas de los servicios sociales}

Manuel Moix Martínez. Catedrático de Trabajo Social y Servicios Sociales. «Universalidad» versus «Selectividad» en los Servicios Sociales. La "discriminación positiva»

María del Carmen Alemán Bracho. Catedrática de Servicios Sociales de la EUTS de la Universidad de Granada.

Una perspectiva de los Servicios Sociales en España

M. ${ }^{2}$ Asunción Martínez Román, M. ${ }^{2}$ Teresa Mira-Perceval Pastor y Hortensia Redero Bellido. Profesoras titulares de SS.SS. de la EUTS de Alicante.

¿Viejos o nuevos? Orientaciones actuales de los Servicios Sociales en España 
Rafael Barranco Vela. Profesor de Derecho Administrativo de la EUTS de la Universidad de Granada.

El principio de participación en las Leyes de Servicios Sociales

\section{Miscelánea}

Manuel Oliver Narbona y M." Dolores Vargas Llovera. Profesores del Departamento de Humanidades Contemporáneas. Y M. ${ }^{\mathrm{a}}$ José Escartín Caparrós, Josefa Lorenzo García, Antonio Bellido Alonso, Roberto Mohedano Menéndez, Manuela Palomar Villena, Esperanza Suárez Soto y Esther Villegas Castrillo. Profesores de la EUTS de Alicante.

Inmigración y cultura: Reflexiones críticas sobre las diferencias sociales y culturales que produce el hecho migratorio

Carmen Gimeno Escrig, Médica Experta Universitaria en Drogodependencias; $M^{a}$ Angeles Amérigo Martínez, Trabajadora Social y Experta Universitaria en Drogodependencias; Ma José Martí García, Psicóloga Experta Universitaria en Drogodependencias.

Perfil de los drogodependientes y familias atendidos en el Servicio Municipal de Drogodependencias de la Vila Joiosa

Francisco Martínez Carrasco y M. ${ }^{a}$ Dolores Vargas Llovera. División de Antropología. EUTS de Alicante.

Cultura y salud mental. Influencia del medio institucional en los enfermos profundos adultos

Agustín Bueno Bueno. Departamento de Psicología de la Salud. Universidad de Alicante

Autoconcepto adolescente y clase social

\section{Actualidad bibliográfica}

M. Asunción Martínez Román, Ma Teresa Mira-Perceval Pastor y Hortensia Redero Bellido. Profesoras titulares de SS.SS. de la EUTS de Alicante.

Bienestar Social y Politica Social

\section{NUMERO 3 (1995)}

M. ${ }^{a}$ Teresa Mira-Perceval Pastor. Directora E.U. Trabajo Social. Universidad de Alicante.

Presentación

M. José Escartín Caparrós, Esperanza Suárez Soto.

Editorial

\section{Trabajos sobre la mujer}

Jose Manuel Díez Fuentes. Universidad de Alicante.

República y Primer Franquismo: La mujer española entre el esplendor y la miseria, 1930-1950

M. José Frau Llinares. Departamento Ciencias Sociales y de la Educación. Universidad de Alicante.

La tipificación sexual del trabajo mercantil. El caso valenciano

M. ${ }^{2}$ Dolores Díez García y Sergio Quesada Rettschlag. Catedráticos Matemáticas E.U. Trabajo Social. Departamento de Economía Aplicada. Universidad de Alicante. Silvia M. ${ }^{a}$ Quesada Díez. ICADE. Madrid.

Una empresaria de los 90 . Análisis y valoración de un caso 
María José Escartín Caparrós. Profesora titular de Trabajo Social. Universidad de Alicante.

Violencia y Mujer. La intervención de crisis con mujeres maltratadas y sus hijos

Trinidad Pablo Cervera, Ruth Pérez Segovia y M. ${ }^{2}$ Dolores Vargas Llovera. Area de Antropología. Escuela Universitaria de Trabajo Social. Universidad de Alicante.

Mujer, Familia y mundo rural. Dos modelos para un cambio social

Yolanda Domenech López. Profesora ayudante del Area de Trabajo Social y Servicios Sociales. Universidad de Alicante.

La situación de la mujer en Honduras

II. Tribuna Libre

Carmen Gimeno Escrig. Médica Servicio Municipal de Alcoholismo y Drogodependencia. Villajoyosa. Angeles Amérigo Martínez. Trabajadora Social, Servicio Municipal de Alcoholismo y Drogodependencia. Villajoyosa.

Programa de intervención en familias. Evaluación con el cuestionario de salud general de Goldberg

Agustín Bueno Bueno. Profesor titular de Psicología Social de la Escuela Universitaria de Trabajo Social. Universidad de Alicante. $M^{a}$ Teresa Mira-Perceval Pastor: Profesora titular de Servicios Sociales de la Escuela Universitaria de Trabajo Social. Universidad de Alicante.

Reflexiones ante la Ley de la Infancia de la Comunidad Valenciana

Antonio Gutiérrez Resa. Profesor titular de Servicios Sociales. Universidad de Zaragoza.

Las ONGs y su papel en el futuro de la sociedad

María José Gallego Ayllón. Trabajadora Social. Estrella Gualda Caballero. Socióloga. Octavio Vázquez Aguado. Trabajador Social. Departamento de Filosofía, Sociología y Trabajo Social. Universidad de Huelva.

Las ideas previas de los aluminos de $1^{\circ}$ de Trabajo Social de Huelva respecto a la profesion

Yolanda Domenech López. Profesora ayudante del Area de Trabajo Social y Servicios Sociales. Universidad de Alicante. Juan Carlos Gómez Díaz. Licenciado en Ciencias Económicas y Empresariales. Universidad de Alicante.

Una alternativa al trabajo social institucionalizado: El trabajo social en la empresa privada

\section{Apéndice documental}

Ley $7 / 1994$, de 5 de diciembre, de la Generalitat Valenciana, de la Infancia. DOGV n.. 2

La Declaración de Pekín. Conclusiones de la IV Conferencia Mundial sobre las Mujeres. Beijing. Septiembre 1995

\section{Libros}

M. ${ }^{\text {a }}$ Carmen Santos Aguado. Profesora de la E.U. de Trabajo Social de la Universidad Complutense de Madrid.

Título: «Las enseñanzas de Trabajo Sociol en España: 1932-1983. Estudio socio-educativo». Autora: M. Victoria Molina Sánchez. 


\section{NUMERO 4 (1996)}

Esperanza Suárez Soto. Directora técnica del consejo editorial de la revista "Alternativas. Cuadernos de Trabajo Social».

Presentación

\section{Trabajos sobre migración}

Abel Albet-Mas. Departamento de Geografía. Universidad Autónoma de Barcelona. Maria Dolors Garcia-Ramon. Universidad Autónoma de Barcelona. Joan Nogué-Font. Departamento de Geografía. Universidad de Gerona. Lluis Ruidor-Gorgas. Facultad de Humanidades. Universidad Pompeu Fabra. Barcelona.

Geografia, ordenación del territorio y colonialismo español en Marruecos.

Mikel de Epalza. Catedrático de Estudios Arabes e Islámicos. Universidad de Alicante

Estructuras de acogida de los moriscos emigrantes de España en el Magreb (siglos XIII a XVIII).

Joan Lacomba. Departamento de Trabajo Social y Servicios Sociales. Escuela Universitaria de Trabajo Social. Universidad de Valencia.

Identidad y religión en inmigración. A propósito de las estrategias de inserción de los musulmanes senegaleses.

M." Dolores Vargas Llovera. Area de Antropología. Universidad de Alicante. Inmigración, etnicidad y pluralismo cultural.

José Cabanes Hernández. Sociólogo. Luz Vera García. Trabajadora social. Asociación P.G. Arakerando. Alicante. María Isabel Bertomeu Martínez. Trabajadora social. Asociación P.G. Arakerando. Alicante.

Gitanos: historia de una migración.

D. Ribera, A. Reig, M. Carrillo, J.L. Talavera, A. Caruana, C. Ferrera, A. Majos, R. Climent, C. Clavijo, M. Verdú. Escuela Universitaria de Enfermería. Universidad de Alicante. Hospital General de Alicante. Facultad de Medicina. Universidad de Alicante. Ayuntamiento de Alfaz del Pi (Alicante).

Hábitos y necesidades de cuidados en el colectivo de extranjeros de 80 y más años residentes en la costa mediterránea.

Mercedes González. Octavio Vázquez. Departamento de Filosofía, Sociología y Trabajo Social. Universidad de Huelva.

Trabajo social e inmigrantes. Las intervenciones del trabajo social.

Carmen Santos Aguado. Escuela Universitaria de Trabajo Social. Universidad Complutense de Madrid.

Trabajo social en el campo de actuación de inmigración y refituio.

Socorro Escobar Rubio. Trabajadora social. IRCOSAN. Madrid. Nieves Gascón Navarro. Trabajadora social. Mancomunidad Intermunicipal de La Encina. Madrid.

Metodología del trabajo social con inmigrantes y refugiados.

Ana M. ${ }^{a}$ Ortiz Duque. Trabajadora social. Ayutamiento de Majadahonda. Madrid.

Fases de la intervención social con inmigrantes.

M. a Jesús Vega Pascual. Trabajadora social. Alto Comisariado de las Naciones Unidas para los Refugiados (ACNUR). Secretaria de la sección legal.

Fases de la intervención social con refugiados. 
II. Tribuna libre

Nieves Lillo Herranz. Trabajadora social. Area de bienestar social del Excmo. Ayuntamiento de Elche (Alicante).

El educador gitano, profesional clave para una intervención integral con el pueblo gitano.

Sonia Ródenas Picardat. Trabajadora social. Asociación ciudadana contra el SIDA de la provincia de Alicante.

Grupos de ayuda mutua: una respuesta alternativa en la práctica del trabajo social.

Alfredo Hidalgo Lavié. E.U. Relaciones Laborales - Trabajo Social. Jerez. Universidad de Cádiz.

El marco juridico-administrativo de los Servicios Sociales de la Comunidad Autónoma Andaluza.

Jorge Hurtado Jordá. Departamento de Ciencias Sociales. Universidad de Alicante.

Lecciones de la informalidad.

Idris M. Iwaki. Hector O. Beaton. Ernesto A. López. Departamento de Sociología. Universidad de Oriente-Santiago. Cuba. Javier M. Ferrer. Departamento de Trabajo Social. Universidad de Alicante.

Turismo y cambio social en Santiago de Cuba.

III. Actualidad bibliográfica

Carmen Santos Aguado. M." Jesús Vega Pascual. Socorro Escobar Rubio. Ana M." Ortiz Duque.

Actualidad bibliográfica sobre inmigración y refugio.

IV. Libros

Gonzalo Musitu. Coordinador del Area de Psicología Social. Universidad de Valencia.

Título: «Estudio longitudinal de la presencia de la mujer en los medios de comunicación de prensa escita». Cuadernos de Investigación de Psicología Comunitaria. Universidad de Valencia. Nau Llibres. Valencia, 1996. Autor: José Ramón Bueno Abad.

\section{NUMERO 5 (1997)}

Esperanza Suárez Soto. Directora técnica del consejo editorial de la revista "Alternativas. Cuadernos de Trabajo Social».

Presentación

\section{Trabajos sobre violencia}

M. Asunción Martínez Román. Departamento de Trabajo Social y Servicios Sociales. Universidad de Alicante.

"Pobreza y exclusión social como formas de violencia estructural". La lucha contra la pobreza y la exclusión social es la lucha por la paz.

Gonzalo Musitu Ochoa. Profesor y director del Area de Psicología Social. Facultad de Psicología. Universidad de Valencia.

Violencia y terrorismo: Un análisis desde la perspectiva ecológica. 
E. Bosch-Fiol, M. Gili-Planas y V.A. Ferrer-Pérez. Departamento de Psicología. Universidad de las Islas Baleares.

La violencia doméstica como una forma de expresión deactitudes misóginas.

Dra. M. ${ }^{a}$ Dolores Díez García. Profesora de la E.U. de Trabajo Social. Universidad de Alicante. Dr. Sergio Quesada Rettschlag. Profesor de la E.U. de Trabajo Social. Universidad de Alicante. M. ${ }^{a}$ Dolores Sala Bonmatí. Trabajadora social.

El maltrato a menores en la provincia de Alicante en el periodo 1980-1997.

Agustín Bueno Bueno. Profesor de Psicología Social. Universidad de Alicante.

El maltrato psicológico/emocional como expresión de violencia hacia la in. fancia.

Javier Domínguez, José R. Brocal, José J. Cases, Virginia Tovar y Agustín Bueno.

Análisis del programa de seguimiento de medidas judiciales de régimen abierto en la ciudad de Alicante durante 1996.

José Conrado Moya Mira. Psicólogo. Jefe de la Sección de Familia, Infancia y Juventud de la Dirección Territorial de Bienestar Social de Alicante

Organización de los Servicios de Protección a la Infancia en la Comunidad Valenciana. Análisis normativo y funcional.

M. José Escartín Caparrós. Profesora Titular de Trabajo Social. Departamento de Trabajo Social y Servicios Sociales. Universidad de Alicante.

Los niños maltratados y sus familias. Algunas indicaciones para la intervención del trabajador social.

\section{Tribuna libre}

Salvador Amigó Borrás. Profesor asociado de la Facultad de Psicología. Universidad de Valencia.

El "problema de la droga" y la prevención del consumo de drogas: mitos y alternativas, con una especial referencia al consumo de cannabis.

M. José Salvador Pedraza, Eva Domínguez Sánchez, Raquel Carracedo Manzanera. Técnicos de la Consejería de Sanidad y Bienestar Social de la Junta de Castilla y León.

Marco operativo de las intervenciones de inserción asociadas a la percepción de rentas minimas.

Jesús Moragón Nava. Trabajador Social. Centro de Salud de Atención Primaria. INSALUD. Albacete.

La realidad rural: situación en una región. La organización de equipamientos.

Trinidad Banda Gallego. Profesora titular de la Escuela Universitaria de Trabajo Social. Universidad de Huelva.

El debate sobre la provisión pluralista de los Servicios Sociales.

Víctor M. Giménez Bertomeu. Trabajador Social. Coordinador del Centro Social $n .^{\circ} 4$. Servicios Municipales del Ayuntamiento de Alicante.

El trabajador social en la dirección de un Centro de Servicios Sociales.

Enrique di Carlo. Equipo E.I.E.M. Universidad Nacional de Mar del Plata. Argentina.

El paradigma humanista como sustancia del Trabajo Social. El Trabajo Social y el paradigma humanista dialéctico. Alternativa de reorganización teorética y metodología del trabajo social profesional 


\section{Libros}

M. José Escartín Caparrós. Profesora Titular del Departamento de Trabajo Social y Servicios Sociales. Universidad de Alicante.

Titulo: "Violencia. Memoria amarga». Siglo XXI de España Editores, S.A. Madrid, 1997, 303 páginas. Autor: Javier Urra Portillo. Defensor del Menor en la Comunidad de Madrid.

M.a Asunción Martínez Román. Departamento de Trabajo Social y Servicios Sociales. Universidad de Alicante.

Título: «Los Modelos en Trabajo Social. Intervención con personas y familias». Siglo XXI de España Editores, S.A. Madrid, 1996, 405 páginas. Autora: Mathilde du Ranquet.

M. Victoria Molina Sánchez. Catedrática de Trabajo Social. Universidad Complutense de Madrid.

Título: «Introducción al Trabajo Social II. Trabajo Social con individuos y familias». Editorial Aguaclara. Alicante, 1997, 287 páginas. Autoras: Escartín Caparrós, M.J., Palomar Villena, M., Suárez, Soto, E. 



\section{PAUTAS GENERALES PARA LA PRESENTACION DE ARTICULOS}



1. La Revista «Alternativas. Cuadernos de Trabajo Social» está abierta a aportaciones, investigaciones, trabajos teóricos y metodológicos, de carácter profesional o académico, tanto del trabajo social, política social y servicios sociales, como de otras disciplinas y profesiones que desde un punto de vista multi e interdisciplinar enriquecen y complementan la acción profesional.

2. Contenido de los artículos.

El Consejo Editorial solicitará el asesorammiento de expertos independientes quienes, valorando la calidad técnica y científica de los artículos, realizarán la correspondiente selección. Los autores de los artículos publicados recibirán un ejemplar de la Revista.

3. Los artículos publicados quedan en propiedad de la Revista, siendo necesaria la autorización del Consejo Editorial para su reproducción total o parcial.

4. Los artículos que no sean inéditos se publicarán bajo la valoración del Consejo editorial y en función de:

- Que su difusión haya sido en algún medio de difícil acceso a la profesión y disciplina del trabajo social.

- Que haya sido publicado en otro idioma.

- Que se consideren de particular relevancia e interés científico profesional.

5. Normas de presentación

- Los artículos deberán ser remitidos a la Redacción de la Revista «Alternativas. Cuadernos de Trabajo Social», Escuela Universitaria de Trabajo Social. Universidad de Alicante. 03690 San Vicente del Raspeig. Alicante.

- Tres copias escritas y diskette (Microsoft Word y Word Perfect para Windows). Mecanografiados en papel tamaño DIN-A4, a doble espacio (escritura en $12 \mathrm{CPI}$ ), por una sola cara.

- La extensión deberá ajustarse a un mínimo de 10-12 páginas y un máximo de 40.

- De cada uno de los artículos los autores presentarán las claves conceptuales y un «abstract» de 12/15 líneas al comienzo del trabajo.

- Todos los artículos deberán ir acompañados en folio aparte de los datos personales del autor/res: nombre y apellidos, D.N.I., dirección, teléfono, profesión, actividad, cargo, teléfono de con- 
tacto, indicando claramente el título del artículo y si ha sido publicado en algún otro medio.

- Las anotaciones a pie de página se numerarán por orden de aparición en el texto y se mecanografiaran en hoja aparte.

- Las referencias bibliográficas se presentarán al final del texto y por orden alfabético de autores, en la forma siguiente:

- Para los libros: apellidos e inicial del nombre del autor/a/ o autores/as, título de la obra (cursiva), editorial, ciudad, año y número de las páginas a que se hace referencia.

- Para las revistas: Apellidos e inicial del nombre del autor/a o autores/as, título del artículo (entre comillas), nombre de la revista (en cursiva), nombre de la entidad editora, ciudad, año, número de la revista y el de las páginas a que se hace referencia.

- Las tablas y figuras deberán presentarse en hoja aparte numerándose correlativamente e indicando el lugar de colocación en el artículo.

- Los apartados y subapartados se confeccionarán de manera homogénea utilizando la numeración I, II, III; 1.1.,1.2; etc. 
Próxima sección monográfica:

\section{INTEGRACIÓN SOCIO-LABORAL}

Plazo para presentación de artículos: 30 de mayo de 1999 



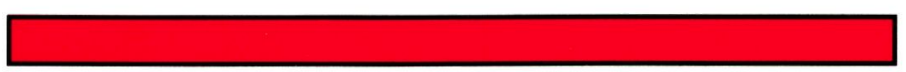

